University of Louisville

ThinkIR: The University of Louisville's Institutional Repository

$5-2011$

\title{
Rational design of mesoporous gallium oxide and gallium-based mixed oxide catalysts.
}

Chinmay A. Deshmane

University of Louisville

Follow this and additional works at: https://ir.library.louisville.edu/etd

\section{Recommended Citation}

Deshmane, Chinmay A., "Rational design of mesoporous gallium oxide and gallium-based mixed oxide catalysts." (2011). Electronic Theses and Dissertations. Paper 338.

https://doi.org/10.18297/etd/338

This Doctoral Dissertation is brought to you for free and open access by ThinkIR: The University of Louisville's Institutional Repository. It has been accepted for inclusion in Electronic Theses and Dissertations by an authorized administrator of ThinkIR: The University of Louisville's Institutional Repository. This title appears here courtesy of the author, who has retained all other copyrights. For more information, please contact thinkir@louisville.edu. 


\title{
RATIONAL DESIGN OF MESOPOROUS GALLIUM OXIDE AND GALLIUM-BASED MIXED OXIDE CATALYSTS
}

By

\author{
Chinmay A. Deshmane
}

\begin{abstract}
A Dissertation
Submitted to the Chemical Engineering Department of the University of Louisville in Partial Fulfilment of the Requirements for the Degree of
\end{abstract}

Doctor of Philosophy

Department of Chemical Engineering

University of Louisville

Louisville, Kentucky

May 2011 



\title{
RATIONAL DESIGN OF MESOPOROUS \\ GALLIUM OXIDE AND GALLIUM-BASED \\ MIXED OXIDE CATALYSTS
}

\author{
By \\ Chinmay A. Deshmane \\ A Dissertation Approved on \\ April 21 ${ }^{\text {st }}, 2011$ \\ by the following Dissertation Committee: \\ Dr. Moises A. Carreon (Dissertation Director) \\ Dr. Aames $C$. Watters \\ Tr. Gerold Willing \\ Dr. Xiao-An Fu \\ Dr. Craig/fFapperhaus
}




\section{DEDICATION}

This dissertation is dedicated to my grandfather

(Late) Mr. Annasaheb Magdum,

my parents

Mr. Avinash Deshmane and Mrs. Jayashri Deshmane,

and

my wife

Shivani Deshmane 


\section{ACKNOWLEDMENTS}

I would first like to express my gratefulness to my supervisor, Professor Moises A Carreon, who has guided me throughout my graduate work. I appreciate his advice, his professional comments and guidance, which have always enlightened me and I really appreciate his patience in reading my manuscript countless times. I would also like to acknowledge Dr. Paul Ratnasamy who has been a co-advisor to me and for providing a new direction to our work.

Special thanks to thesis committee members Dr. James Watters, Dr. Gerold Willing, Dr. Xiao an Fu and Dr. Craig Grapperhaus, for their suggestions to complete this dissertation.

I also wish to thank Dr. Jasinski from Conn center, for helping me in characterizing and analyzing the samples with highly professional skill and advice. I would also like to acknowledge all the administrative staff and technicians; especially Ms. Patricia Lumley from Department of Chemical Engineering, University of Louisville, who helped me in solving problems.

I wish to express my gratitude to my colleagues, Surrendar, Chandrshekhar, and Praveen who always helped me whenever I was confronted with any difficulties. Thanks also to all my friends who have helped me in completing my $\mathrm{PhD}$ degree. My greatest thankfulness goes to my wife Shivani and my parents for their love and support and for always being understanding and supportive throughout my life.

Chinmay A. Deshmane

April 2011 


\section{ABSTRACT \\ RATIONAL DESIGN OF MESOPOROUS GALLIUM OXIDE AND GALLIUM-BASED MIXED OXIDE CATALYSTS}

\section{Chinmay A. Deshmane}

\section{April 21 ${ }^{\text {st }}, 2011$}

In the present study, we report the synthesis of thermally stable mesoporous gallium oxide and novel gallium-niobium mixed oxides employing EvaporationInduced Self-Assembly (EISA), Self-Assembly Hydrothermal-Assisted (SAHA) and Self-Assembly Microwave-Assisted approaches. These methods offer the possibility to synthesize thermally stable mesoporous oxides with controlled morphological, textural and structural properties.

EISA led to partially crystalline mesoporous gallium oxide phases displaying unimodal pore size distribution in the $\sim 2-5 \mathrm{~nm}$ range and surface areas as high as 300 $\mathrm{m}^{2} / \mathrm{g}$. SAHA led to nanocrystalline mesoporous uniform micron-sized gallium oxide spheres $(\sim 0.3-6.5 \mu \mathrm{m})$ with narrow size distribution displaying cubic spinel type structure. These mesophases displayed surface areas as high as $220 \mathrm{~m}^{2} / \mathrm{g}$ and unimodal pore-size distribution in the $5-15 \mathrm{~nm}$ range. Microwave-assisted approach led to the formation of nanocrystalline mesoporous gallium oxide phases at low reaction temperature $\left(130^{\circ} \mathrm{C}\right)$ and short reaction times $(\sim 15-120 \mathrm{~min})$. Novel semicrystalline mesoporous Gallium-Niobium mixed oxide phases were prepared via SelfAssembly Hydrothermal-Assisted (SAHA) method. This method led to the formation of uniform $\sim$ 0.3-2 $\mu \mathrm{m}$ micron-sized mesoporous mixed gallium-niobium oxide spheres with narrow size distribution displaying surface areas as high as $360 \mathrm{~m}^{2} / \mathrm{g}$ and 
unimodal pore size distribution in the 3-6 $\mathrm{nm}$ range. Due to their high surface areas, tunability of pore sizes and their acidic nature these single phase and mixed mesoporous gallium-niobium oxides were employed as catalysts in the epoxidation of cyclooctene and isomerization of methyl oleate.

For the epoxidation of cyclooctene to epoxycyclooctane carried out at $60^{\circ} \mathrm{C}$ the mesoporous gallium oxide displayed $100 \%$ selectivity towards epoxide with the conversion of cyclooctene in the 4 to $16 \%$ range. As the reaction temperature was increased to $80^{\circ} \mathrm{C}$, an increase in the cyclooctene conversion was observed. The highest cyclooctene conversion observed was $\sim 52 \%$ with a selectivity of $83 \%$ toward the epoxide. A clear correlation was observed between the cyclooctene conversion and gallium oxide particle size at both reaction conditions. Agglomerate size between 2-3 $\mu \mathrm{m}$ led to higher cyclooctene conversion, whereas the agglomerate sizes between 4.5-7.5 $\mu \mathrm{m}$ led to lower cyclooctene conversions. For the isomerisation of methyl oleate, highest conversion of $57 \%$ with the selectivity of $86 \%$ and yield of $\sim 50 \%$ was observed over a sample with gallium-niobium composition of 0.3:0.7 wt\%. The superior catalytic performance of the gallium-niobium mixed oxide was attributed to its high acidity, crystallinity and mesoporosity. 


\section{TABLE OF CONTENTS}

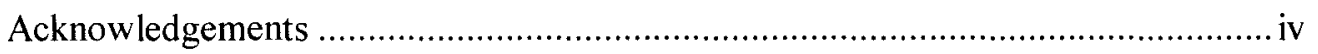

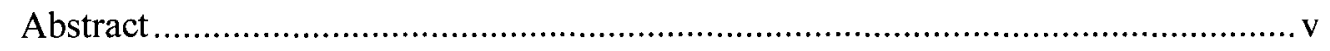

Table of contents .........................................................................................

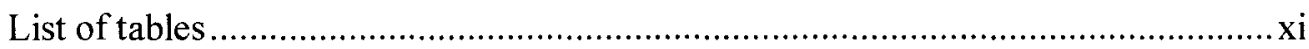

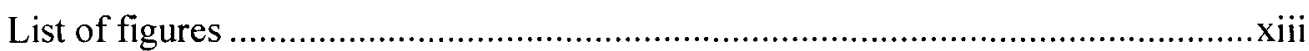

Chapter 1. Introduction.................................................................................................... 1

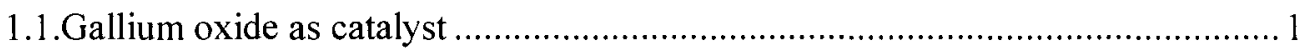

1.2. Conventional synthesis methods of gallium oxide ......................................... 3

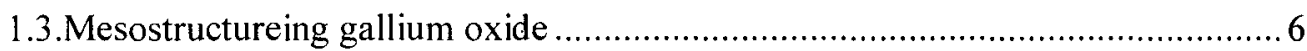

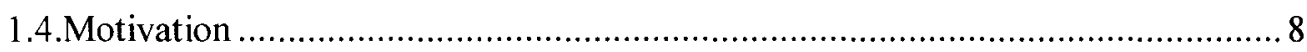

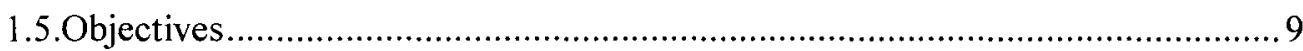

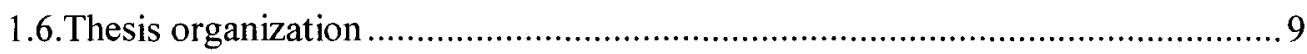

Chapter 2. Background .............................................................................................. 12

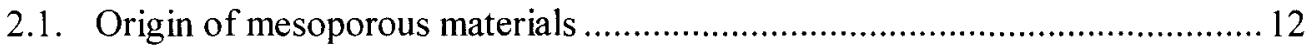

2.2. Surfactant-assisted self-assembly of mesoporous materials ....................... 13

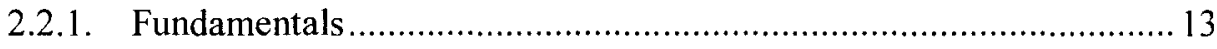

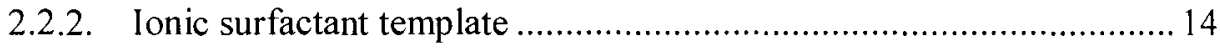

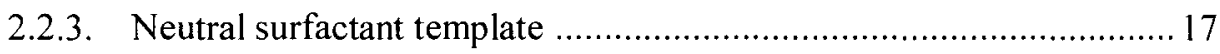

2.3. Evaporation-induced self-assembly origins ............................................ 18

2.3.1. Basics of evaporation-induced self-assembly ..................................20

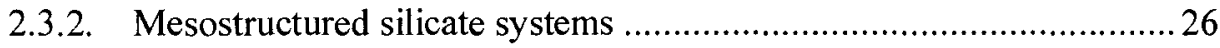


2.3.3. Mesostructured non-silicate system

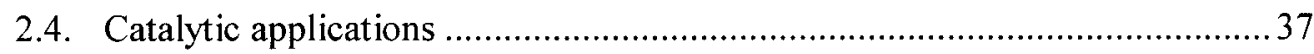

2.4.1. Catalytic applications of mesoporous metal oxides......................... 37

2.5. Self-assembly hydrothermal-assisted approach (SAHA) ......................... 40

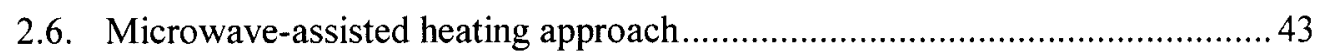

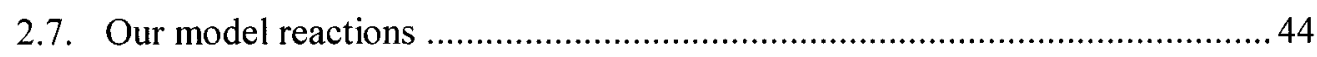

2.7.1. Reaction of interest I: epoxidation of alkenes ................................. 44

2.7.2. Reaction of interest II: skeletal isomerisation of fatty acid and fatty acid methyl esters ....................................................... 47

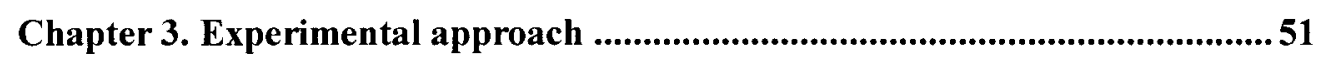

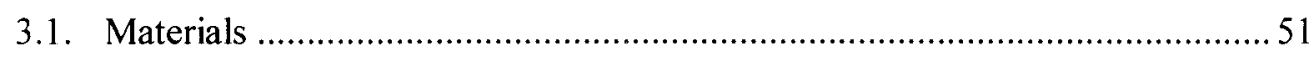

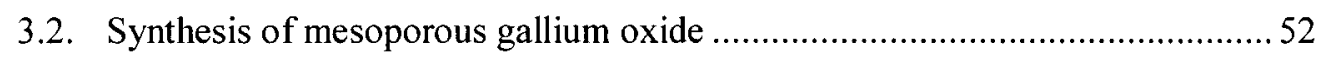

3.2.1. Evaporation-induced self-assembly (EISA) ................................... 52

3.2.2. Synthesis of hollow mesoporous nanocrystalline gallium oxide spheres by SAHA......................................................... 54

3.2.3. Microwave-assisted synthesis of nanocrystalline mesoporous

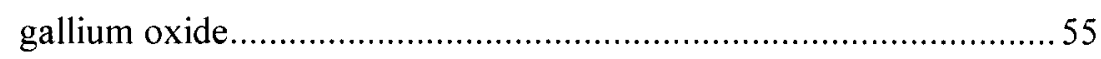

3.2.4. Synthesis of mesoporous gallium-based mixed oxides.................... 57

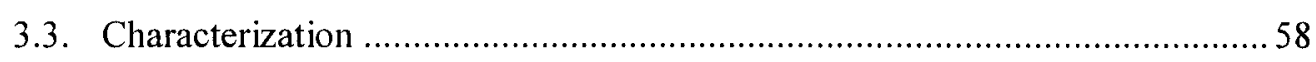

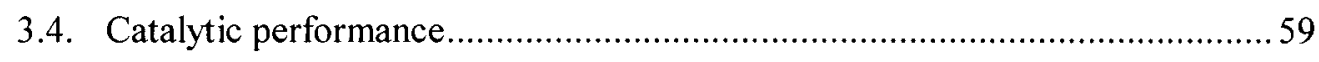

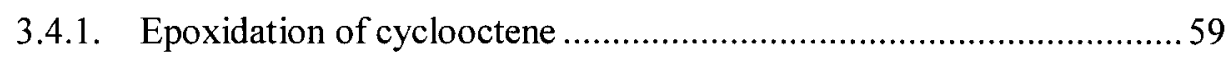

3.4.2. Isomerization of methyl oleate and transformation of biodiesel ........6 60

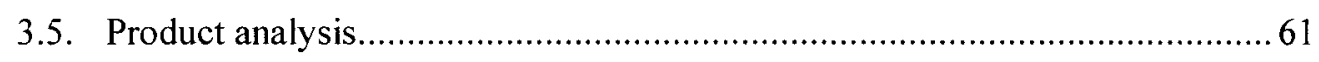

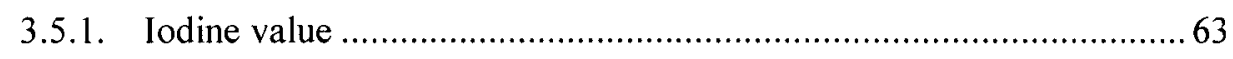

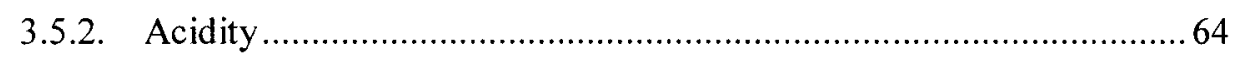


Chapter 4. Synthesis and characterization of thermally stable nanocrystalline mesoporous gallium oxide phases .....................................................................6 65

4.1. Evaporation-induced self-assembly (EISA) .......................................6 66

4.2. Self-assembly hydrothermal-assisted (SAHA) approach ............................ 71

4.2.1. Effect of hydrothermal temperature .......................................... 76

4.2.2. Effect of ethylene glycol ......................................................... 78

4.3. Microwave-assisted synthesis of nanocrystalline mesoporous gallium oxide.. 81

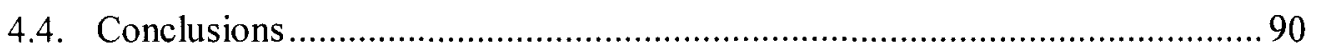

Chapter 5. Synthesis and characterization of novel mesoporous gallium-niobium

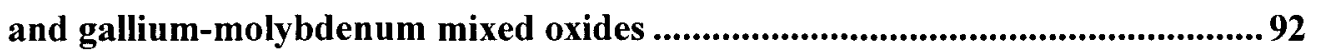

5.1. Mesoporous gallium-niobium mixed oxide phases ......................................93

5.2. Mesoporous gallium-molybdenum mixed oxide phases .............................. 101

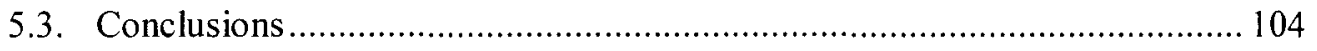

Chapter 6. Catalytic performance of mesoporous gallium oxide and gallium-

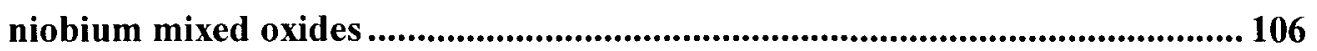

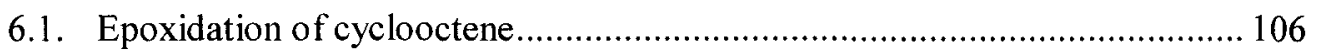

6.1.1. Study of epoxidation activity with different solvents ..................... 111

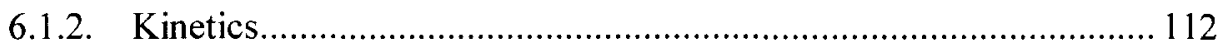

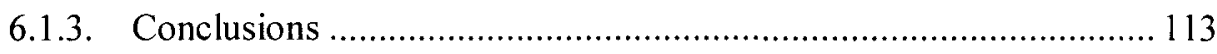

6.2. Skeletal isomerisation of methyl oleate ............................................ 114

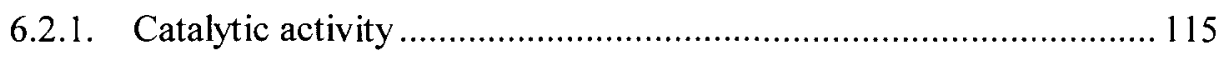

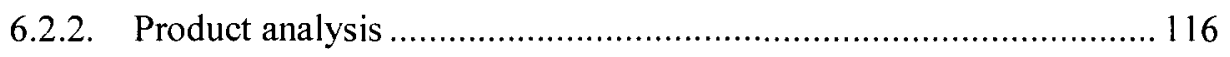

6.2.3. Catalytic transformations of biodiesel .................................... 120

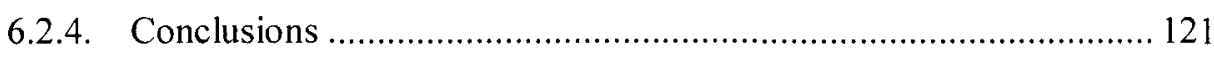

Chapter 7. Concluding remarks and future directions.................................. 122 


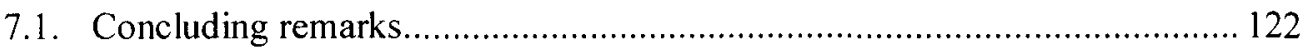

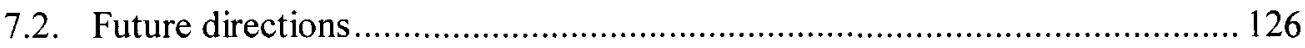

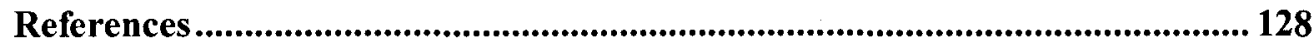

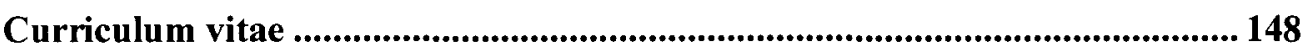




\section{LIST OF TABLES}

Table 2.1. Isoelectric points of common transition metal oxides .....................22

Table 2.2. Mesostructured silica films and particles prepared by EISA ............2 29

Table 2.3. Mesostructured titania films and particles prepared by EISA............ 33

Table 2.4. Mesostructured metal oxide films and particles prepared by EISA ... 35

Table 2.5. Emerging catalytic applications of mesoporous metal oxides ........... 39

Table 2.6. Average compositions of soybean and rapeseed biodiesels.............. 48

Table 4.1. Synthesis conditions and textural properties of mesoporous $\mathrm{Ga}_{2} \mathrm{O}_{3}$

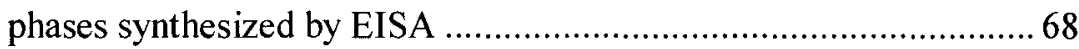

Table 4.2. General synthesis conditions and textural properties and average sphere size of mesoporous nanocrystalline $\mathrm{Ga}_{2} \mathrm{O}_{3}$ phases synthesized by

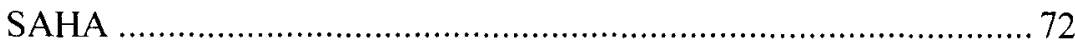

Table 4.3. Textural properties of mesoporous $\mathrm{Ga}_{2} \mathrm{O}_{3}$ phases synthesized by EISA and SAHA calcined at $450^{\circ} \mathrm{C}$

Table 4.4. General synthesis conditions and textural properties of mesoporous nanocrystalline $\mathrm{Ga}_{2} \mathrm{O}_{3}$ phases synthesized via self-assembly microwave-assisted heating approach calcined at $350^{\circ} \mathrm{C}$ .82

Table 5.1. Chemical composition, textural properties and average agglomerate size of mesoporous $\mathrm{Ga}_{2} \mathrm{O}_{3}$, $\mathrm{Ga}-\mathrm{Nb}$ mixed oxides and $\mathrm{Nb}$-oxide phases synthesized by employing F127 as SDA via SAHA .

Table 5.2. Textural properties of mesoporous $\mathrm{Ga}_{2} \mathrm{O}_{3}, \mathrm{Ga}-\mathrm{Nb}$ mixed oxides and $\mathrm{Nb}$-oxide phases synthesized via SAHA calcined at $600^{\circ} \mathrm{C}$ 
Table 5.3. Chemical composition and textural properties of Ga-Mo mixed oxide phases synthesized by employing F127 as SDA via SAHA at $180^{\circ} \mathrm{C}$

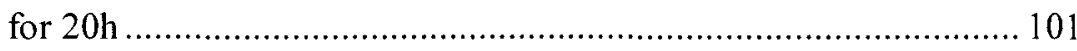

Table 6.1. Catalytic epoxidation of cis-cyclooctene over mesoporous $\mathrm{Ga}_{2} \mathrm{O}_{3}$ prepared via EISA and SAHA approaches ................................. 108

Table 6.2. Influence of solvents on the epoxidation of cyclooctene with $50 \mathrm{wt} \% \mathrm{H}_{2} \mathrm{O}_{2}$ over $\mathrm{Ga}_{2} \mathrm{O}_{3}$ prepared by employing $\mathrm{P} 123$ as

SDA

Table 6.3. Catalytic properties of methyl oleate over mesoporous $\mathrm{Ga}_{2} \mathrm{O}_{3}$,

$\mathrm{Ga}-\mathrm{Nb}$ mixed oxides, and $\mathrm{Nb}$-oxide ......................................... 116

Table 6.4. Catalytic transformation of biodiesel over mesoporous Ga-Nb

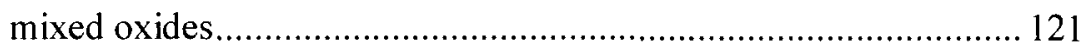




\section{LIST OF FIGURES}

Figure 1.1. Three dimensional crystal structure of A) a-Ga2O3 and

B) b-Ga2O3 with a unit cell . 2

Figure 2.1. Formation of mesoporous phases by liquid crystal templating (LCT) mechanism

Figure 2.2. Three types of structures observed for silica-surfactant mesophases:

A) MCM-41 (hexagonal), B) MCM-48 (cubic) and

C) MCM-50 (lamellar) 14

Figure 2.3. Schematic phase diagram for cationic surfactant ......................... 16

Figure 2.4. Mesostructured thin-film formation via EISA ............................. 20

Figure 2.5. Schematic representation of EISA for the preparation of longrange ordered mesostructures

Figure 2.6. Typical EISA trajectory for the formation of mesostructured films by dip-coating

Figure 2.7. Mesoporous oxides synthesis procedure employing SAHA approach

Figure 2.8. Schematic representation of epoxidation of alkenes... 45

Figure 2.9. Major components of soy and rapeseed oil 48

Figure 2.10. Schematic representation of skeletal isomerisation of linear ester to its branched isomer

Figure 3.1. A) Hexadecyltrimethyl ammonium bromide (CTAB),

Pluronics B) F127 and C) P123 were employed as the structure 
directing agents (SDA)

Figure 3.2. Schematic representation of EISA for the synthesis of $\mathrm{Ga}_{2} \mathrm{O}_{3} \ldots \ldots \ldots . . .53$

Figure 3.3. Schematic representation of SAHA for the synthesis

of mesoporous $\mathrm{Ga}_{2} \mathrm{O}_{3}$

Figure 3.4. Schematic representation of self-assembly microwave-assisted

heating procedure for the synthesis of $\mathrm{Ga}_{2} \mathrm{O}_{3}$

Figure 3.5. Schematic representation of the experimental setup for the epoxidation reaction

Figure 3.6. Batch-autoclave reactors employed to carry out the isomerisation and biodiesel transformation reactions experiments

Figure 3.7. A) HP 5890 Gas Chromatograph equipped with 5970 Mass

Selective Detector and B) Varian 7600 AS NMR spectrometer employed for product analysis

Figure 4.1. TEM images of mesoporous $\mathrm{Ga}_{2} \mathrm{O}_{3}$ synthesized by EISA employing A) F127 and B) P123 as SDA .68

Figure 4.2. $\quad \mathrm{N}_{2}$ adsorption-desorption isotherms and $\mathrm{BJH}$ pore size distribution from adsorption branch of mesoporous $\mathrm{Ga}_{2} \mathrm{O}_{3}$ phases synthesized by EISA employing a-b) CTAB (E1, E2), c-d) F127 (E3, E4) and e-f) P123 (E5, E6) as SDA

Figure 4.3. A) Low-angle and B) High-angle XRD patterns of mesoporous $\mathrm{Ga}_{2} \mathrm{O}_{3}$ phases synthesized by EISA employing a) CTAB, b) F127 and c) P123 as SDA. X-ray radiation $\mathrm{Cu}_{k \alpha}(\lambda=1.54 \AA)$

Figure 4.4. A) SAED pattern and B) intensity profile measured for mesoporous $\mathrm{Ga}_{2} \mathrm{O}_{3}$ synthesized by EISA employing P123 as SDA

Figure 4.5. SEM images of mesoporous $\mathrm{Ga}_{2} \mathrm{O}_{3}$ phases synthesized by SAHA 
at $180^{\circ} \mathrm{C}$ employing A) CTAB $\left.(3 \mu \mathrm{m}), \mathrm{B}\right) \mathrm{F} 127(2.2 \mu \mathrm{m})$ and

C) $\mathrm{P} 123(2.0 \mu \mathrm{m})$ as SDA

Figure 4.6. $\quad \mathrm{N}_{2}$ adsorption-desorption isotherms and BJH pore size distribution from adsorption branch of nanocrystalline $\mathrm{Ga}_{2} \mathrm{O}_{3}$ phases synthesized by SAHA 73

Figure 4.7. High-angle XRD patterns of mesoporous $\mathrm{Ga}_{2} \mathrm{O}_{3}$ phases synthesized by SAHA employing a) CTAB, b) F127 and c) P123 as SDA. X-ray radiation $\mathrm{Cu}_{k \alpha}(\lambda=54 \AA)$ 74

Figure 4.8. A) SAED pattern and B) intensity line profile measured for mesoporous $\mathrm{Ga}_{2} \mathrm{O}_{3}$ synthesized by SAHA 75

Figure 4.9. A) HRTEM image of nanocrystals on the surface of mesoporous $\mathrm{Ga}_{2} \mathrm{O}_{3}$ spheres synthesized by SAHA, B) Magnified image and C) FT of the area marked with dashed square in A .76

Figure 4.10. SEM images showing effect of hydrothermal treatment on sphere size at A) $\left.150^{\circ} \mathrm{C}, \mathrm{B}\right) 180^{\circ} \mathrm{C}$, and C) $200^{\circ} \mathrm{C}$ employing F127 as SDA 77

Figure 4.11. TGA profiles for the mesoporous gallium oxide phases synthesized employing CTAB, F127 and P123 as structure directing agents calcined at A) $350^{\circ} \mathrm{C}$ and B) $450^{\circ} \mathrm{C}$ .77

Figure 4.12. A) SEM and B) TEM images of mesoporous nanocrystalline $\mathrm{Ga}_{2} \mathrm{O}_{3}$ phases obtained by SAHA and employing $\mathrm{F} 127$ as SDA and ethylene glycol as organic additive .78

Figure 4.13. High-angle XRD patterns of $\mathrm{Ga}_{2} \mathrm{O}_{3}$ synthesized by SAHA, employing gthylene glycol as an additive 79 
Figure 4.14. $\mathrm{N}_{2}$ adsorption-desorption isotherms and $\mathrm{BJH}$ pore size distribution from adsorption branch of mesoporous $\mathrm{Ga}_{2} \mathrm{O}_{3}$ synthesized by SAHA employing F127 as SDA and A) $0.5 \mathrm{~mL}$ and B) $2 \mathrm{~mL}$ of ethylene glycol as an organic additive 80

Figure 4.15. $\mathrm{N}_{2}$ adsorption-desorption isotherms and $\mathrm{BIH}$ pore size distribution of mesoporous nanocrystalline $\mathrm{Ga}_{2} \mathrm{O}_{3}$ phases synthesized employing F127 as SDA via self-assembly microwave-assisted heating at a) 15 , b) 30 , c) 60 , and d) 120 min calcined at $350^{\circ} \mathrm{C}$ .84

Figure 4.16. $\mathrm{N}_{2}$ adsorption-desorption isotherms and $\mathrm{BIH}$ pore size distribution of mesoporous nanocrystalline $\mathrm{Ga}_{2} \mathrm{O}_{3}$ phases synthesized employing CTAB as SDA via self-assembly microwave-assisted heating at a) 15 , b) 30 , c) 60 , and d) 120 min calcined at $350^{\circ} \mathrm{C}$ .84

Figure 4.17. High-angle XRD patterns of mesoporous $\mathrm{Ga}_{2} \mathrm{O}_{3}$ phases synthesized employing A) F127 and B) CTAB as SDA via self-assembly microwave-assisted heating at a) 15 , b) 30 , c) 60 , and d) $120 \mathrm{~min}$. $\mathrm{X}$-ray radiation $\mathrm{Cu}_{K \alpha}(\lambda=54 \AA)$

Figure 4.18. SAED patterns for mesoporous $\mathrm{Ga}_{2} \mathrm{O}_{3}$ phases synthesized employing A) F127 and B) CTAB as SDA via self-assembly microwave-assisted heating at a) 15, b) 30, c) 60 and d) $120 \mathrm{~min}$ 88

Figure 4.19. HRTEM images of mesoporous $\mathrm{Ga}_{2} \mathrm{O}_{3}$ synthesized employing F127 as SDA via self-assembly microwave-assisted heating at a) 15 , b) 30 , c) 60 , and d) $120 \mathrm{~min}$

Figure 4.20. SEM images of mesoporous $\mathrm{Ga}_{2} \mathrm{O}_{3}$ synthesized by self-assembly microwave-assisted heating at A) 15 , B) 30, C) 60 and D) $120 \mathrm{~min}$ employing F127 as SDA 
Figure 5.1. SEM images of (a-e) mesoporous mixed Ga-Nb (1-5) mixed oxides and (f) mesoporous $\mathrm{Nb}_{2} \mathrm{O}_{5}$ synthesized by SAHA employing F127 as SDA calcined at $350^{\circ} \mathrm{C}$

Figure 5.2. $\quad \mathrm{N}_{2}$ adsorption desorption isotherms and BJH pore size distribution from adsorption branch of (a)-(e) mixed mesoporous $\mathrm{GaNb}(1-5)$ oxides and (f) mesoporous Nb-oxide synthesized by SAHA 95

Figure 5.3. High-angle XRD patterns of a) mesoporous $\mathrm{Ga}_{2} \mathrm{O}_{3}$, b)-f) mixed $\mathrm{GaNb}(1-5)$ oxides, and g) mesoporous $\mathrm{Nb}_{2} \mathrm{O}_{5}$ calcied at $350^{\circ} \mathrm{C}$ .96

Figure 5.4. High-angle XRD patterns of mesoporous a) $\mathrm{Ga}_{2} \mathrm{O}_{3}$, b)-f) $\mathrm{Ga}-\mathrm{Nb}$ mixed oxides, and g) $\mathrm{Nb}_{2} \mathrm{O}_{5}$ phases synthesized by SAHA employing $\mathrm{F} 127$ as SDA calcined at $600^{\circ} \mathrm{C}$. .97

Figure 5.5. HRTEM images of the crystals of mesoporous (a) $\mathrm{Ga}_{2} \mathrm{O}_{3}$, (b) GaNb3 mixed oxide; (c) GaNb4 mixed oxide and (d) $\mathrm{Nb}_{2} \mathrm{O}_{5}$ with their respective SAED patterns as inset .98

Figure 5.6. a) $\mathrm{SAED}$ pattern of mesoporous $\mathrm{Nb}_{2} \mathrm{O}_{5}$ synthesized by $\mathrm{SAHA}$ calcined at $600^{\circ} \mathrm{C}, \mathrm{b}$ ) Magnified image of the crystals displaying the lattice fringes and c) HRTEM image of the crystals on the surface of the oxide.

Figure 5.7. $\quad \mathrm{N}_{2}$ adsorption-desorption isotherms and $\mathrm{BJH}$ pore size distribution from adsorption branch of the mesoporous a) $\mathrm{Ga}_{2} \mathrm{O}_{3}$, b)-f) $\mathrm{Ga}-\mathrm{Nb}$ mixed oxides, and $g$ ) $\mathrm{Nb}_{2} \mathrm{O}_{5}$ synthesized by $\mathrm{SAHA}$ employing F127 as SDA and calcined at $600^{\circ} \mathrm{C}$ 100

Figure 5.8. $\quad \mathrm{N}_{2}$ adsorption-desorption isotherms and BJH pore size distribution from adsorption branch of A) mesoporous GaMol, B) GaMo2 and B) GaMo3 mixed oxides synthesized by employing 
Figure 5.9. High-angle XRD patterns of a) mesoporous $\mathrm{Ga}_{2} \mathrm{O}_{3}$,

b) mesoporous GaMol, c) GaMo2 and d) GaMo3

mixed oxides calcined at $350^{\circ} \mathrm{C}$

Figure 5.10. SEM images of A) GaMol, B) GaMo2 and C) GaMo3 mixed

oxide phases synthesized via SAHA employing F127 as SDA

calcined at $350^{\circ} \mathrm{C}$ 104

Figure 6.1. The epoxidation of cyclooctene with hydrogen peroxide

over mesoporous $\mathrm{Ga}_{2} \mathrm{O}_{3}$ 106

Figure 6.2. $\mathrm{SEM}$ images of mesoporous $\mathrm{Ga}_{2} \mathrm{O}_{3}$ phases synthesized via A-B) EISA

(E1 and E2) and C-H) SAHA (S1-S6) employing CTAB (C, D), F127

$(\mathrm{E}, \mathrm{F})$ and $\mathrm{P} 123(\mathrm{G}, \mathrm{H})$ as the SDA 108

Figure 6.3. Correlation between the cyclooctene conversion and

$\mathrm{Ga}_{2} \mathrm{O}_{3}$ agglomerate size 108

Figure 6.4. Gas chromatograph of pure cyclooctene. 109

Figure 6.5. Gas chromatograph of the epoxidation products of cis-cyclooctene after $2 \mathrm{~h}$ of reaction at $60^{\circ} \mathrm{C}$

Figure 6.6. Cyclooctene conversion, epoxide selectivity and epoxide yield over mesoporous $\mathrm{Ga}_{2} \mathrm{O}_{3}$ synthesized by $\mathrm{SAHA}$ after $2 \mathrm{~h}$ of reaction at $80^{\circ} \mathrm{C}$ 110

Figure 6.7. Gas chromatogram of the epoxidation products of cyclooctene after $2 \mathrm{~h}$ of reaction at $80^{\circ} \mathrm{C}$

Figure 6.8. Cyclooctene conversion and epoxide selectivity with respect to time over A) $\mathrm{Ga}_{2} \mathrm{O}_{3}$ prepared by employing P123 as SDA 113

Figure 6.9. A general schematic representation of skeletal isomerisation of 
methyl oleate to its branced isomers

Figure 6.10. a) ${ }^{1} \mathrm{H}$ NMR and b) ${ }^{13} \mathrm{C}$ NMR patterns for the isomerization products of methyl oleate obtained by using GaNb4 catalyst ......... 118

Figure 6.11. Plot of Composition of GaNb against Methyl oleate conversion and Acidity of the catalyst.

Figure 6.12. HRTEM images of the crystals of mesoporous a) $\mathrm{Ga}_{2} \mathrm{O}_{3}$,

b) GaNb3 mixed oxide, c) GaNb4 mixed oxide and

d) $\mathrm{Nb}_{2} \mathrm{O}_{5}$ with their respective $\mathrm{SAED}$ patterns as inset 


\section{CHAPTER 1}

\section{INTRODUCTION}

\subsection{Gallium oxide as Catalyst}

Gallium occurs below aluminium in group 13 of the periodic table and resembles aluminium in its chemical properties. It is present in all naturally occurring aluminium minerals. Gallium oxide displays polymorphism similar to alumina, and the various polymorphs are designated as $\alpha, \beta, \gamma, \delta$, and $\varepsilon-\mathrm{Ga}_{2} \mathrm{O}_{3}[1-4]$. However, $\beta$ $\mathrm{Ga}_{2} \mathrm{O}_{3}$ is the only stable crystalline phase $[3,5,6]$, whereas all the other polymorphs are metastable and transform into the $\beta$-form at sufficiently high temperatures. Among these polymorphs $\alpha-\mathrm{Ga}_{2} \mathrm{O}_{3}$ is rhombohedral, $\beta-\mathrm{Ga}_{2} \mathrm{O}_{3}$ is monoclinic, and $\gamma$ $\mathrm{Ga}_{2} \mathrm{O}_{3}$ is cubic. Based on the crystallographic data regarding the atomic positions, the three dimensional crystal structures for $\alpha-\mathrm{Ga}_{2} \mathrm{O}_{3}$ and $\beta-\mathrm{Ga}_{2} \mathrm{O}_{3}$ are shown in Figure 1.1 [7]. Unfortunately, such crystallographic data are unavailable for $\gamma-\mathrm{Ga}_{2} \mathrm{O}_{3}$. These different crystal structures significantly influence the surface properties of $\mathrm{Ga}_{2} \mathrm{O}_{3}$, accounting for the variation in catalytic activity among the polymorphs [4, 7-9]. The $\gamma-\mathrm{Ga}_{2} \mathrm{O}_{3}$ polymorph is of particular interest because of its high surface area, which opens the possibility of using this material as an efficient catalyst $[2,6]$. Gallium oxide is mainly an acidic oxide, with only negligible amount of basic sites, thus implying that acidic sites may play a more important role in catalysis [10]. Based on the analogy of $\mathrm{Ga}_{2} \mathrm{O}_{3}$ to $\mathrm{Al}_{2} \mathrm{O}_{3}$, these acid sites should be Lewis acid sites. 


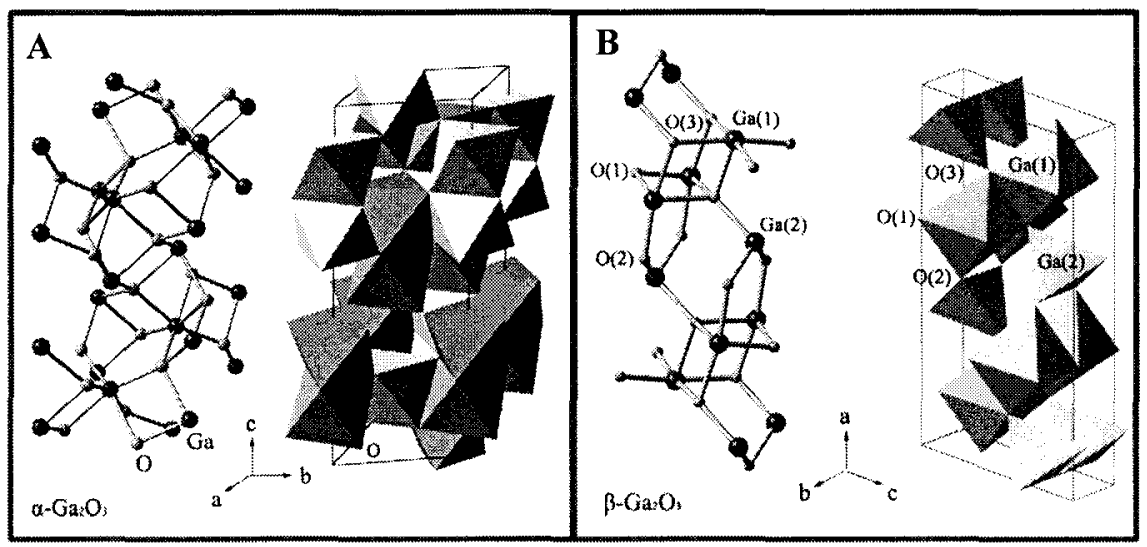

Figure 1.1. Three dimensional crystal structure of $A) \alpha-\mathrm{Ga}_{2} \mathrm{O}_{3}$ and $\left.\mathrm{B}\right) \beta-\mathrm{Ga}_{2} \mathrm{O}_{3}$ [7]. Gallium oxides and gallium-based mixed oxides are of great interest in the field of heterogeneous catalysis. $\mathrm{Ga}_{2} \mathrm{O}_{3}$-based catalysts are active in the dehydrogenation of light alkanes [11] and in the selective catalytic reduction of $\mathrm{NO}_{x}$ by hydrocarbons in the presence of oxygen [12]. Supported gallium oxides are preferred over zeolites in the de- $\mathrm{NO}_{x}$ reaction because of their acidity [13]. These catalysts are also effective in the aromatization of ethane in the presence of $\mathrm{CO}_{2}$ [11]. Different polymorphs of gallium oxide have been employed for the dehydrogenation of alkanes to alkenes $[10,14]$. The dehydrogenation reactions seem to be catalyzed by the acid sites on $\mathrm{Ga}_{2} \mathrm{O}_{3}$. The acidity of $\mathrm{Ga}_{2} \mathrm{O}_{3}$ is further enhanced in the presence of $\mathrm{CO}_{2}$, as slightly acidic $\mathrm{CO}_{2}$ may be strongly adsorbed onto the basic sites of $\mathrm{Ga}_{2} \mathrm{O}_{3}$

[11]. The catalytic dehydrogenation of alkanes into their corresponding alkenes is of great importance because of the growing demand for alkenes. For example propane is an important raw material for the production of propylene, polyacrylonitrile, acrolein, cumene and acrylic acid $[10,15]$. Different polymorphs of $\mathrm{Ga}_{2} \mathrm{O}_{3}$ have also been reported in the photocatalytic destruction of volatile aromatic pollutants in air. The photocatalytic performance of the $\mathrm{Ga}_{2} \mathrm{O}_{3}$ polymorphs is strongly influenced by their crystal structure, pore structure and size of the photocatalysts [7]. Recently, gallium oxide has been studied as catalyst in the epoxidation of alkenes, since it is active in 
the presence of aqueous hydrogen peroxide, it is selective and it does not contain transition metals [16]. However, its stability and its efficiency in using $\mathrm{H}_{2} \mathrm{O}_{2}$ need to be improved before it can meet the requirements for industrial applications. Epoxides are versatile intermediate compounds that are used in the synthesis of a number of fine chemicals with relevant industrial applications [16, 17].

\subsection{Conventional Synthesis Methods of Gallium Oxide}

Bhom first reported the synthesis of this gallia polymorph by the calcination of "gallium hydroxide gel" $[18,19]$ but the synthesis of this phase is not an easy task; the most important point is that the gel must be quickly dried. Bhom made it clear that prolonged contact of hydroxide gel particles with water causes the formation of $\mathrm{GaO}(\mathrm{OH})$ monohydrate, having a diaspore type structure. Once this structure is attained, the calcination does not lead to $\gamma-\mathrm{Ga}_{2} \mathrm{O}_{3}$ but to the $\alpha$ - or $\beta$-gallia polymorphs instead [3]. According to Roy and co-workers, $\gamma-\mathrm{Ga}_{2} \mathrm{O}_{3}$ prepared by this method transforms in to $\beta-\mathrm{Ga}_{2} \mathrm{O}_{3}$ at $650^{\circ} \mathrm{C}$ or $300^{\circ} \mathrm{C}$ in dry and wet conditions, respectively [3]. Phol [20] reported the precipitation of cubic $\gamma-\mathrm{Ga}_{2} \mathrm{O}_{3}$ with a defect spinel structure by heating metallic gallium with an organic solution at $150^{\circ} \mathrm{C}$ for several days. Gallium oxide has been synthesized using diverse techniques such as thermal decomposition [15], homogeneous precipitation using ammonia [2, 15, 21-23], surface layer adsorption [24], and solvothermal oxidation of gallium metal [19].

Thermal decomposition of various metal nitrates is commonly used to prepare metal dispersed catalysts. Typically the metal nitrates are dispersed on suitable porous supports and are decomposed to form oxides that are in a subsequent step, reduced to metal in the presence of $\mathrm{H}_{2}$. The first stage thermal decomposition of gallium nitrate hydrate leads to the formation of $\mathrm{Ga}(\mathrm{OH})_{2} \mathrm{NO}_{3}$ which further undergoes decomposition to $\mathrm{Ga}(\mathrm{OH})_{3}$ and $\mathrm{Ga}\left(\mathrm{NO}_{3}\right) \mathrm{O}$, compounds that then decompose 
respectively to $\mathrm{Ga}(\mathrm{OH}) \mathrm{O}$ and finally to $\mathrm{Ga}_{2} \mathrm{O}_{3}$ and directly to $\mathrm{Ga}_{2} \mathrm{O}_{3}$ [25]. $\beta-\mathrm{Ga}_{2} \mathrm{O}_{3}$ prepared by thermal decomposition has been employed as a dehydrogenation catalyst for ethane. Though the catalyst showed activity in the presence of $\mathrm{CO}_{2}$ at $650^{\circ} \mathrm{C}$, the surface area was low and the material displayed poor crystallinity.

Surface layer absorption technique is believed to be a general, simple and cheap approach to prepare hollow spheres of various transition metal salts. The traditional templating process employed latex or silica as the templaes, and a coating is deposited on the sacrificial core by controlled surface precipitation/adsorption of the inorganic precursors from a solution or suspension. Alkoxides are generally used as the starting materials in this process. The core is subsequently removed by thermal or chemical means, leading to the formation of hollow spheres. Sun et.al [24] reported a facile surface-layer adsorption (SLA) templating technique to obtain monodispersed $\mathrm{Ga}_{2} \mathrm{O}_{3}$ hollow spheres. The strategy used to obtain monodispersed $\mathrm{Ga}_{2} \mathrm{O}_{3}$ hollow spheres can be divided in two steps: 1) the adsorption of gallium ions from solution into surface layer; 2) calcination of the composite spheres in air to remove the carbon core, which results in oxide hollow spheres. The structure of these spheres make it a promising material for catalysis and light advanced ceramic materials. Even though SLA is a cheap and simple method to prepare size-tunable $\mathrm{Ga}_{2} \mathrm{O}_{3}$ hollow spheres with uniform shells, the as synthesized oxides displayed poor crystallinity [24].

Different polymorphs of gallium oxide have been synthesized most commonly by the homogeneous precipitation method using ammonia under continuous stirring. Hou et.al [7] reported the synthesis of $\alpha-, \beta-$ and $\gamma-\mathrm{Ga}_{2} \mathrm{O}_{3}$ by homogeneous precipitation of alocoholic solution of gallium nitrate using aqueous ammonia along with their photocatalytic activity toward the degradation of aromatic compounds. Only a few preparation methods other than those mentioned above have been 
reported: hydrothermal oxidation of gallium metal $[20,26]$, glycothermal reaction of gallium acetylacetonate [27], and solvothermal reaction of $\mathrm{GaCl}_{3}$ in DMF in the presence of an amine base [28]. Solvothermal oxidation has been examined for other metals such as aluminium $[29,30]$ and cerium [31] oxidized by straight chain primary alcohols. S. Kim et al. reported the solvothermal oxidation of gallium metal with various aminoalcohols at $300^{\circ} \mathrm{C}$ under the autogenous vapor pressure of the solvents, yielding $\gamma-\mathrm{Ga}_{2} \mathrm{O}_{3}$. The product obtained by this reaction has relatively large crystallite size with cubic-spinel type structure, but lacked the presence of mesopores [19]. Conventional synthesis methods for the preparation of gallium oxide and galliumbased mixed oxide catalysts offer limited control over structural, morphological and compositional properties, which may negatively affect its catalytic performance.

Recently, gallium oxide nanotubes as well as nanowires have been successfully grown using various materials and have received attention due to their mesoscopic phases, which provide new physical properties and strong applications for devices. Various independent growth mechanisms have been suggested for the growth of nanostructures:

1) vapour-liquid-solid (VLS) growth, where nanowires continue to grow via eutectic alloys existing at the tip of nanowires [32-34];

2) catalytic growth assisted by small amount of transition metal [35-37];

3) template-induced growth where carbon nanotubes are employed as templates [38-40];

4) oxide assisted growth, where oxides play a dominant role in the nucleation and growth of high-quality semiconductor nanowires [41, 42].

Monoclinic gallium oxide exhibits a wide bandgap of $4.9 \mathrm{eV}$ and can be an insulator or $\mathrm{n} n$-type semiconductor depending on the growth conditions employed. It 
also has potential applications in optoelectronic devices and high-temperature-stable sensors. Gallium oxide nanowires have been recently synthesized by various hightemperature methods, including arc-discharge method [42, 43], the vapour-liquidsolid (VLS) method [39, 44], carbothermal reduction [45, 46], thermal oxidation via the vapour-solid (VS) process [47, 48], and physical evaporation [49, 50]. Additional nanostructures such as nanoribbions and nanosheets were obtained via hightemperature reaction of $\mathrm{Ga}^{\circ}$ with water [51] or by evaporation of gallium nitride at high temperature in the presence of oxygen [47]. All these methods produced crystalline $\mathrm{Ga}_{2} \mathrm{O}_{3}$ nanowires with relatively low specific surface areas. Furthermore, these techniques are complex, time consuming and costly.

\subsection{Mesostructuring Gallium Oxide}

The surfactant-assisted self-assembly approach reported by researchers at Mobil Research and Development Corporation $[52,53]$ represents an alternative and attractive method for the synthesis of novel transition metal oxide catalytic phases with desirable structural, compositional, and morphological properties [54-56]. In the seminal work done by researchers at Mobil Corporation, ordered periodic mesoporous inorganic oxides were first reported in the nineties $[52,53,57]$. According to the IUPAC definition, mesoporous materials are the materials with pore sizes in the 2 to $50 \mathrm{~nm}$ range. These materials with well defined pores and high surface areas $(>1000$ $\mathrm{m}^{2} / \mathrm{g}$ ), belong to the family of so-called M41S aluminosilicate molecular sieves. These materials break past the pore size constraints of microporous zeolites and have a high potential for applications, particularly in the field of catalysis, separation processes and host guest chemistry. The preparation of the M41S phases represents a new approach in the organic template-assisted synthesis, where, instead of individual organic molecules (as in the case of zeolites), self-assembled molecular aggregates or 
supramolecular assemblies are employed as the structure-directing agents. The discovery of M41S silicas has simulated the search for other ordered mesostructured non-siliceous materials [58-60].

Carreon and Guliants have reviewed the guiding principles for the synthesis of metal oxide mesostructures relevant to applications in catalysis [56]. Due to its unique and remarkable catalytic properties, gallium oxide is an attractive system for mesostructuring. Only a few reports have been published on mesoporous gallium oxide synthesized employing surfactants as structure directing agents. Arean et.al [2, 23] reported the synthesis of mesoporous $\gamma-\mathrm{Ga}_{2} \mathrm{O}_{3}$ via calcination of gallia gel obtained by adding ammonia to an ethanolic solution of gallium nitrate. Yada et al. $[21,22]$ synthesized mesostructured gallium oxide, with hexagonal and layered structures by employing sodium dodecyl sulfate as the structure directing agent (SDA). Tas et al. reported the formation of $\mathrm{GaOOH}$ particles by forced hydrolysis of $\mathrm{Ga}^{3+}$ ions in pure water or in the presence of decomposing urea [61, 62]. This method has also been used for the synthesis of mesostructured aluminium and rare earth oxides templated by alkyl sulphate assemblies [63-68]. Although the resultant mesophases displayed relatively high surface areas, they showed poor crystallinity and were thermally unstable at temperature above $300^{\circ} \mathrm{C}$.

In this work, our focus is on the rational design of mesoporous gallium oxide and novel gallium-based mixed oxides employing self-assembly approaches, namely a) Evaporation-Induced Self-Assembly (EISA), b) Self-Assembly HydrothermalAssisted (SAHA) and c) Self-Assembly Microwave-Assisted approaches. The resulting mesophases display unique properties such as high surface area, and unimodal pore size distribution with controlled crystallinity, thus making them highly attractive as heterogeneous catalysts. We demonstrate the poly-functional nature of 
these mesophases as effective catalysts in the a) Epoxidation of alkenes in the presence of $\mathrm{H}_{2} \mathrm{O}_{2}$, b) Isomerization of Methyl Oleate, a major component of Biodiesel and c) Transformation of Biodiesel to their branched isomers over gallium based mixed oxides. Epoxides are a class of versatile highly useful intermediates that can be employed in the synthesis of many important fine chemicals with relevant industrial applications [69]. Methyl oleate is a fatty acid methyl ester (FAME) and is a major component of biodiesel obtained from triglyceride oils, like soy beans oil, by transesterification with methanol. One of the major drawbacks of such FAME biodiesels, compared to petro diesels, is their high freezing points because of which they cannot be used in very cold climates. Skeletal isomerisation, over acid sites, of the linear, unsaturated esters to branched esters or dehydrogenation (over redox sites) of the mono-olefinic esters to the diolefinic esters can reduce their freezing points. Branched FAME has lately emerged as an alternative fuel of wide acceptance due to its lower environmental impact as compared to diesel petroleum fuels [70-72].

\subsection{Motivation}

Conventional synthesis methods for the preparation of gallium oxide and gallium-based mixed oxide catalysts offer limited control over structural, morphological and compositional properties, which may negatively affect catalytic performance. The current project is focused on the development of thermally stable mesoporous gallium oxide and gallium-based mixed oxide catalysts with high surface areas, controlled crystallinity (from semi-crystalline to fully crystalline), tunability of pore sizes and structures to achieve high rate of molecular transport and possibly shape selectivity for the diverse model reactions. Three distinctive approaches were employed for the synthesis of these mesophases, namely a) Evaporation-Induced SelfAssembly (EISA), b) Self-Assembly Hydrothermal-Assisted (SAHA) and c) Self- 
Assembly Microwave-Assisted approaches. These methods not only eliminate the need for the high synthesis temperatures commonly required for solid-state reactions, but also offer the possibility to synthesize thermally stable mesoporous oxides.

\subsection{Objectives}

The main thrust of this project is to overcome the limitations offered by the conventional synthesis methods and develop polyfunctional ordered mesoporous $\mathrm{Ga}_{2} \mathrm{O}_{3}$ and $\mathrm{Ga}$-based mixed oxide catalysts via self-assembling inorganic building blocks in the presence of supramolecular crystalline phases. The specific goals of this work include:

1. Rational design of hierarchical ordered mesoporous (2-30 $\mathrm{nm}$ pore size) gallium oxide and gallium based mixed metal oxides with high surface areas, controlled crystallinity (amorphous to fully crystalline), tunability of pore sizes and structures.

2. Elucidate and understand the basic mechanisms directing the formation of these mesoporous materials on confined nanotemplate environments.

3. Study the catalytic performance of these ordered mesoporous single and mixed gallium oxide catalysts in the isomerisation, and epoxidation reactions.

4. Establish the relationship between the hierarchical structure and the catalytic properties of these novel mesoporous oxide catalysts.

\subsection{Thesis Organization}

In the first chapter, a brief introduction is presented about the material of interest i.e. gallium oxide. Also the various conventional synthesis methods are described along with the need for mesostructured gallium oxide is demonstrated. The motivation of this work and objectives are stated in this chapter too. 
In the second chapter, a brief description about the origin of the mesoporous materials is given. Also described in this chapter are the various structure directing agents used for the synthesis of mesoporous materials and the mechanism involved in the formation of these mesophases. Different techniques employed for the synthesis of mesoporous materials are presented. Finally, a brief description of the model reactions of interest is discussed.

Chapter three presents, experimental details on the preparation of mesoporous gallium oxide and gallium based mixed metal oxides via various techniques namely: Evaporation-Induced Self-Assembly (EISA), Self-Assembly Hydrothermal-Assisted (SAHA) and Self-Assembly Microwave-Assisted approaches is presented. The characterization, catalytic performance of these oxides and analysis of the reaction products is also described.

In the fourth chapter, a detailed description on the characterization of thermally stable nanocrystalline mesoporous gallium oxide displaying high surface area and unimodal pore size distribution employing different structure directing agents and synthesis techniques is presented.

Chapter five describes the detailed characterization of mesoporous galliumbased mixed transition metal oxides namely: gallium-niobium and galliummolybdenum mixed oxides.

In Chapter six, we discuss the catalytic performance of mesoporous gallium oxide, niobium oxide and gallium-niobium mixed oxides in various model reactions such as epoxidation of cyclooctene, isomerisation of methyl oleate and transformation of biodiesel. 
Chapter seven includes the meaningful conclusions obtained in the present study and some suggestions and recommendations for further work. Finally future research directions are proposed. 


\section{CHAPTER 2}

\section{BACKGROUND}

In this chapter, generalities on mesoporous materials are presented. First we discuss the origin of mesoporous materials and their synthesis using various types of templates. In the second part fundamentals of mesostructuring metal oxides via coassembly between inorganic entities and liquid crystalline phases on evaporation are discussed, along with relevant structural, textural and compositional properties of silicate and non-silicate systems synthesized by evaporation-induced self-assembly. This section is followed by a brief description about emerging catalytic applications of the mesophases synthesized via EISA. In the third part the importance of selfassembly hydrothermal-assisted and microwave-assisted heating approaches are highlighted. Finally, we discuss the model reactions that were employed to test the catalytic performance of mesoporous gallium oxide and gallium-based mixed oxides.

\subsection{Origin of Mesoporous Materials}

Ordered periodic mesoporous inorganic oxides were first reported by researchers at Mobil Research and Development Corporation [52, 53, 57]. These materials have well defined pores in the range of $\sim 2$ to $30 \mathrm{~nm}$ and high surface areas $\left(>1000 \mathrm{~m}^{2} / \mathrm{g}\right)$. These materials break past the pore size constraints of microporous zeolites and have a high potential for applications, particularly in the fields of catalysis, separation processes, and host guest chemistry. The preparation of mesophases 
represents a new approach in organic-template-assisted synthesis, where, instead of individual organic molecules (as in the case of zeolites), self-assembled molecular aggregates or supramolecular assemblies are employed as the structure-directing agents.

\subsection{Surfactant-Assisted Self-Assembly of Mesoporous Materials}

\subsubsection{Fundamentals}

The original M41S family of mesoporous molecular sieves was synthesized by reacting a silica source (e.g., tetraethylorthosilicate (TEOS), Ludox, fumed silica, etc.), an alkyltrimethylammonium halide surfactant (e.g., cetyltrimethylammonium bromide (CTAB)), a base (e.g., sodium hydroxide), and water at $>100^{\circ} \mathrm{C}$ for $24-144$ h. Since then, most of the studies have employed charged (cationic and anionic) and neutral surfactants as templates, which direct the mesophase formation based on the electrostatic interaction [73] and hydrogen-bonding interactions [74], respectively. As far as formation mechanism is concerned, the liquid-crystal templating (LCT) mechanism displayed in Figure 2.1 was proposed by Beck et al. [53], based on the similarity between liquid crystalline surfactant assemblies (i.e. lyotropic phases) and M41S.

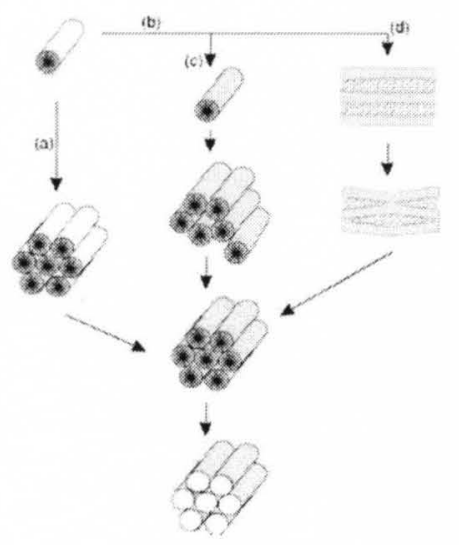

Figure 2.1. Formation of mesoporous phases by liquid crystal templating (LCT) mechanism [57]. 
The formation of these mesophases takes place by the following pathway:

a) via pre-existing liquid crystal phase

b) via the formation of silica-coated surfactant species

c) either from micelles which agglomerate to form ordered and disordered arrays or,

d) a lamellar phase which undergoes a phase transition into the final hexagonal phase.

An ordered mesoporous phase exhibiting a hexagonal MCM-41, cubic MCM-48 and lamellar MCM-50 array of ordered pores can be obtained after template removal as shown in Figure 2.2.

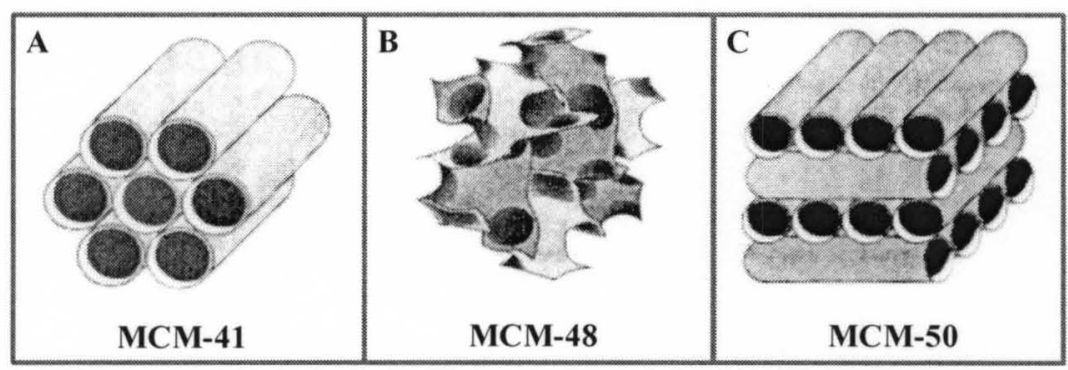

Figure 2.2. Three types of structures observed for silica-surfactant mesophases: A) MCM-41 (hexagonal), B) MCM-48 (cubic) and C) MCM-50 (lamellar) [56].

\subsubsection{Ionic Surfactant Template}

Mobil researchers were first to introduce self-assembling surfactants as structure directing agents in order to direct the formation of mesostructured silica materials [75]. According to the Mobil's researchers, long-chain quaternary ammonium surfactants tend to minimize their energy in solution by assembling into micelles [53]. Under certain synthesis conditions these micelles can adopt a rod-like shape and even organize into long-range hexagonal arrays with the charged head groups pointing toward the solution and the long hydrocarbon chains (hydrophobic) 
pointing toward the center of the micelles. The ability of the long-chain quaternary ammonium cations to form rod-like micelles and long-range hexagonal arrays in aqueous solutions (with rod diameters in the mesoporous range 2.0 to $4.0 \mathrm{~nm}$ ) has been known since the pioneering work of Luzzati in 1970 [76-79]. The formation of the micellar rods and their organization into hexagonal arrays is primarily controlled by the alkyl chain length and concentration of the surfactant, the nature of the halide counter-ion, and temperature of the solution as shown in Figure 2.3. As soon as the silicate precursor is added to the surfactant solution, the negatively charged silica species $\left(\mathrm{I}^{-}\right)$condense and polymerize on the surface of the positively charged micelles $\left(\mathrm{S}^{+}\right)$, giving rise to the hexagonal $\mathrm{S}^{+} \mathrm{I}^{-}$organic-inorganic phase. Upon calcination of the phase revealed the hexagonal solid framework of this particular mesoporous molecular sieve (denoted MCM-41). A number of mechanistic pathways have been proposed for the formation of ordered mesophase structures in the form of hexagonal, cubic or lamella found in these materials from varied starting materials under different reaction conditions.

The ionic surfactant templating pathways to form ordered mesostructures employ assemblies of charged surfactant ions $\left(\mathrm{S}^{+}\right.$or $\left.\mathrm{S}^{-}\right)$as templates to organize an inorganic framework from charged inorganic oxide precursors $\left(\mathrm{I}^{-}\right.$or $\left.\mathrm{I}^{+}\right)$. This formation mechanism was further extended by Stucky and co-workers [83-85] to a whole series of other electrostatic assembly mechanisms, such as a reversed $\mathrm{S}^{-} \mathrm{I}^{+}$ mechanism and counterion mediated $\mathrm{S}^{+} \mathrm{XI}^{-}$and $\mathrm{S}^{-} \mathrm{M}^{+} \mathrm{I}^{-}$pathways. The use of anionic surfactant via $\mathrm{SI}^{-}$or $\mathrm{SM}^{-} \mathrm{S}^{-}$interaction has resulted in lamellar and disordered mesostructures. These charged templates are strongly bonded to the charged inorganic framework, and are difficult to recover. In general, the electrostatically bonded 
templates are removed from the framework of materials by either a calcination process or solvent extraction method.

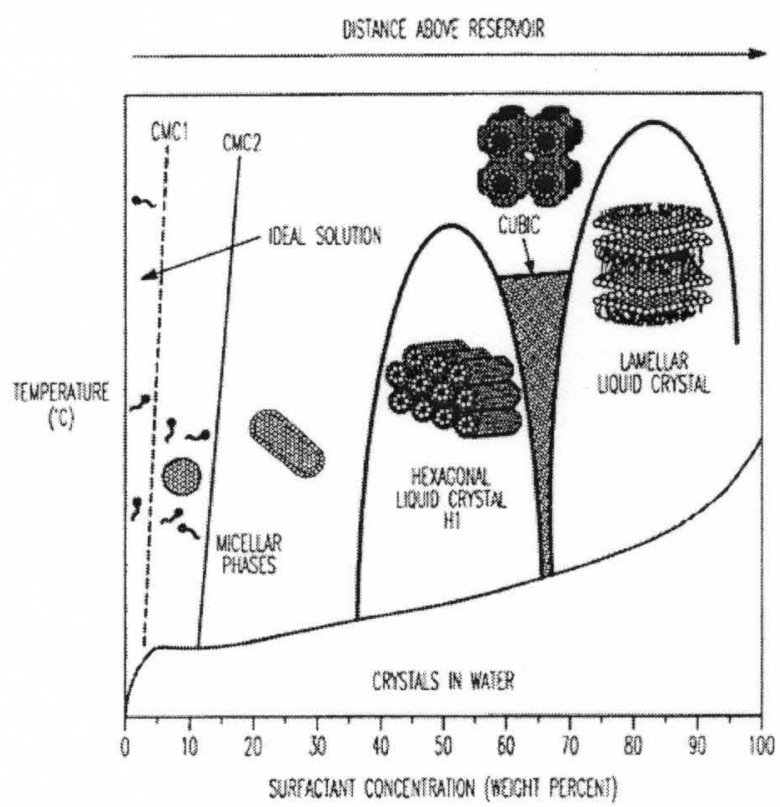

Figure 2.3. Schematic phase diagram for cationic surfactant, $\mathrm{CH}_{3}\left(\mathrm{CH}_{2}\right)_{15} \mathrm{~N}\left(\mathrm{CH}_{3}\right)_{3}{ }^{+} \mathrm{Br}^{-}$ $\left(\mathrm{C}_{16} \mathrm{TMABr}\right)$ in water. $\mathrm{c}<\mathrm{CMC1}$, the surfactant is present as free molecules dissolved in solution; $\mathrm{CMC} 1<\mathrm{c}<\mathrm{CMC} 2$, surfactants in the form of spherical aggregates (micelles); $\mathrm{CMC} 2<\mathrm{c}<\mathrm{LC}$, spherical micelles coalesce to form elongated cylindrical micelles; $\mathrm{c}=\mathrm{LC}$, liquid-crystalline (LC) phase form. Initially, rodlike micelles aggregate to form hexagonal close-packed LC arrays, then cubic bicontinuous LC phases form followed by LC lamellar phases [80-82].

A number of silica-based mesoporous materials as well as materials with nonsilica frameworks have been reported to be formed via these electrostatic assembly pathways [54]. From the catalytic point of view, these materials are of great interest as long as the pores are open (after template removal) and the internal surface is accessible [55]. MCM-41 and the analogues have great potential in practical applications owing to their large surface areas and pore volumes, along with ordered arrangement of uni-dimensional pores much greater than zeolites. The large pores of mesoporous materials may alleviate, if not eliminate, the internal diffusion limitation of mass transport in the matrix and result in an improved reaction rate. 


\subsubsection{Neutral Surfactant Templates}

Most of the early mesoporous materials were thermally instable due to the existence of several relatively unstable oxidation states of the metal centers. Thus the oxidation and reduction reactions during calcination led to structural collapse [86]. Pinnavaia et al. developed two additional approaches for the synthesis of mesoporous materials based on non-ionic organic-inorganic interactions by employing neutral surfactants such as primary amines and poly(ethylene oxides) [55]. Mesoporous materials prepared in the presence of neutral surfactants as the template usually have improved stability [74]. In case of primary amine (with carbon tail lengths between $\mathrm{C} 8$ and $\mathrm{C} 18$ ) as templates, the pore size of the final mesoporous silicas (designed as HMS) may be adjusted by changing the hydrophobic tail length of amines. The hydrogen bonding interactions and self-assembly between neutral primary amine micelles $\left(\mathrm{S}^{\circ}\right)$ and neutral inorganic precursors $\left(\mathrm{I}^{\circ}\right)$ directs the formation of mesophases. The template can be removed by solvent extraction, which is advantageous both from an economical and an ecological point of view. The mesoporous materials have greater wall thickness $(1.7-3.0 \mathrm{~nm})$ due to the absence of electrostatic or charge-matching effects and thus higher thermal stability than M41S materials. However, the materials exhibit only short range hexagonal ordering. The high cost and toxicity of amines also limit their use in large-scale production.

Polyethylene oxide (PEO) surfactants are a convenient alternative to primary amines and have demonstrated advantage in solving the problems of ionic surfactant, since the PEO surfactants are neutral, nontoxic, and biodegradable [87-90]. In this $\mathrm{S}^{\mathrm{0}} \mathrm{I}^{\mathrm{o}}$ templating pathway, hydrogen bonding interactions between the hydrophilic surfaces of flexible rod- or worm-like micelles and intermediate hydrolysis products are postulated to be the driving force in the formation of the mesophases. The pore 
size of the materials (designated as MSU) can be tuned by varying the length and structure of the surfactant molecules. One of the most useful groups of surfactants are the triblock copolymers consisting of poly(ethylene oide $)_{x}$-poly(propylene oxide $)_{y}$ poly(ethylene oxide $)_{x},(\mathrm{PEO})_{\mathrm{x}}(\mathrm{PPO})_{\mathrm{y}}(\mathrm{PEO})_{\mathrm{x}}$ (trade name: Pluronics) which show the ability to form liquid-crystal structures. This approach can be employed for the preparation of variety of ordered mesoporous materials with rather large framework wall thickness, small particle sizes, and complementary framework-confined and textural mesoporosity. In addition, this approach allows for cost reduction by employing less expensive reagents and mild reaction conditions while providing for the effective and environmentally benign recovery and recyclability of the template.

\subsection{Evaporation-Induced Self-Assembly Origins}

A more elegant approach to direct the formation of a mesostructure was reported by Ozin's [91, 92] and Brinker's [93] groups. In these first examples, mesoporous silica films were grown on cleaved mica substrates and at the air-water interface [91, 92]. Firstly, elongated mesoporous silica film islands formed on the surface of mica that was used as the substrate, implying that the crystal growth was regulated by charge and structure matching at the interface. These crystalline islands then expanded in size, and continuous assembly of the silica-micellar species led to the growth of the mesoporous film. Mesoporous films were grown also at the airliquid interface; where it was proposed that the film formation involved polymerization of silicates in the surfactant head-group regions of the hexagonal mesophase, which concentrated with time at the liquid-air surface interface. Preexisting incipient silica mesostructures present at solid-liquid and liquid-vapor interfaces at $\mathrm{Co}<\mathrm{CMC}$ (where $\mathrm{Co}$ is the initial surfactant concentration and $\mathrm{CMC}$ is the critical micelle concentration) helped to nucleate and orient the mesophase 
development. Therefore, this pre-organized surfactant layer was gradually formed with time and facilitated the organization of the ordered mesoporous film.

Later, the EISA concept was formally introduced [93], where it was demonstrated that a homogeneous solution of polymeric silica sol with an initial surfactant concentration below the critical micelle concentration, led to ordered mesoporous films. By varying the initial surfactant concentration, the film symmetry (i.e., hexagonal or cubic) was selectively tailored. The proposed formation mechanism involved cooperative assembly of silica-surfactant micellar species with supramolecular cylindrical or hemicylindrical micelles that self-assembled at the substrate-liquid interface at the initial stage of the deposition method. The method devised for the formation of thin films is known as the dip-coating method shown in Figure 2.4, which follows the principles of EISA. In this case, the surfactant enrichment by gradual solvent evaporation exceeded the critical micelle concentration leading to a cooperative self-assembly between the inorganic precursor and the surfactant micelles forming a well-defined mesostructure. The initial surfactant concentration for these reports was far below the critical micelle concentration. 


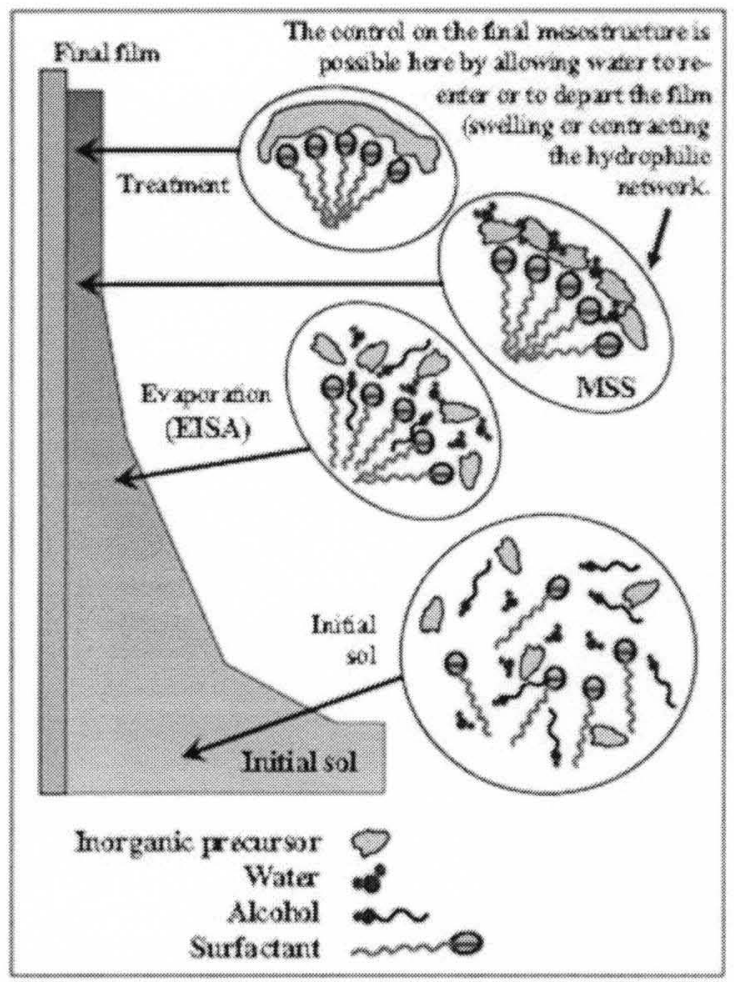

Figure 2.4. Mesostructured thin-film formation by via EISA [94].

\subsubsection{Basics of Evaporation-Induced Self-Assembly}

EISA is a well-suited approach to prepare ordered mesoporous thin films.

When a homogeneous solution of soluble silica and surfactant is prepared in the presence of ethanol or other volatile solvents and water with $\mathrm{Co}<<\mathrm{CMC}$, preferential evaporation of ethanol concentrates the film in surfactant and silica species. Then, a progressive increase in surfactant concentration drives the self-assembly of silicasurfactant micelles leading to a final organization into liquid crystalline mesophases. Through variation of the initial alcohol/water/surfactant mole ratio it is possible to obtain different mesostructures [95-96]. While preparing mesostructured films, via EISA, several parameters that influence the self-assembly process must be considered. These parameters have been divided in two categories [94]: 
(a) Chemical parameters, related to sol-gel hydrolysis-condensation reactions and relative quantities of surfactant and inorganic precursor; and

(b) Processing parameters related to the diffusion of alcohol, water, catalysts ( $\mathrm{HCl}, \mathrm{HNO}_{3}, \mathrm{H}_{2} \mathrm{SO}_{4}$ ) to or from the film.

Let us analyze first, the chemical parameters. The knowledge of the electrokinetic behavior (i.e., the isoelectric points) of the inorganic species in solution, and the nature, and density of chemical groups of the inorganic species, is required for fine-tuning electrostatic and other interactions at the inorganic-organic interface. For instance, the formation of the mesostructure is favored when neutral templates such as block copolymers are combined with inorganic precursor solutions in the vicinity of the isoelectric point. Above the isoelectric point, the metallic species carry a net negative charge and therefore cationic templates favour the self-assembly process, below the isoelectric point, metallic species carry net positive charge, and anionic templates favour the formation of well-defined mesostructures. The isoelectric points of various metal oxides and hydroxides are shown in Table 2-1 [97, 98]. It is of great importance that the dimensions of the inorganic species present in the initial solution do not exceed the mesostructure wall thickness (which are typically in the $1-10 \mathrm{~nm}$ range). The sol-gel chemistry reactions (hydrolysis and condensation) need to be controlled by adjusting the relative quantities of its components, such as water, the amount of catalyst, $\mathrm{pH}$, etc. For example, the rapid organization of thin film mesophases requires suppression of inorganic polymerization during the coating process [96]. For the most common system (i.e., silicates), this is achieved under acidic conditions (near the isoelectric point of silica, $\mathrm{pH} \sim 2$ ). Therefore, by turning off siloxane species condensation, the cooperative silica-surfactant self-assembly can take place [96]. 
Table 2.1. Isoelectric points of common transition metal oxides.

\begin{tabular}{|c|c|c|}
\hline Metal oxide & Isoelectric point & General comments \\
\hline $\mathrm{V}_{2} \mathrm{O}_{5}$ & 0.5 & oxovanadium(V) species \\
\hline $\mathrm{MoO}_{3}$ & $<0.5$ & $\mathrm{NA}$ \\
\hline $\mathrm{Nb}_{2} \mathrm{O}_{5}$ & $<0.5$ & natural rutile \\
\hline $\mathrm{TiO}_{2}$ & 4.7 & synthetic rutile, anatase \\
\hline $\mathrm{TiO}_{2}$ & 6.2 & natural mineral \\
\hline $\mathrm{ZrO}_{2}$ & 4.0 & $\mathrm{Zr}\left(\mathrm{NO}_{3}\right)_{4}+\mathrm{NaOH}$ \\
\hline $\mathrm{ZrO}_{2}$ & 6.7 & $\mathrm{Y}\left(\mathrm{NO}_{3}\right)_{3}+\mathrm{NaOH}$ \\
\hline $\mathrm{Y}_{2} \mathrm{O}_{3}(\mathrm{hydrous})$ & 8.95 & $\mathrm{NiO}$ \\
\hline $\mathrm{NiO}$ & $10.3 \pm 0.4$ & $\mathrm{Na}_{2} \mathrm{WO}_{4}+\mathrm{HCl}$ \\
\hline $\mathrm{WO}_{3}(\mathrm{hydrous})$ & 0.5 & $\mathrm{MgO}$ \\
\hline $\mathrm{MgO}$ & $12.4 \pm 0.3$ & $\mathrm{Mn}\left(\mathrm{NO}_{3}\right)_{2}+\mathrm{HCl}$ \\
\hline $\mathrm{MnO}_{2}$ & $4.0-4.5$ & natural magnetic \\
\hline$\alpha-\mathrm{Fe}_{2} \mathrm{O}_{3}$ & 8.7 & hydrolysis of Fe $(\mathrm{NO})_{3}$ solution \\
\hline$\gamma-\mathrm{Fe}_{2} \mathrm{O}_{3}$ & $6.7 \pm 0.2$ & precipitation of FeOOH \\
\hline $\mathrm{Fe}_{3} \mathrm{O}_{4}$ & $6.5 \pm 0.2$ & \\
\hline
\end{tabular}

Obviously, the molar ratios of inorganic precursors and surfactant need to be fixed to allow the organization of the mesostructure. Typical surfactant volume ratios are in the $20-80 \%$ vol. range based on surfactant-water-alcohol phase diagrams. For example, it has been shown that the CTAB/TEOS molar ratios between 0.1 and 0.35 lead to the formation of ordered periodic silica mesostructures with Pm3n cubic, p6m 2D hexagonal, $\mathrm{P} 63 / \mathrm{mmc} 3 \mathrm{D}$ hexagonal, or lamellar symmetries [99]. Other chemical parameters that need to be considered are the volatility and wettability of the alcohol with hydrophobic substrates. Typically, highly volatile alcohols, such as ethanol and butanol, with high wettability to substrates are desired for the preparation of homogeneous continuous films. Finally, the solution aging time is another important parameter to be controlled, since the extent of condensation of the inorganic species influences the formation of the final mesostructure. 
The processing parameters play a critical role once the initial solution is deposited on the substrate via dip-coating or spin-coating. Evaporation of volatile components takes place at the air-film interface as soon as the inorganic precursortemplate solution is deposited. At this point, preferential evaporation of volatile species occurs at the air-film interface. Gradual evaporation of volatile species leads to an increase in the surfactant and silica concentration in the film. At some point, the surfactant concentration reaches the critical micelle concentration leading to the formation of micelles with the subsequent formation of the organized mesostructure. It has been demonstrated that the critical processing parameter for the formation of ordered mesostructures is the relative humidity $(\mathrm{RH})$ [99]. In other words, the quantity of water in the film changes with RH and determines the final mesostructure. Obviously, the content of water and alcohol in the film can be adjusted by changing the relative humidity conditions in the medium in which the film is being aged. It has been demonstrated that an inorganic precursor-surfactant solution with low viscosity evaporates faster than more viscous solutions [100]. As a result, there is a short time needed for volatile species to diffuse through the film, leaving less time for intermediate phases to form. Therefore, by employing diluted solutions we can avoid intermediate multiphase formation. The formation of diverse mesophases by EISA strongly depends on the kinetics of competitive processes of condensation versus organization. Both processes are influenced by the diffusion of volatile species from or to the film surface.

The resultant as-synthesized mesostructure is treated thermally to eliminate the organic structure directing agents. This step is used to stabilize the inorganic framework and to obtain the open porous mesostructure. Calcination temperatures depend on the decomposition temperature of the structure directing agent. Typical 
values are in the $300-500^{\circ} \mathrm{C}$ range. Alternatively, the structure directing agents can be eliminated by solvent extraction [100] or ultraviolet (UV) photodegradation [101]. Figure 2.5 summarizes the steps involved in the organization of ordered periodic mesostructures.

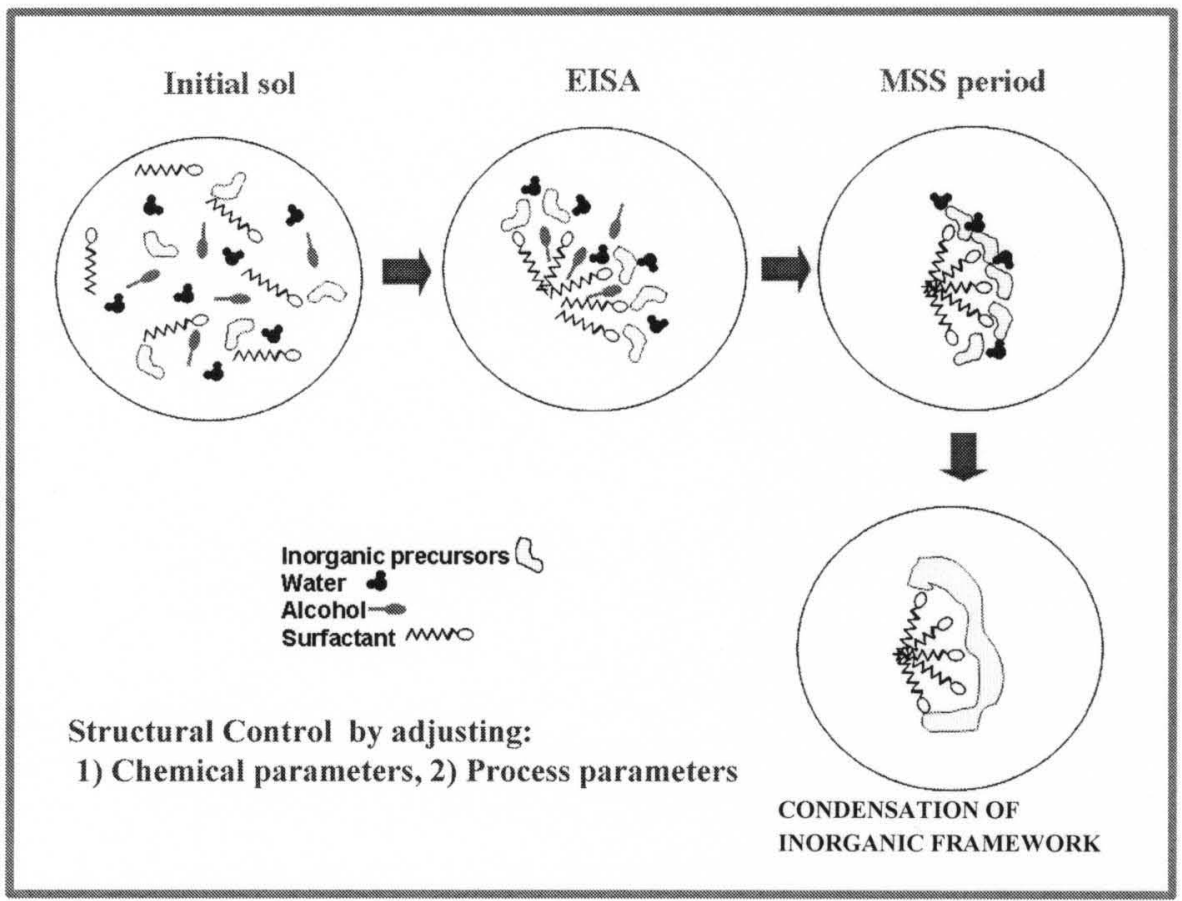

Figure 2.5. Schematic representation of evaporation-induced self-assembly for the preparation of long-range ordered mesostructures [102].

The initial solution contains the inorganic species, surfactant, and volatile components. As the evaporation of volatiles proceeds, surfactant concentration increases, and it aggregates to form micellar structures above the critical micelle concentration (EISA). When the mesostructure is initially formed, the inorganic framework is not fully condensed, and the control of the final mesostructure can be adjusted by modifying the RH conditions (i.e., water molecules can diffuse in and out of the film). At this point, the flexible mesostructure experiences a transition state known as modulable steady state (MSS) [99]. Finally, the inorganic framework fully condenses, forming the final mesostructure. One notable characteristic of EISA is the 
fact that in the mesostructured films made by dip-coating, the boundaries (vaporsolid) of the liquid impose alignment of the surfactant structures, and the presence of concentration gradients in the film and flow velocity may help in aligning the final mesostructure along certain preferred direction [103]. Therefore, it is possible to envision the preparation of oriented mesoporous thin films, which may represent ideal candidates for several important nanotechnological applications in bioseparations. A typical pathway for the formation of a final hexagonal mesostructure via EISA is shown in Figure 2.6. Point $\mathrm{A}$ is the initial solution composition, point $\mathrm{B}$ is the region in the vicinity of the drying line, and point $\mathrm{C}$ corresponds to the final dried film [96]. By changing the chemical parameters, such as initial solution concentration, and processing parameters, such as water content in the film, it is possible to follow different trajectories in this compositional space and, therefore, synthesize mesoporous materials with different space groups and pore symmetries.

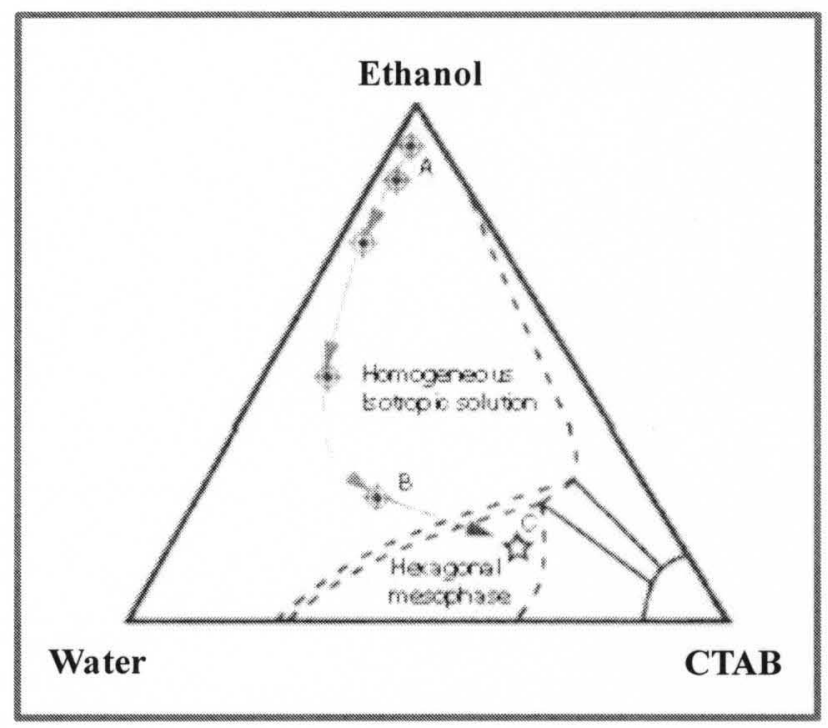

Figure 2.6. Typical EISA trajectory for the formation of mesostructured films by dipcoating [96]. 


\subsubsection{Mesostructured Silicate Systems}

The following paragraphs, describe relevant work done in the preparation of silicate-based films and particles via EISA. As discussed previously, the EISA concept was formally introduced in 1996. In that report, the authors showed a simple and continuous process for the formation of hexagonal and cubic silica mesostructures in thin film form. Spatially resolved fluorescence-depolarization experiments were employed to gain improved mechanistic understanding of the in situ micelle formation during the film deposition. For the initial diluted solution $(\mathrm{Co}<<\mathrm{CMC})$, it was found that the degree of polarization or molecular anisotropy was zero; then, as evaporation proceeded, the polarization increased abruptly to 0.18 (the point which was identified as the $\mathrm{CMC}$ ), which indicated that the silica surfactant micellar structures self-assembled by induced evaporation of the volatiles.

This polarization change was associated with the nearly isotropic nature of the micelles. Later, it was demonstrated that not only films but also spherical particles displaying long-range order hexagonal and cubic symmetries could be prepared via EISA employing an aerosol process $[95,96]$. It was proposed that evaporation during aerosol processing created in each droplet a radial gradient in surfactant concentration, with a maximum concentration at the surface of the droplet. As the evaporation proceeds, the CMC is exceeded from the surface throughout the droplet. This surfactant enrichment caused the organization of the final mesostructure. Based on the surfactant nature, mesoporous particles with different symmetries were prepared. For example, CTAB led to a hexagonal mesophase, Brij-58 favoured the cubic mesophase, and P-123 resulted in the formation of a vesicular mesophase. Alternatively, mesoporous films can be prepared by the aerosol method via coalescence of aerosol droplets. This method was successfully used with a variety of 
inorganic precursors (TEOS, silsesquioxane monomers) and surfactants (ionic: CTAB, SDS; copolymer: P-123; and non-ionic: Brij-56, Brij-58) [93, 95, 96, 104]. For example, Brinker's group reported the preparation of polybridged silsesquioxane films and particle-like mesostructures with organic moieties incorporated in the mesostructured inorganic framework via EISA [104]. Spin-coating and dip-coating were used to prepare homogeneous films, and an aerosol dispersion was used to prepare particles. In both approaches, the preferential evaporation of ethanol concentrated the sol in water, surfactant, and organic polysilsesquioxane species. The progressively increase in surfactant concentration led to the self-assembly of polysilsesquioxane surfactant micelles and their further organization into liquid crystalline phases. Typically, the formation of these mesostructured films or particles oriented with respect to the solid-liquid or liquid-air interfaces takes place in several seconds. Furthermore, modification of the surfactant shape, charge, and initial concentration led to different film or particle mesostructures.

Through EISA, it has been possible to molecularly design silicates with diverse chemical, physical, morphological, and structural properties. For example, a modified aerosol process (vibrating orifice aerosol generator) based on evaporation driven self-assembly for the synthesis of spherical silicate porous particles was proposed [105]. In this method, all the chemical species in solution are initially confined to microdroplets which experience evaporation-driven concentration changes. These concentration gradients led to self-assembled liquid crystalline surfactant structures that serve as templates for the organization of the inorganic precursors. Finally, the inorganic silica-based framework solidified by condensation, left a mesoporous silica mesostructure after template removal. Interestingly, this method offered control over particle size $(1-50 \mu \mathrm{m})$ and monodispersity, as well as 
control over internal mesostructure and pore size $(2.2-2.8 \mathrm{~nm})$. CTAB and Brij-58 were used as structure directing agents, TEOS as inorganic precursor and ethanol and water as solvents.

The same research group reported the preparation of smaller mesoporous spherical silica particles $(0.2-1 \mu \mathrm{m})$ with pore sizes of $2.7-3.1 \mathrm{~nm}$ by EISA of aerosols [106]. These spherical submicron particles displayed 2D hexagonally ordered mesostructures with 3D interconnected network of pores and BET surface areas up to $1300 \mathrm{~m}^{2} / \mathrm{g}$. The mesostructures were successfully obtained from acidic aqueous solutions $(\mathrm{pH}=2)$ of TEOS and CTAB. This $\mathrm{pH}$ near the isoelectric point of silica slows the rate of silica condensation, allowing a more efficient self-assembly during EISA. The CTAB/Si molar ratio was a critical chemical parameter to form hexagonally ordered mesostructures. These mesostructures were formed only in the $0.09<\mathrm{CTAB} / \mathrm{Si}<0.28$ range. The spheroidal shape, broad particle size regime, high accessible surface area, monodisperse pore size, and mesoporous nature make these materials highly attractive for its use as catalytic supports, sorbents, and chromatographic media.

Smaller pore size $(1.6-1.8 \mathrm{~nm})$ mesoporous silica with 2D hexagonal $(\mathrm{p} 6 \mathrm{~mm})$, 3D cubic $(\mathrm{Pm}-3 \mathrm{n})$, and 3D hexagonal $(\mathrm{p} 63 / \mathrm{mmc})$ pore structures have been prepared via EISA employing a polyoxyethylene alkyl amine surfactant (PN-430) and tetrahydrofuran (THF) to direct the synthesis [107]. The resultant mesophases displayed BET surface areas up to $730 \mathrm{~m}^{2} / \mathrm{g}$ and pore volume of $0.36 \mathrm{~cm}^{3} / \mathrm{g}$. Interestingly, solvothermal post-treatment with n-hexane at $70^{\circ} \mathrm{C}$ led to phase transformation from 3D cubic to 3D hexagonal mesophase. The structural order of these mesophases was improved by incorporating non-ionic co-surfactants (Brij-78 or TritonX-100). Table 
2.2 summarizes some of the relevant work done on the preparation of mesoporous silica-based films and particles by EISA.

Table 2.2. Mesostructured silica films and particles prepared by EISA.

\begin{tabular}{|c|c|c|c|c|}
\hline Structure & Precursors & Substrate & Deposition method & Reference \\
\hline $\begin{array}{l}\text { 3D hexagonal and cubic } \\
\text { films }\end{array}$ & TEOS, CTAB, EtOH, $\mathrm{H}_{2} \mathrm{O}, \mathrm{HCl}$ & $(100) \mathrm{Si}$ & Dip-coating & 93 \\
\hline $\begin{array}{l}\text { Hexagonal and cubic } \\
\text { particles }\end{array}$ & $\begin{array}{c}\text { TEOS, CTAB, Brij56, Brij58, P123 } \\
\text { EtOH, } \mathrm{H} 2 \mathrm{O}, \mathrm{HCl}\end{array}$ & None & Aerosol dispersion & 95 \\
\hline $\begin{array}{l}\text { ID hexagonal and cubic } \\
\text { (fcc) film particles }\end{array}$ & $\begin{array}{c}\text { Silsesquioxane TEOS, CTAB, SDS, P123 } \\
\text { EtOH, } \mathrm{H}_{2} \mathrm{O}, \mathrm{HCl}\end{array}$ & $(100) \mathrm{Si}$ & $\begin{array}{l}\text { Spin-coating, dip-coating, } \\
\text { aerosol dispersion }\end{array}$ & 104 \\
\hline Hexagonal particles & TEOS, CTAB, Brij58, EtOH, $\mathrm{H}_{2} \mathrm{O}, \mathrm{HCl}$ & None & $\begin{array}{l}\text { Vibrating orifice aerosol } \\
\text { generator }\end{array}$ & 105 \\
\hline 2D hexagonal particles & TEOS, CTAB, $\mathrm{H}_{2} \mathrm{O}, \mathrm{HCl}$ & None & Aerosol generator & 106 \\
\hline $\begin{array}{l}\text { Hexagonal and cubic ( } \mathrm{fcc}) \\
\text { films }\end{array}$ & $\begin{array}{l}\text { Methyl triethoxy silane, PS35-b-PEO, } \\
\qquad \mathrm{H}_{2} \mathrm{O}, \mathrm{HCl}, \mathrm{THF}\end{array}$ & Si wafers & Dropwise & 108 \\
\hline $\begin{array}{l}\text { 2D hexagonal }(p 6 m), 3 \mathrm{D} \\
\text { hexagonal (P63/mmc) cubic } \\
\text { and lamellar films }\end{array}$ & TEOS, CTAB, EtOH, $\mathrm{H}_{2} \mathrm{O}, \mathrm{HCl}$ & Siwafers & Dip-coating & 94 \\
\hline $\begin{array}{l}\text { 2D hexagonal }(p 6 m), 3 \mathrm{D} \\
\text { cubic ( } \mathrm{Pm} 3 \mathrm{n}), 3 \mathrm{D} \text { hexagonal } \\
(\mathrm{P} 63 / \mathrm{mmc}) \text { particles }\end{array}$ & $\begin{array}{c}\text { TEOS, polyoxoethylene alkylamine (PN- } \\
\text { 430), Brij78, Triton X100, } \mathrm{HCl}, \mathrm{H}_{2} \mathrm{O} \text {, } \\
\text { THF }\end{array}$ & None & Casting & 107 \\
\hline Hexagonal filaments & $\begin{array}{c}\text { TEOS, CTAB, Brij56, P123, EtOH, } \mathrm{H}_{2} \mathrm{O}, \\
\mathrm{HCl}\end{array}$ & $\begin{array}{l}\text { Alumina } \\
\text { membrane }\end{array}$ & Soaking & 109 \\
\hline Hexagonal films & $\begin{array}{c}\text { Silsesquioxanes, TEOS, CTACl, } \mathrm{HCl} \text {, } \\
\text { EtOH, } \mathrm{H}_{2} \mathrm{O}\end{array}$ & Si wafers & Spin-coating & 110 \\
\hline 2D hexagonal films & TEOS, $\mathrm{F} 127, \mathrm{EtOH}, \mathrm{HCl}, \mathrm{H}_{2} \mathrm{O}$ & Si wafers, slides & Dip-coating & 111 \\
\hline 2D hexagonal films & $\begin{array}{c}\text { TEOS, CTAB, } \mathrm{H}_{2} \mathrm{SO}_{4}, \mathrm{EtOH}, \mathrm{MeOH}, \\
\mathrm{H}_{2} \mathrm{O}\end{array}$ & Si wafers & Spin-coating & 112 \\
\hline Hexagonal films & $\begin{array}{l}\text { TEOS, EtOH, } \mathrm{Pl23}, \mathrm{AgNO}_{3}, \mathrm{HCl}, \\
\mathrm{NH}_{4} \mathrm{OH}\end{array}$ & Glass & Dip-coating & 113 \\
\hline
\end{tabular}

\subsubsection{Mesostructured Non-Silicate Systems}

EISA method has been successfully extended to transition metal oxides.

Mesostructuring transition metal oxides is still challenging due to their higher reactivities towards condensation, lower Tamman temperatures of the constituent metal oxides, less flexible metal-oxygen-metal bond angles as compared to $\mathrm{Si}$ and the occurrence of redox reactions in the metal oxide wall. Mesostructured transition metal oxides are of great interest because of their unique catalytic, electrical, optical, and magnetic properties [114-116]. To date, most of the research efforts on mesostructured transition metal oxides by EISA have been done on titania $[100,117$ 124]. Titania possesses very interesting catalytic, photochemical, and electrical 
properties, which make it an attractive system for several applications. For instance, $\mathrm{TiO}_{2}$ is commonly used as a photocatalyst [125]. Crystalline titania modified with sulfate ions is an active catalyst for low-temperature esterification, isomerization, alkylation, and cracking of hydrocarbons [126]. Other applications of titania are: as an electrode material in electrochemistry, a capacitor in electronics, in humidity and gas sensors, and in photovoltaic solar cells [127].

2D hexagonal mesoporous titania displaying high surface areas (up to 370

$\mathrm{m}^{2} / \mathrm{g}$ ) and 2.0-2.5 $\mathrm{nm}$ pore size was prepared by EISA [117]. The proposed formation pathway for these mesophases indicated the hydrolysis of Ti precursor that leads to the formation of Ti-hydroxochloroalkano species which condensed into colloidal Tioxonanobuilding blocks (NBB). Evaporation of the solvent allowed the formation of a liquid crystalline mesophase by the assembly of the Ti-oxo nanobuilding blocks around the tubular micelles. Bromide and chloride anions helped to counterbalance the positive charges of the surfactant $\mathrm{CTAB}$ and NNB. The formation of these mesostructures depended on the $\mathrm{CTAB} / \mathrm{Ti}$ ratio. At low surfactant-to-metal ratios, wormlike mesostructures were formed. It was suggested that the template molecules could not act cooperatively enough to impose curvature to the Ti-oxo NBB. For intermediate $\mathrm{CTAB} / \mathrm{Ti}$ ratios, the mesostructures are well organized in hexagonal symmetries. Finally, high surfactant-to-metal ratios produced inverse micelles with Ti-oxo cores. The amorphous nature of the resultant mesophase limited the use of this material for practical applications in which a well-developed crystalline structure is required.

Later, the same research group reported the synthesis of mesoporous nanocrystalline anatase films displaying wormlike, 2D hexagonal and 3D cubic symmetries [118]. In their approach, poly(ethylene oxide)-based surfactants (F-127, 
P-123, Brij-56, Brij-58) were used to direct the synthesis. For Pluronic-templated titania films, the crystallization of the inorganic framework started at $\sim 350^{\circ} \mathrm{C}$ with the formation of anatase. At $400^{\circ} \mathrm{C}$, few anatase crystallites of $\sim 5 \mathrm{~nm}$ appeared in the amorphous matrix. Further heating $\left(600^{\circ} \mathrm{C}\right)$ led to the growth of these nanocrystallites to $\sim 12 \mathrm{~nm}$, with anatase as the only present phase. The authors suggested that at this temperature fully crystallized inorganic mesoporous framework was formed. A careful control over synthesis conditions and post-synthesis treatments led to the formation of anatase nanocrystals in the mesoporous walls. The authors proposed the water content entering and departing the films as the key variable that determined the final mesophase.

Alternatively, phosphorus could be introduced in the titania framework to form self-standing mesoporous titania-phosphorus oxide films containing $\sim 2.4 \mathrm{~nm}$ anatase nanocrystals via EISA [1 19]. The resultant hexagonal mesostructures displayed pore diameter of $\sim 4.3 \mathrm{~nm}$ and BET surface area of $330 \mathrm{~m}^{2} / \mathrm{g}$. In this case, the presence of phosphate prevented excessive crystal growth and improved the thermal stability of the final mesostructure. As in the previous example, a triblock copolymer surfactant (P123) was employed to direct the synthesis, ethanol-water as solvent, titanium tetraisopropoxide, and phosphorus pentachloride as inorganic sources. The coexistence of amorphous and rutile phases in mesoporous titania films synthesized by EISA have been reported [120]. The mesostructure formation was driven by EISA. Unfortunately, these materials were composed of lamellar mesophases which limits their practical applications. Various synthesis modifications have led to improved mesoporous nanocrystalline titania phases. For example, it has been shown recently that post-synthesis modification of mesoporous titania with $\mathrm{NH} 4 \mathrm{OH}$ or $\mathrm{NaOH}$ helps in stabilizing anatase nanocrystals in the mesostructure [121]. 
The resultant mesostructures had high surface areas (up to $573 \mathrm{~m}^{2} / \mathrm{g}$ ), large pore volumes $\left(0.71 \mathrm{~cm}^{3} / \mathrm{g}\right)$, and high sorption capacities for rhodamine $6 \mathrm{G}$.

Recently, EISA has been used to prepare ultrathin mesostructured nanocrystalline anatase films [124]. In this approach, diblock copolymer KLE ( $\left.\mathrm{H}\left(\mathrm{CH}_{2} \mathrm{CH}_{2} \mathrm{CH}_{2}(\mathrm{CH})-\mathrm{CH}_{2} \mathrm{CH}_{3}\right)_{89}-\left(\mathrm{OCH}_{2} \mathrm{CH}_{2}\right)_{79} \mathrm{OH}\right)$ and Brij-58 led to spherical and cylindrical micelles, respectively. The synthesis approach employed by the authors led to thin $(17-18 \mathrm{~nm})$ titania films displaying a monolayer or bilayer of highly ordered mesopores arranged on a 2D cubic lattice in which the inorganic matrix was composed of $\sim 6-10 \mathrm{~nm}$ anatase crystals. Other successful examples of mesoporous nanocrystalline titania prepared by EISA and displaying anatase crystals with pore sizes in the 5-23 $\mathrm{nm}$ range and crystal size in the $4.5-23 \mathrm{~nm}$ range have been reported [128-131]. Cubic mesoporous films deposited on Si wafers and displaying $7.5 \mathrm{~nm}$ anatase crystals and pore size of $\sim 5.5 \mathrm{~nm}$ were prepared by EISA employing F-127 as template [128]. The films were used for the photocatalytic degradation of methylene blue and lauric acid. Mixed inorganic titania precursors (titanium chloride and titanium isopropoxide) combined with $\mathrm{P}-123$ were used to prepare wormlike anatase mesoporous films [129]. These mesophases displaying BET surface areas up to 190 $\mathrm{m}^{2} / \mathrm{g}$, pore size of $\sim 7.4 \mathrm{~nm}$, and anatase nanocrystal size of $4.5 \mathrm{~nm}$ were employed as dye-sensitized solar cells. Mesoporous titania films synthesized with F-127 as template has been successfully employed as sensitized solar cells [130]. Recently, mesoporous nanocrystalline nitrided-titania films have been reported [131]. These $\mathrm{N}$ doped mesoporous films were prepared by annealing mesoporous nanocrystalline anatase under ammonia flow. The mesoporous structure composed of 10-14 nm anatase nanocrystals was maintained at temperatures as high as $700^{\circ} \mathrm{C}$. Nitrogen doping is particularly useful in decreasing the effective bandgap of anatase. Table 2.3 
summarizes some of the relevant work done on the preparation of mesoporous titania films and particles by EISA.

Table 2.3. Mesostructured titania films and particles prepared by EISA.

\begin{tabular}{|c|c|c|c|c|}
\hline Structure & Precursors & Substrate & Deposition method & Reference \\
\hline $\begin{array}{l}\text { 2D hexagonal and wormlike } \\
\text { particles }\end{array}$ & $\mathrm{Ti}(\mathrm{EtO})_{4}, \mathrm{CTAB}, \mathrm{HCl}, \mathrm{H}_{2} \mathrm{O}$ & None & Casting & 117 \\
\hline 2D hexagonal, 3D cubic films & $\begin{array}{c}\mathrm{TiCl}_{4}, \mathrm{Ti}(\mathrm{EtO})_{4}, \mathrm{~F} 127, \mathrm{P} 123, \mathrm{Brij} 56 \\
\text { Brij58, EtOH, } \mathrm{H}_{2} \mathrm{O}\end{array}$ & $\begin{array}{l}\text { Si wafers, fused } \\
\text { silica, glass }\end{array}$ & Dip-coating & 118 \\
\hline Hexagonal films & $\mathrm{Ti}\left(\mathrm{EtO}_{4}, \mathrm{PCl}_{5}, \mathrm{Pl} 23, \mathrm{EtOH}, \mathrm{HCl}, \mathrm{H}_{2} \mathrm{O}\right.$ & None & Casting & 119 \\
\hline Lamellar films & $\mathrm{TiCl}_{4}, \mathrm{Brij} 58, \mathrm{EtOH}, \mathrm{H}_{2} \mathrm{O}$ & $\begin{array}{c}\text { Si wafers, }(100) \mathrm{Si}, \\
\text { glass }\end{array}$ & Dip-coating & 120 \\
\hline $\begin{array}{c}\text { Mesoporous not periodic } \\
\text { particles }\end{array}$ & $\begin{array}{l}\text { Titanium tetra-isopropoxide, } \mathrm{HAD} \text {, } \\
\mathrm{CTAB}, \mathrm{EtOH}, \mathrm{NH}_{4} \mathrm{OH}\end{array}$ & None & Casting & 121 \\
\hline $\begin{array}{l}\text { 3D hexagonal, } 2 \mathrm{D} \text { hexagonal, } \\
\text { 3D cubic films }\end{array}$ & $\mathrm{Ti}(\mathrm{EtO})_{4}, \mathrm{P} 123, \mathrm{BuOH}, \mathrm{HCl}, \mathrm{H}_{2} \mathrm{O}$ & Glass & Spin-coating & 122,123 \\
\hline 1D hexagonal, 2D cubic films & $\mathrm{TiCl}_{4}, \mathrm{KLE}, \mathrm{EtOH}, \mathrm{THF}, \mathrm{H}_{2} \mathrm{O}$ & $\mathrm{Si}$, glass & Dip-coating & 124 \\
\hline Cubic films & $\mathrm{TiCl}_{4}, \mathrm{~F} 127, \mathrm{EtOH}, \mathrm{H}_{2} \mathrm{O}$ & Si wafers & Dip-coating & 128 \\
\hline Wormlike films & $\begin{array}{c}\text { Titanium isopropoxide, } \mathrm{TiCl}_{4}, \mathrm{PI} 23, \\
\text { EtOH }\end{array}$ & $\begin{array}{c}\mathrm{F} \text {-d oped } \mathrm{SnO}_{2} \text { coated } \\
\text { glass }\end{array}$ & $\begin{array}{l}\text { Doctor biading } \\
\text { technique }\end{array}$ & 129 \\
\hline Mesoporous films & $\mathrm{TiCl}_{4}, \mathrm{~F} 127, \mathrm{EtOH}, \mathrm{H}_{2} \mathrm{O}$ & $\begin{array}{l}\text { F-doped } \mathrm{SnO}_{2} \text { coated } \\
\text { glass }\end{array}$ & Spin-coating & 130 \\
\hline Mesoporous films & $\mathrm{TiCl}_{4}, \mathrm{~F} 127, \mathrm{EtOH}, \mathrm{H}_{2} \mathrm{O}$ & Si wafers, quartz & Dip-coating & 131 \\
\hline Mesoporous films & Ti foil, $\mathrm{NH}_{4} \mathrm{~F}$, glycerol, SDS, $\mathrm{H}_{2} \mathrm{O}$ & None & Anodization & 132 \\
\hline Mesoporous films & $\begin{array}{c}\mathrm{Ti}(\mathrm{OB})_{4}, \mathrm{AgNO}_{3}, \mathrm{NaBH}_{4}, \mathrm{Pl} 23, \mathrm{EtOH}, \\
\mathrm{HCl}\end{array}$ & Glass slides & Dip-coating & 133 \\
\hline Cubic mesoporous films & $\begin{array}{c}\mathrm{TiCl}_{4}, \mathrm{EtOH} \text {, acetone, } \mathrm{H}_{2} \mathrm{O} \text {, toluene, } \\
\text { FI27, DMF, NMP, TFA, TIS }\end{array}$ & Si wafers & Dip-coating & 134 \\
\hline
\end{tabular}

$\mathrm{Ti}(\mathrm{EtO})_{4}$ : titanium tetraethoxide, $\mathrm{PCl}_{5}$ : phosphorous pentachloride, $\mathrm{NH}_{4} \mathrm{~F}$ : ammonium fluoride, $\mathrm{Ti}(\mathrm{OB})_{4}$ : tetraorthobutyltitanate, $\mathrm{AgNO}_{3}$ : silver nitrate, $\mathrm{NaBH}_{4}$ : sodium borohydride, NMP: 1-methyl2-pyrrolidone, TFA: trifluoroacetic acid, TIS: triisopropylsilane.

Other transition metal oxides that have been successfully mesostructured by EISA are summarized in Table 2-4 [125, 135-142]. Brezesinski et. al. reported the synthesis of large pore (10-25 nm) highly ordered mesosotructured $\mathrm{WO}_{3}, \mathrm{CeO}_{2}$, and $\mathrm{MoO}_{3}$ ultrathin films deposited on Si wafers and galss slides and employing KLE and Brij-58 as structure-directing agents [124]. Interestingly, these three mesostructures displayed well-developed nanocrystalline monoclinic, cerianite and fcc phases for $\mathrm{WO}_{3}, \mathrm{CeO}_{2}$, and $\mathrm{MoO}_{3}$, respectively. The bulk phases of these oxides have found several interesting applications, namely, $\mathrm{WO}_{3}$ as a semiconductor material [115], 
$\mathrm{CeO}_{2}$ as oxygen sensing material [143], and Mo-based oxides as catalytic phases in the selective oxidation and reduction of hydrocarbons [144]. Recently, crystalline mesostructured $\mathrm{Y}_{2} \mathrm{O}_{3}$ films doped with rare earth metals and displaying nanocrystals in the $10-17 \mathrm{~nm}$ range and average pore sizes between 8.5 and $14 \mathrm{~nm}$ have been reported [135]. These mesofilms were prepared employing a polyethylene oxidebased copolymer structuring agent (KLE-22 (poly(ethylene-co-butylene)-bpoly(ethylene oxide). Because of its high dielectric constant, low absorption, and high thermal conductivity, bulk $\mathrm{Y}_{2} \mathrm{O}_{3}$ has been used in luminescent displays [145]. Nanocrystalline mesostructured $\mathrm{CeO}_{2}, \mathrm{ZrO}_{2}$ and $\mathrm{CeO}_{2}-\mathrm{ZrO}_{2}$ thin films with ordered arrays of $\sim 9-10 \mathrm{~nm}$ mesopores and displaying crystals sizes in the $2-10 \mathrm{~nm}$ range have been synthesized [136]. The successful preparation of these mesophases was mainly attributed to the KLE surfactant employed in synthesis. It was proposed that KLE accelerates the mesostructure formation, avoiding the insufficient build-up or loss of mesostructure typically observed when other surfactants are used [136]. Also, KLE polymer is more thermally stable, and, therefore, it may maintain the

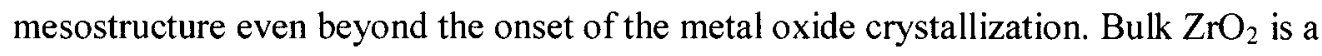
particularly interesting catalytic system, which found many uses in chemical and petrochemical processes because it possesses acidic, basic, and redox properties. For example, it is an effective catalyst for the selective formation of isobutane and isobutene from the synthesis gas (Fischer-Tropsch process) [146, 147]. 
Table 2.4. Mesostructured metal oxide films and particles prepared by EISA.

\begin{tabular}{|c|c|c|c|c|}
\hline Structure & Precursors & Substrate & Deposition method & Reference \\
\hline $\begin{array}{c}\mathrm{WO}_{3}, \mathrm{MoO}_{3}, \mathrm{CeO}_{2}, \mathrm{ID} \\
\text { hexagonal, 2D cubic films }\end{array}$ & $\begin{array}{c}\mathrm{WCl}_{2}, \mathrm{MoCl}_{5}, \mathrm{CeCl}_{3}>\mathrm{H}_{2} \mathrm{O}, \mathrm{KLE}, \mathrm{EtOH} \\
\mathrm{THF}, \mathrm{H}_{2} \mathrm{O}\end{array}$ & Si wafers, glass & Dip-coating & 124 \\
\hline $\begin{array}{l}\mathrm{Y}_{2} \mathrm{O}_{3} \text { doped with } \mathrm{Eu}, \mathrm{Sm}, \mathrm{Er} \\
\text { mesoporous films }\end{array}$ & $\begin{array}{c}\mathrm{YCl}_{3} 6 \mathrm{H}_{2} \mathrm{O}, \mathrm{EuCl}_{3} 6 \mathrm{H}_{2} \mathrm{O}, \mathrm{KLE} 22, \mathrm{EtOH} \\
\mathrm{NH}_{4} \mathrm{OH}, \mathrm{H}_{2} \mathrm{O}\end{array}$ & Siwafers & Dip-coating & 135 \\
\hline $\begin{array}{l}\mathrm{CeO}_{2}, \mathrm{ZrO}_{2}, \mathrm{CeO}_{2}-\mathrm{ZrO}_{2} \text { cubic } \\
\text { (bbc) films }\end{array}$ & $\begin{array}{c}\mathrm{CeCl}_{3} 7 \mathrm{H}_{2} \mathrm{O}, \mathrm{ZrCl}_{4}, \mathrm{KLE}, \mathrm{EtOH}, \mathrm{THF}, \\
\mathrm{H}_{2} \mathrm{O}\end{array}$ & Siwafers & Dip-coating & 136 \\
\hline $\mathrm{Al}_{2} \mathrm{O}_{3}$ cubic (fcc) films & $\begin{array}{c}\mathrm{AlCl}_{3} 6 \mathrm{H}_{2} \mathrm{O}, \mathrm{KLE} 22, \mathrm{KLE} 23, \mathrm{EtOH}, \\
\mathrm{H}_{2} \mathrm{O}, \mathrm{NH}_{4}\end{array}$ & Si wafers & Dip-coating & 137 \\
\hline $\begin{array}{c}\mathrm{Fe}_{2} \mathrm{O}_{3}, \mathrm{FeOOH} \text { mesoporous } \\
\text { films }\end{array}$ & $\mathrm{FeCl}_{3}$, PIB-PEO, KLE, EtOH, THF, $\mathrm{H}_{2} \mathrm{O}$ & Si wafers, glass & Dip-coating & 138 \\
\hline $\begin{array}{c}\mathrm{SrTiO}_{3}, \mathrm{MgTa}_{2} \mathrm{O}_{6}, \mathrm{Co}_{\times} \mathrm{Ti}_{1 \times \times} \mathrm{O}_{2-x} \\
3 \mathrm{D} \text { and } 2 \mathrm{D} \text { pore films }\end{array}$ & $\begin{array}{c}\mathrm{SrCl}_{2} 6 \mathrm{H}_{2} \mathrm{O}, \mathrm{TiCl}_{4}, \mathrm{CoCl}_{2}, \mathrm{Mg}(\mathrm{OH})_{2}, \\
\mathrm{Ta}\left(\mathrm{OC}_{2} \mathrm{H}_{5}\right)_{5}, \mathrm{THF}, \mathrm{EtOH}, \mathrm{H}_{2} \mathrm{O}\end{array}$ & Siwafers & Dip-coating & 139 \\
\hline $\begin{array}{c}\text { Nb-M oxides }(\mathrm{M}=\mathrm{V}, \mathrm{Mo}, \mathrm{Sb}) \\
\text { particles }\end{array}$ & $\begin{array}{c}\mathrm{NbCl}_{5}, \mathrm{~V}_{2} \mathrm{O}_{5}, \mathrm{VOSO}_{4}, \mathrm{MoO}_{3}, \mathrm{Sb}_{2} \mathrm{O}_{3}, \\
\mathrm{P123}, \mathrm{EtOH}\end{array}$ & None & Casting & 140 \\
\hline Co-Ni oxide particles & $\begin{array}{c}\left(\mathrm{Ni}_{0.33} \mathrm{Co}_{67}\right)(\mathrm{OMe})(\mathrm{acac})(\mathrm{MeOH}), \text { Brij35, } \\
\text { BuOH }\end{array}$ & None & Casting & 141 \\
\hline $\mathrm{WO}_{3} \cdot \mathrm{TiO}_{2}$ cubic films & $\begin{array}{c}\mathrm{Ti}(\mathrm{O} t \mathrm{PC})_{4}, \mathrm{~W} \text { pentaethoxide, } \mathrm{F} 127 \\
\text { EtOH, } \mathrm{HCl}, \mathrm{H}_{2} \mathrm{O}\end{array}$ & Pirex glass & Spin-coating & 142 \\
\hline $\mathrm{SiO}_{2}-\mathrm{TiO}_{2}$ nanowires & TEOS, Ti(OiPC) $)_{4}, \mathrm{PS}-\mathrm{b}-\mathrm{PEO}, \mathrm{EtOH}, \mathrm{HCl}$ & Porous alumina & $\begin{array}{l}\text { Immersion of sol in } \\
\text { porous alumina }\end{array}$ & 148 \\
\hline
\end{tabular}

Mesostructured nanocrystalline $\gamma-\mathrm{Al}_{2} \mathrm{O}_{3}$ with ellipsoidal disk-shaped pores $(\sim 9-29 \mathrm{~nm})$ and interconnecting windows of 2 or $5 \mathrm{~nm}$ in diameter have been synthesized employing KLE-22 and KLE-23 surfactants [137]. The stabilization of the $\gamma-\mathrm{Al}_{2} \mathrm{O}_{3}$ nanoparticles into a well-ordered mesostructure was attributed to the stability of the KLE-22 template above the dehydration temperature of the inorganic phase. Furthermore, when the thermal treatment reached the decomposition temperature of the template $\left(\sim 350^{\circ} \mathrm{C}\right)$ the amorphous inorganic framework was rigid enough to prevent the mesostructure collapse. Alumina has a broad range of applications as an adsorbent, catalyst, support, and ultrafiltration media [144, 149, 150]. Mesoporous films composed of 7-10 nm crystals of $\alpha-\mathrm{Fe}_{2} \mathrm{O}_{3}$ with average pore diameter of $\sim 10 \mathrm{~nm}$ were synthesized employing a novel PIB-PEO (poly(isobutylene)-blockpoly-(ethylene oxide)) copolymer and KLE [138]. The retention of the structural order in these films was attributed to the high thermal stability of these surfactants. The films retained the well-ordered mesostructure up to 
$450^{\circ} \mathrm{C}$. Interestingly, when $\mathrm{F}-127$ was employed as template, the resulting $\alpha-\mathrm{Fe}_{2} \mathrm{O}_{3}$ mesostructure collapsed at $350^{\circ} \mathrm{C}$. Some of the most relevant applications that iron oxides have found are as magnetic data storage devices, catalysts, magnetic-optical devices, electrodes, and sensors [151-154].

$\mathrm{SiO}_{2}-\mathrm{TiO}_{2}$ hybrid nanowires consisting of a silica core containing linear arrays of mesocages and titania shell have been prepared by EISA [148]. The silica inorganic precursor-template (TEOS-PS-b-PEO copolymer) solution was infiltrated into porous alumina. The gradual evaporation of ethanol by EISA and subsequent gelation and calcination produce mesostructured silica $\sim 50-60 \mathrm{~nm}$ nanowires containing spherical mesocages of $\sim 15-40 \mathrm{~nm}$. When PS(9500)-b-PEO(9500) template was used small mesocages of $15 \mathrm{~nm}$ were obtained; when PS(9500)-bPEO(18000) template was used bigger mesocages of $40 \mathrm{~nm}$ were obtained. The nanowires were released from the alumina by wet chemical etching, and finally coated with $\mathrm{TiO}_{2}$ by atomic layer deposition. This method allowed internal mesoscopic fine structure (by EISA) and compositional control over outer nanowire surface (atomic layer deposition).

Mixed mesoporous Nb-M (M = V, Mo, Sb) metal oxides with surface areas up to $200 \mathrm{~m}^{2} / \mathrm{g}$, pore sizes in the $5-14 \mathrm{~nm}$ range and high pore volumes $\left(0.46 \mathrm{~cm}^{3} / \mathrm{g}\right)$ have been prepared by EISA [1140]. Various oxides $\left(\mathrm{Sb}_{2} \mathrm{O}_{3}, \mathrm{~V}_{2} \mathrm{O}_{5}, \mathrm{MoO}_{3}\right)$ and salts $\left(\mathrm{NbCl}_{5}, \mathrm{VOSO}_{4}\right)$ were used as inorganic sources, and $\mathrm{P}-123$ as the structure directing agent. Bulk phases of these mixed metal oxides are active and selective catalysts for alkane oxidation [144]. Uniform nanocrystalline mesoporous cobalt-nickel oxide spinels have been prepared by employing a heterometallic alkoxide precursor $\left(\mathrm{Ni}_{0.33} \mathrm{Co}_{0.67}\right)(\mathrm{OMe})(\mathrm{acac})(\mathrm{MeOH})$ and oligomeric alkyl-ethylene oxide surfactant (Brij-35) as a structure-directing agent via EISA at $50^{\circ} \mathrm{C}$ and $60 \% \mathrm{RH}[141]$. In this 
synthesis approach, the desired metal oxide stoichiometries were introduced on a molecular level by reacting the heterometallic alkoxide precursor in the presence of supramolecular liquid crystalline phases. The resultant mesoporous phases displayed unimodal pores in the 7-12 nm range and relatively high specific surface areas upto $83 \mathrm{~m}^{2} / \mathrm{g}$. The mesoporous phases were composed mainly of $\sim 8-11 \mathrm{~nm} \mathrm{Co-Ni-O}$ spinel nanocrystals.

\subsection{Catalytic Applications}

Finely tuned meso-structures, controlled metal oxide wall structures, high surface areas, and enhanced accessibility of the active surface sites are some of the properties that make these ordered porous metal oxides highly attractive for a wide range of catalytic applications. We will next review the emerging applications of these ordered mesoporous metal oxides in catalysis.

\subsubsection{Catalytic Applications of Mesoporous Metal Oxides}

Examples of catalytic mesoporous silicates have been reviewed by Sayari [155]. However, only a few reports exist on catalytic applications of mesoporous transition metal oxides. The photocatalytic behaviour of mesoporous $\mathrm{TiO}_{2}$ films has been reported [156]. It was found that the photocatalytic activity of the films for the oxidation of $\mathrm{NO}_{\mathrm{x}}$ was higher for the mesoporous films than for conventional gel films, due to the higher surface areas and pore architectures of the mesoporous films. Mesoporous $\mathrm{Ta}_{2} \mathrm{O}_{5}$ doped with $\mathrm{NiO}$ was found to display higher photocatalytic activity than nanoporous amorphous and crystalline $\mathrm{NiO}-\mathrm{Ta}_{2} \mathrm{O}_{5}$ [157]. It was claimed that the higher surface area and better $\mathrm{NiO}$ dispersion over the mesoporous $\mathrm{Ta}_{2} \mathrm{O}_{5}$ host were responsible for the superior catalytic performance of these materials. The photocatalytic activity of mesoporous phosphated $\mathrm{TiO}_{2}$ and $\mathrm{Nb}_{2} \mathrm{O}_{5}$ catalysts has been studied in the dehydration of 2-propanol to acetone [158]. Surprisingly, a lower 
activity of the mesoporous $\mathrm{Ti}$ and $\mathrm{Nb}$ oxides was observed than for the bulk anatase phase. The amorphous nature of mesoporous walls and the surface defects in these mesoporous oxides were probably responsible for the recombination of photogenerated electron-hole pairs and the poor catalytic performance.

The photocatalytic activity of mesoporous nanocrystalline titania films has been reported by independent research groups [123, 159, 160]. In these reports, superior photocatalytic efficiency has been observed for the mesoporous nanocrystalline films prepared via EISA as compared to conventional and nonperiodic nonporous nano-crystalline titania. For example, it was found that $\mathrm{NH}_{4} \mathrm{OH}$-modified mesoporous nano-crystalline titania degraded rhodamine $6 \mathrm{G}$ faster than commercially available Degussa P25 titania [159]. Periodic ordered hexagonal and cubic nanocrystalline anatase films photodegraded methylene blue approximately two times faster than nanocrystalline titania [123]. Mesoporous titania comprised of $\sim 7.5 \mathrm{~nm}$ crystals displayed improved photocatalytic performance for methylene blue degradation as compared to $\mathrm{TiO}_{2}$ control sample [160]. Superior photocatalytic activity in all these systems may be related to the periodic open porous structures with organized framework of nanocrystals, which provide facile diffusion pathways for guest molecules.

Mesoporous $\mathrm{Fe}_{2} \mathrm{O}_{3}-\mathrm{TiO}_{2}$, has been used as a catalyst for the oxidation of cyclohexane to cyclohexanol and cyclohexanone [161]. These mesoporous catalysts displayed slightly higher (by $5 \%$ ) cyclohexane conversion under the same conditions as compared to catalysts, in which $\mathrm{Fe}_{2} \mathrm{O}_{3}$ was incorporated into nonporous $\mathrm{TiO}_{2}$. Vanadium oxide incorporated into mesoporous $\mathrm{TiO}_{2}$ has been studied as a catalyst for propane combustion [162]. It was found that the rate of propane combustion to $\mathrm{CO}$ and $\mathrm{CO}_{2}$ was about 18 times higher for mesoporous $\mathrm{VO}_{\mathrm{x}}-\mathrm{TiO}_{2}$ catalysts than for a 
conventional $\mathrm{VO}_{\mathrm{x}}-\mathrm{TiO}_{2}$ catalyst. High surface areas displayed by these mesoporous catalysts and improved dispersion of active surface sites in the mesoporous hosts were responsible for their enhanced catalytic performance. $\mathrm{Cu}, \mathrm{Ni}$ and $\mathrm{Cu}-\mathrm{Ni}$ bimetallic catalysts supported on mesoporous ceria doped with lanthanum display high activity in the water-gas-shift reaction. These catalysts are highly selective towards hydrogen production by WGS reaction. The incorporation of $\mathrm{Cu}$ suppressed the methane formation; whereas the addition of Ni enhanced the overall WGS activity [164]. Table 2.5 summarizes the examples of catalytic applications of mesoporous metal oxides.

Table 2.5. Emerging catalytic applications of mesoporous metal oxides.

\begin{tabular}{|c|c|c|c|c|}
\hline Mesostructurea & Reaction & Product & Activity/Selctivity & Reference \\
\hline $\mathrm{TiO}_{2}$ & NO photooxidation & $\mathrm{NO}_{2}$ & $15 \% \mathrm{NO}$ removal, $10 \% \mathrm{NO}_{2}$ generation & 156 \\
\hline $\mathrm{NiO}-\mathrm{Ta}_{2} \mathrm{O}_{5}$ & $\begin{array}{l}\text { Water photocatalytic } \\
\text { decomposition }\end{array}$ & $\mathrm{H}_{2}+\mathrm{O}_{2}$ & $515 \mu \mathrm{mol} / \mathrm{h} \mathrm{H}_{2}, 272 \mu \mathrm{mol} / \mathrm{hO}_{2}$ & 157 \\
\hline $\begin{array}{l}\mathrm{PO}_{3}-\mathrm{TiO}_{2-}- \\
\mathrm{Nb}_{2} \mathrm{O}_{3}\end{array}$ & $\begin{array}{c}\text { 2-propnol } \\
\text { dehydrogenation }\end{array}$ & Acetone & $\begin{array}{c}\text { Quantumyield }{ }^{\mathrm{b}}: 0.0089\left(\mathrm{TiO}_{2}\right), 0.45 \\
\text { (Degussa P25), } 0.0041 \& 0.217\left(\mathrm{Nb}_{2} \mathrm{O}_{5}\right)\end{array}$ & 158 \\
\hline $\mathrm{TiO}_{2}$ & $\begin{array}{l}\text { Photocatalytic } \\
\text { degradation of } \\
\text { rhodamine } 6 \mathrm{G}\end{array}$ & $\mathrm{CO}_{2}+\mathrm{H}_{2} \mathrm{O}$ & $-30 \%$ decomposition after $1 \mathrm{~h}$ irradiation & 159 \\
\hline $\mathrm{TiO}_{2}$ & $\begin{array}{c}\text { Photocatalytic } \\
\text { degradation of MB }\end{array}$ & $\mathrm{CO}_{2}+\mathrm{H}_{2} \mathrm{O}$ & $\begin{array}{l}\text { Apparent rate constants } \mathrm{k}=15.25 / \mathrm{min} \\
\qquad \mathrm{cm}^{3} \mathrm{TiO}_{2}\end{array}$ & 123 \\
\hline $\mathrm{TiO}_{2}$ & $\begin{array}{c}\text { Photocatalytic } \\
\text { degradation of MB \& } \\
\text { lauric acid }\end{array}$ & $\mathrm{CO}_{2}+\mathrm{H}_{2} \mathrm{O}$ & $\begin{array}{l}\text { Decomposition of MB up to } \sim 100 \\
\mathrm{mmol}_{\mathrm{g} \mathrm{TiO}} ; \text { NA for lauric acid }\end{array}$ & 160 \\
\hline $\mathrm{Fe}_{2} \mathrm{O}_{3}-\mathrm{TiO}_{2}$ & $\begin{array}{l}\text { Cyclohexane } \\
\text { oxidation }\end{array}$ & $\begin{array}{l}\text { Cyclohexanol, } \\
\text { cyclohexanone, } \\
\text { acetic acid }\end{array}$ & $\begin{array}{l}\text { Conversion }=25.8 \% \text {; selectivity to } \\
\text { cyclohexanol and cyclohexanone }=90 \%\end{array}$ & 161 \\
\hline $\mathrm{Vo}_{\mathrm{x}}-\mathrm{TiO}_{2}$ & Propene oxidation & $\mathrm{CO}+\mathrm{CO}_{2}$ & $\begin{array}{c}\text { Activity }\left(\mathrm{min}^{-1}\right): \mathrm{CO}=\mathrm{v} 0.091, \mathrm{CO}_{2}= \\
0.279 ; \text { selectivity to } \mathrm{CO}_{2}=75 \%\end{array}$ & 162 \\
\hline VPO & n-Butane oxidation & $\begin{array}{l}\text { Maleic } \\
\text { anhydride }\end{array}$ & $\begin{array}{c}\text { n-Butane conversion }=10 \% \text {; selectivity } \\
\text { to maleic anhydride }=40 \%\end{array}$ & 163 \\
\hline $\mathrm{Cu}-\mathrm{Ni} / \mathrm{CeLaO}$ & $\begin{array}{l}\text { Water gas shit } \\
\text { reaction }\end{array}$ & Hydrogen & $\begin{array}{l}\mathrm{Cu}_{4} \mathrm{Ni}_{16} / \mathrm{CeLaO} \text { catalyst is highly active } \\
\text { and } \mathrm{H}_{2} \text { selective in WGS reaction }\end{array}$ & 164 \\
\hline
\end{tabular}




\subsection{Self-Assembly Hydrothermal-Assisted Approach (SAHA)}

For many structure-sensitive applications, such as in heterogeneous catalysis, it is highly desirable to have a well defined crystalline phase. In this respect, the hydrothermal synthesis approach is an alternative self-assembly method to prepare nanocrystalline oxide phases. Hydrothermal research was initiated in the middle of the 19 th century by geologists and was aimed at laboratory simulations of natural hydrothermal phenomena. Later, in the 20 th century, hydrothermal synthesis was clearly identified as an important technology for materials synthesis, predominantly in the fields of hydrometallurgy and single crystal growth [165]. However, the severe (supercritical) reaction conditions required particularly for growing single crystals have discouraged extensive research and commercialization for many materials. In recent years, commercial interest in hydrothermal synthesis has been revived in part because a steadily increasing large family of materials, primarily ceramic powders, has emerged that can be prepared under mild conditions $\left(T<350^{\circ} \mathrm{C}, P<100 \mathrm{MPa}\right)$.

Hydrothermal synthesis is a process that utilizes single or heterogeneous phase reactions in aqueous media at elevated temperature $\left(T>25^{\circ} \mathrm{C}\right)$ and pressure $(P>100$ $\mathrm{kPa}$ ) to crystallize ceramic materials directly from solution. However, researchers also use this term to describe processes conducted at ambient conditions. Syntheses are usually conducted at autogeneous pressure, which corresponds to the saturated vapor pressure of the solution at the specified temperature and composition of the hydrothermal solution. Upper limits of hydrothermal synthesis extend to over $1000^{\circ} \mathrm{C}$ and $500 \mathrm{MPa}$ pressures [166]. However, mild conditions are preferred for commercial processes where temperatures are less than $350^{\circ} \mathrm{C}$ and pressures less than approximately $50 \mathrm{MPa}$. Intensive research has led to a better understanding of hydrothermal chemistry, which has significantly reduced the reaction time, 
temperature, and pressure for hydrothermal crystallization of materials $\left(T<200^{\circ} \mathrm{C}\right.$, $P<1.5 \mathrm{MPa}$ ) [167-169]. This breakthrough has made hydrothermal synthesis more economical since processes can be engineered using cost-effective and proven pressure reactor technology and methodologies already established by the chemical process industry.

Hydrothermal synthesis offers many advantages over conventional and nonconventional synthetic methods. The ability to precipitate already crystallized powders directly from solution regulates the rate and uniformity of nucleation, growth and aging, which results in improved control of size and morphology of crystallites and significantly reduced aggregation levels, which is not possible with many other synthesis processes [170]. Hydrothermal processing can take place in a wide variety of combinations of aqueous and solvent mixture-based systems. In general, processing with liquids allows for automation of a wide range of unit operations such as charging, transportation, mixing and product separation. Moreover, relative to solid state processes, liquids give a possibility for acceleration of diffusion, adsorption, reaction rate and crystallization, especially under hydrothermal conditions [168]. However, unlike many advanced methods that can prepare a large variety of forms and chemical compounds, such as chemical vapor-based methods, the respective costs for instrumentation, energy and precursors are far less for hydrothermal methods. Hydrothermal methods are more environmentally benign than many other synthesis methods, which can be attributed in part to energy conserving low processing temperatures, absence of milling, ability to recycle waste, and safe and convenient disposal of waste that cannot be recycled [168]. The low reaction temperatures also avoid other problems encountered with high temperature processes, for example poor 
stoichiometry control due to volatilization of components (e.g., Pb volatilization in Pb-based ceramics).

A variety of powders have been synthesized by hydrothermal methods. Most common are oxide materials, both simple oxides, such as $\mathrm{ZrO}_{2}, \mathrm{TiO}_{2}, \mathrm{SiO}_{2}, \mathrm{ZnO}$, $\mathrm{Fe}_{2} \mathrm{O}_{3}, \mathrm{Al}_{2} \mathrm{O}_{3}, \mathrm{CeO}_{2}, \mathrm{SnO}_{2}, \mathrm{Sb}_{2} \mathrm{O}_{5}, \mathrm{Co}_{3} \mathrm{O}_{4}, \mathrm{HfO}_{2}$, etc., and complex oxides, such as $\mathrm{BaTiO}_{3}, \mathrm{SrTiO}_{3}, \mathrm{PZT}, \mathrm{PbTiO}_{3}, \mathrm{KNbO}_{3}, \mathrm{KTaO}_{3}, \mathrm{LiNbO}_{3}$, ferrites, apatites, tungstates, vanadates, molybdates, zeolites, etc., some of which are metastable compounds, which cannot be obtained using classical synthesis methods at high temperatures. Hydrothermal synthesis of a variety of oxide solid solutions and doped compositions is common. Crystalline products can be in a variety of forms, such as equiaxed (for example cubes, spherical), elongated (fibers, whiskers, nanorods, nanotubes), plates, nanoribbons, nanobelts, etc. Core-shell particles $\left(\mathrm{CdS} / \mathrm{ZnO}, \mathrm{CoAl}_{2} \mathrm{O}_{4} / \mathrm{ZnAl}_{2} \mathrm{O}_{4}\right)$ and composite powders consisting of a mix of at least two different powders $\left(\mathrm{TiO}_{2} / \mathrm{HAp}\right.$, $\mathrm{TiO}_{2} / \mathrm{SiO}_{2}$ ) can be also prepared. Quite often, the size and morphology can be engineered over a wide range and even adopt nonequilibrium morphologies [171]. Herein we have combined the self-assembly approach with the hydrothermal heating in order to obtain nanocrystalline mesoporous oxide materials. The schematic representation of the Self-Assembly Hydrothermal-Assisted method is shown in Figure 2.7. 


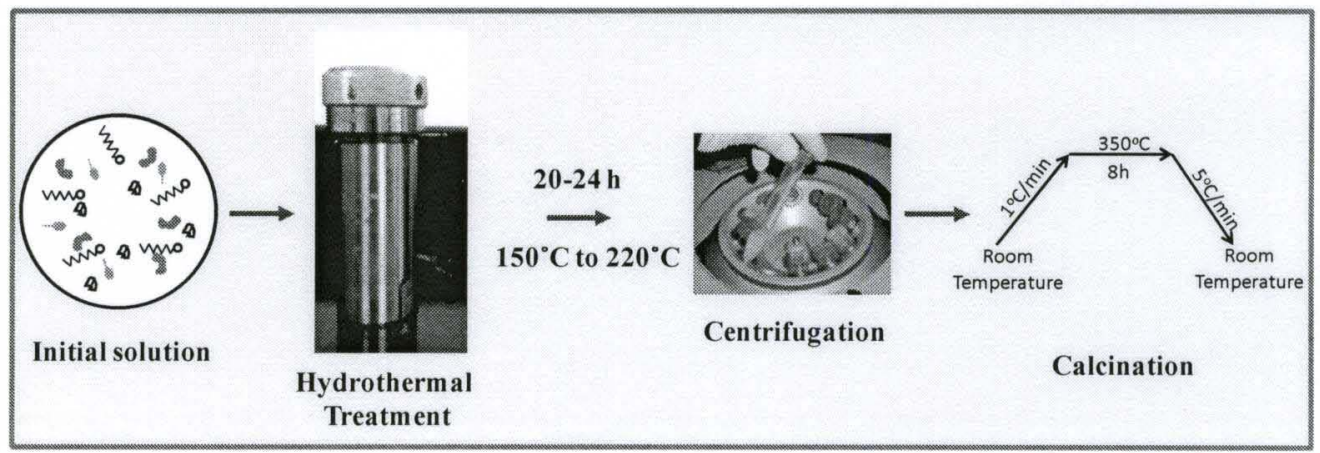

Figure 2.7. Mesoporous oxides synthesis procedure employing self-assembly hydrothermal-assisted approach [172].

\subsection{Microwave heating approach}

The traditional synthesis method of mesoporous molecular sieves is hydrothermal synthesis, the general process of which is a certain amount of surfactants, and acid or alkali are added to compose mixed aqueous. Next, inorganic sources are added to generate a water gel, and then heated in the autoclave at a certain temperature to crystallize, and after filtering, washing, drying, calcination or extraction to remove the template agent. Finally, ordered mesoporous materials are obtained. Recently, we reported the synthesis of thermally stable nanocrystalline mesoporous oxides with controlled morphological, textural and structural properties via evaporation-induced self-assembly and self-assembly hydrothermal-assisted approaches [172]. Both methods required relatively long synthesis time and high reaction temperatures.

Conventional heating has a heat source on the outside and relies on transferring the heat to the surface of the material and then conducting the heat to the middle of the material. Compared with conventional heating, microwave dielectric heating has the following advantages for chemical synthesis [173] (thermal effects of microwave): 
a) the introduction of microwave energy into a chemical reaction can lead to much higher heating rates than those which are achieved conventionally;

b) the microwave energy is introduced into the chemical reactor remotely without direct contact between the energy source and the reacting chemicals;

c) it is volumetric and instantaneous (or rapid) heating with no wall or heat diffusion effects;

d) it can realize selective heating because chemicals and the containment materials for chemical reactions do not interact equally with microwaves;

e) "hot spots" yielded on local boundaries by reflections and refractions may result in a "super-heating" effect, which can be described best as local overheating and is comparable to the delayed boiling of overheated liquids under conventional conditions.

Microwave heating can remarkably reduce synthesis time compared with conventional heating. In the synthesis of porous materials, it has been reported that the microwave synthesis method could provide an efficient way to control particle size distribution, phase selectivity, and macroscopic morphology.

\subsection{Our Model Reactions}

\subsubsection{Reaction of Interest 1: Epoxidation of alkenes}

Epoxides are versatile highly useful intermediates that can be employed in the synthesis of many important fine chemicals with relevant industrial applications [69]. The most common way to prepare epoxides is by the oxidation of alkenes in the presence of a catalyst. This method is applicable for the production of epoxides on both laboratory as well as industrial scale. Figure 2.8 displays the general schematic representation of the epoxidation reaction of alkenes in the presence of a catalyst and an oxidizing agent. 


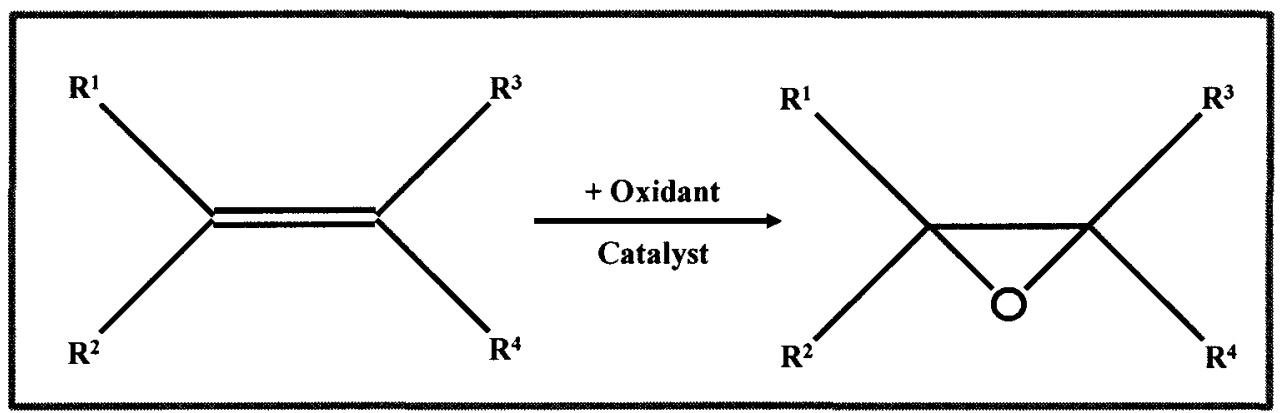

Figure 2.8. Schematic representation of epoxidation of alkenes.

Several homogeneous and heterogeneous catalysts for the epoxidation of alkenes have been reported $[16,174-176]$. However, none of them meet all the requirements for efficient and sustainable chemistry. An ideal epoxidation catalyst should demonstrate the following features:

a) The catalyst must be active under mild reaction conditions for a wide range of substrates, with selectivity towards the formation of epoxide, implying that it should not contain too strong acidic sites that might cause further reaction of the formed epoxides.

b) It should be compatible with hydrogen peroxide $\left(\mathrm{H}_{2} \mathrm{O}_{2}\right)$ as the oxidant since this readily available, cheap compound yields water as a by-product.

c) It should be a stable heterogeneous catalyst, to allow easy separation from the products and could be recycled without loss of activity.

d) It should not leach transition metals into the reaction mixture, or preferably should not contain them at all.

e) It should show optimum performance in environmentally acceptable solvents or in the absence of solvents.

Currently oxygen, peroxides and peracids are used for the direct oxidation of alkenes on industrial scale. For example ethylene is commercially epoxidized by vapor phase oxidation with oxygen or air using a supported silver catalyst [177]. 
Propylene oxide is produced by the metal catalyzed liquid phase oxidation of propylene using organic hydroperoxides produced by hydrocarbon autoxidation [178]. Homogeneous $\mathrm{Mo}^{\mathrm{VI}}[179]$ and heterogeneous $\mathrm{Ti}^{\mathrm{IV}}[180]$ are efficiently used as catalysts and tert-butyl hydroperoxide or ethylbenzene hydroperoxide as oxidants. Epoxides of substituted alkenes that are widely used in the fine chemicals industry can be successfully prepared by using stoichiometric amounts of peracids such as peracetic acid and m-chlorobenzoic acid $[176,181]$. The employment of peracids is not a clean method, since equivalent amount of acid waste is produced. Also safety issues related to the handling of peracids is a matter of concern. Hydrogen peroxide is probably the best terminal oxidant after dioxygen with respect to environmental and economic considerations [182-185]. It is cheap, readily available and gives water as the only by-product. In certain circumstances it is better than oxygen itself, as $\mathrm{O}_{2}$ l organic mixtures can sometimes, spontaneously ignite.

There is a strong need to develop new epoxidation methods which not only employ safes oxidants and produce little waste, with easy separation of the catalysts. The use of heterogenized homogeneous catalysts has had limited success due to poor product yields and catalyst stability, that leads to leaching during reactions and thus limits the potential for recyclability. Heterogeneous catalysts offer advantages of easy catalyst separation and sometimes higher selectivity. Titanium containing silicates, including amorphous titania silica materials and Ti-substituted molecular sieves are one of the most efficient heterogeneous catalysts for epoxidation reactions. However, the employment of catalysts such as titanium-silicate (TS-1) is limited to linear alkenes. The main drawback of this catalyst is its small pore dimensions of $5.3 \AA$ which makes it accessible to only relatively small reactants. 
Recently it was discovered that a new set of transition-metal-free catalysts, demonstrated the capacity to form surface peroxide groups (B-OOH, Al-OOH, Ga$\mathrm{OOH})$ that are capable of serving as epoxidation catalysts. Aluminium oxide is a good catalyst, in agreement with the literature data [186-191], however gallium oxide was identified as a new, promising epoxidation catalyst.

\subsubsection{Reaction of Interest II: Skeletal Isomerization of Fatty acid and Fatty Acid Methyl Esters}

Branched chain fatty acids (FA) and fatty acid methyl esters (FAME) are another important class of feedstock for the production of a number of chemicals. The fatty acids are aliphatic carboxylic acids containing straight hydrocarbon chains with an even number of carbons, most commonly with 12-24 carbons [192, 193]. Branched fatty acids have applications as detergents, surfactants and are also used in the lubricant industry. Branched FAME are a major component of biodiesel, that has lately emerged as an alternative fuel of wide acceptance because of its lower environmental impact compared to petroleum diesel fuels [70-72].

Biodiesel does not contain harmful aromatic hydrocarbons, it does not produce sulfur oxides $\left(\mathrm{SO}_{\mathrm{x}}\right)$ and the particulate emissions are also decreased. Additionally, the most appealing part of biodiesel is that it is made from renewable resources and is biodegradable. It is obtained from triglyceride oils like soy bean oil, rapeseed oil, canola oil, or other vegetable oil by transesterification with methanol. Biodiesel obtained from transesterification contains five main esters with very similar structures summarized in Figure 2.9. The average composition of the biodiesel fuels is given in Table 2.6. These esters are made of a long alkyl chain attached to an ester group and the main differences are the length of chain (16 to 18 carbon atoms) and the number of double bonds in the chain. Methyl oleate $\left(\mathrm{C}_{19} \mathrm{H}_{36} \mathrm{O}_{2}\right)$ is the main component found 
in the rapeseed biodiesel and it represents about $60 \%$ of its mass content. This ester has an alkyl chain of 18 carbon atoms with one double bond in the middle.

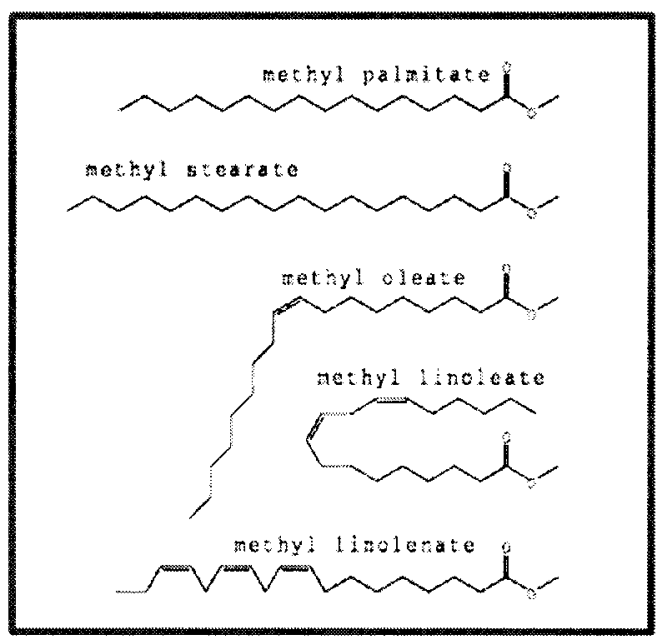

Figure 2.9. Major components of soy and rapeseed oil biodiesel fuel.

Table 2.6. Average compositions (\%) of soybean and rapeseed biodiesels [194].

\begin{tabular}{|c|c|c|}
\hline \multirow{2}{*}{ Esters } & \multicolumn{2}{c|}{ Average composition (mass\%) } \\
\cline { 2 - 3 } & Rapeseed & Soybean \\
\hline Methyl palmitate $\left(\mathrm{C}_{17} \mathrm{H}_{34} \mathrm{O}_{2}\right)$ & 4 & $6-10$ \\
\hline Methyl stearate $\left(\mathrm{C}_{19} \mathrm{H}_{38} \mathrm{O}_{2}\right)$ & 2 & $2-5$ \\
\hline Methyl oleate $\left(\mathrm{C}_{19} \mathrm{H}_{36} \mathrm{O}_{2}\right)$ & 60 & $20-30$ \\
\hline Methyl linoleate $\left(\mathrm{C}_{19} \mathrm{H}_{34} \mathrm{O}_{2}\right)$ & 21 & $50-60$ \\
\hline Methyl linolenate $\left(\mathrm{C}_{19} \mathrm{H}_{32} \mathrm{O}_{2}\right)$ & 13 & $5-11$ \\
\hline
\end{tabular}

The application of biodiesel is however limited despite its significant environmental benefits. The production cost of biodiesel is still greater than the cost of producing petrodiesel [72]. Also two critical factors namely oxidation stability and cold flow properties (cloud point, pour/melting points and viscosity) need to be addressed when fatty acids are used directly or to make derivatives. Saturated fatty chains are stable whereas unsaturated fatty chains are prone to oxidation in air [193]. Cold flow properties are a concern when the temperature of operation goes below 
$10^{\circ} \mathrm{C}$. Cloud point is defined as the temperature at which a liquid fatty material becomes cloudy due to the formation of crystals and solidification of saturates. Pour point is defined as the lowest temperature at which the liquid material still flows. Biodiesel containing saturated fatty chains has typically poor cold flow properties $[192,195]$. High percentages of saturated fatty acids of long and linear chains are responsible for high cloud points [72]. Direct catalytic isomerization of fatty acids or esters represents an emerging technology that converts linear fatty molecules to branched ones. The general schematic representation of isomerisation of linear fatty acid methyl esters to their branched isomers is shown in Figure 2.9.

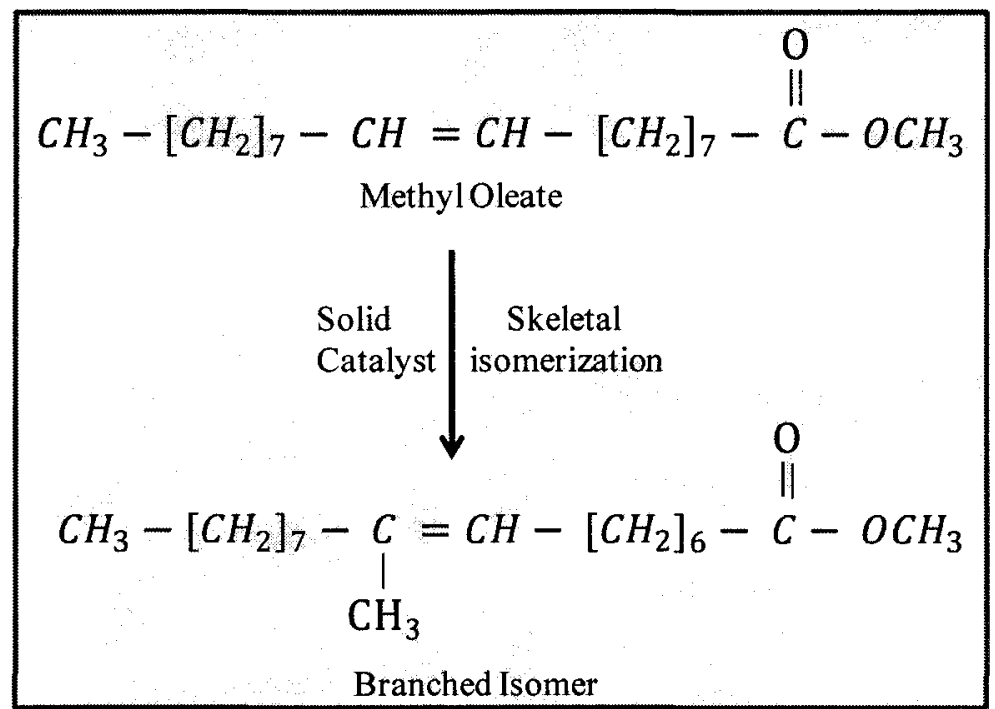

Figure 2.10. Schematic representation of skeletal isomerisation of linear ester to its branched isomer.

Though it is a common practise in the petrochemical industry to isomerize straight chain hydrocarbons to branched ones for octane number improvement, the task of converting straight chain fatty acids or corresponding alkyl esters to branched ones is much more challenging. Most solid acids failed to produce branched products due to the poisoning effect of carboxylic group that weakens the acidity of most catalyst surfaces during the isomerization of hydrocarbons. Acidic clays have been 
used for the conversion of fatty acids, but mainly to produce dimmers as an additive for resin application $[192,196]$. There have been a few reports on the use of zeolites with intermediate pore/channel size for the isomerization of unsaturated fatty acids. The reaction takes place in the pore space of the zeolite material that contains the acid sites. The side chain created from branching can lower the cloud point of the fatty acid or fatty acid methyl ester. And by lowering the cloud point of a substance, the cold flow properties can be improved $[176,181]$. Various zeolites, such as Mordenite, zeolite L and/or zeolite Omega, Pentacyl and Beta, all showed some activities.

However, high catalyst loading and coke formation are still some problems that need to be addressed. Promising results were reported on the conversion of unsaturated fatty acid to branched isomers using modified Ferrierite [193, 197, 198], but the catalysts' activity decayed with successive reuse and catalyst regeneration was not achieved. Amongst all the zeolite materials Beta zeolite displayed superior performance due to high acid site density and existence of mesopores that are critical to the catalytic activity for unsaturated fatty acid isomerization. Mesoporosity is an added advantage as it provides easy accessibility of the acid sites to the feed molecules, thus avoiding transport and diffusional limitations. 


\section{CHAPTER 3}

\section{EXPERIMENTAL APPROACH}

One of the main goals of this work is to design ordered mesoporous $(2-30 \mathrm{~nm}$ pore size) gallium oxide and gallium based mixed metal oxides. Mesoporosity is an added advantage as it provides easy accessibility for the guest molecules, thus avoiding transport and diffusional limitations. We employed several techniques for the synthesis of mesoporous gallium oxide and gallium-based mixed oxides. Specifically we employed: a) Evaporation-Induced Self-Assembly (EISA), b) SelfAssembly Hydrothermal-Assisted (SAHA) and c) Self-Assembly MicrowaveAssisted approaches. Optimum mesoporous gallium and gallium-based mixed oxide phases were evaluated as catalysts for the following reactions: a) Epoxidation of cyclooctene, b) Isomerization of Methyl Oleate, and c) Transformation of Biodiesel to its branched isomers. In this chapter, we discuss the synthesis approaches employed for mesostructuring the oxide phases as well as the catalytic tests performed for these mesophases.

\subsection{Materials}

Gallium (III) nitrate hydrate (99.99\%, Strem Chemicals) was used as the inorganic precursor. Hexadecyltrimethylammonium bromide (CTAB, 99\%, Sigma), Pluronic P123 ((PEO) $\left.)_{20}(\mathrm{PPO})_{70}(\mathrm{PEO})_{20}\right)(\mathrm{BASF})$ and $\mathrm{F} 127$ $\left((\mathrm{PEO})_{200}(\mathrm{PPO})_{65}(\mathrm{PEO})_{200}\right)(\mathrm{BASF})$ were used as structure directing agents (SDA).

CTAB is a cationic surfactant and Pluronics P123 and F127 are triblock copolymers that are neutral. Based on this, it is expected that mesostructure formation is guided 
via electrostatic charge matching between the positively charged surfactants and negatively charged inorganic species when $\mathrm{CTAB}$ is used as SDA, where as in the case of neutral SDAs hydrogen bonding is considered to be the driving force for mesostructure formation. The various structure directing agents used in the synthesis of these mesoporous materials are shown in the Figure 3.1. Ethanol (ca. 99\% Sigma) and 1-butanol (ca. 99\% Sigma-Aldrich) were used as the organic solvents. Ethylene glycol (ca. 99\% Sigma-Aldrich) was used in some synthesis as an organic additive.

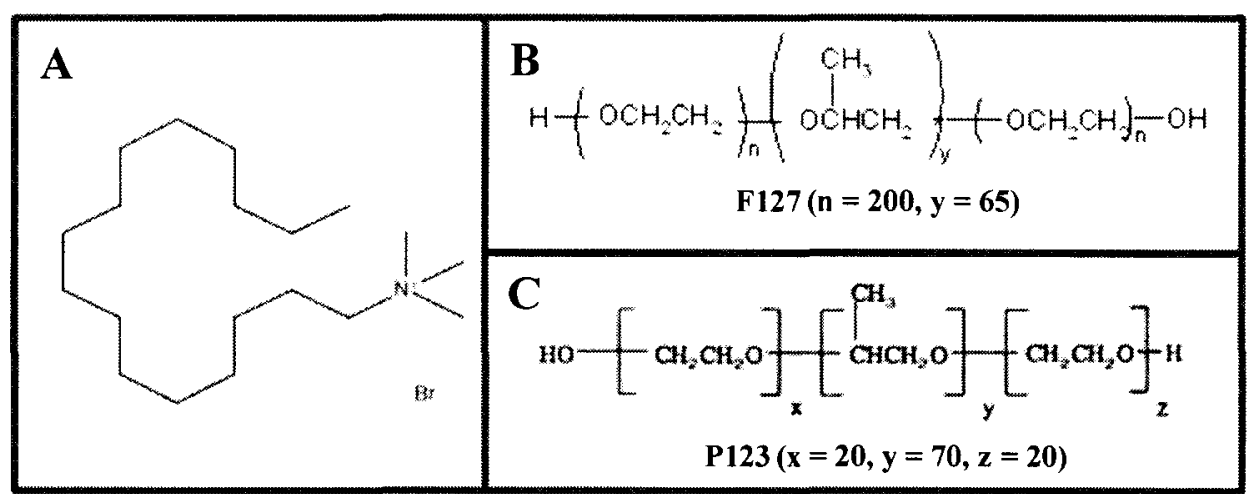

Figure 3.1. A) Hexadecyltrimethyl ammonium bromide (CTAB), Pluronics B) F127 and C) P123 were employed as the structure directing agents (SDA).

\subsection{Synthesis of Mesoporous Gallium Oxide}

Three approaches were employed for the synthesis of mesoporous gallium oxide: a) Evaporation-Induced Self-Assembly (EISA), b) Self-Assembly Hydrothermal-Assisted (SAHA) and c) Self-Assembly Microwave-Assisted heating. In this section we briefly describe each of these synthetic routes.

\subsubsection{Evaporation-Induced Self-Assembly (EISA)}

Mesoporous gallium oxide was prepared under mild synthesis conditions by reacting alcoholic solutions of gallium nitrate hydrate with SDA solutions. In a typical synthesis, the inorganic precursor was dissolved in the organic solvent (ethanol or 1- 
butanol). The solution was vigorously stirred at $40^{\circ} \mathrm{C}(280 \mathrm{rpm})$ until the precursor was dissolved completely. A homogeneous alcoholic solution of the different structure directing agents $(\mathrm{CTAB}, \mathrm{F} 127$ or $\mathrm{P} 123)$ was prepared at $40^{\circ} \mathrm{C}$. The molar concentrations of the SDA were varied between $6.1 \times 10^{-3}-350 \times 10^{-3}(0.3$ to $1 \mathrm{~g})$. The SDA alcohol solution was then added dropwise to the precursor solution under continuous stirring for about $30 \mathrm{~min}$. During the entire process the temperature was kept constant at $40^{\circ} \mathrm{C}$. The gel was then transferred to a petri dish and kept in the temperature-humidity chamber (Associated Environmental Systems) that was set at the desired conditions (typically $\mathrm{T}=30-40^{\circ} \mathrm{C}, \mathrm{RH}=65-85 \%$ ). These processing parameters were employed because they favor the mesostructure formation. Similar conditions have been used for mesoporous silica and titania [94]. The resultant gel was aged in the temperature-humidity chamber for $48 \mathrm{~h}$, and then dried completely at $60^{\circ} \mathrm{C}$ for $24 \mathrm{~h}$. The surfactant was removed by calcination in air at $350^{\circ} \mathrm{C}$ for $10 \mathrm{~h}$ to yield the mesoporous oxide phase. Typical synthesis compositions on molar basis were precursor:surfactant:solvent $=1:\left(6.1 \times 10^{-3}\right.$ to $\left.350 \times 10^{-3}\right): 9$. The schematic representation of the EISA procedure is shown in Figure 3.2.

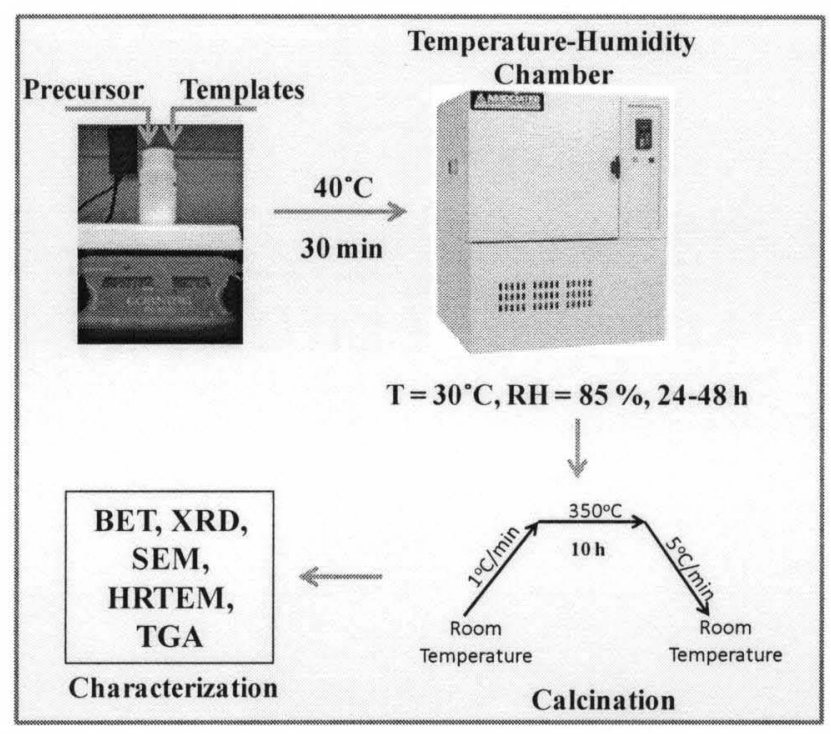

Figure 3.2. Schematic representation of EISA for the synthesis of mesoporous $\mathrm{Ga}_{2} \mathrm{O}_{3}$. 


\subsubsection{Synthesis of Hollow Mesoporous Nanocrystalline Gallium Oxide Spheres by SAHA}

In heterogeneous catalysis; it is highly desirable to have a well defined crystalline phase. Hydrothermal synthesis approach provides an alternative selfassembly method to prepare nanocrystalline oxide phases. Hydrothermal reactions are usually performed in moderate conditions, do not require expensive precursors or equipment and may yield homogeneous crystalline powders. These methods offer, thus, significantly reduced reaction time, relatively low temperature (up to $300^{\circ} \mathrm{C}$ ) and low pressure to produce fine oxide powders. This has made hydrothermal synthesis more economical as the processes can be engineered using cost-effective and proven reactor technology.

In a typical synthesis, an inorganic precursor-alcoholic solution was mixed with the SDA solution and was homogenized for $30 \mathrm{~min}$ at $40^{\circ} \mathrm{C}(280 \mathrm{rpm})$. The homogeneous gel was then transferred to a $45 \mathrm{~mL}$ Teflon-lined stainless steel autoclave (Parr Instrument Company) and heated under autogenous pressure in a static condition in conventional oven at $150^{\circ} \mathrm{C}-200^{\circ} \mathrm{C}$ for $20 \mathrm{~h}$. The resultant white solids were separated from the solution by centrifugation ( $4000 \mathrm{rpm}, 20 \mathrm{~min}$ ), washed three times with deionized water and dried overnight at $60^{\circ} \mathrm{C}$. The fine powder was then calcined in air at $350^{\circ} \mathrm{C}$ for $6 \mathrm{~h}$ yielding mesoporous hollow nanocrystalline gallium oxide spheres. In some synthesis, ethylene glycol was used as an organic additive to reduce the size of the mesoporous oxide hollow spheres. It is well known that ethylene glycol is able to mediate nucleation and growth, and thus improves the size uniformity of the resultant colloids. Ethylene glycol was added dropwise to the homogeneous gel with constant stirring and then transferred to the Teflon-lined stainless steel autoclaves and placed in the oven for hydrothermal treatment at 
different temperatures $\left(180^{\circ} \mathrm{C}, 200^{\circ} \mathrm{C}\right)$ for $8 \mathrm{~h}$. The molar concentration of ethylene glycol varied in the 2-8.3 range. Typical synthesis compositions employed for SAHA were similar to those used for EISA. The schematic representation of the SAHA procedure is shown in Figure 3.3.

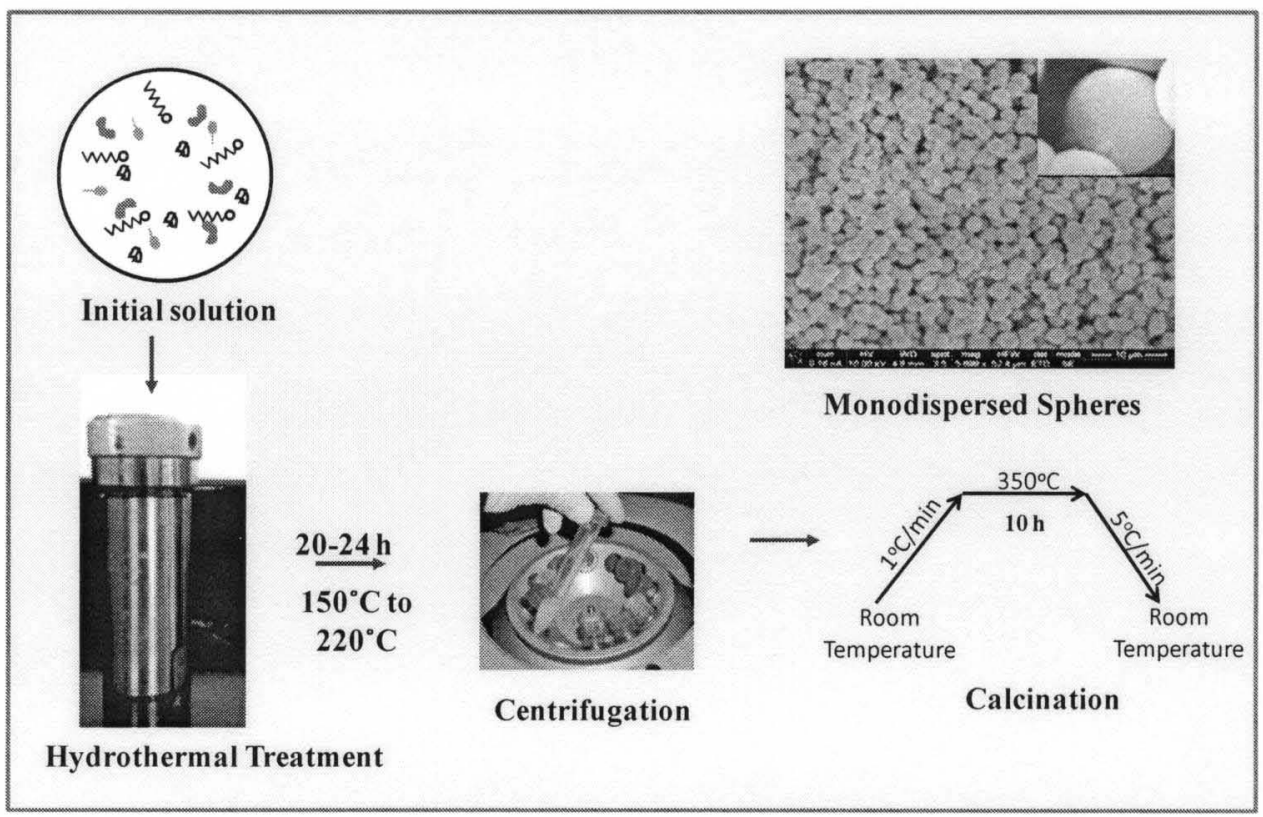

Figure 3.3. Schematic representation of SAHA for the synthesis of mesoporous $\mathrm{Ga}_{2} \mathrm{O}_{3}$.

\subsubsection{Microwave-assisted synthesis of nanocrystalline mesoporous gallium oxide}

Microwave-assisted heating is an attractive synthesis method due to its particular property of localized heating which leads to homogeneous and quick thermal reactions. It is advantageous as compared to the conventional heating methods which require relatively long synthesis time and high reaction temperatures. Microwave-assisted heating is an effective synthesis option since it provides fast crystallization, abundant nucleation, uniformity of particle size, high-reaction rate, phase selectivity and short-reaction synthesis time [173]. 
Homogeneous SDA-ethanol solution was prepared at $50^{\circ} \mathrm{C}$. The molar concentrations of the SDA were in the $6.1 \times 10^{-3}-350 \times 10^{-3}$ range. The SDA-alcoholic solution was then added dropwise to the precursor solution under continuous stirring for about $30 \mathrm{~min}$. The gel was transferred to a glass tube and was microwave heated for different times (15-200 min) with continuous stirring in a computer controlled microwave oven (Mars 5, CEM corp.) at $130^{\circ} \mathrm{C}$ and 250 psi. After cooling, the product was separated by centrifugation (20 min at $4000 \mathrm{rpm}$ ), washed three times with deionized water and dried overnight at $60^{\circ} \mathrm{C}$. The as-synthesized samples were then calcined in air at 350 or $400^{\circ} \mathrm{C}$ for $10 \mathrm{~h}$ (from 25 to $350^{\circ} \mathrm{C}$ at $1^{\circ} \mathrm{C} / \mathrm{min}$ and cooled down to $25^{\circ} \mathrm{C}$ at $5^{\circ} \mathrm{C} / \mathrm{min}$ ) in order to remove the SDA. Typical synthesis compositions on molar basis were precursor:surfactant:solvent $=1:\left(6.1 \times 10^{-3}-50 \times 10^{-}\right.$ $\left.{ }^{3}\right): 9$. The schematic representation of Microwave heating procedure for synthesis of mesoporous $\mathrm{Ga}_{2} \mathrm{O}_{3}$ is shown in Figure 3.4.

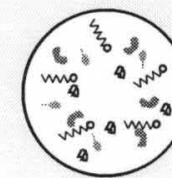

Initial solution

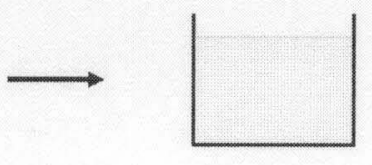

Microwave Reactor

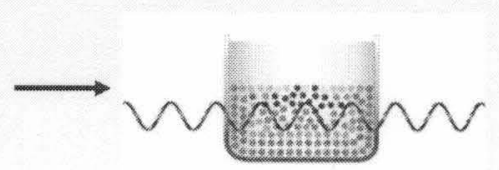

Microwave Heating $130^{\circ} \mathrm{C}, 250 \mathrm{psi}$

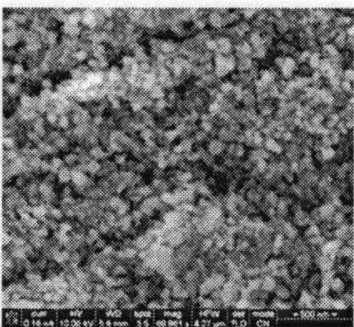

Nanocrystalline mesoporous oxide Centifugation

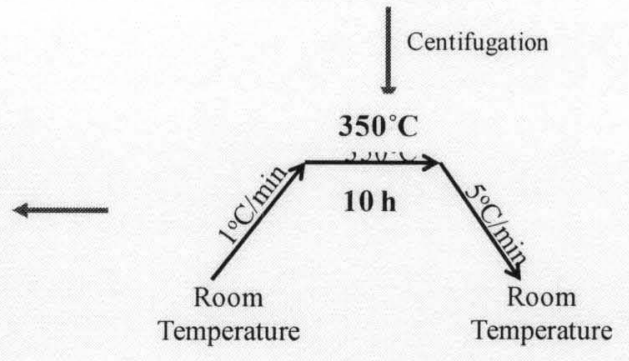

Calcination

Figure 3.4. Schematic representation of self-assembly microwave-assisted heating procedure for the synthesis of mesoporous $\mathrm{Ga}_{2} \mathrm{O}_{3}$. 


\subsubsection{Synthesis of mesoporous gallium-based metal oxides}

The acidic/basic properties of the supported catalysts are found to be a strong determining factor in the catalytic performance. Supported gallium oxide catalysts exhibit interesting catalytic properties for selective reduction of $\mathrm{NO}_{x}$ by hydrocarbons in the presence of excess oxygen [12] and for dehydrogenation or aromatization of light alkanes [11]. Supported gallium oxides are preferred to zeolites due to their weaker acidity and lower deactivation by the formation of carbonaceous deposits [13]. Also the Lewis acid sites of supported gallium oxides are suspected to be active sites for dehydrogenation of ethane [11]. In order to further enhance the catalytic properties, different transition metal oxides are employed to obtain novel mesoporous gallium-based mixed oxides. For example, niobium oxides and materials containing niobia display special properties such as redox properties, photosensitivity, and acidity which cause interesting catalytic behaviour. Incorporating small amounts of niobia enhance the catalytic activity, selectivity and prolong the catalyst life [199, 200].

Mixed mesoporous gallium-niobium mixed oxide phases were prepared under mild synthesis conditions by reacting alcoholic solution of inorganic precursors (eg. niobium chloride or molybdenum chloride) with alcoholic solution of F127. The inorganic precursor-alcoholic solution was mixed with the SDA solution and was homogenized for $30 \mathrm{~min}$ at $40^{\circ} \mathrm{C}(280 \mathrm{rpm})$. The homogeneous gel was then transferred to a $45 \mathrm{ml}$ Teflon lined stainless steel autoclave (Parr Instrument) and heated under autogenous pressure in a static condition in conventional oven at $180^{\circ} \mathrm{C}$ for $20 \mathrm{~h}$. The resultant solids were separated from the solution by centrifugation at $4000 \mathrm{rpm}$ and $20 \mathrm{~min}$, washed three times with deionized water and dried overnight at $60^{\circ} \mathrm{C}$. The resultant powder was then calcined in air at $350^{\circ} \mathrm{C}$ for $10 \mathrm{~h}$ yielding 
mesoporous gallium-niobium mixed oxide phases. A similar method was employed for the synthesis of mesoporous niobium oxide. Typical synthesis compositions on molar basis were Precursor:Surfactant:Solvent:1:0.01:9, while the molar ratio of gallium to niobium varied between 0.2 to 6.6 .

The procedure for the synthesis of mesoporous Ga-Mo mixed oxide phases is similar to that of mesoporous $\mathrm{Ga}-\mathrm{Nb}$ mixed oxides. The alcoholic solution of inorganic precursor (molybdenum chloride) was homogeneously mixed with the alcoholic solution of F127 (SDA). The homogeneous gel was then transferred to a 45 $\mathrm{ml}$ Teflon lined stainless steel autoclave (Parr Instrument) and heated under autogenous pressure in a static condition in conventional oven at $180^{\circ} \mathrm{C}$ for $20 \mathrm{~h}$. The resultant solids were separated from the solution by centrifugation at $4000 \mathrm{rpm}$ and 20 min, washed three times with deionized water and dried overnight at $60^{\circ} \mathrm{C}$. The resultant powder was then calcined in air at $350^{\circ} \mathrm{C}$ for $10 \mathrm{~h}$ yielding mesoporous gallium-molybdenum mixed oxide phases.

\subsection{Characterization}

The morphology and crystal size of the mesophases were analyzed with a FESEM (FEI Nova 600) with an acceleration voltage of $6 \mathrm{kV}$. The XRD patterns were collected on Bruker D8 Discover diffractometer employing $\mathrm{Cu} K \alpha(\lambda=1.54 \AA)$ as the source. $\mathrm{N}_{2}$ adsorption BET surface areas were determined in a Micromeritics Tristar3000 porosimeter. Before the surface area measurements, the samples were degassed at $300^{\circ} \mathrm{C}$ for $3 \mathrm{~h}$. TEM, HRTEM images and SAED patterns were collected on Technai F20 FEI TEM using a field emission gun, operating with an accelerating voltage of $200 \mathrm{kV}$. TGA analysis was performed to determine the amount of pyrolyzed carbon that remained in the mesophases. ICP chemical analysis was 
performed over the mesoporous Ga-Nb mixed oxide phases to determine the ratio of $\mathrm{Ga} / \mathrm{Nb}$.

\subsection{Catalytic Performance}

The catalytic performance of mesoporous gallium and gallium-based mixed oxide phases was evaluated for the following reactions: a) Epoxidation of cyclooctene, b) Isomerization of Methyl Oleate, and c) Transformation of Biodiesel to its branched isomers. In this section, we discuss the catalytic tests performed for these mesophases.

\subsubsection{Epoxidation of Cyclooctene}

The catalytic activity of mesoporous gallium oxide was evaluated in the epoxidation of cyclooctene with hydrogen peroxide. The catalyst was ground to fine powder in a ceramic crucible and was activated in air overnight at $220^{\circ} \mathrm{C}$. A $50 \mathrm{wt} \%$ aqueous solution of hydrogen peroxide was used as the oxidizing agent and ethyl acetate, acetonitrile and methanol were used as the solvent. Cyclooctene $(7.45$ $\mathrm{mmol} / 0.82 \mathrm{~g})$, ethyl acetate $(50 \mathrm{mmol} / 4.5 \mathrm{~g})$ and hydrogen peroxide $(5.0 \mathrm{mmol} / 0.169$ g) were added to $0.1 \mathrm{~g}$ of catalyst. The cyclooctene to hydrogen peroxide ratio was kept constant at 3 for all the experiments. The catalyst was added to a solution containing cyclooctene and ethyl acetate with stirring. Then the oxidizing agent was added dropwise to the solution. The reaction mixture was stirred at $300 \mathrm{rpm}$ for $2 \mathrm{hr}$ at $60^{\circ} \mathrm{C}$ in a three-neck round bottom flask coupled with a reflux system. The epoxidation reaction was also carried out at $80^{\circ} \mathrm{C}$ for $2 \mathrm{~h}$. Figure 3.5 shows the schematic representation of the experimental set up. The catalyst was removed by filtration and the reaction products were analyzed by gas chromatography-cum-mass spectrometry (HP 5890 Gas Chromatograph equipped with 5970 Mass Selective Detector, $30 \mathrm{~m} \times 0.32 \mathrm{~mm}$ HP-5 column coated with $5 \%$ phenyl poly siloxane 
stationary phase). The temperature profile during the analysis was as follows: $70 \mathrm{C}$ to $220 \mathrm{C}$ at $15 \mathrm{C} / \mathrm{min}$. The analysis time for each sample was approximately $20 \mathrm{~min}$.

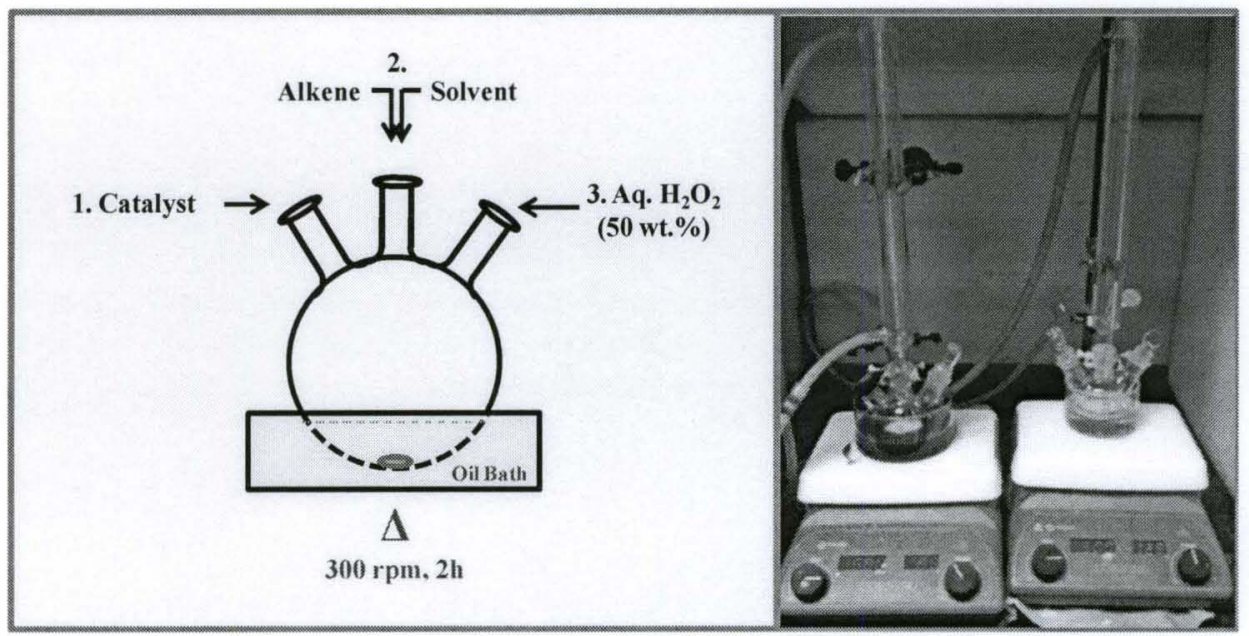

Figure 3.5. Schematic representation of the experimental setup for the epoxidation reaction.

\subsubsection{Isomerization of Methyl Oleate and Transformation of Biodiesel to its}

\section{branched isomers}

The catalytic activity of the mesoporous gallium oxide, niobium oxide, and gallium-niobium mixed oxide was evaluated by reacting $0.2 \mathrm{~g}$ of the catalyst (activated in nitrogen overnight at $220^{\circ} \mathrm{C}$ ) with $2 \mathrm{ml}$ of the probe molecule (methyl oleate) in a standard batch autoclave (Parr Instruments) at $220^{\circ} \mathrm{C}$ and autogeneous pressures for $20 \mathrm{~h}$ as shown in Figure 3.6. No solvents or carrier gases were used. At the end of the period, the reactor was cooled to room temperature. The catalyst was removed by filtration and the reaction products were analyzed. 


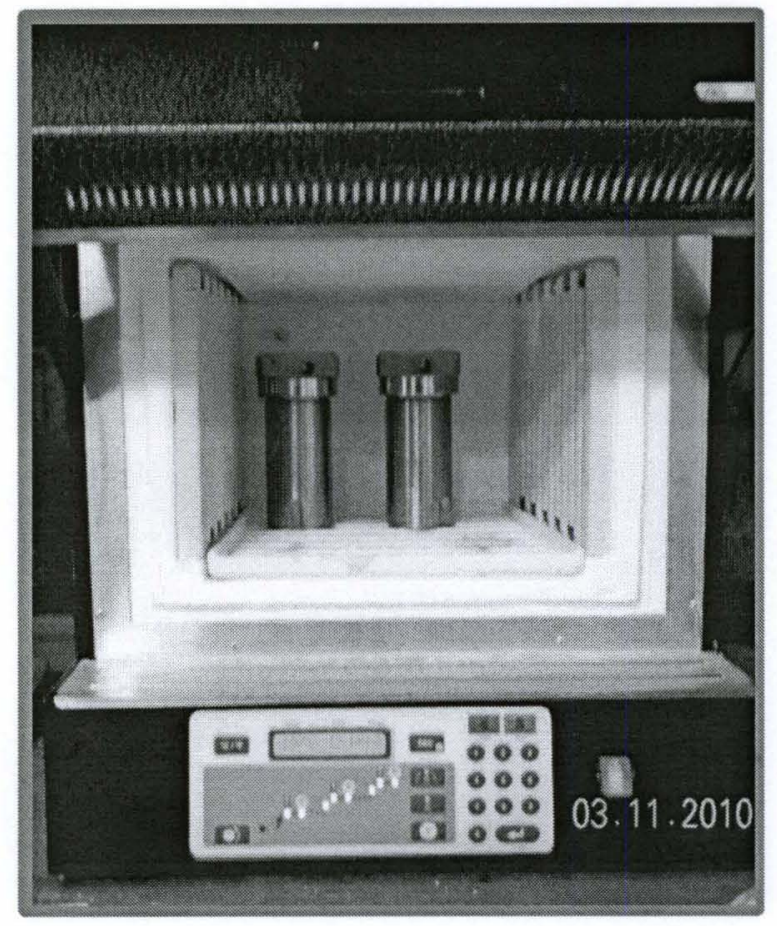

Figure 3.6. Batch-autoclave reactors employed to carry out the isomerisation and biodiesel transformation reactions experiments.

\subsection{Product Analysis}

The methyl oleate, biodiesel and the products of their reaction with the various catalysts were analyzed by gas chromatography-cum-mass spectrometry (HP 5890 Gas Chromatograph equipped with 5970 Mass Selective Detector; Agilent J \& W biodiesel capillary G.C. column ( $30 \mathrm{~m}$ X $0.32 \mathrm{~mm} \mathrm{X} 0.25 \mu \mathrm{m})$ coated with BDEN14103 stationary phase), and ${ }^{1} \mathrm{H} /{ }^{13} \mathrm{C}$ NMR spectrometry (Varian 7600 AS (400 MHz)), shown in Figure 3.7.

Product identification was done by a combination of gas chromatography, mass spectrometry and ${ }^{1} \mathrm{H} /{ }^{13} \mathrm{C}$ NMR spectroscopies. The gas chromatographic peaks corresponding to the $\mathrm{M}^{+} 296, \mathrm{M}^{+} 294, \mathrm{M}^{+} 298$ and $\mathrm{M}^{+} 270$ peaks in the mass spectra were used to identify and quantify the concentrations of methyl oleate, linoleate, stearate and palmitate, respectively. 


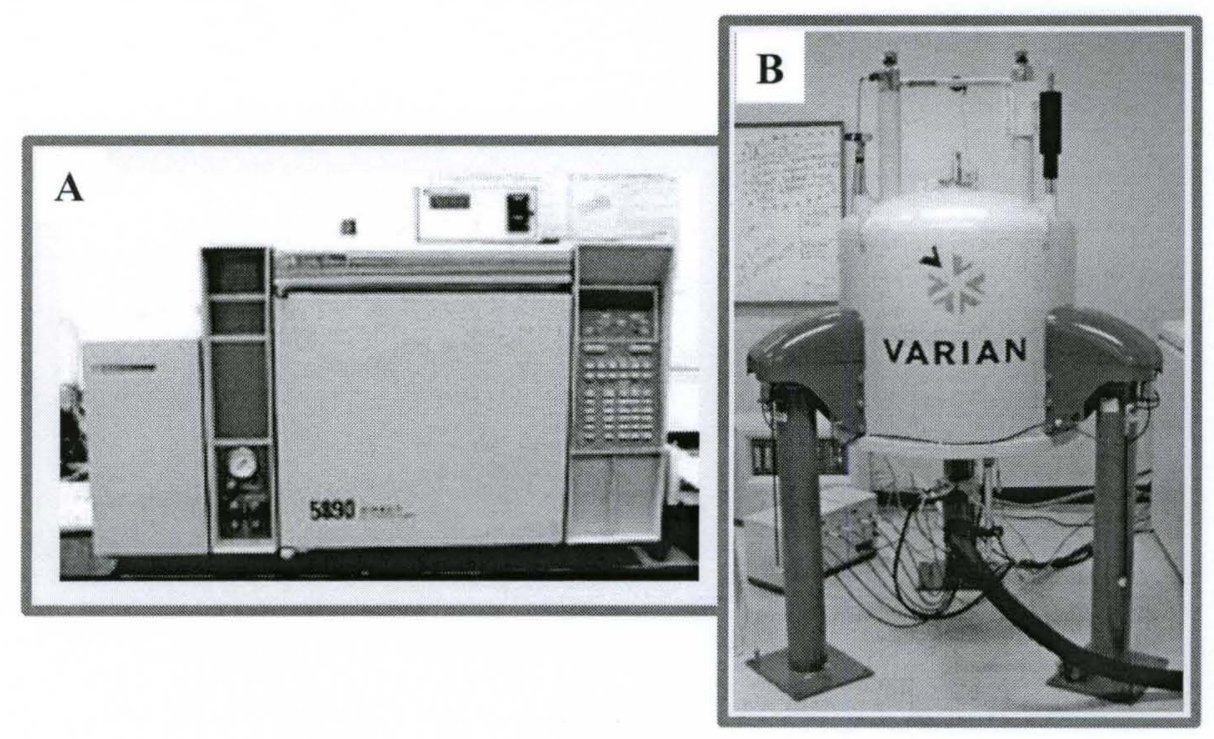

Figure 3.7. A) HP 5890 Gas Chromatograph equipped with 5970 Mass Selective Detector and B) Varian 7600 AS NMR spectrometer employed for product analysis.

The injection temperature and column temperature in the GC were kept constant in all experiments at $280^{\circ} \mathrm{C}$ and $220^{\circ} \mathrm{C}$ respectively. It was difficult to distinguish between the various linear isomers formed by simple, double bond isomerization of the unsaturated linear esters. Hence, all such linear olefinic isomers were lumped together and "conversion" refers to the conversion of the linear unsaturated fatty acid methyl esters to dehydrogenated products, the branched isomers and cracked/dimeric products. The concentration of the linear olefinic esters was estimated from the intensity of the proton at $5.3-5.5 \mathrm{ppm}$ (characteristic of internal olefinic $\mathrm{C}-\mathrm{H}$ protons). Selectivity for skeletal isomerisation was obtained from the increase in the intensity of the ${ }^{13} \mathrm{C}$ NMR peaks at $30.91 \mathrm{ppm}$ (characteristic of the $\mathrm{CH}$ - carbon) and $18.36 \mathrm{ppm}$ (characteristic of the $-\mathrm{CH}_{3}$ group). The selectivity for allylic branching was obtained from changes in the ratio of the intensities of the ${ }^{1} \mathrm{H}$ NMR peaks at $1.92-2.08 \mathrm{ppm}$ (characteristic of the allylic $\mathrm{C}-\mathrm{H}$ protons) and those at 5.3 - $5.5 \mathrm{ppm}$, respectively. In the case of the products from reactions of the biodiesel, 
it was difficult to analyze the structure of the individual branched isomeric esters in detail. They were, generally, mixtures of a large number of isomers which have some branched alkyl chains having 1-2 carbon atoms at different branching positions in the principal alkyl chains (indicated by ${ }^{1} \mathrm{H}$ and ${ }^{13} \mathrm{C}$ NMR data). Oligomerisation of the olefinic esters to dimers was also observed, to some extent, over all catalysts, the extent of isomerization varying with the type of catalyst and reaction conditions. The yield of dimers was estimated by distillation of the reaction products under reduced pressure and estimating the amount from the residue collected. The concentration of dimers was also estimated from the decrease in iodine number (see section 3.5.1) as well as that of the olefinic protons from ${ }^{1} \mathrm{H}$ NMR spectroscopy. Decrease in the iodine number was an additional indication for the formation of dimers. The concentration of oleic acid (formed when traces of water was present in the biodiesel) was estimated from gas chromatography, acid- base titration as well as changes in the concentration of the ${ }^{13} \mathrm{C}$ NMR peaks of the carbonyl carbon of the ester (at $174.3 \mathrm{ppm}$ ) and the methyl carbon of the ester at $51.5 \mathrm{ppm}$.

\subsubsection{Iodine value}

The unsaturation in the product (a measure of the number of double bonds in the FAME molecules) was estimated by iodine value measurements. About $0.2 \mathrm{~g}$ of sample was taken in a clean dry stoppered bottle of $500 \mathrm{ml}$ capacity. It was then dissolved in $10 \mathrm{ml}$ of dichloromethane (Aldrich). Twenty five $\mathrm{ml}$ of iodine monochloride solution (Wijs' solution; Aldrich) was then added from a burette. In the resulting mixture was turbid, it was cleared by adding more dichloromethane. The bottle was gently rotated to mix the contents thoroughly. The bottle was then set aside for about half an hour. Then $20 \mathrm{ml}$ of $10 \% \mathrm{KI}$ solution (Aldrich) was added and the mixture was diluted with $200 \mathrm{ml}$ of water. This mixture was then titrated with 
standard thiosulphate solution (Aldrich) using starch as indicator. A blank determination was carried out without the oil.

$$
\text { Iodine value }=\frac{\Delta V \times 0.12692 \times S}{W} \times 100
$$

where,

$\Delta V=$ Difference in the titer volumes of thiosulphate required for the product and the blank, (ml).

$\mathrm{S}=$ Strength of the thiosulfate solution, (normality) and

$\mathrm{W}=$ Mass of the product sample $(\mathrm{g})$.

\subsubsection{Acidity}

The acid value of biodiesel and the products (dissolved in a mixture of equal parts of $96 \%$ ethanol and diethyl ether) was determined by titration against $(0.1 \mathrm{~N})$ sodium hydroxide solution using phenolphthalein as an indicator. About $0.1 \mathrm{~g}$ of the product sample was weighed with an accuracy of $0.01 \mathrm{~g}$ and dissolved in $10 \mathrm{ml}$ of neutral solvent. The mixture of ethanol and diethyl ether mixture was neutralized immediately before use by titration with $0.1 \mathrm{~N}$ sodium hydroxide solution.

Acid value $=\frac{56.1(N \times V)}{W}$

where,

$\mathrm{W}=$ weight of the sample $(\mathrm{g})$

$\mathrm{N}=$ Normality of the sodium hydroxide solution used and

$\mathrm{V}=$ Volume of the sodium hydroxide solution used $(\mathrm{ml})$. 


\section{CHAPTER 4}

\section{SYNTHESIS AND CHARACTERIZATION OF THERMALLY STABLE}

\section{NANOCRYSTALLINE MESOPOROUS GALLIUM OXIDE PHASES}

Gallium oxide has been synthesized using diverse techniques, such as thermal decomposition [15], homogeneous precipitation using ammonia [2, 21-23], and surface layer adsorption [24]. However, these methods offer poor control over structural, morphological and compositional properties. It has been prepared in nanowire form by a number of techniques, including arc-discharge $[42,43]$, vaporliquid-solid (VLS) [39, 44], carbothermal reduction [45, 46], and thermal oxidation $[47,48]$. All these methods produced crystalline $\mathrm{Ga}_{2} \mathrm{O}_{3}$ nanowires with relatively low specific surface areas. Furthermore, these techniques are complex, time consuming and costly.

Surfactant assisted self assembly approach reported by researchers at Mobil Research and Development Corporation $[52,53]$ represents an alternative and attractive method for the synthesis of novel transition metal oxide catalytic phases with desirable structural, compositional and morphological properties [54-56]. Carreon and Guliants have reviewed the guiding principles for the synthesis of metal oxide mesostructures relevant to applications in catalysis [56]. Gallium oxide displays polymorphism similar to alumina, it is principally an acidic oxide which plays a key role in catalysis, and hence gallium oxide is an attractive system for mesostructuring. 
Only few reports have been published on mesoporous gallium oxide synthesized employing surfactants as structure directing agents. Yada et al. [21, 22] synthesized mesostructured gallium oxide, with hexagonal and layered structures by employing sodium dodecyl sulfate as the structure directing agent (SDA). Although the resultant mesophases displayed relatively high surface areas, they showed poor crystallinity and were thermally unstable at temperature above $300^{\circ} \mathrm{C}$.

Herein, we present the synthesis of thermally stable mesoporous gallium oxide employing: a) Evaporation-Induced Self-Assembly (EISA), b) Self-Assembly Hydrothermal-Assisted (SAHA) and c) Microwave-Assisted heating approaches. These methods not only eliminate the need for the high synthesis temperatures commonly required for solid-state reactions, but also offer the possibility of synthesizing thermally stable mesoporous oxides with controlled morphological, textural and structural properties.

\subsection{Evaporation-Induced Self-Assembly (EISA)}

EISA is a well-suited approach to prepare ordered mesophases with fine tuned structural and morphological properties $[95,96,102]$. In this study, cationic surfactant (CTAB) and non-ionic triblock copolymers (P123 and F127) were used as the structure directing agents to guide the mesostructure formation. The resulting assynthesized mesophases were treated thermally to stabilize the inorganic framework and eliminate the SDA. At the synthesis $\mathrm{pH}$ of $\sim 2$, the dominant species in the solution are polycations $[201,202]$ since the isoelectric point of the gallium hydroxo species is $\sim 9$ [203]. Therefore, the assembly process was likely controlled by electrostatic charge-matching between the inorganic ions in solution $\left(\mathrm{I}^{-}\right)$charged surfactant headgroups $\left(\mathrm{S}^{+}\right)$or non-ionic surfactants $\left(\mathrm{S}^{\circ}\right)$ and inorganic counterions $\left(\mathrm{NO}^{3-}\right)$. Positively charged gallium hydroxo species assembled through hydrogen 
bonding mediation with $\mathrm{CTAB}$ or hydronium ion solvated neutral block copolymers. A similar mediated mechanism has been proposed for ordered mesoporous silica phases $[87,204]$.

Mesoporous oxides synthesized by employing F127 and P123 as SDA by EISA led to the formation of porous spheres non-homogeneous in size as seen in Figure 4.1. The sphere size range of the mesophase prepared with F127 as SDA was 0.05 to $0.5 \mu \mathrm{m}$ (Fig. 4.1 A), while the sphere size range of the mesophases prepared by employing P123 as SDA was 0.06 to $0.2 \mu \mathrm{m}$ (Fig. 4.1B). This Figure shows the porous nature of the spheres displaying average pore size of $\sim 4-4.5 \mathrm{~nm}$ in agreement with pore size analysis. The samples prepared with $\mathrm{CTAB}$ as structure directing agent showed irregular morphologies (not shown here). Table 4.1 summarizes general synthesis conditions and textural properties of the mesoporous gallium oxide phases obtained by EISA approach. Surface area as high as $298 \mathrm{~m}^{2} / \mathrm{g}$ with unimodal average pore sizes in the range of $\sim 2$ to $4.6 \mathrm{~nm}$ were obtained. The nature of the structure directing agents helped to fine tune the pore size of the resulting mesophases. For instance, CTAB, F127 and P123 led to the formation of mesophases with average pore size of $2.0-2.8 \mathrm{~nm}, 3.2-3.6 \mathrm{~nm}$ and $\sim 4.2-4.6 \mathrm{~nm}$ respectively. Due to their larger micellar size, amphiphilic block copolymers such as F127 and P123 led to larger average pore sizes. 

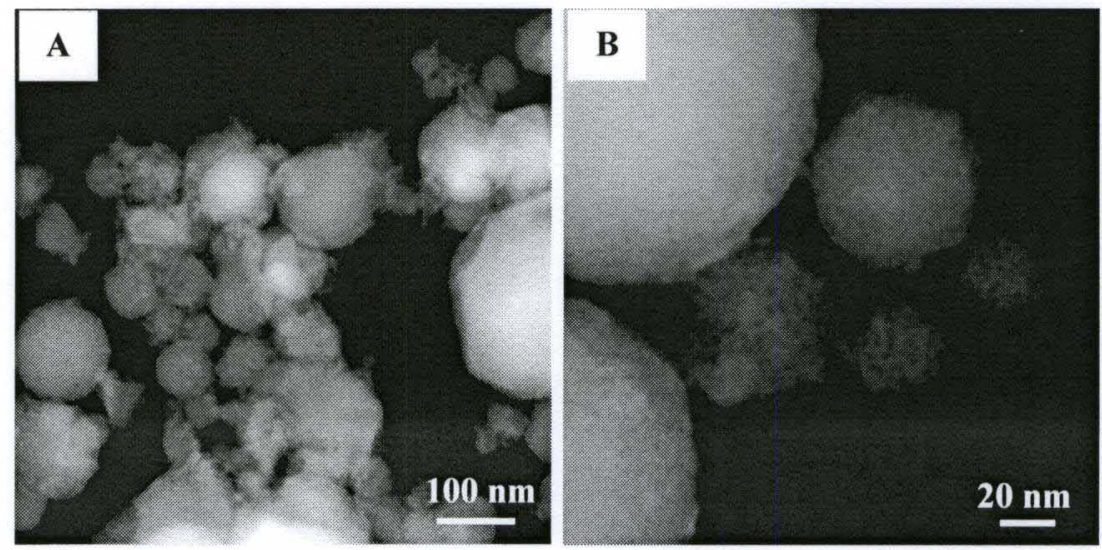

Figure 4.1. TEM images of mesoporous $\mathrm{Ga}_{2} \mathrm{O}_{3}$ synthesized by EISA employing $\mathrm{A}$ ) F127 and B) P123 as SDA.

Table 4.1. Synthesis conditions and textural properties of mesoporous $\mathrm{Ga}_{2} \mathrm{O}_{3}$ phases synthesized by EISA.

\begin{tabular}{|c|c|c|c|c|c|c|c|}
\hline \multirow[t]{2}{*}{$\begin{array}{l}\text { Sample } \\
\text { ID }\end{array}$} & \multicolumn{2}{|c|}{$\begin{array}{c}\text { Surfactant/ } \\
\text { A mount (gm) }\end{array}$} & \multicolumn{2}{|c|}{$\begin{array}{l}\text { Processing } \\
\text { Conditions }\end{array}$} & \multirow[t]{2}{*}{$\begin{array}{l}\text { Surface area } \\
\qquad\left(\mathrm{m}^{2} / \mathrm{g}\right)\end{array}$} & \multirow[t]{2}{*}{$\begin{array}{l}\text { Pore Diameter } \\
\quad(\mathrm{nm})\end{array}$} & \multirow[t]{2}{*}{$\begin{array}{l}\text { Pore Volume } \\
\left(\mathrm{cm}^{3} / \mathrm{g}\right)\end{array}$} \\
\hline & & & $\mathrm{T}\left({ }^{\circ} \mathrm{C}\right)$ & RH $(\%)$ & & & \\
\hline E1 & CTAB & 0.3 & 30 & 65 & 144 & 2.8 & 0.11 \\
\hline E2 & CTAB & 0.5 & 30 & 65 & 298 & 3.0 & 0.12 \\
\hline E3 & F 127 & 0.5 & 35 & 85 & 173 & 3.6 & 0.16 \\
\hline E4 & F127 & 1.0 & 35 & 85 & 187 & 3.2 & 0.15 \\
\hline E5 & P123 & 0.3 & 30 & 65 & 152 & 4.2 & 0.16 \\
\hline E6 & P123 & 0.8 & 30 & 65 & 173 & 4.6 & 0.20 \\
\hline
\end{tabular}

All the samples (E1-E6) displayed type IV isotherms typical of mesoporous materials [141, 205, 206]. Figure 4.2 shows the $\mathrm{N}_{2}$ adsorption-desorption isotherms and $\mathrm{BJH}$ pore size distributions from adsorption branch of the mesoporous gallium oxide phases synthesized via EISA. For example, the sample synthesized using CTAB as SDA (Fig. 4.2a), had a specific surface area of $\sim 144 \mathrm{~m}^{2} / \mathrm{g}$ with average unimodal pore diameter of $\sim 2.8 \mathrm{~nm}$. The sample synthesized using F127 as the SDA (Fig. 4.2c) showed a specific surface area of $\sim 173 \mathrm{~m}^{2} / \mathrm{g}$ and average pore diameter of $\sim 3.6 \mathrm{~nm}$. The sample synthesized using P123 as SDA (Fig. 4.2e) displayed a specific surface 
area of $\sim 152 \mathrm{~m}^{2} / \mathrm{g}$ and average pore diameter of $\sim 4.2 \mathrm{~nm}$. The isotherms for samples E2, E4 and E6 are also shown in Figure 4.2.

a)

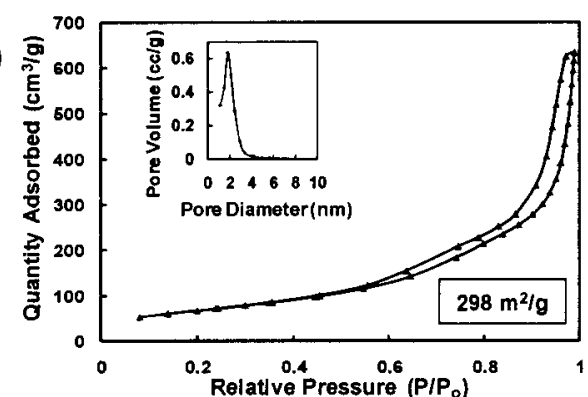

c)

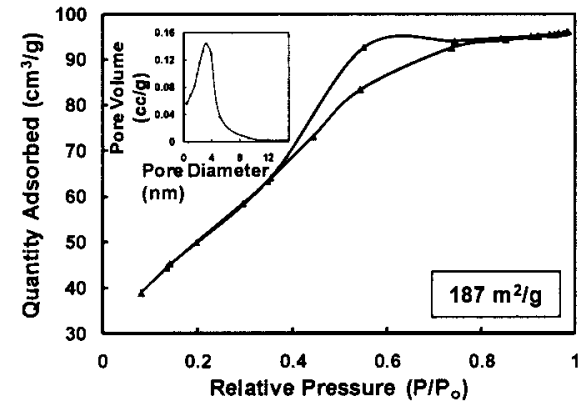

e)

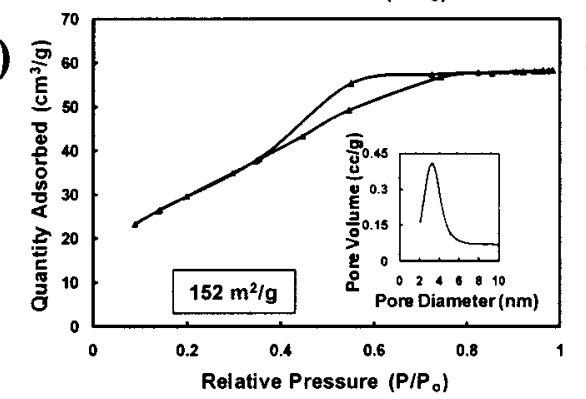

b)

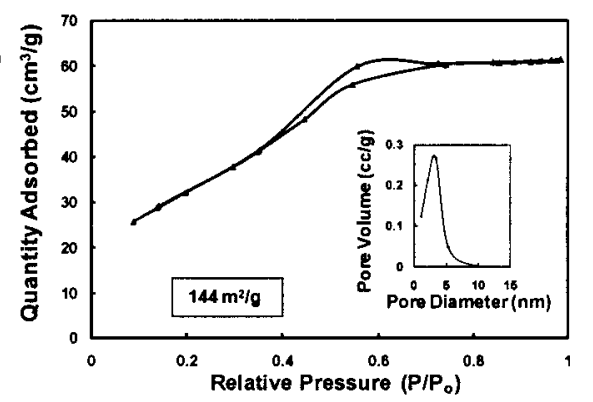

d)

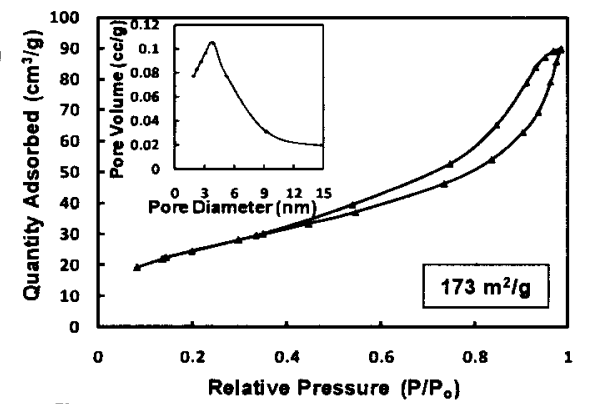

f)

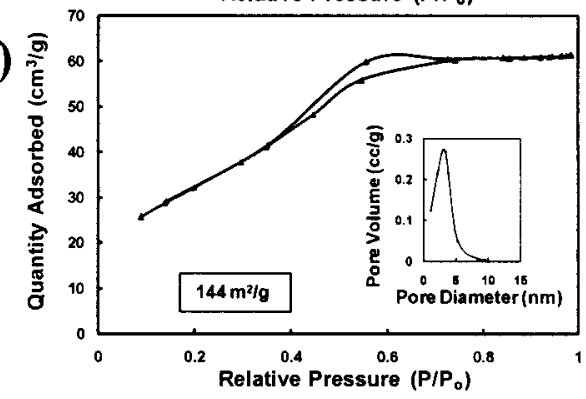

Figure 4.2. $\mathrm{N}_{2}$ adsorption-desorption isotherms and $\mathrm{BJH}$ pore size distribution from adsorption branch of mesoporous $\mathrm{Ga}_{2} \mathrm{O}_{3}$ phases synthesized by EISA employing a-b) CTAB (E1, E2), c-d) F127 (E3, E4) and e-f) P123 (E5, E6) as SDA.

The mesostructure formation was confirmed by low angle XRD (Figure 4.3a).

These mesostructures showed a single broad peak at a $d_{\text {spacing }}$ of $40.7,42.9$, and 42.5

$\AA$ for the samples prepared with CTAB, F127 and P123 as SDA respectively, suggesting the formation of a wormhole mesostructure. High angle $\mathrm{X}$-ray diffraction patterns for these three samples displayed two broad peaks tentatively assigned to the 
(311) and (440) planes of cubic spinel confirming the semi-crystalline nature of the mesoporous walls as seen in Figure 4.3b.
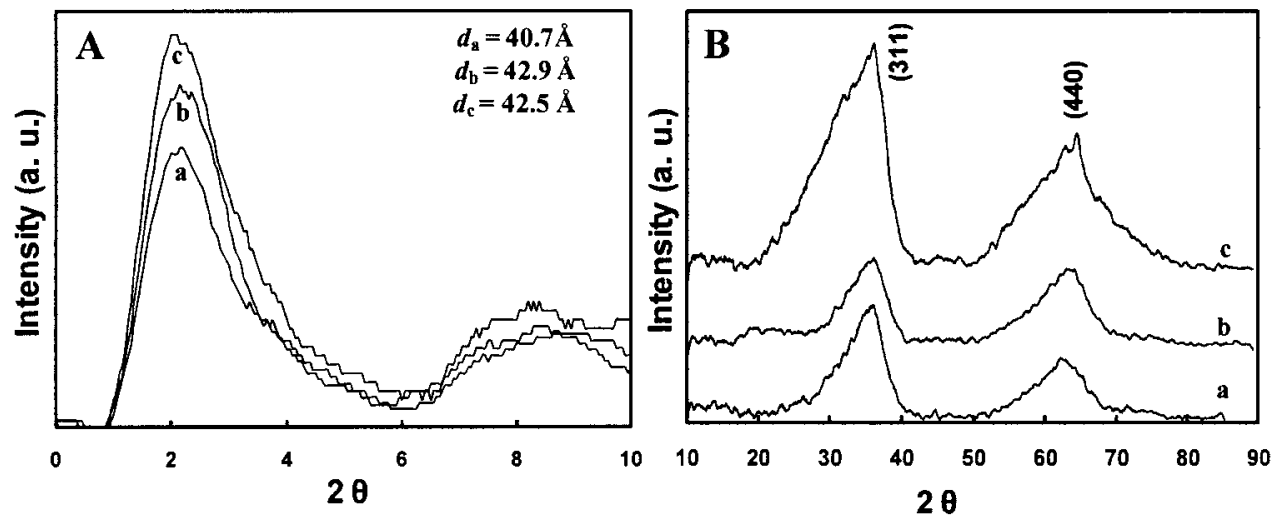

Figure 4.3. A) Low-angle and $\mathrm{B}$ ) High-angle $\mathrm{XRD}$ patterns of mesoporous $\mathrm{Ga}_{2} \mathrm{O}_{3}$ phases synthesized by EISA employing a) CTAB, b) F127 and c) P123 as SDA. X-ray radiation $\mathrm{Cu}_{k \alpha}(\lambda=1.54 \AA)$.

Selected area electron diffraction (SAED) of samples synthesized by EISA employing P123 as SDA yields a diffuse ring pattern indicating fine nanocrystalline or nearly amorphous structure. Two broad rings are observed (Fig. 4.4A) and their average $d_{\text {spacing }}$ of about 0.25 and $0.15 \mathrm{~nm}$ correlate well with the $d_{\text {spacing }}$ of (311) and (400) planes in a spinel-type cubic $\mathrm{Ga}_{2} \mathrm{O}_{3}[2,3,19,23]$. The intensity line profile measured across the SAED pattern (Fig. 4.4B) resembles high-angle XRD patterns obtained from EISA-synthesized samples (Fig. 4.3B). 

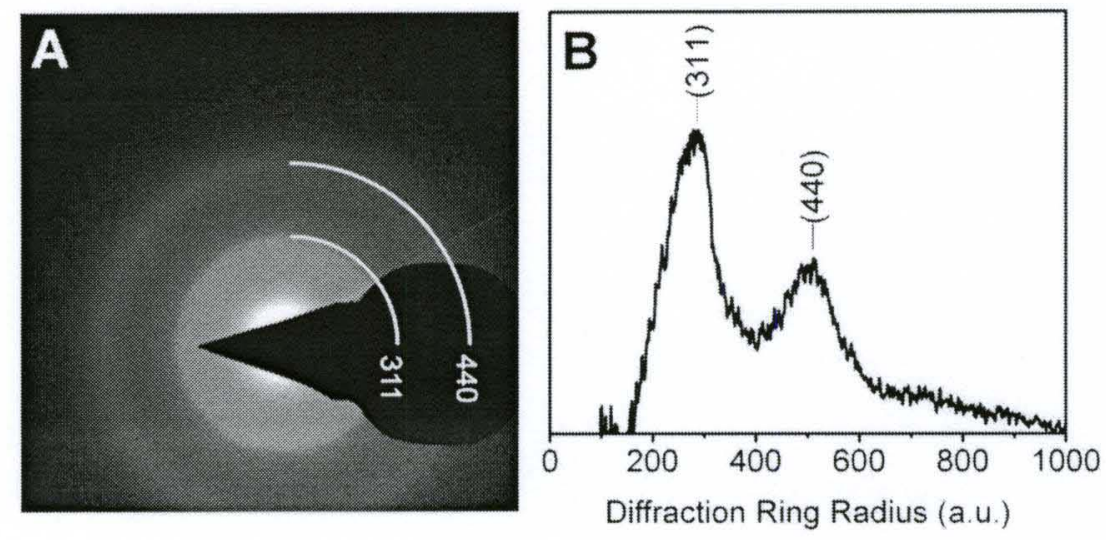

Figure 4.4. A) SAED pattern and B) intensity profile measured for mesoporous $\mathrm{Ga}_{2} \mathrm{O}_{3}$ synthesized by EISA employing P123 as SDA.

\subsection{Self-Assembly Hydrothermal-Assisted (SAHA) Approach}

For many structure-sensitive applications, such as in heterogeneous catalysis, it is highly desirable to have a well-defined crystalline phase. In this respect, SAHA approach is an alternative self-assembly method to prepare nanocrystalline mesoporous gallium oxide phases. Nanocrystalline micron-sized mesoporous gallium oxide spheres with narrow particle size distribution prepared by using different structure directing agents are shown in Figure 4.5. The average size of the spheres obtained at hydrothermal temperature of $180^{\circ} \mathrm{C}$ varied from $\sim 2 \mu \mathrm{m}$ to $3 \mu \mathrm{m}$. These nanocrystalline mesophases showed relatively high specific surface areas and unimodal pore size distribution as shown in Table 4.2. In general, it was observed that as the hydrothermal treatment temperature increased the specific surface area decreased, the average pore diameter increased, and the average sphere size increased. 

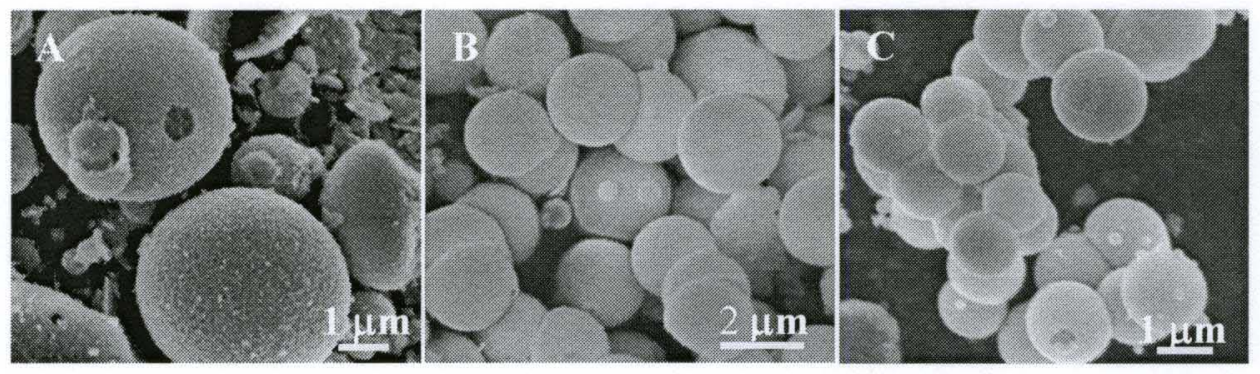

Figure 4.5. $\mathrm{SEM}$ images of mesoporous $\mathrm{Ga}_{2} \mathrm{O}_{3}$ phases synthesized by $\mathrm{SAHA}$ at $180^{\circ} \mathrm{C}$ employing A) CTAB $(3 \mu \mathrm{m})$, B) F127 $(2.2 \mu \mathrm{m})$ and C) P123 $(2.0 \mu \mathrm{m})$ as SDA.

Table 4.2. General synthesis conditions and textural properties and average sphere size of mesoporous nanocrystalline $\mathrm{Ga}_{2} \mathrm{O}_{3}$ phases synthesized by SAHA.

\begin{tabular}{|c|cc|c|c|c|c|}
\hline $\begin{array}{c}\text { Sample } \\
\text { ID }\end{array}$ & $\begin{array}{c}\text { Surfactant/ } \\
\text { Amount (gm) }\end{array}$ & $\begin{array}{c}\text { Hyd rothermal } \\
\text { Temperature }\left({ }^{\circ} \mathbf{C}\right)\end{array}$ & $\begin{array}{c}\text { Surface area } \\
\left(\mathbf{m}^{2} / \mathbf{g}\right)\end{array}$ & $\begin{array}{c}\text { Pore Diameter } \\
(\mathbf{n m})^{[\mathbf{a}]}\end{array}$ & $\begin{array}{c}\text { Pore Volume } \\
\left(\mathbf{c m}^{3} / \mathbf{g}\right)\end{array}$ \\
\hline S1 & CTAB & 0.5 & 180 & 139 & $4.9[3.0]$ & 0.21 \\
\hline S2 & CTAB & 1.0 & 200 & 107 & $5.6[4.5]$ & 0.16 \\
\hline S3 & F127 & 0.5 & 180 & 152 & $4.3[2.2]$ & 0.20 \\
\hline S4 & F127 & 1.0 & 200 & 122 & $7.6[2.5]$ & 0.30 \\
\hline S5 & P123 & 0.3 & 180 & 123 & $11.5[2.0]$ & 0.26 \\
\hline S6 & P123 & 0.9 & 200 & 74 & $12.2[6.5]$ & 0.26 \\
\hline
\end{tabular}

[a] Numbers in square brackets represent average sphere size of the samples synthesized by SAHA.

The nitrogen adsorption-desorption isotherms and BJH pore size distributions from the adsorption branch of these nanocrystalline mesoporous gallium oxide phases synthesized employing CTAB (S1), F127 (S3), and P123 (S6), are shown in Figure 4.6. The shape of the isotherms and the hysteresis loops for all the samples indicated the mesoporous nature of these materials $[13,112,206]$. The sample synthesized with CTAB (Fig. 4.6A) showed a specific surface area of $\sim 139 \mathrm{~m}^{2} / \mathrm{g}$ with average unimodal pore diameter of $\sim 5.0 \mathrm{~nm}$. The mesophase synthesized using F127 (Fig. 4.6C) displayed a specific surface area of $\sim 152 \mathrm{~m}^{2} / \mathrm{g}$ and an average pore diameter of $\sim 4.3 \mathrm{~nm}$. The sample synthesized with P123 (Fig. 4.6F) showed a specific surface area of $\sim 70 \mathrm{~m}^{2} / \mathrm{g}$ with an average pore diameter of $\sim 12.2 \mathrm{~nm}$. The high surface area, 
unimodal pore size distribution, and nanocrystalline nature of these mesophases, are highly desirable properties for potential applications in heterogeneous catalysis.
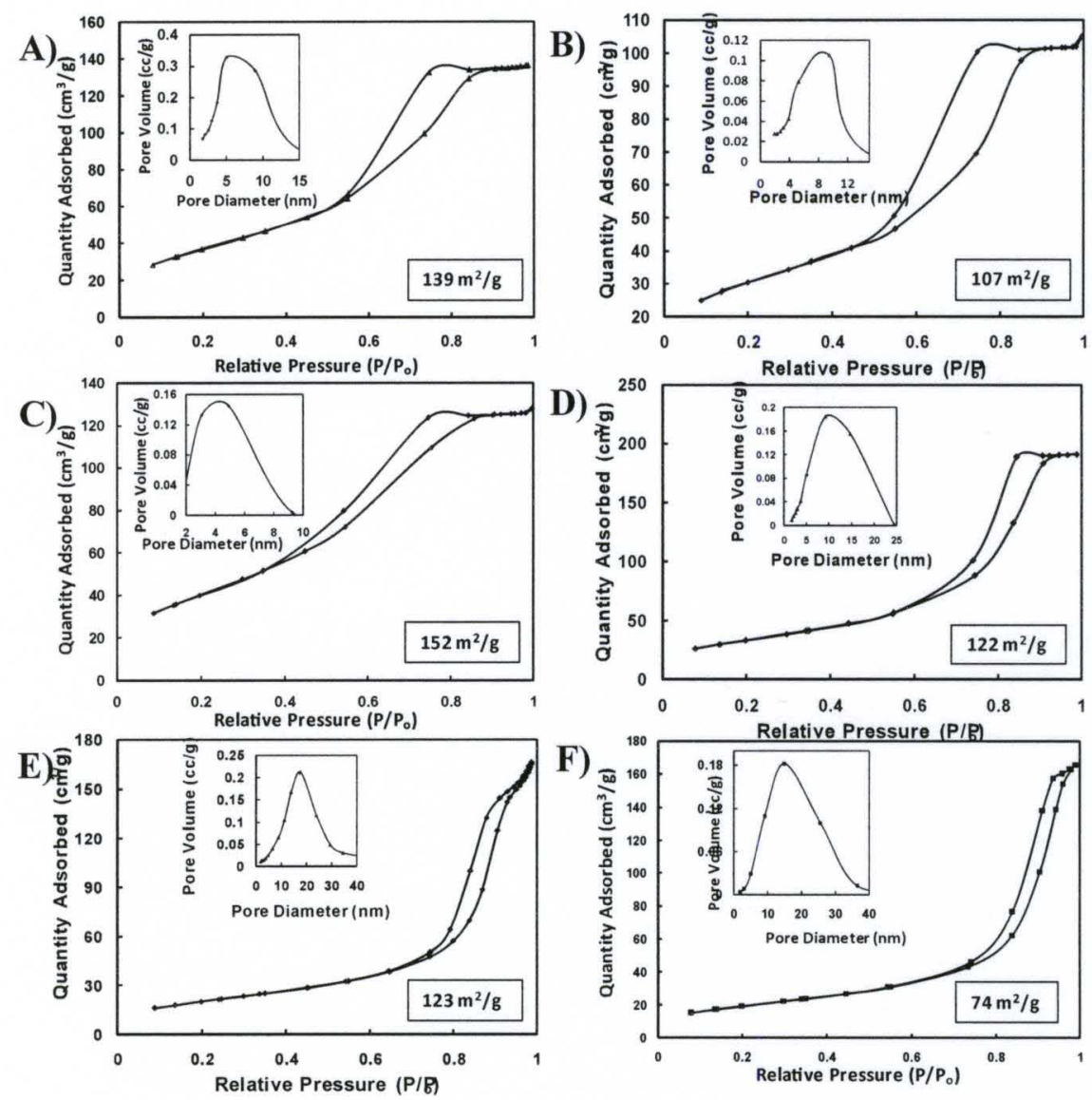

Figure 4.6. $\mathrm{N}_{2}$ adsorption-desorption isotherms and $\mathrm{BJH}$ pore size distribution from adsorption branch of nanocrystalline $\mathrm{Ga}_{2} \mathrm{O}_{3}$ phases synthesized by SAHA.

The high angle X-ray diffraction patterns of a gallium oxide mesophases synthesized employing CTAB, F127 and P123 as SDA are shown in Figure 4.7. The high angle XRD patterns, revealed strong reflections at $d_{\text {spacing }} 4.7,2.5,2.02,1.6$, and $1.5 \AA$ corresponding to the (111), (311), (400), (333), and (440) planes of cubic spinel type respectively (Fig. 4.7). The high angle XRD patterns observed for these mesophases are in agreement with previous reports [2, 3, 19, 23]. 


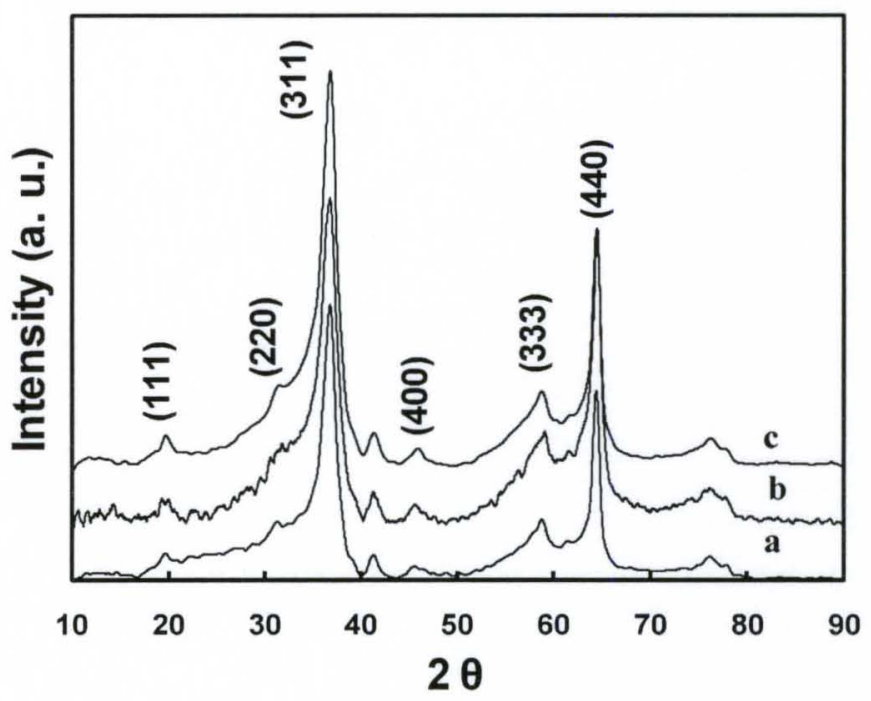

Figure 4.7. High-angle XRD patterns of mesoporous $\mathrm{Ga}_{2} \mathrm{O}_{3}$ phases synthesized by SAHA employing a) CTAB, b) F127 and c) P123 as SDA. X-ray radiation $\mathrm{Cu}_{k \alpha}(\lambda=$ $54 \AA)$.

The SAED pattern obtained for sample synthesized by SAHA employing F127 as SDA is shown in Figure 4.8A, whereas its intensity line profile is shown in Figure 4.8B. A spot-like form of the pattern and sharp, well-defined diffraction rings are the indications of a large-grain nanocrystalline material morphology, which is in agreement with TEM observations and XRD data. SAED ring diameter measurements, performed after using a standard gold specimen and calibrating the camera constant, provided the following $d_{\text {spacing }}$ values: $0.466,0.285,0.249,0.222$, $0.203,0.192,0.160$, and $0.147 \mathrm{~nm}$. All diffraction rings but the one corresponding to the $d_{\text {spacing }}$ of $0.222 \mathrm{~nm}$ could be unequivocally indexed within a spinel-type cubic structure. The cubic lattice parameter a $=0.829 \pm 0.003 \mathrm{~nm}$, derived from the two most intense and sharp rings (eg. (311) and (440)), agrees very well with the value reported previously for $\mathrm{Ga}_{2} \mathrm{O}_{3}[2,3,19,23]$. 

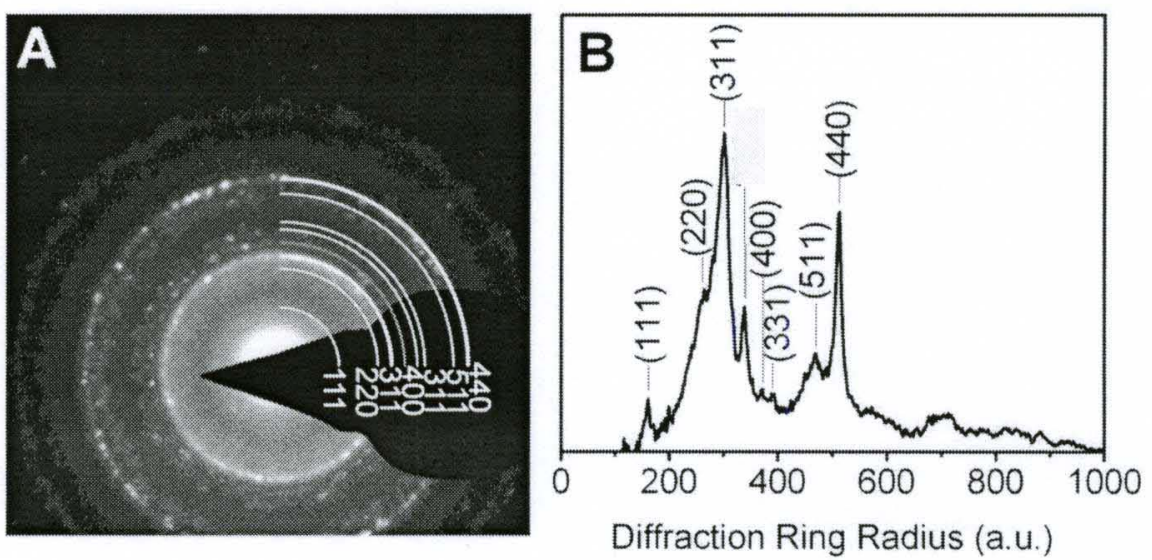

Figure 4.8. A) SAED pattern and B) intensity line profile measured for mesoporous $\mathrm{Ga}_{2} \mathrm{O}_{3}$ synthesized by SAHA.

HRTEM image of several nanocrystals present on the surface of the spheres (sample synthesized with F127 as SDA) is shown in Figure 4.9A. Lattice fringes are clearly visible in this image confirming the crystallinity of the material. The orientation of the nanocrystal on the left side of the image coincides with one of the main crystallographic directions resulting in the strong visibility of two perpendicular sets of lattice fringes. For clarity, the area marked by the square is magnified in Figure 4.9B. In addition, the bottom left quarter of the magnified image was enhanced by mask filtering of its Fourier transform (FT). Fringe spacing values of 0.25 and 0.29 $\mathrm{nm}$ were measured for these two sets of lattice fringes, as shown in the image. They coincide with the $d_{\text {spacing }}$ of $\{311\}$ and $\{220\}$ families of planes in previously mentioned spinel-type cubic $\mathrm{Ga}_{2} \mathrm{O}_{3}$. This is also in agreement with the FT produced from this HRTEM image (Figure 4.9C). The FT can be consistently indexed when the (311) and (002) reflection are chosen for the base, which leads to the (233) zone axis pattern. 


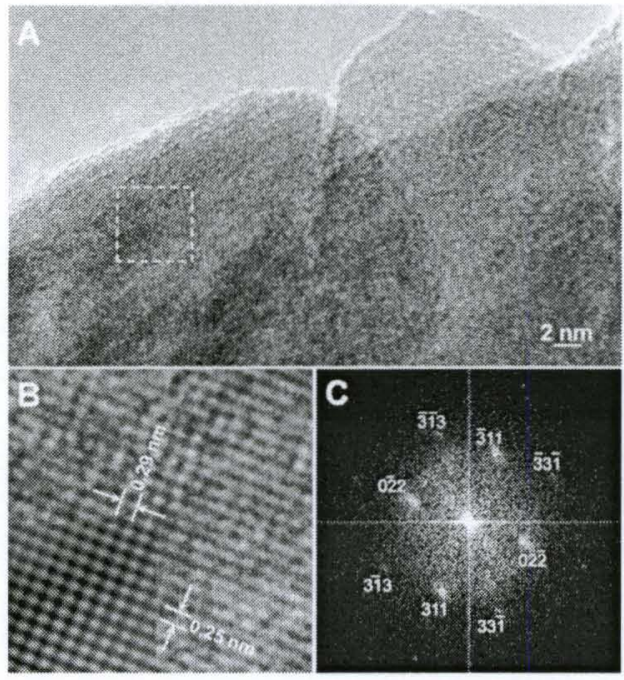

Figure 4.9. A) HRTEM image of nanocrystals on the surface of mesoporous $\mathrm{Ga}_{2} \mathrm{O}_{3}$ spheres synthesized by SAHA, B) Magnified image and C) FT of the area marked with dashed square in A.

\subsubsection{Effect of Hydrothermal Temperature}

The samples synthesized by employing F127 as the SDA showed the highest surface areas as compared to CTAB or P123. Therefore, we present the effect of hydrothermal temperature as a function of sphere size on the samples synthesized using F127 as structure directing agent in Figure 4.10. At hydrothermal temperature of $150^{\circ} \mathrm{C}$, the average size of the spheres was $\sim 1.8 \mu \mathrm{m}$ (Fig. $4.10 \mathrm{~A}$ ), the size increased to $\sim 2.2 \mu \mathrm{m}$ at $180^{\circ} \mathrm{C}$ (Fig. $4.10 \mathrm{~B}$ ) and to $4.5 \mu \mathrm{m}$ (Fig. $4.10 \mathrm{C}$ ) at $200^{\circ} \mathrm{C}$. Therefore, by adjusting the hydrothermal treatment temperature, micron-sized spheres of different sizes were obtained. All mesophases were stable up to $450^{\circ} \mathrm{C}$. At this temperature a decrease of surface area $(\sim 10-40 \%)$ was observed shown in Table 4.3. The TGA analysis indicated that the weight loss at temperatures below $150^{\circ} \mathrm{C}$ corresponds to water desorption. The weight loss between 150 to $400^{\circ} \mathrm{C}$ is due to the thermal decomposition of the template. TGA showed that only $1.6 \%$ and $\sim 1.2 \%$ pyrolized 
template remained occluded in the pores of the mesoporous gallium oxide phases

calcined at $350^{\circ} \mathrm{C}$ and $450^{\circ} \mathrm{C}$ respectively as shown in Figure 4.11 .

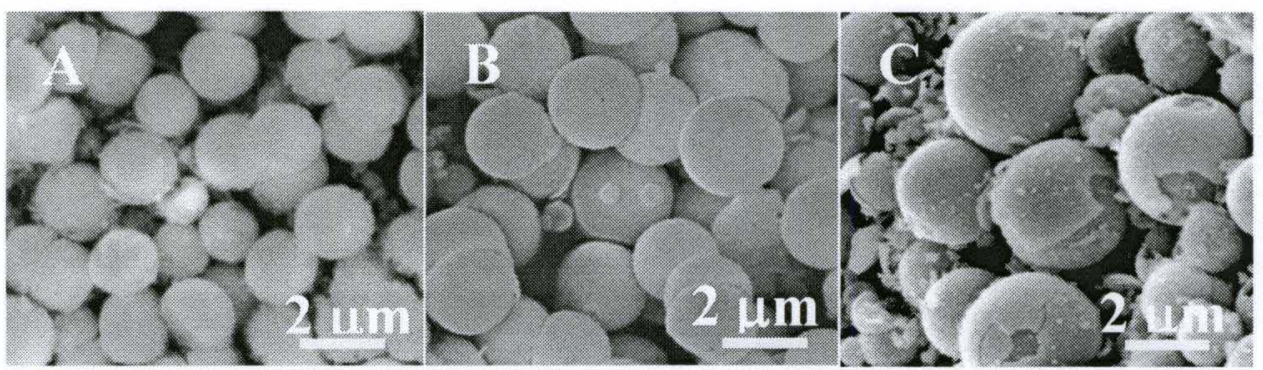

Figure 4.10. SEM images showing effect of hydrothermal treatment on sphere size at A) $150^{\circ} \mathrm{C}$, B) $180^{\circ} \mathrm{C}$, and C) $200^{\circ} \mathrm{C}$ employing F127 as SDA.

Table 4.3. Synthesis conditions and textural properties of mesoporous $\mathrm{Ga}_{2} \mathrm{O}_{3}$ phases synthesized by EISA and SAHA calcined at $450^{\circ} \mathrm{C}$.

\begin{tabular}{|c|c|c|c|c|c|c|c|c|}
\hline \multirow[t]{2}{*}{$\begin{array}{l}\text { Sample } \\
\text { ID }\end{array}$} & \multicolumn{2}{|c|}{$\begin{array}{l}\text { Surfactant/ } \\
\text { Amount (gm) }\end{array}$} & \multicolumn{2}{|c|}{$\begin{array}{l}\text { Processing } \\
\text { conditions }\end{array}$} & \multirow{2}{*}{$\begin{array}{l}\text { Hydrothermal } \\
\text { Temperature } \\
\left({ }^{\circ} \mathrm{C}\right)\end{array}$} & \multirow[t]{2}{*}{$\begin{array}{l}\text { Surface area } \\
\qquad\left(\mathrm{m}^{2} / \mathrm{g}\right)\end{array}$} & \multirow{2}{*}{$\begin{array}{c}\text { Pore } \\
\text { Diameter } \\
(\mathrm{nm})\end{array}$} & \multirow[t]{2}{*}{$\begin{array}{l}\text { Pore Volum } \\
\left(\mathrm{cm}^{3} / \mathrm{g}\right)\end{array}$} \\
\hline & & & $\mathrm{T}\left({ }^{\circ} \mathrm{C}\right)$ & $\mathrm{RH}(\%)$ & & & & \\
\hline E1 & CTAB & 0.3 & 30 & 65 & & 86 & 3.1 & 0.08 \\
\hline E3 & F127 & 0.5 & 35 & 85 & & 115 & 3.7 & 0.12 \\
\hline E5 & P123 & 0.3 & 30 & 65 & & 125 & 7.7 & 0.28 \\
\hline S1 & СТAB & 0.5 & & & 180 & 112 & 5.1 & 0.17 \\
\hline S3 & F127 & 0.5 & & & 180 & 111 & 8.9 & 0.32 \\
\hline S6 & P123 & 0.9 & & & 200 & 69 & 14.5 & 0.30 \\
\hline
\end{tabular}
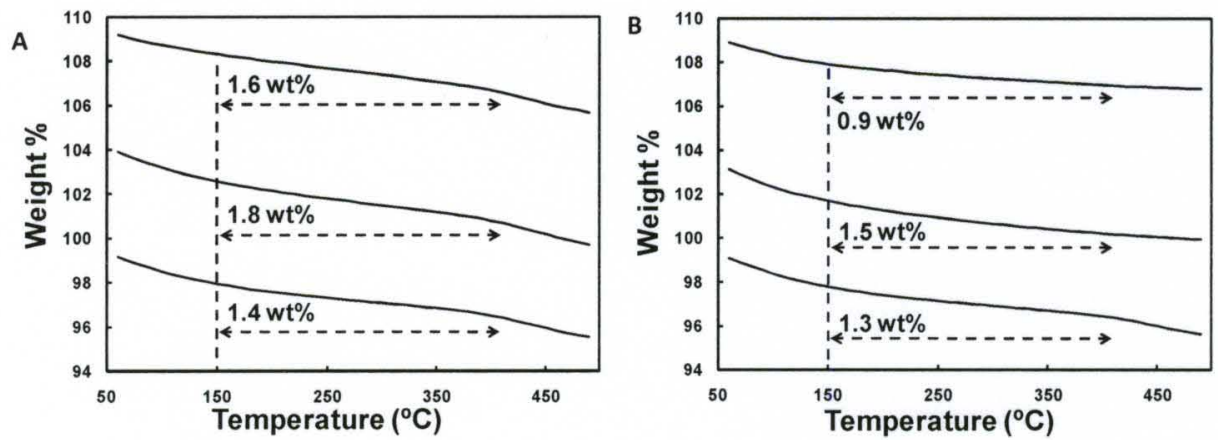

Figure 4.11. TGA profiles for the mesoporous gallium oxide phases synthesized employing CTAB, F127 and P123 as structure directing agents calcined at A) $350^{\circ} \mathrm{C}$ and $\mathrm{B}) 450^{\circ} \mathrm{C}$. 


\subsubsection{Effect of Ethylene Glycol}

Smaller nanocrystalline mesoporous gallium oxide spheres were obtained when ethylene glycol was used as an organic additive as shown in Figure 4.12A. The addition of ethylene glycol resulted in the formation of uniform $\sim 0.3-0.7 \mu \mathrm{m}$ sized hollow spherical particles that are characterized by smooth surfaces. Ethylene glycol serves as a reagent that is able to mediate nucleation and growth, and thus improves the size uniformity of the resultant colloids [207]. Figure 4.12B shows the TEM micrograph of this nanocrystalline gallium oxide mesophase prepared by employing hydrothermal temperature of $180^{\circ} \mathrm{C}$. These hollow spheres have a shell thickness of about $30 \mathrm{~nm}$ and the surface of the particles is covered with nanocrystals of size $\sim 14$ nm. High angle XRD patterns indicated the formation of cubic spinel-type structure shown in Figure 4.13.
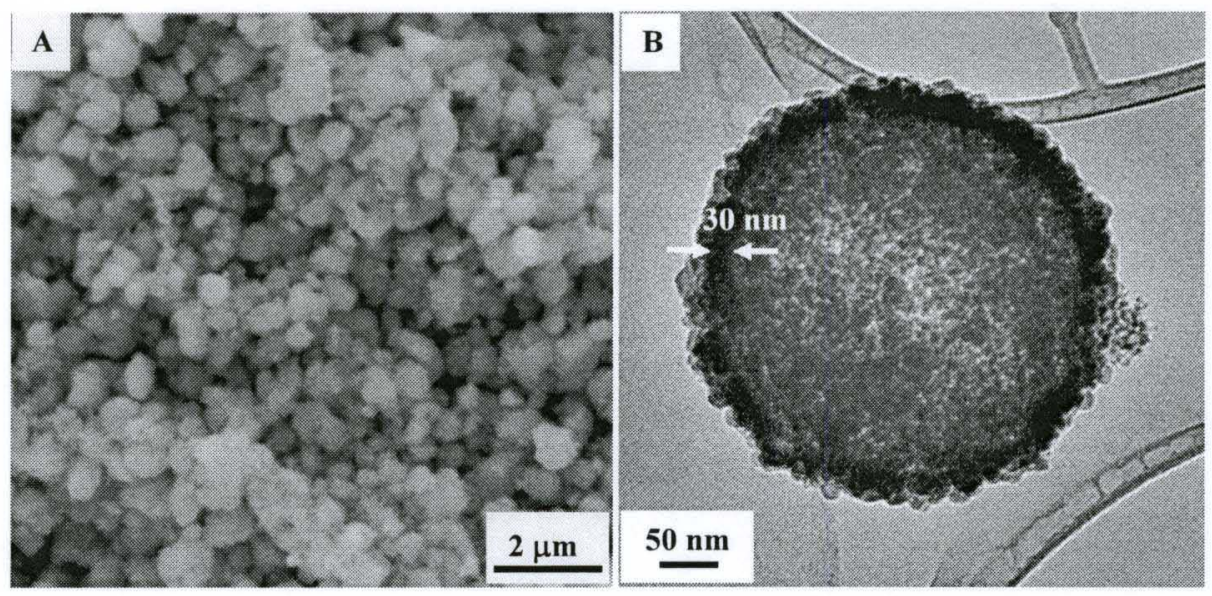

Figure 4.12. A) SEM and B) TEM images of mesoporous nanocrystalline $\mathrm{Ga}_{2} \mathrm{O}_{3}$ phases obtained by SAHA and employing F127 as SDA and ethylene glycol as organic additive. 


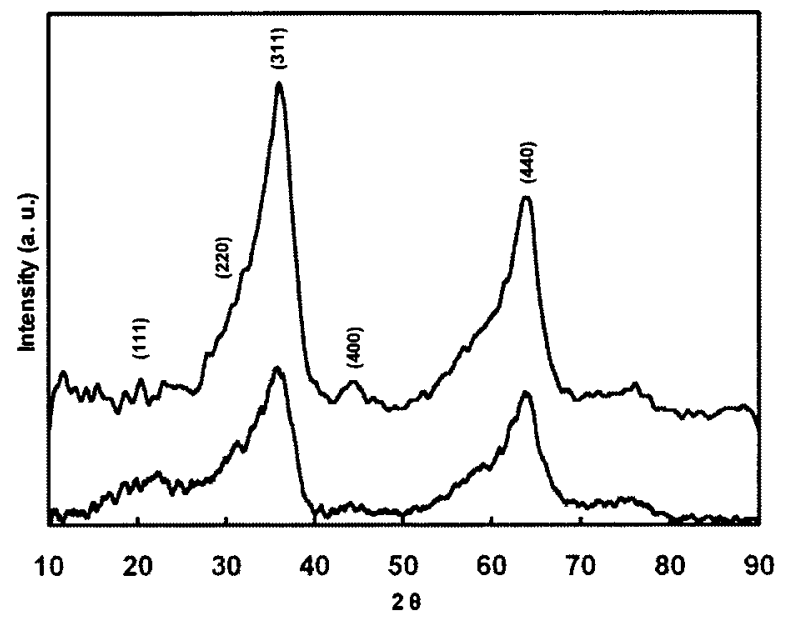

Figure 4.13. High-angle XRD patterns of $\mathrm{Ga}_{2} \mathrm{O}_{3}$ synthesized by SAHA, employing gthylene glycol as an additive.

Figure 4.14 shows the nitrogen adsorption-desorption isotherms and $\mathrm{BJH}$ pore size distribution from adsorption branch of mesoporous nanocrystalline gallium oxide phases synthesized by SAHA and employing different concentrations of ethylene glycol and hydrothermal temperature of $180^{\circ} \mathrm{C}$. Type IV isotherms with $\mathrm{H} 2$ hysteresis loop confirmed the formation of the mesostructure. The sample prepared with $0.5 \mathrm{ml}$ of ethylene glycol showed a specific surface area of $\sim 175 \mathrm{~m}^{2} / \mathrm{g}$ and an average unimodal pore diameter of $\sim 7.3 \mathrm{~nm}$ (Fig. 4.14A). The sample synthesized using $2 \mathrm{ml}$ of ethylene glycol showed a specific surface area of $\sim 221 \mathrm{~m}^{2} / \mathrm{g}$ with average unimodal pore diameter of $\sim 5.2 \mathrm{~nm}$ (Fig. 4.14B). Therefore, the concentration of ethylene glycol allows one to fine tune the textural properties of the resultant mesophases. 


\section{A}
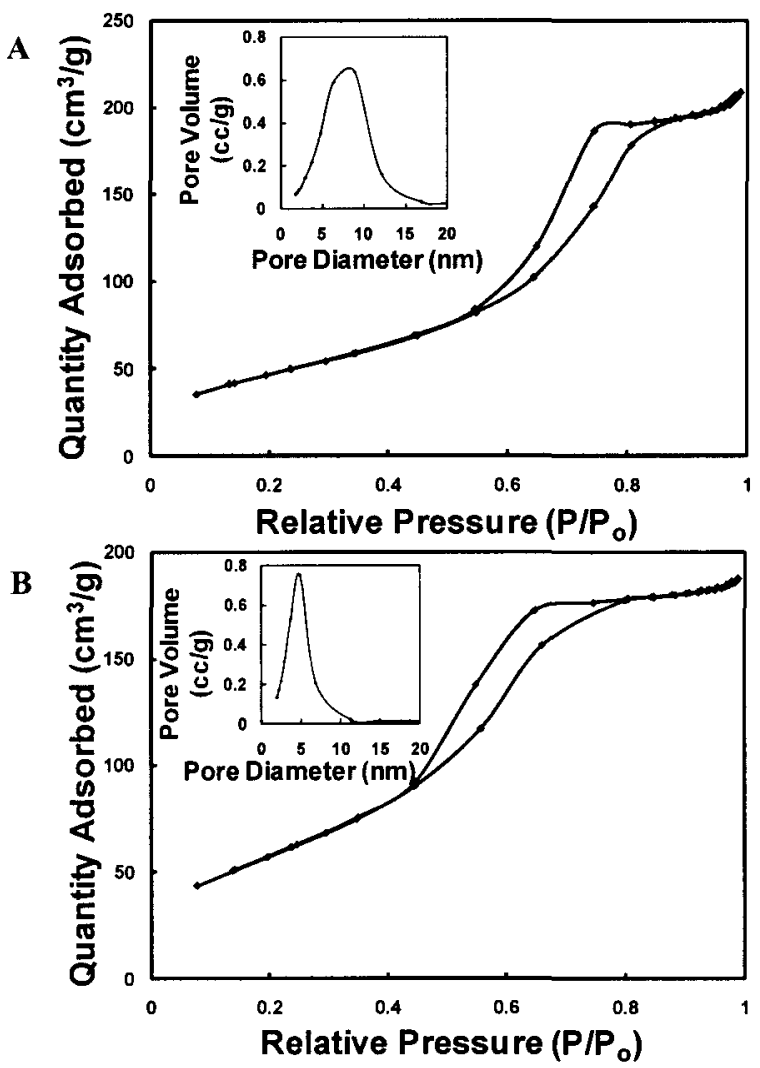

Figure 4.14. $\mathrm{N}_{2}$ adsorption-desorption isotherms and $\mathrm{BJH}$ pore size distribution from adsorption branch of mesoporous $\mathrm{Ga}_{2} \mathrm{O}_{3}$ synthesized by SAHA employing $\mathrm{F} 127$ as SDA and A) $0.5 \mathrm{~mL}$ and B) $2 \mathrm{~mL}$ of ethylene glycol as an organic additive.

The macroscopic morphology of mesoporous oxide phases is dictated by the local curvature energy present at the interface of the inorganic species and the amphiphilic surfactant species [208]. In particular a minimization of this local surface energy leads to sphere-like shapes [209]. Previous reports on mesoporous silica spheres [208-210] suggest that the use of CTAB and triblock copolymers under acidic conditions, and the control of synthesis stirring rates in the 200-400 rpm range, (prevailing conditions in our synthesis) favor the surface energy minimization promoting the formation of spheres shapes. Other factors such as condensation rate of inorganic species, concentration of SDA and co-surfactants have been also proposed 
as potential shape controlling factors in the formation of mesoporous silica spheres [208].

\subsection{Microwave-Assisted Synthesis of Nanocrystalline Mesoporous Gallium Oxide}

So far we have discussed the synthesis of thermally stable nanocrystalline mesoporous gallium oxide with controlled morphological, textural and structural properties via evaporation-induced self-assembly and self-assembly hydrothermalassisted approaches. Both methods required relatively long synthesis time and high reaction temperatures. The application of microwave-assisted heating in materials synthesis has attracted the attention of scientists due to its particular property of localized heating which leads to homogeneous and quick thermal reactions [211214]. Microwave-assisted heating is an alternative and effective synthesis option since it provides fast crystallization, abundant nucleation, and uniformity of particle size [215], high-reaction rate, phase selectivity and short-reaction synthesis time [212].

In the next paragraphs we describe the synthesis of mesoporous gallium oxide nanoclusters via self-assembly microwave-assisted heating approach. This synthesis method is fast and simple eliminating the need for high synthesis temperature and long reaction times. This approach led to the formation of uniform crystalline mesoporous gallium oxide clusters displaying high surface areas and unimodal pore sizes. The microwave-assisted heating approach provides a better heat power density than conventional oven and considerably reduces the synthesis time [216].

Microwave-assisted heating has several advantages over conventional heating, such as phase selectivity, narrow particle size distribution, abundant nucleation, rapid crystallization and uniform heating [217]. Mesoporous gallium oxide phases were 
obtained by microwave-assisted heating and employing cationic surfactant (CTAB) or non-ionic tri-block copolymer (F127) as SDA to guide the mesostructure formation.

Table 4.4 shows the general synthesis conditions and textural properties of the mesoporous gallium oxide phases obtained by MW heating at different synthesis time. Mesophases displaying specific surface areas as high as $360 \mathrm{~m}^{2} / \mathrm{g}$ with unimodal pore size distribution in the range of 3.4-6.4 nm were obtained. The mesophases synthesized employing F127 as SDA displayed surface areas in the $\sim 170$ to $\sim 200 \mathrm{~m}^{2} / \mathrm{g}$ range with unimodal pore size distribution in the $4-6.4 \mathrm{~nm}$ range. On the other hand the samples synthesized with CTAB as SDA displayed smaller pore sizes, in the range of 3.4-3.6 $\mathrm{nm}$ and specific surface areas in the $180-360 \mathrm{~m}^{2} / \mathrm{g}$ range. The specific surface areas were determined using the linear part of the BET equation at $0.01<\mathrm{P} / \mathrm{P}_{\mathrm{o}}$ $<0.3$. The smaller micellar size of $\mathrm{CTAB}$ as compared to F127 led to smaller pore sizes and higher surface areas. For both SDAs, the highest surface areas were observed at $120 \mathrm{~min}$ of microwave-assisted heating. The lowest surface areas of these samples may be associated with the amount of pyrolized template occluded in the mesopores. TGA data showed that samples synthesized at 120 min displayed the smallest amount of remaining pyrolized template.

Table 4.4. General synthesis conditions and textural properties of mesoporous nanocrystalline $\mathrm{Ga}_{2} \mathrm{O}_{3}$ phases calcined at $350^{\circ} \mathrm{C}$ via self-assembly microwave-assisted heating.

\begin{tabular}{|c|c|c|c|c|c|c|}
\hline $\begin{array}{c}\text { Microwave- } \\
\text { assisted heating } \\
\text { time (min) }\end{array}$ & $\begin{array}{c}\text { BET S.S.A. } \\
\left(\mathbf{m}^{\mathbf{2}} \mathbf{g}\right)\end{array}$ & $\begin{array}{c}\text { Pore } \\
\mathbf{d i a m e t e r} \\
(\mathbf{n m})\end{array}$ & $\begin{array}{c}\text { Pore volume } \\
\left(\mathbf{c m}^{\mathbf{3}} / \mathbf{g}\right)\end{array}$ & $\begin{array}{c}\text { BET S.S.A. } \\
\left(\mathbf{m}^{\mathbf{2}} / \mathbf{g}\right)\end{array}$ & $\begin{array}{c}\text { Pore } \\
\text { diameter } \\
(\mathbf{n m})\end{array}$ & $\begin{array}{c}\text { Pore } \\
\text { volume } \\
\left(\mathbf{c m}^{\mathbf{3}} / \mathrm{g}\right)\end{array}$ \\
\hline 15 & 176 & 6.4 & 0.7 & 213 & 3.4 & 0.2 \\
\hline 30 & 172 & 4.0 & 0.3 & 200 & 3.5 & 0.2 \\
\hline 60 & 183 & 6.0 & 0.6 & 180 & 3.5 & 0.2 \\
\hline 120 & 203 & 4.7 & 0.4 & 360 & 3.6 & 0.4 \\
\hline
\end{tabular}


The nitrogen adsorption-desorption isotherms and $\mathrm{BJH}$ pore size distributions from the adsorption branch of the mesoporous gallium oxide phases synthesized by employing F127 as the SDA at different synthesis times are shown in Fig. 4.15. The observed hysteresis loops for the entire samples exhibit the shape that is characteristic for mesoporous materials $[218,219]$. These mesophases exhibit a two-step in the $\mathrm{N}_{2}$ adsorption-desorption isotherms. For the samples obtained after 15, 60 and $120 \mathrm{~min}$ of heating the first step was observed at $\mathrm{P} / \mathrm{P}_{\mathrm{o}}$ between $\sim 0.5$ and 0.8 due to the filling of framework mesopores and the second step at $\mathrm{P} / \mathrm{P}_{\mathrm{o}}>0.8$ due to the filling of interparticle textural pores [220]. In the case of the sample obtained after $30 \mathrm{~min}$ of MW heating the first step was observed at $\mathrm{P} / \mathrm{P}_{\mathrm{o}}$ between $\sim 0.3$ and 0.8 and the second step at $\mathrm{P} / \mathrm{P}_{\mathrm{o}}>0.8$. The $\mathrm{C}$ constants of the BET equation range from $\sim 41$ to 71 , and correspond to net heat of adsorption of $2.3-2.7 \mathrm{~kJ} / \mathrm{mol}$. Similar heat of adsorption has been reported for transition metal MCM-Al type mesoporous phases [221]. Mesoporous MCM-Si has lower heat of adsorption $\sim 1.8 \mathrm{~kJ} / \mathrm{mol}[221]$. These results suggest different interaction of nitrogen with the gallium oxide framework than that with silica. All mesophases were stable up to $400^{\circ} \mathrm{C}$. At this temperature a decrease of surface area ( $18-33 \%)$ was observed. The samples obtained from microwaveassisted heating and employing CTAB as the SDA displayed Type IV isotherms typical of mesoporous materials $[141,205,206,216]$. The isotherms for these samples are shown in Fig. 4.16. 

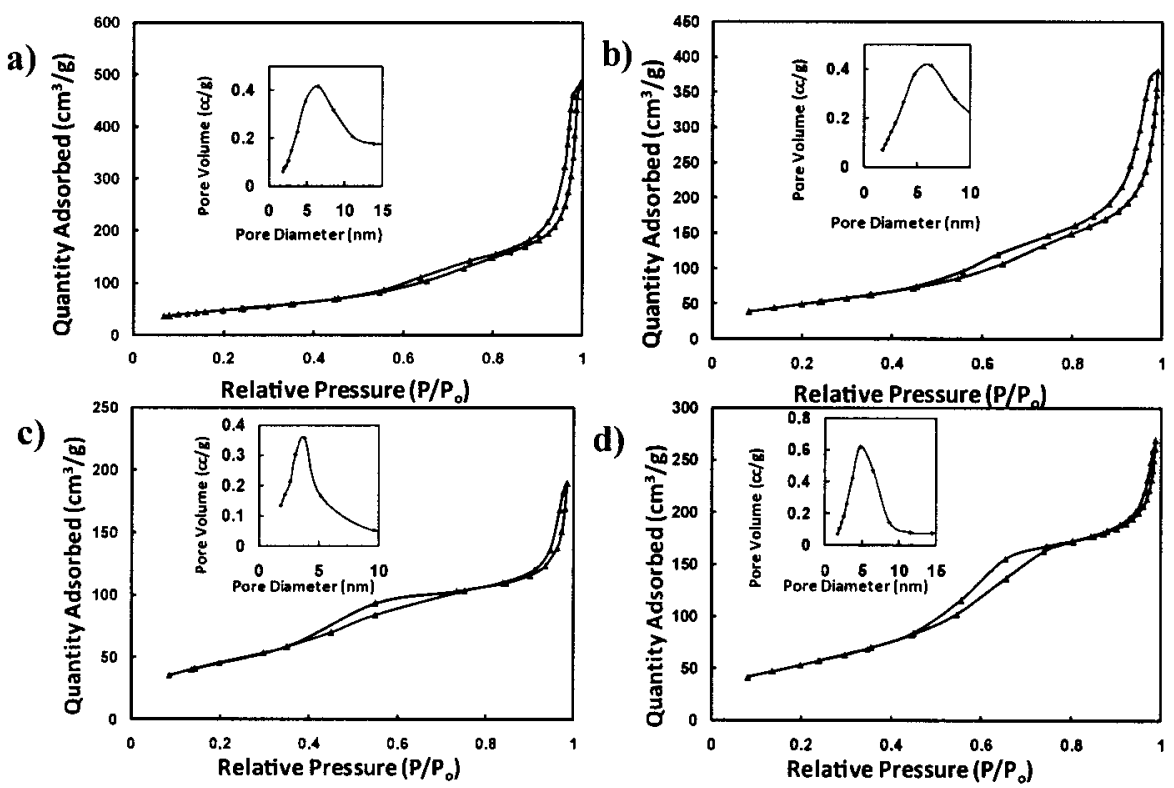

Figure 4.15. $\mathrm{N}_{2}$ adsorption-desorption isotherms and $\mathrm{BIH}$ pore size distribution of mesoporous nanocrystalline $\mathrm{Ga}_{2} \mathrm{O}_{3}$ phases synthesized employing $\mathrm{F} 127$ as SDA via self-assembly microwave-assisted heating at a) 15 , b) 30 , c) 60 , and d) $120 \mathrm{~min}$ calcined at $350^{\circ} \mathrm{C}$.
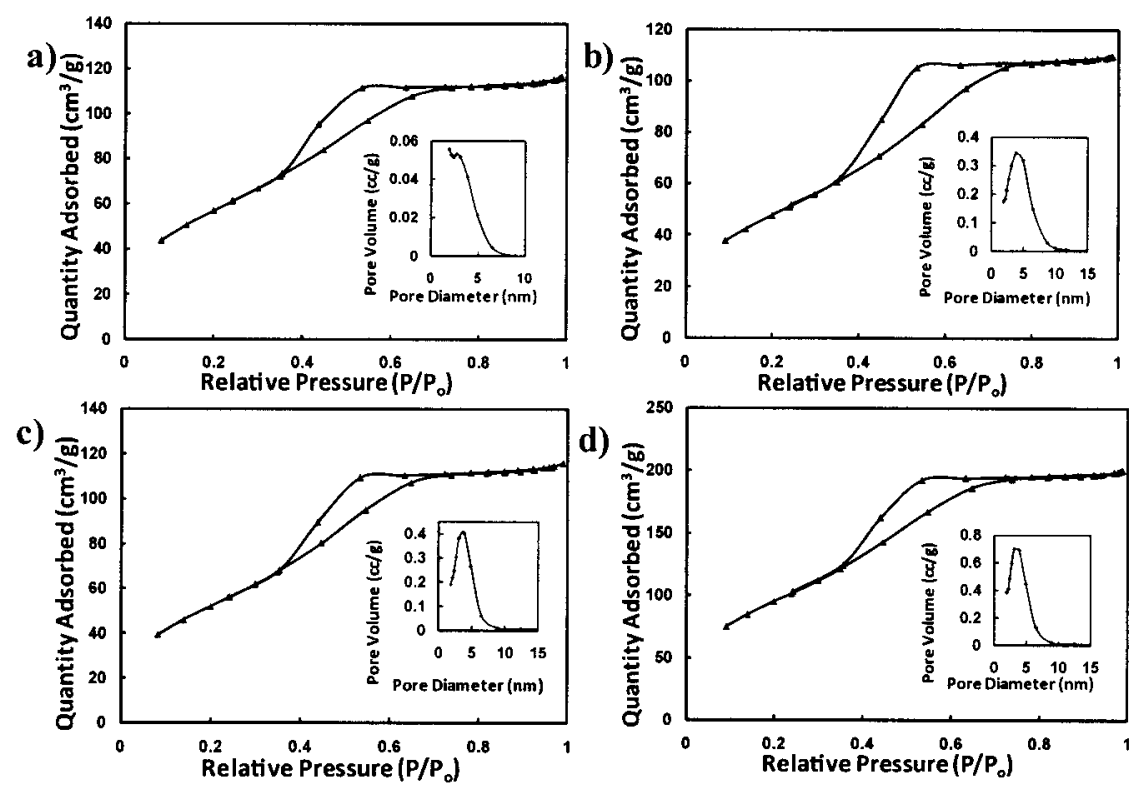

Figure 4.16. $\mathrm{N}_{2}$ adsorption-desorption isotherms and $\mathrm{BIH}$ pore size distribution of mesoporous nanocrystalline $\mathrm{Ga}_{2} \mathrm{O}_{3}$ phases synthesized employing CTAB as SDA via self-assembly microwave-assisted heating at a) 15 , b) 30 , c) 60 , and d) $120 \mathrm{~min}$ calcined at $350^{\circ} \mathrm{C}$. 
The mesostructure formation was confirmed by low angle XRD. These mesostructures showed a single broad peak at a $d_{\text {spacing }}$ of $\sim 42-43 \AA$ for the samples prepared with CTAB and $d_{\text {spacing }}$ of $\sim 46-48 \AA$ for the samples prepared with $\mathrm{F} 127$ as SDA, suggesting the formation of a wormhole mesostructure. High-angle X-ray diffraction patterns of gallium oxide mesophases synthesized by employing F127 as SDA are shown in Figure 4.17. The sample obtained after $15 \mathrm{~min}$ of microwaveassisted heating showed two weak broad peaks at $d_{\text {spacing }}=2.5$ and $2.02 \AA$ tentatively assigned to (3 11 ) and (4 40 ) planes of cubic-spinel confirming the semicrystalline nature of the mesophases. The samples synthesized at 30 and 60 min showed the presence of three well defined peaks at $d_{\text {spacing }}=2.5,2.02$ and $1.5 \AA$ corresponding to the (3 111$),\left(\begin{array}{lll}4 & 0 & 0\end{array}\right)$ and $\left(\begin{array}{lll}4 & 4 & 0\end{array}\right)$ plane of cubic-spinel. As the heating time was increased to $120 \mathrm{~min}$ the XRD patterns revealed strong reflections at $d_{\text {spacing }}=2.8,2.5$, 2.02, 1.6 and $1.5 \AA$ corresponding to the (2 20$),\left(\begin{array}{lll}3 & 1 & 1\end{array}\right),\left(\begin{array}{lll}4 & 0 & 0\end{array}\right),\left(\begin{array}{l}3 \\ 3\end{array} 3\right)$ and $(440)$ planes of cubic-spinel type respectively. The XRD patterns confirm the transition of semi-crystalline $(15,30,60 \mathrm{~min})$ to fully crystalline $(120 \mathrm{~min})$ mesoporous gallium oxide phases. Similar behavior was observed for the samples synthesized employing $\mathrm{CTAB}$ as the SDA (Fig. 4.17B). The XRD patterns observed for these mesophases are in agreement with previous reports on gallium oxides $[2,3,19,23,172]$. 

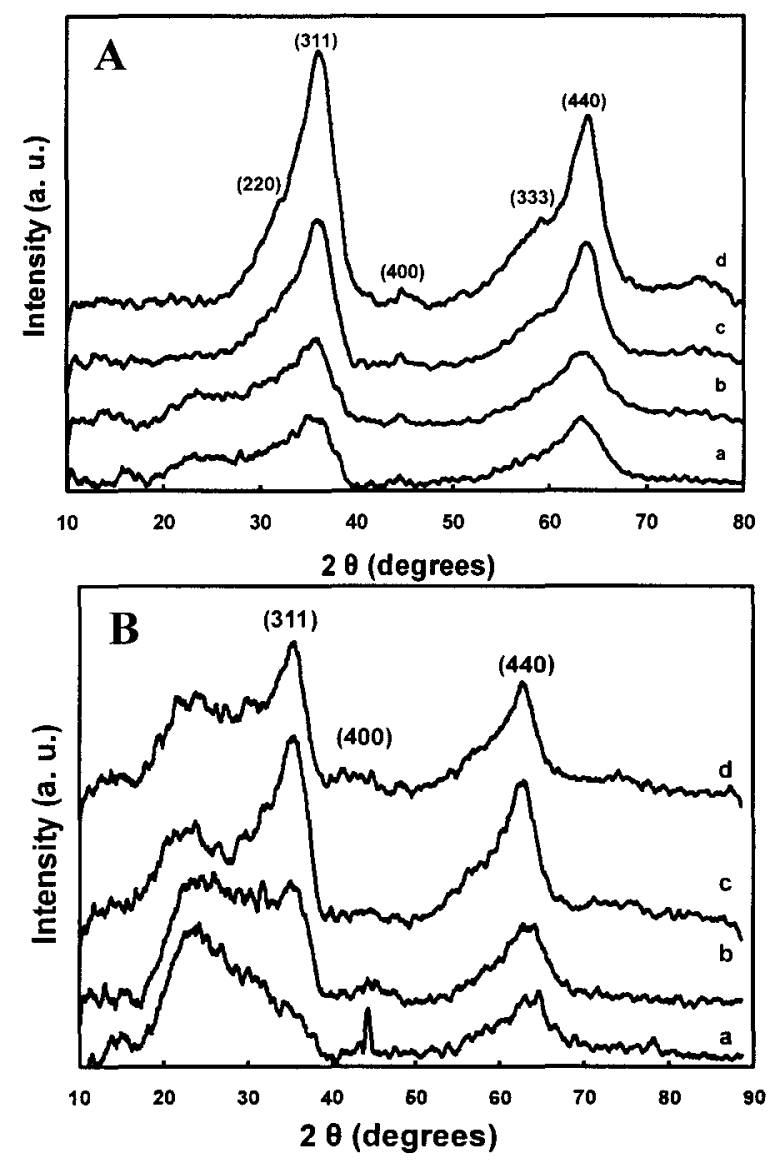

Figure 4.17. High-angle XRD patterns of mesoporous $\mathrm{Ga}_{2} \mathrm{O}_{3}$ phases synthesized employing A) F127 and B) CTAB as SDA via self-assembly microwave-assisted heating at a) 15 , b) 30 , c) 60 , and d) $120 \mathrm{~min}$. X-ray radiation $\mathrm{Cu}_{K \alpha}(\lambda=54 \AA)$.

Selected area electron diffraction (SAED) patterns obtained for samples synthesized employing F127 as SDA at different MW heating times are shown in Fig. 4.18. The intensity line profiles measured from these patterns are included as insets in Fig. 4.18. For the phases obtained after MW heating of 15, 30 and $60 \mathrm{~min}$, two diffraction rings are visible: one at the $d_{\text {spacing }}$ of about 0.25 and second at the dspacing of about $0.15 \mathrm{~nm}$, which agrees with the $d_{\text {spacing }}$ of $\left\{\begin{array}{lll}3 & 1 & 1\end{array}\right\}$ and $\left\{\begin{array}{lll}4 & 4 & 0\end{array}\right\}$ families of planes in spinel cubic $\mathrm{Ga}_{2} \mathrm{O}_{3}[2,23]$. The sample obtained after $120 \mathrm{~min}$ of MW heating displayed more diffraction rings in addition to $\left\{\begin{array}{lll}3 & 1 & 1\end{array}\right\}$ and $\left\{\begin{array}{lll}4 & 4 & 0\end{array}\right\}$ which are assigned as $\left\{\begin{array}{lll}4 & 0 & 0\end{array}\right\}$ and $\left\{\begin{array}{llll}5 & 1 & 1\end{array}\right\}$ corresponding to the $d_{\text {spacing values of } 0.22 \text { and } 0.19 \text { of }}$ 
cubic-spinel type $\mathrm{Ga}_{2} \mathrm{O}_{3}$. Other rings were not clearly detectable due to their low intensity, indicated by the XRD data, and substantial ring broadening originating from the small sizes of the nanocrystals. However, as expected from the XRD and HRTEM data, phases obtained after $120 \mathrm{~min}$ of MW heating, i.e. the sample with the largest nanocrystals, produced the sharpest SAED rings. Similar behavior was also observed for CTAB samples (Fig. 4.18B). Figure 4.19 shows the HRTEM images obtained for the samples synthesized at $15-120 \mathrm{~min}$. For the sample synthesized at $15 \mathrm{~min}, \sim 3 \mathrm{~nm}$ crystallites lacking of well defined shapes, and pore sizes of $\sim 6-6.5 \mathrm{~nm}$ were observed (Fig. 4.19a). For the samples synthesized at 30 and $60 \mathrm{~min}$ of MW heating, the size of nanoparticles increased to $\sim 5-6 \mathrm{~nm}$ (Fig. $4.19 \mathrm{~b}$ and c). Finally, the sample prepared at $120 \mathrm{~min}$, displayed significantly bigger nanocrystals $(\sim 8 \mathrm{~nm})$ with welldeveloped crystalline structure and clear facets terminating their surfaces (Fig. 4.19d). SEM studies also revealed clear differences between all samples. In particular, the average size of the clusters for the sample synthesized at $15 \mathrm{~min}$ was $\sim 50 \mathrm{~nm}$, and increased to $\sim 120 \mathrm{~nm}$ for the sample synthesized at 120 min, suggesting the sintering of the crystallites with synthesis time. The corresponding SEM images are shown in Figure 4.20. 

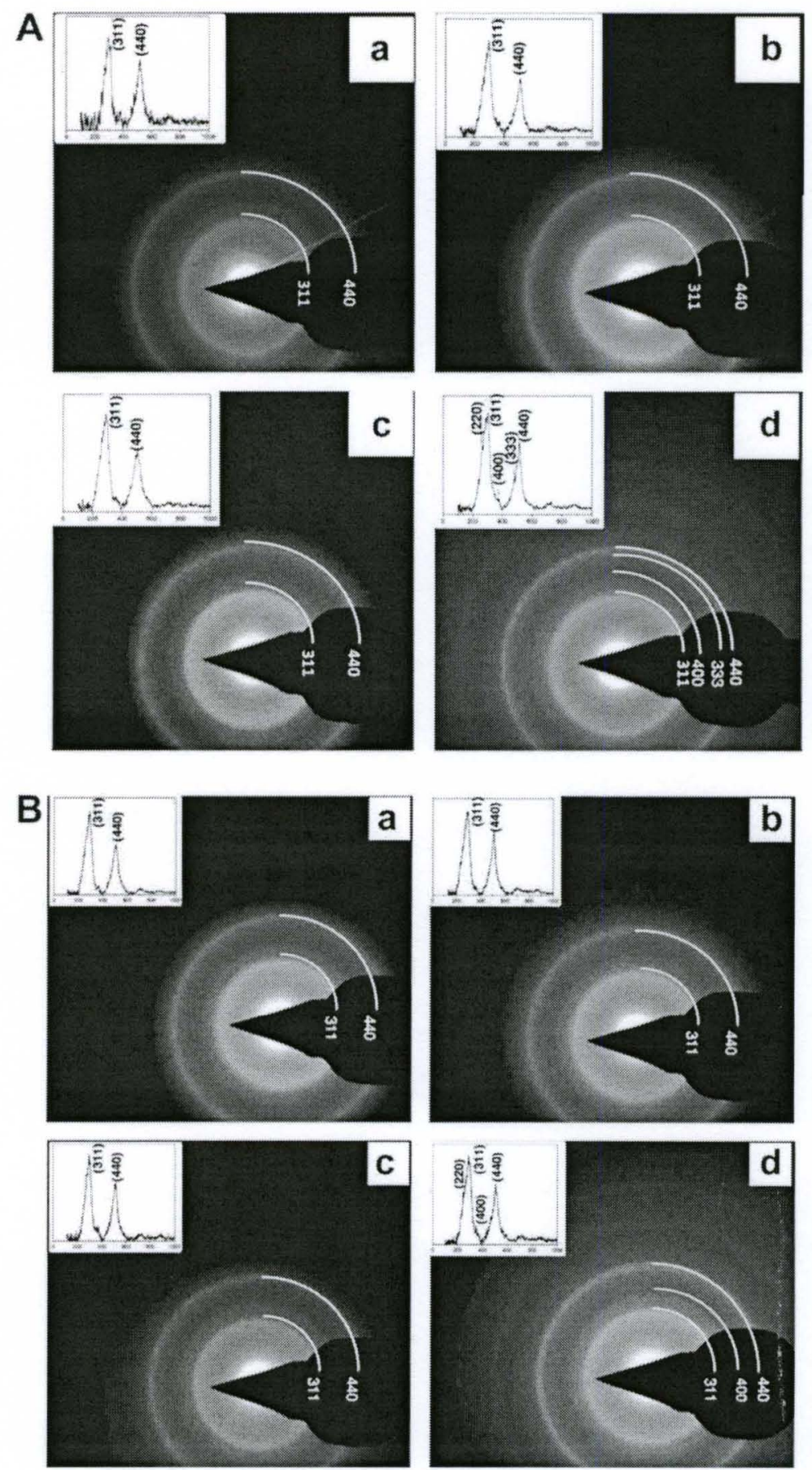

Figure 4.18. $\mathrm{SAED}$ patterns for mesoporous $\mathrm{Ga}_{2} \mathrm{O}_{3}$ phases synthesized employing A) F127 and B) CTAB as SDA via self-assembly microwave-assisted heating at a) 15 , b) 30, c) 60 and d) $120 \mathrm{~min}$. 

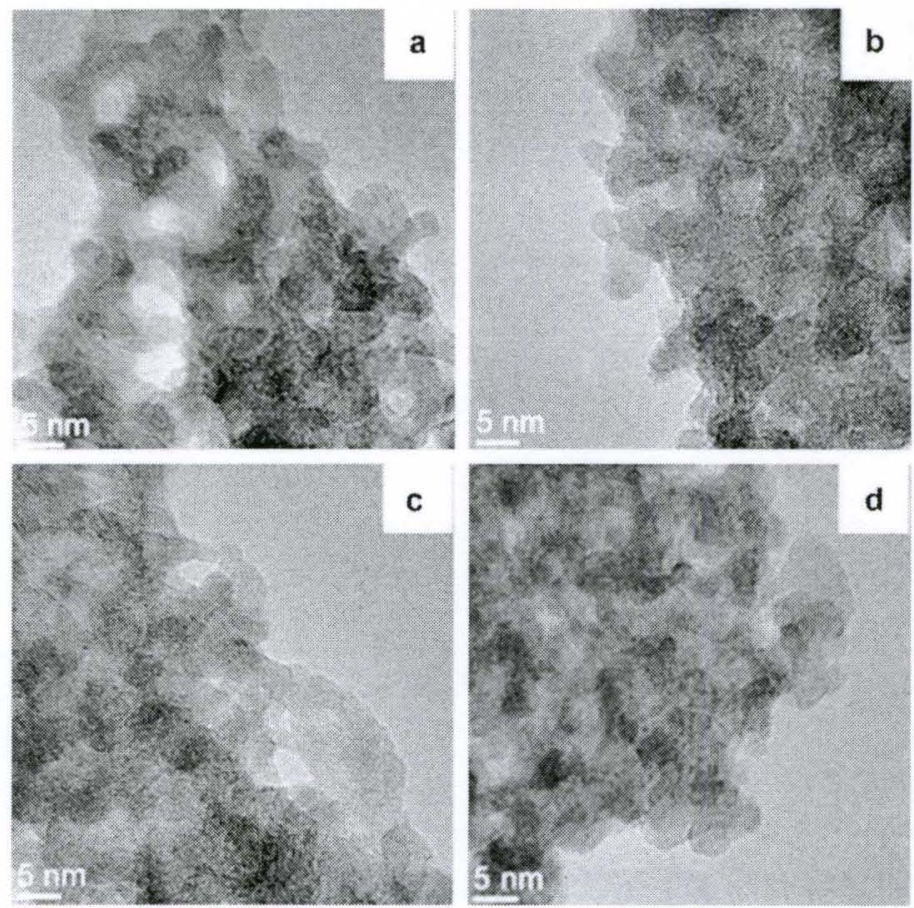

Figure 4.19. HRTEM images of mesoporous $\mathrm{Ga}_{2} \mathrm{O}_{3}$ synthesized employing $\mathrm{F} 127$ as SDA via self-assembly microwave-assisted heating at a) 15 , b) 30, c) 60 , and d) 120 $\min$.

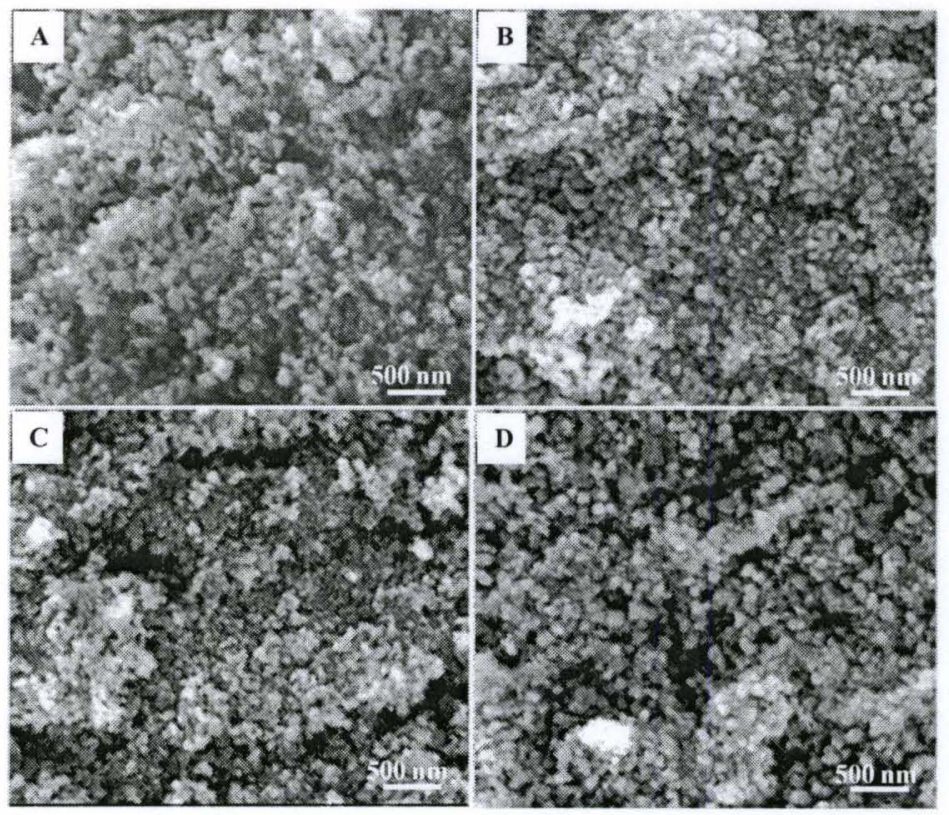

Figure 4.20. SEM images of mesoporous $\mathrm{Ga}_{2} \mathrm{O}_{3}$ synthesized by self-assembly microwave-assisted heating at A) 15, B) 30, C) 60 and D) 120 min employing F127 as SDA. 


\subsection{Conclusions}

Thermally stable mesoporous gallium oxide phases were successfully synthesized by employing EISA, SAHA and microwave-assisted heating approaches. Various surfactants such as CTAB (cationic surfactant), F127 and P123 (neutal surfactants) were employed as structure directing agents for the mesostructure formation. The self-assembly between the negatively charged inorganic species ( $\left.\mathrm{I}^{-}\right)$ and the positively charged surfactants $\left(\mathrm{S}^{+}\right)$is guided by the electrostatic charge matching when CTAB is employed as SDA, and by hydrogen bonding when neutral SDA (P123 and F127) are employed.

EISA produced semi-crystalline mesoporous gallium oxide phases that displayed unimodal pore size distribution in the $2-15 \mathrm{~nm}$ range and relatively high specific surface areas up to $\sim 300 \mathrm{~m}^{2} / \mathrm{g}$. High angle XRD patterns for these samples displayed two broad peaks assigned to the (311) and (440) planes of cubic spinel confirming the semi-crystalline nature of the mesoporous walls. This was further confirmed by the SAED analysis which displayed a diffused ring pattern, suggesting the formation of $\sim 3$ to $5 \mathrm{~nm}$ small crystals.

SAHA led to the formation of uniform nanocrystalline mesoporous gallium oxide hollow spheres with narrow size distribution. The average size of the spheres was successfully adjusted in the range of about $0.3-6.5 \mu \mathrm{m}$ by varying the hydrothermal treatment temperature and employing ethylene glycol as an organic additive. These mesophases displayed surface areas as high as $221 \mathrm{~m}^{2} / \mathrm{g}$ with unimodal pore diameter in the $5-15 \mathrm{~nm}$ range. The high angle XRD patterns revealed strong reflections corresponding to cubic spinel type structure. SAED analysis displayed a spot-like form of the pattern with sharp, well-defined diffraction rings that are the indications of a large-grain nanocrystalline material morphology, which is in 
agreement with TEM observations and XRD data. The cubic lattice parameter $\mathrm{a}=$ $0.829 \pm 0.003 \mathrm{~nm}$, were derived from the two most intense and sharp rings (eg. (311) and (440)), and correspond very well with the cubic spinel type structure of $\mathrm{Ga}_{2} \mathrm{O}_{3}$. Mesoporous gallium oxide nanoclusters were also synthesized by selfassembly microwave-assisted heating, using non-ionic tri-block copolymer (F127) and cationic surfactant $(\mathrm{CTAB})$ as structure directing agents. The uniform, rapid and localized heating provided by microwave-assisted heating, led to the formation of homogeneous crystalline nanoclusters of mesoporous gallium oxide. The crystallite size of these gallium oxide nanoparticles varied from $\sim 3$ to $8 \mathrm{~nm}$. The XRD patterns confirm the transition from semi-crystalline to fully crystalline mesoporous gallium oxides displaying cubic-spinel type structure with the increase in microwave heating time from 15 to $120 \mathrm{~min}$. These mesophases displayed surface areas as high as 360 $\mathrm{m}^{2} / \mathrm{g}$ with unimodal pore size distribution in the $\sim 3-7 \mathrm{~nm}$ range. These mesophases are particularly attractive for catalytic applications because of their high surface areas, tunability of pore sizes, and nature of the wall structure. 


\section{CHAPTER 5}

\section{SYNTHESIS AND CHARACTERIZATION OF NOVEL MESOPOROUS GALLIUM-NIOBIUM AND GALLIUM-MOLYBDENUM MIXED OXIDES}

In the previous chapter we discussed the synthesis of thermally stable, high surface area, nanocrystalline mesoporous gallium oxides via various synthetic routes. In this chapter we describe the synthesis and characterization of mesoporous galliumbased mixed metal oxides. Mixed oxides are known to exhibit higher reaction activity and stronger acidity than single metal oxides [222]. In particular, transition metal oxides (TMO) are an important class of materials that posses a unique feature of variable oxidation states and populated d-bands, features not found in silicates [223, 224]. They also exhibit a variety of interesting physical properties, such as excellent chemical stability, high melting temperature, catalytic activity, etc. [225]. Among the oxides of various transition metals, niobium and molybdenum oxides are attractive because they can be developed as catalysts, adsorbents, sensors, photochromatic and electrochromatic materials, and recording devices [224, 226-229].

The characteristic features of niobium compounds are the promoter effect and support effect. Niobium oxides remarkably enhance catalytic activity and prolong catalyst life when small amounts are added to known catalysts. Moreover, niobium oxides exhibit a pronounced effect as supports of metal and metal oxide catalysts. Mixed oxides containing niobium and niobium oxide supported on other oxides display acidic property, redox property and/or photosensitivity, which cause interesting catalytic behavior [230,231]. Niobium-based materials are effective 
catalysts in numerous catalytic applications, such as pollution abatement, selective oxidation, hydrocarbon conversion reactions, hydrogenation, dehydrogenation, photochemistry, electrochemistry and polymerization [232]. Molybdenum trioxide is another important TMO that shows excellent catalytic activity in selective oxidation reactions. The applications for this material are not only in petroleum refining and chemical production but also on pollution control industries [233-236]. A wide range of application of $\mathrm{MoO}_{3}$ and its derivatives can also be found in batteries, electronic displays and lubricants [237-243].

Due to these remarkable and appealing catalytic properties, we incorporated niobium and molybdenum transition metal for the synthesis of novel mesoporous gallium-based mixed oxide phases by employing F127 as the structure directing agents via self-assembly hydrothermal-assisted (SAHA) approach.

\subsection{Mesoporous Gallium-Niobium Mixed Oxide Phases}

As described in section 3.2.4; mesoporous mixed gallium-niobium oxides were prepared under mild synthesis conditions by reacting alcoholic solutions of inorganic precursors with an alcoholic solution of a triblock co-polymer (F127). The composition and structural/textural properties of the mesoporous gallium-niobium mixed oxides are summarized in Table 5.1. Surface areas as high as $366 \mathrm{~m}^{2} / \mathrm{g}$ with unimodal average pore sizes in the range of $\sim 3$ to $\sim 7 \mathrm{~nm}$ are observed. The average pore size decreased as the niobium content was increased in the mixed oxides. Micron-sized spheres with a narrow particle size distribution $(\sim 0.3-2 \mu \mathrm{m})$ were obtained as shown in Figure 5.1. In general it was observed that as the amount of niobium increased the size of the agglomerates in the mixed oxides also increased from $\sim 0.3 \mu \mathrm{m}$ for the $\mathrm{Ga} / \mathrm{Nb}$ molar ratio of 2.8 (Fig. 5.1a) to $\sim 1.3 \mu \mathrm{m}$ for the $\mathrm{Ga} / \mathrm{Nb}$ 
molar ratio of 0.03 (Fig. 5.1e). Agglomerate size of $\sim 1.8 \mu \mathrm{m}$ was observed for the pure niobium oxide phases (Fig. 5.1f.)

Table 5.1. Chemical composition, textural properties and average agglomerate size of mesoporous $\mathrm{Ga}$-oxide, $\mathrm{Ga}-\mathrm{Nb}$ mixed oxides and $\mathrm{Nb}$-oxide phases synthesized by employing F127 as SDA via SAHA.

\begin{tabular}{|c|c|c|c|c|c|}
\hline $\begin{array}{c}\text { Sample } \\
\text { ID }\end{array}$ & $\begin{array}{c}\text { ICP Composition } \\
\mathbf{G a} / \text { Nb molar ratio }\end{array}$ & $\begin{array}{c}\text { BET Surface } \\
\text { area }\left(\mathbf{m}^{\mathbf{2}} / \mathbf{g}\right)\end{array}$ & $\begin{array}{c}\text { Average Pore } \\
\text { Size }(\mathbf{n m})\end{array}$ & $\begin{array}{c}\text { Pore Volume } \\
\left(\mathbf{c m}^{\mathbf{3} / \mathbf{g})}\right.\end{array}$ & $\begin{array}{c}\text { Average } \\
\text { Agglomerate size } \\
(\boldsymbol{\mu m})\end{array}$ \\
\hline $\mathrm{Ga}_{2} \mathrm{O}_{3}$ & - & 175 & 7.3 & 0.32 & 0.3 \\
\hline $\mathrm{GaNb} 1$ & 2.80 & 210 & 6.1 & 0.38 & 0.5 \\
\hline $\mathrm{GaNb} 2$ & 0.84 & 366 & 4.4 & 0.42 & 0.8 \\
\hline $\mathrm{GaNb3}$ & 0.14 & 270 & 4.1 & 0.33 & 0.8 \\
\hline $\mathrm{GaNb} 4$ & 0.08 & 231 & 3.7 & 0.25 & 1.0 \\
\hline $\mathrm{GaNb}_{3}$ & 0.03 & 242 & 3.4 & 0.23 & 1.3 \\
\hline $\mathrm{Nb}_{2} \mathrm{O}_{5}$ & - & 196 & 3.2 & 0.17 & 1.8 \\
\hline
\end{tabular}

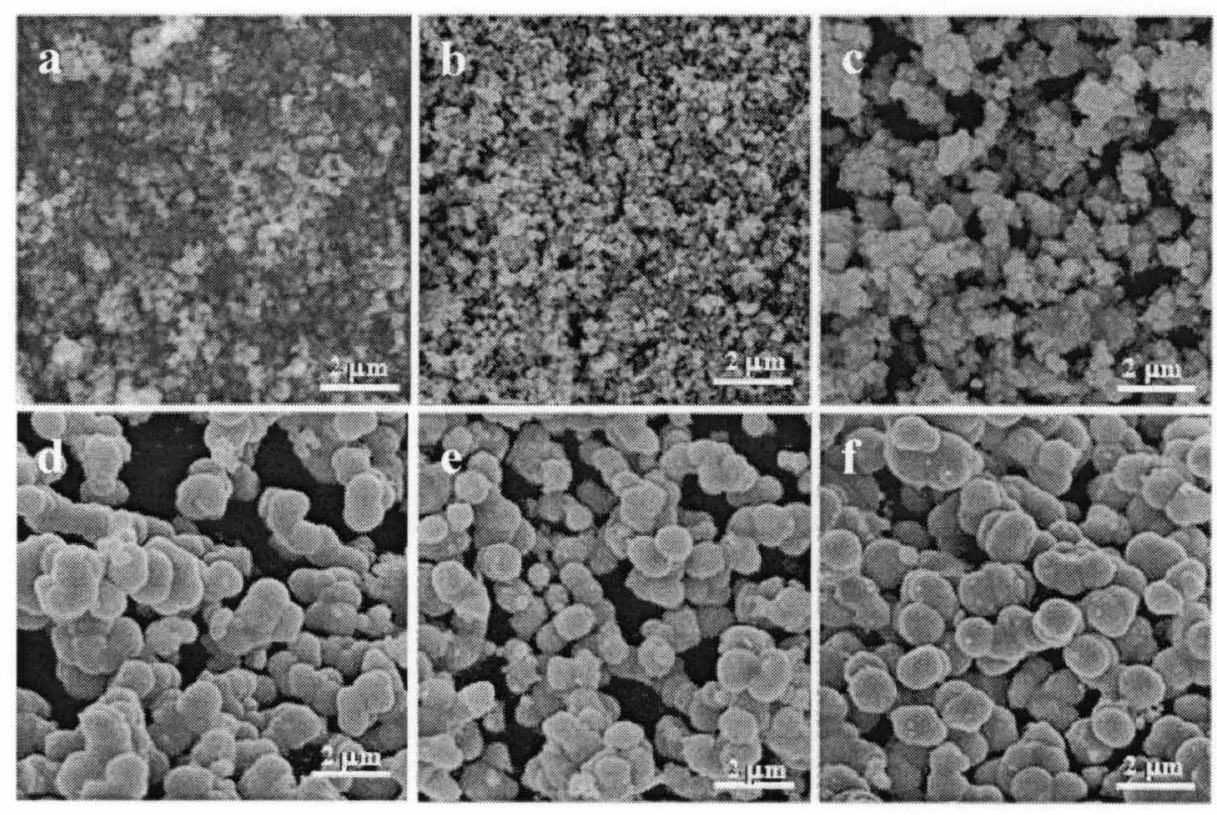

Figure 5.1. SEM images of (a-e) mesoporous mixed Ga-Nb (1-5) mixed oxides and (f) mesoporous $\mathrm{Nb}_{2} \mathrm{O}_{5}$ synthesized by SAHA employing F127 as SDA calcined at $350^{\circ} \mathrm{C}$.

The $\mathrm{N}_{2}$ adsorption-desorption isotherms and $\mathrm{BJH}$ pore size distribution from the adsorption branch of the mesoporous gallium-niobium oxide phases are shown in Figure 5.2. All these samples displayed type-IV adsorption isotherms typical of mesoporous materials. The samples containing lower amounts of niobium (GaNb1 
and $\mathrm{GaNb2}$ ) exhibit a two-step $\mathrm{N}_{2}$ adsorption-desorption isotherm, with one step at $\mathrm{P} / \mathrm{P}_{\mathrm{o}}$ between 0.5 to 0.8 due to the filling of framework mesopores and the second step at $\mathrm{P} / \mathrm{P}_{\mathrm{o}}>0.9$ due to filling of interparticle textural pores. These mesophases displayed specific surface areas of $210 \mathrm{~m}^{2} / \mathrm{g}(\mathrm{GaNb} 1)$ and $366 \mathrm{~m}^{2} / \mathrm{g}(\mathrm{GaNb} 2)$, respectively and an average pore diameter in the range of 4-6 nm. The mixed oxides containing higher amount of niobium displayed surface areas in the range of 230 to $270 \mathrm{~m}^{2} / \mathrm{g}$ with the average pore sizes in the 3-4 $\mathrm{nm}$ range. The surface area of mesoporous niobium oxide was about $200 \mathrm{~m}^{2} / \mathrm{g}$. All samples displayed unimodal pore size distribution (insets of Fig. 5.2).
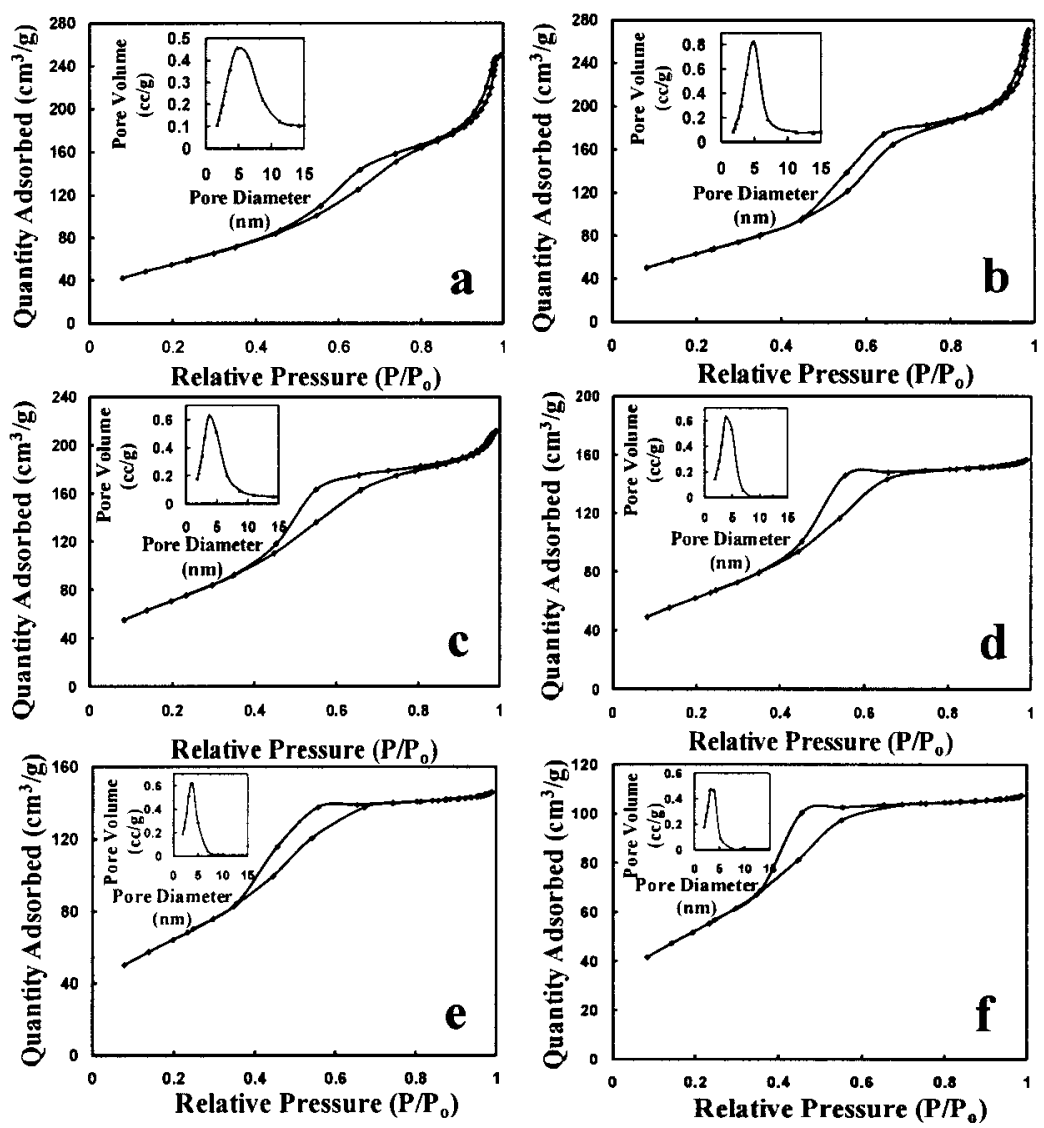

Figure 5.2. $\mathrm{N}_{2}$ adsorption desorption isotherms and $\mathrm{BJH}$ pore size distribution from adsorption branch of (a)-(e) mixed mesoporous $\mathrm{GaNb}(1-5)$ oxides and ( $\mathrm{f}$ ) mesoporous $\mathrm{Nb}$-oxide synthesized by SAHA. 
The X-ray diffraction patterns of mesoporous gallium oxide, niobium oxide and the mixed $\mathrm{Ga}-\mathrm{Nb}$ oxides calcined at $350^{\circ} \mathrm{C}$ are shown in Figure 5.3. The average size of the crystallites for the mixed oxides as well as niobium oxide calculated from Scherrer's equation was in the range of $\sim 3$ to $5 \mathrm{~nm}$ range. The XRD pattern for gallium oxide revealed strong reflections at $d_{\text {spacing }}=4.7,2.5,2.02,1.6$, and $1.5 \AA$ corresponding to the (111), (311), (400), (333), and (440) planes of cubic spinel lattice respectively (Fig 5.3a) in agreement with previous reports $[2,21]$. The different Ga-Nb mixed oxides and mesoporous niobium oxides calcined at $350^{\circ} \mathrm{C}$ displayed broad peaks suggesting semi-crystalline nature (Fig. 5.3b-g). To obtain more structural information, the niobium oxide sample was calcined at $600^{\circ} \mathrm{C}$. The XRD patterns displayed several strong reflections which are in good agreement with the $d_{\text {spacings }}$ of $(001),(180)$, and (181) planes in $\mathrm{Nb}_{2} \mathrm{O}_{5}$ [244-246]. The X-ray diffraction patterns for the samples calcined at $600^{\circ} \mathrm{C}$ are presented in Figure 5.4.

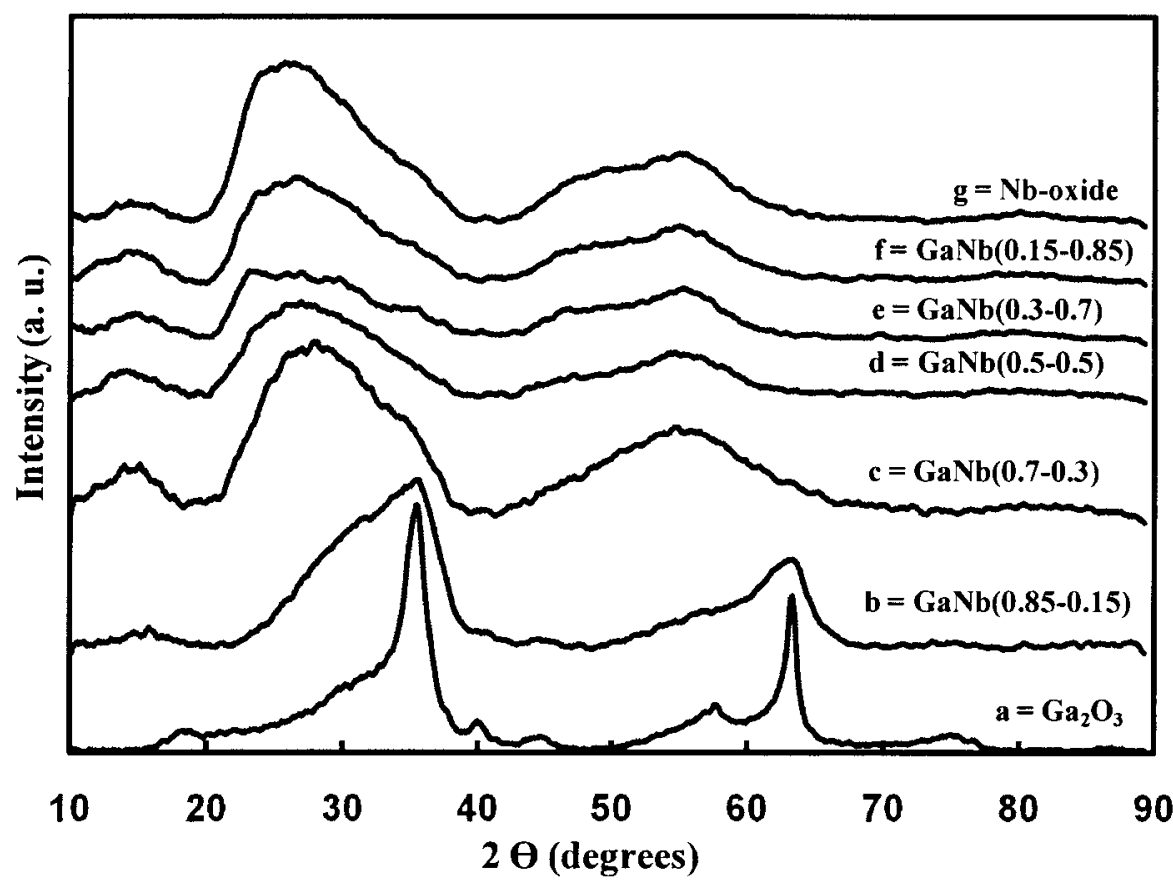

Figure 5.3. High-angle XRD patterns of a) mesoporous $\mathrm{Ga}_{2} \mathrm{O}_{3}$, b)-f) mixed $\mathrm{GaNb}(1$ 5) oxides, and g) mesoporous $\mathrm{Nb}_{2} \mathrm{O}_{5}$ calcied at $350^{\circ} \mathrm{C}$. 


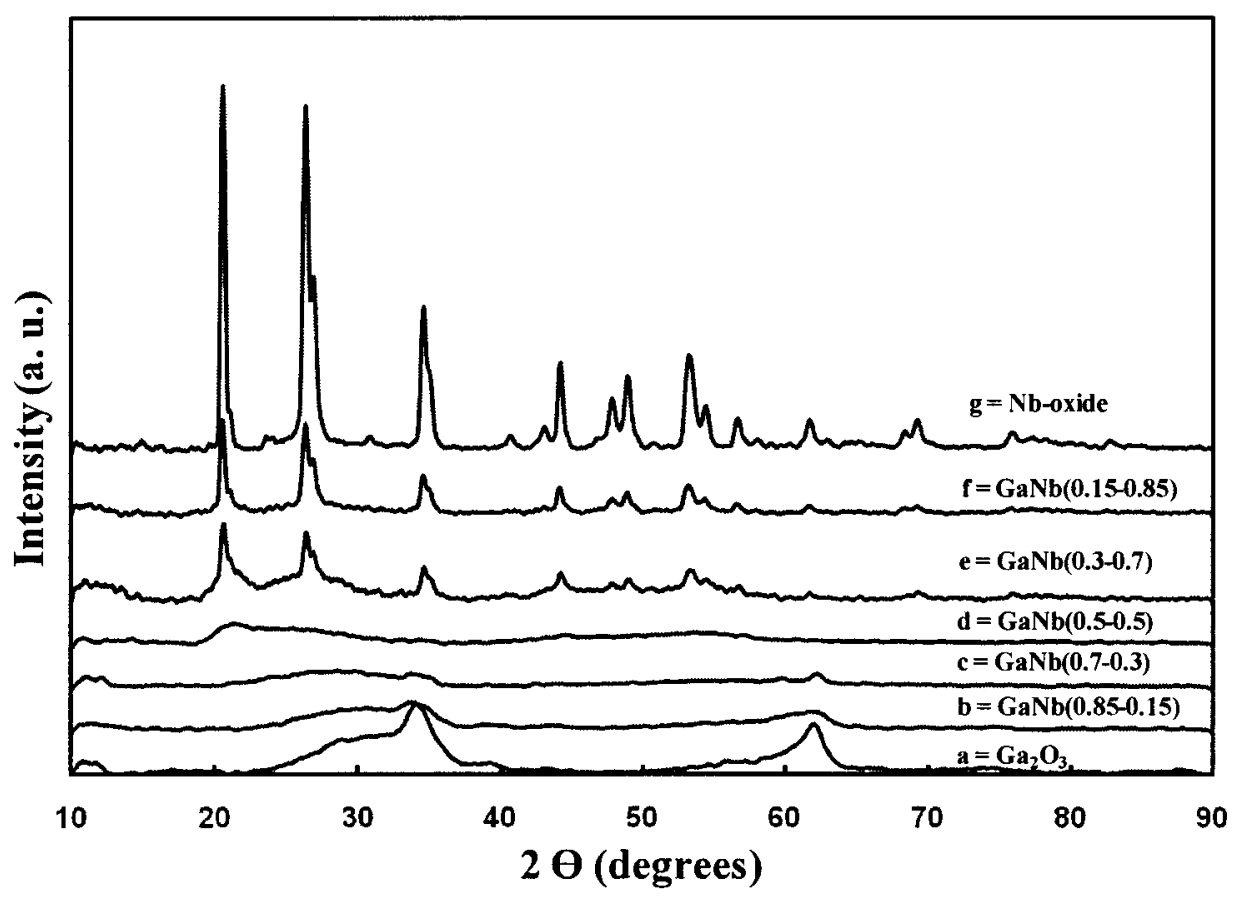

Figure 5.4. High-angle XRD patterns of mesoporous a) $\mathrm{Ga}_{2} \mathrm{O}_{3}$, b)-f) $\mathrm{Ga}-\mathrm{Nb}$ mixed oxides, and g) $\mathrm{Nb}_{2} \mathrm{O}_{5}$ phases synthesized by SAHA employing F127 as SDA calcined at $600^{\circ} \mathrm{C}$.

High-resolution TEM (HRTEM) micrographs and selected area electron diffraction (SAED) patterns of these mesophases calcined at $350^{\circ} \mathrm{C}$ are shown in Figure 5.5. Pure gallium oxide (Fig. 5.5a) shows large crystals of an average size of about $14 \mathrm{~nm}$ and its SAED ring pattern can be indexed consistently within a spineltype cubic structure with the lattice parameter $\mathrm{a}=0.829 \pm 0.003 \mathrm{~nm}$, which agrees with the structure of mesoporous $\mathrm{Ga}_{2} \mathrm{O}_{3}[2,21,172,246]$. HRTEM micrographs of mixed oxide, as well as, niobium oxide samples reveal particles of about 3-4 nm resulting in broad and diffusive SAED rings (Figs.5.5b-d). Only for one of the $\mathrm{Ga}-\mathrm{Nb}$ mixed oxide sample (GaNb4), the rings are better defined suggesting enhanced crystallinity for this sample. These rings correspond to the $d_{\text {spacings }}$ of $0.39 \mathrm{~nm}, 0.199$ $\mathrm{nm}$ and $0.169 \mathrm{~nm}$, which coincide with the $d_{\text {spacings }}$ of $(001),(002)$, and (182) planes in 
pure $\mathrm{Nb}_{2} \mathrm{O}_{5}$ [244-246]. For the pure $\mathrm{Nb}_{2} \mathrm{O}_{5}$, the rings are also rather diffused. For the pure $\mathrm{Nb}_{2} \mathrm{O}_{5}$ sample calcined at $600^{\circ} \mathrm{C}$, much larger grain sizes and well-defined SAED rings are observed that are shown in Figure 5.6 confirming that the large wellcrystalline $\mathrm{Nb}_{2} \mathrm{O}_{5}$ had grown from smaller crystallites of $\mathrm{Nb}_{2} \mathrm{O}_{5}$ present after calcination at $350^{\circ} \mathrm{C}$. Measurements of several most intense rings provided values of $0.396 \mathrm{~nm}, 0.325 \mathrm{~nm}$, and $0.246 \mathrm{~nm}$ which are in good agreement with the d-spacings of (001), (180), and (181) planes, respectively, in $\mathrm{Nb}_{2} \mathrm{O}_{5}$ [248]. The SAED results are, thus, consistent with XRD data.
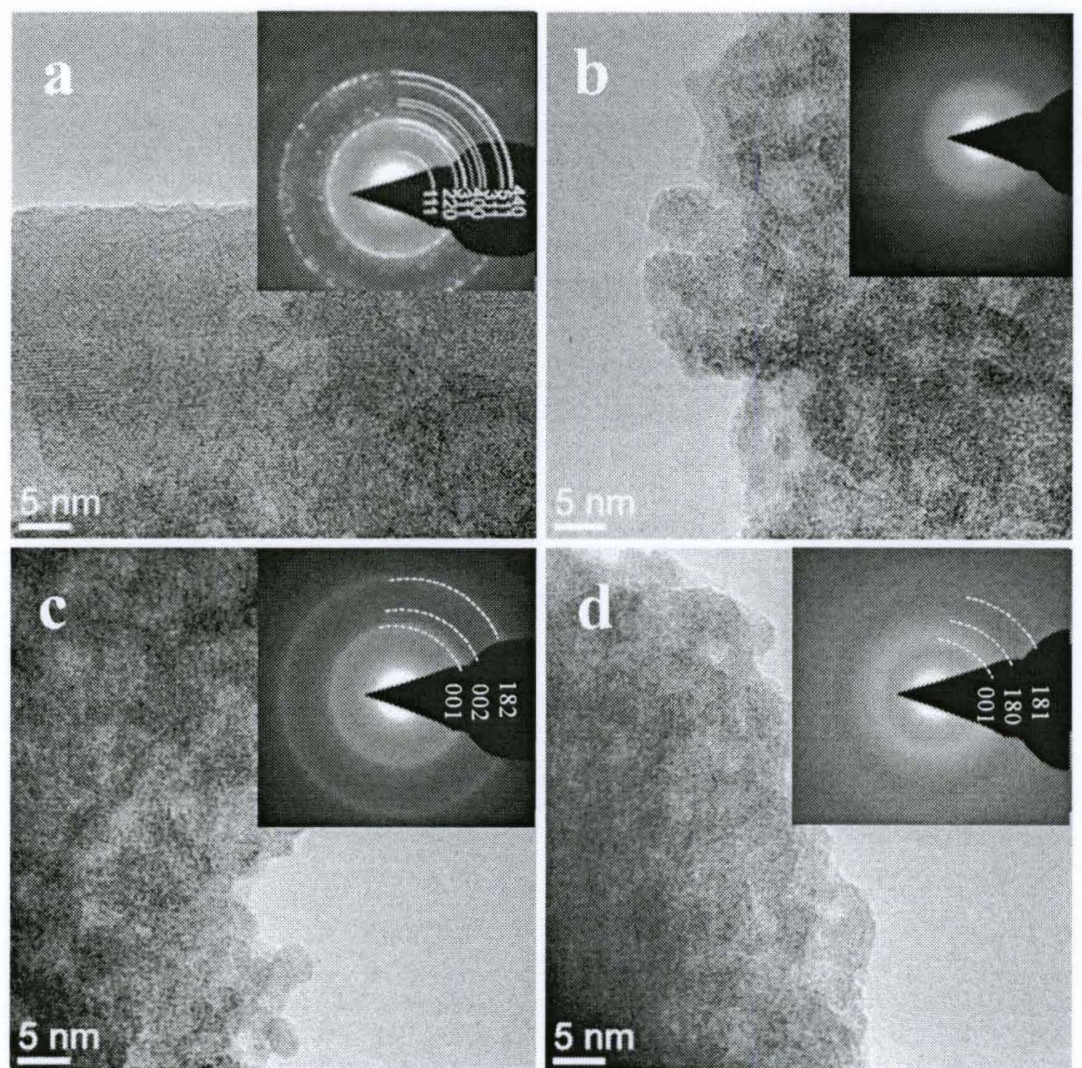

Figure 5.5. HRTEM images of the crystals of mesoporous (a) $\mathrm{Ga}_{2} \mathrm{O}_{3}$, (b) $\mathrm{GaNb} 3$ mixed oxide; (c) GaNb4 mixed oxide and (d) $\mathrm{Nb}_{2} \mathrm{O}_{5}$ with their respective SAED patterns as inset. 


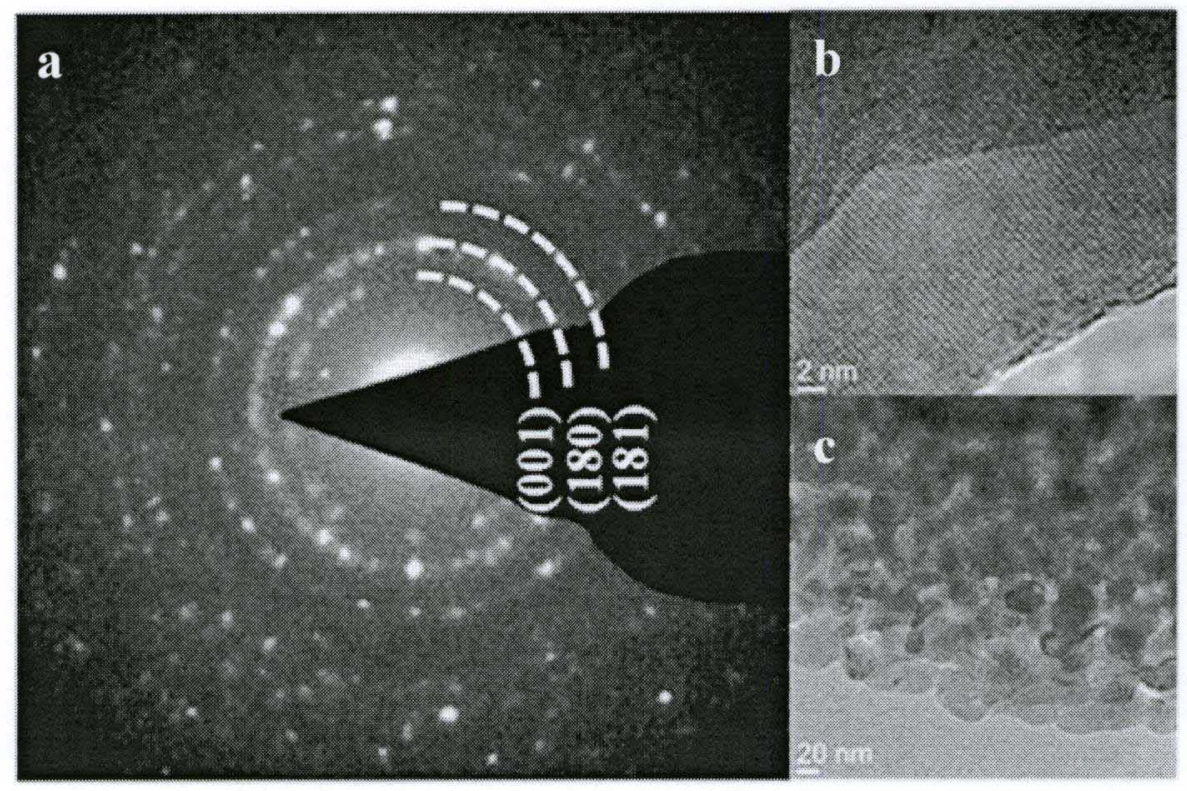

Figure 5.6. a) SAED pattern of mesoporous $\mathrm{Nb}_{2} \mathrm{O}_{5}$ synthesized by SAHA calcined at $600^{\circ} \mathrm{C}, \mathrm{b}$ ) Magnified image of the crystals displaying the lattice fringes and c) HRTEM image of the crystals on the surface of the oxide.

These mesophases were stable up to at least $600^{\circ} \mathrm{C}$. The textural properties of the mesoporous gallium oxide, niobium oxide and gallium-niobium oxides calcined at $600^{\circ} \mathrm{C}$ are shown in Table 5.2. Figure 5.7 shows the BET adsorption desortion isotherms for the samples calcined at $600^{\circ} \mathrm{C}$. The shape of the isotherms indcated that these samples still displayed mesoporous nature. However $\sim 45$ to $85 \%$ decrease in the surface area was observed.

Table 5.2. Textural properties of mesoporous gallium oxide, gallium-niobium mixed oxides and niobium oxide phases synthesized by SAHA calcined at $600^{\circ} \mathrm{C}$.

\begin{tabular}{|c|c|c|c|c|}
\hline $\begin{array}{c}\text { Sample } \\
\text { ID }\end{array}$ & $\begin{array}{c}\text { ICP Composition } \\
\mathbf{G a} \text { /Nb molar ratio }\end{array}$ & $\begin{array}{c}\text { BET Surface } \\
\left(\mathbf{m}^{2} / \mathbf{g}\right)\end{array}$ & $\begin{array}{c}\text { Average Pore } \\
\text { Size }(\mathbf{n m})\end{array}$ & $\begin{array}{c}\text { Pore Volume } \\
\left(\mathbf{c m}^{\mathbf{3}} \mathbf{g}\right)\end{array}$ \\
\hline $\mathrm{Ga}_{2} \mathrm{O}_{3}$ & - & 89 & 11.7 & 0.31 \\
\hline $\mathrm{GaNb} 1$ & 2.80 & 116 & 11.8 & 0.35 \\
\hline $\mathrm{GaNb2}$ & 0.84 & 67 & 23.4 & 0.40 \\
\hline $\mathrm{GaNb3}$ & 0.14 & 101 & 8.2 & 0.25 \\
\hline $\mathrm{GaNb} 4$ & 0.08 & 77 & 7.3 & 0.16 \\
\hline $\mathrm{GaNb}$ & 0.03 & 65 & 11.1 & 0.21 \\
\hline $\mathrm{Nb}_{2} \mathrm{O}_{5}$ & - & 27 & 18.2 & 0.13 \\
\hline
\end{tabular}



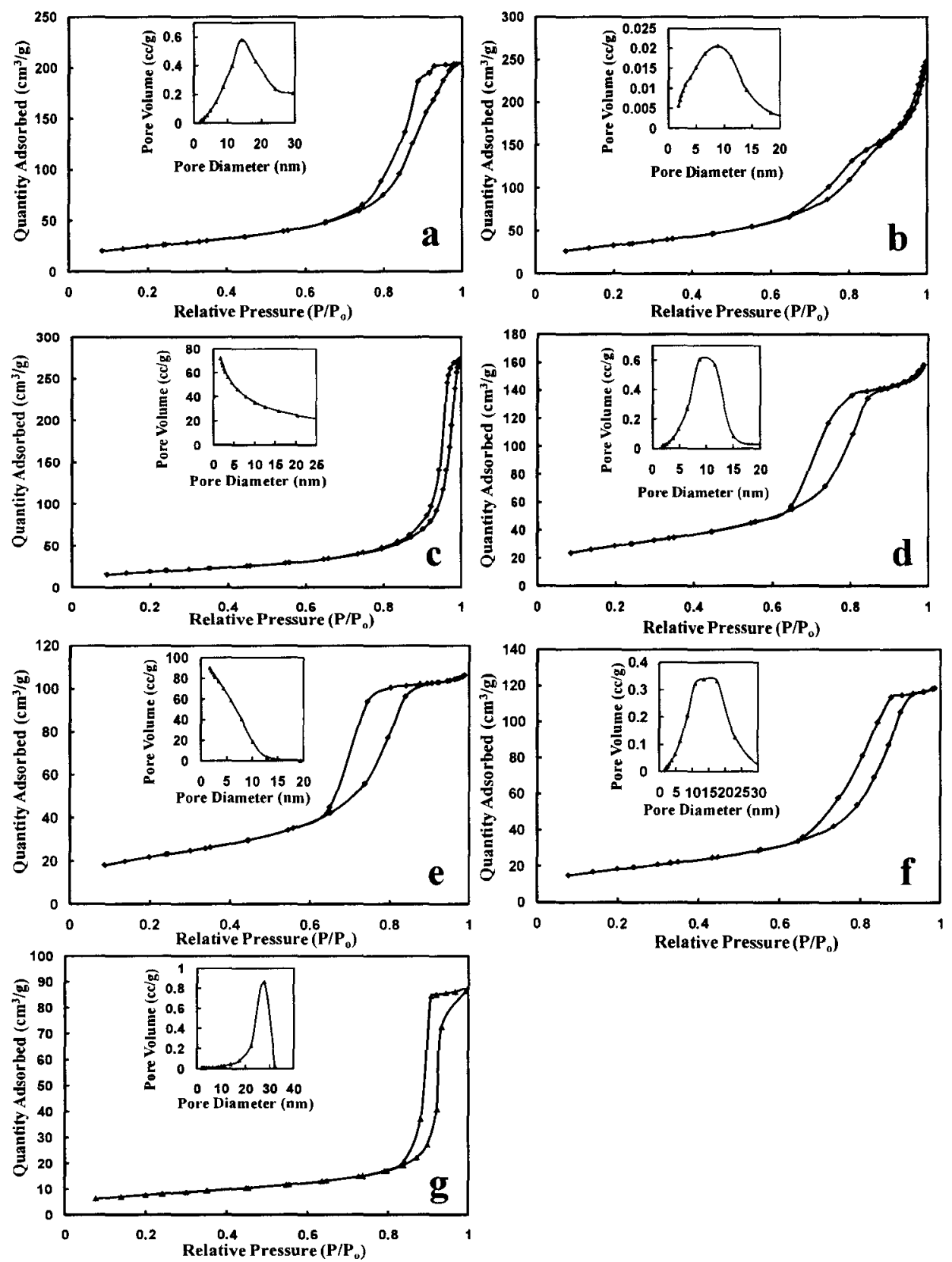

Figure 5.7. $\mathrm{N}_{2}$ adsorption-desorption isotherms and BJH pore size distribution from adsorption branch of the mesoporous a) $\mathrm{Ga}_{2} \mathrm{O}_{3}$, b)-f) $\mathrm{Ga}-\mathrm{Nb}$ mixed oxides, and g) $\mathrm{Nb}_{2} \mathrm{O}_{5}$ synthesized by SAHA employing $\mathrm{F} 127$ as SDA and calcined at $600^{\circ} \mathrm{C}$. 


\subsection{Mesoporous Gallium-Molybdenum Mixed Oxides Phases}

As described in section 3.2.4; mesoporous mixed gallium-molybdenum oxides were prepared under mild synthesis conditions. Initially inorganic precursors; molybdenum chloride and gallium nitrate, were mixed homogeneously in ethanol. This solution was then added drop wise to the F127 (SDA) - ethanol solution. The Ga-Mo mixed oxides were prepared via self-assembly hydrothermal-assisted approach (SAHA). The compositions and the structural/textural properties of these mixed oxides are summarized in Table 5.3.

Table 5.3. Chemical composition and textural properties of Gallium-molybdenum mixed oxide phases synthesized by employing F12\& as SDA via SAHA at $180^{\circ} \mathrm{C}$ for $20 \mathrm{~h}$.

\begin{tabular}{|c|c|c|c|c|}
\hline Sample ID & $\begin{array}{c}\text { Ga/Mo } \\
\text { composition (wt\%) }\end{array}$ & $\begin{array}{c}\text { BET Surface } \\
\text { area }\left(\mathbf{m}^{2} / \mathbf{g}\right)\end{array}$ & $\begin{array}{c}\text { Average Pore } \\
\text { Size }(\mathbf{n m})\end{array}$ & $\begin{array}{c}\text { Pore Volume } \\
\left(\mathbf{c m}^{\mathbf{3}} \mathbf{g}\right)\end{array}$ \\
\hline $\mathrm{Ga}_{2} \mathrm{O}_{3}$ & - & 175 & 7.3 & 0.32 \\
\hline $\mathrm{GaMo} 1$ & $0.85 / 0.15$ & 190 & 4.8 & 0.22 \\
\hline $\mathrm{GaMo} 2$ & $0.7 / 0.3$ & 11 & 15.0 & 0.04 \\
\hline $\mathrm{GaMo3}$ & $0.5 / 0.5$ & 8 & 18.7 & 0.04 \\
\hline
\end{tabular}

Table 5.3 shows the textural properties of the mixed oxide phases that were synthesized at hydrothermal treatment temperature of $180^{\circ} \mathrm{C}$ for $20 \mathrm{~h}$. The GaMol mixed oxide (with Ga-Mo composition of $0.85-0.15 \mathrm{wt} \%$ ) displayed relatively high surface area with unimodal pore size distribution and an average pore diameter of 4.8 $\mathrm{nm}$. It was observed that as the amount of molybdenum increased in the mixed oxide the surface area drastically decreased. More specifically, the GaMo2 (Ga-Mo composition of 0.7-0.3 wt \%) and GaMo3 (Ga-Mo composition of 0.5-0.5 wt \%) samples displayed extremely poor surface areas $\sim 11$ and $8 \mathrm{~m}^{2} / \mathrm{g}$ respectively, suggesting the non-formation of the mesostructure. The $\mathrm{N}_{2}$ adsorption-desorption isotherms and $\mathrm{BJH}$ pore size distribution from the adsorption branch on the galliummolybdenum mixed oxide phases are shown in Figure 5.8. The GaMol sample (Ga- 
Mo composition of $0.85-0.15 \mathrm{wt} \%$ ) was the only sample that displayed type-IV adsorption isotherm, typical of mesoporous materials. This sample exhibits a two-step $\mathrm{N}_{2}$ adsorption-desorption isotherm, with one step between the relative pressure $\left(\mathrm{P} / \mathrm{P}_{0}\right)$ 0.4 to 0.8 due to the filling of the framework mesopores and the second step at $\mathrm{P} / \mathrm{P}_{0}>$ 0.9 which was due to filling of interparticle textural pores (Fig 5.8a). The step of capillary condensation which is typical of type-IV isotherms was not clearly observed in the $\mathrm{N}_{2}$ adsorption-desorption isotherms of the other samples GaMo2 and GaMo3 (Fig 5.8b and c). Instead a $\mathrm{H} 3$ hysteresis loop occurred over the relative pressure range of $\mathrm{P} / \mathrm{P} 0=0.4$ to 0.9 , which indicates the collapsed mesostructure of these mixed phases.
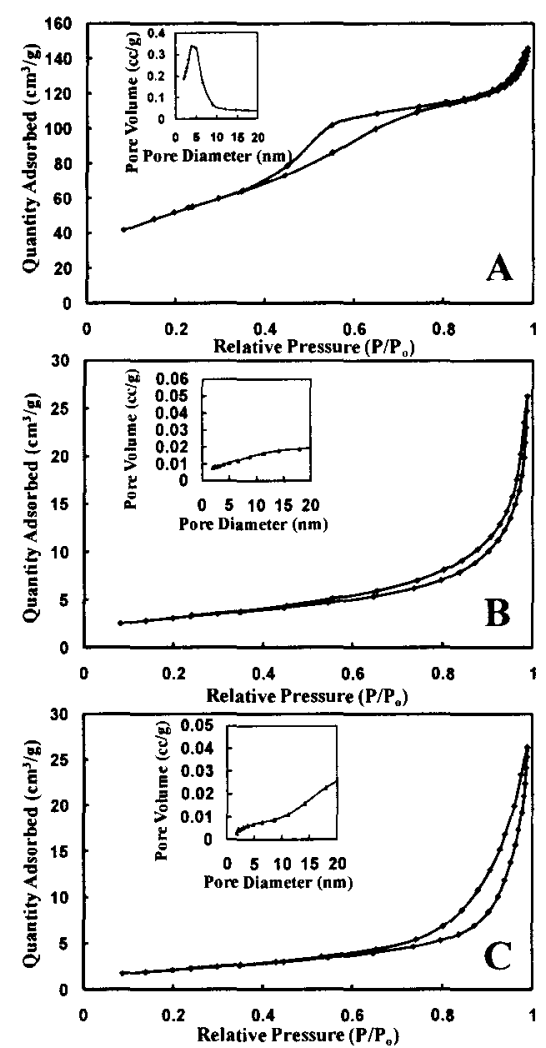

Figure 5.8. $\mathrm{N}_{2}$ adsorption-desorption isotherms and $\mathrm{BJH}$ pore size distribution from adsorption branch of A) mesoporous GaMo1, B) GaMo2 and C) GaMo3 mixed oxides synthesized by employing F127 as SDA via SAHA. 
The X-ray diffraction patterns of gallium oxide and gallium-molybdenum mixed oxides calcined at $350^{\circ} \mathrm{C}$ are shown in Figure 5.9. The XRD pattern of mesoporous gallium oxide revealed strong reflections at dspacing $=4.7,2.5,2.02,1.6$ and $1.5 \AA$ corresponding to the (111), (311), (400), (333) and (440) planes of cubic spinel lattice respectively (Fig. 5.9a) which is in agreement with previous reports [2, 22]. The GaMol sample displayed broad peaks suggesting semi-crystalline nature (Fig. 5.9b). As the amount of molybdenum further increased phase segregation was observed. This was confirmed by the high angle XRD patterns for the GaMo2 and GaMo3 samples. A distinct set of peaks was observed for these two samples with strong reflections corresponding to the (110), (040), (120), (021), (130), (060), and (061) planes of orthorhombic $\mathrm{MoO}_{3}$ (Fig. $5.9 \mathrm{c}$ and d) which is in agreement with previous reports $[243,249,250]$.

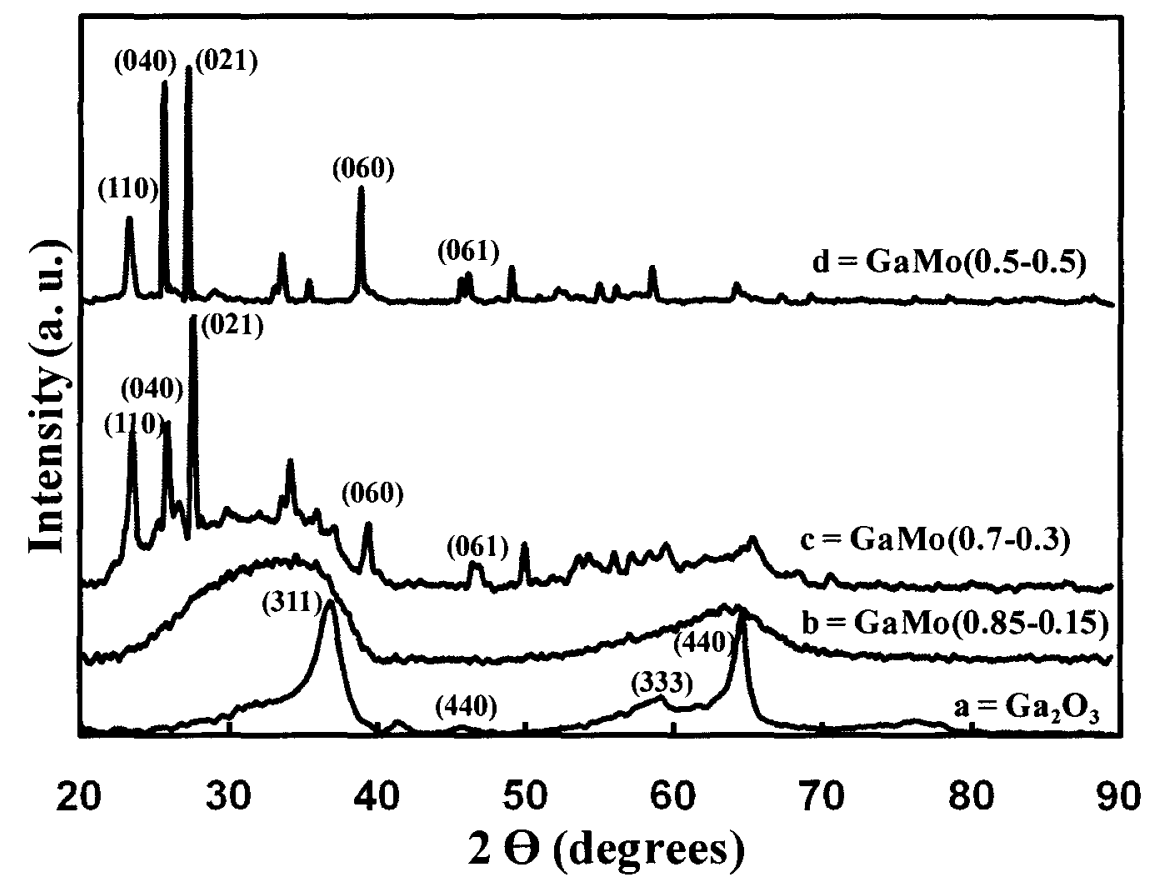

Figure 5.9. High-angle XRD patterns of a) mesoporous $\mathrm{Ga} 2 \mathrm{O} 3$, b) mesoporous GaMol, c) GaMo2 and d) GaMo3 mixed oxides calcined at $350^{\circ} \mathrm{C}$. 
The SEM images of gallium-molybdenum mixed oxide phases are shown in the Figure 5.10. The phase segregation was distinctly evident in these images. The SEM image of GaMo1 sample displayed homogeneously mixed oxide phases as seen in Fig. 5.10A which is consistent with the XRD pattern. As the amount of molybdenum was increased two distinct phases were observed. For the GaMo2 sample larger micron sized spherical particles were observed along with smaller nanoclusters (Fig. 5.10B). Whereas for the GaMo3 sample a distinctive layered platelike structure was observed (Fig. 5.10C) which is believed to be $\mathrm{MoO}_{3}$ phase.
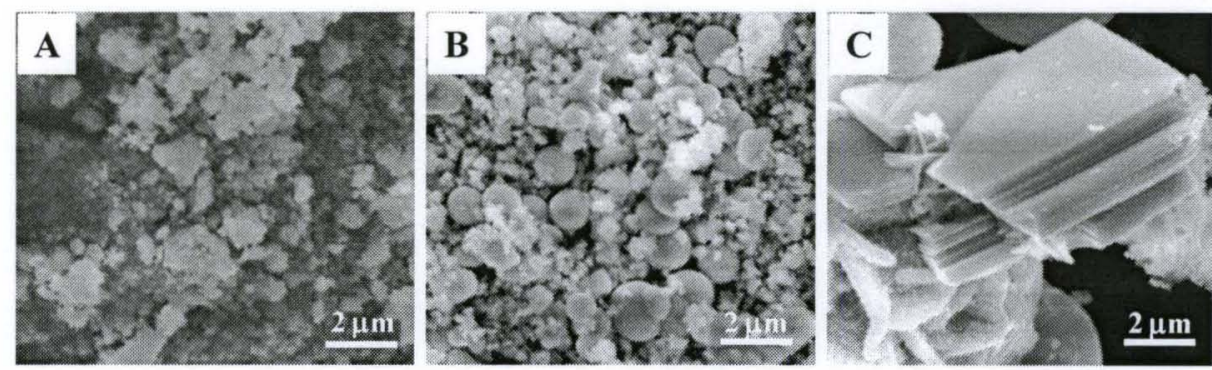

Figure 5.10. SEM images of A) GaMo1, B) GaMo2 and C) GaMo3 mixed oxide phases synthesized via SAHA employing F127 as SDA calcined at $350^{\circ} \mathrm{C}$.

\subsection{Conclusions}

Transition metal such as niobium and molybdenum were incorporated for the synthesis of novel mesoporous gallium-based mixed oxide phases, owing to their remarkable catalytic properties.

Novel mesoporous bi-functional, gallium-niobium mixed oxides and mesoporous $\mathrm{Nb}_{2} \mathrm{O}_{5}$ were successfully synthesized by employing Pluronic (F127) as the structure directing agent via SAHA approach. These mesophases displayed surface areas as high as $366 \mathrm{~m}^{2} / \mathrm{g}$ with unimodal pore size distribution in the $\sim 3$ to 6 $\mathrm{nm}$ range. The average agglomerate size was observed to increase from $\sim 0.3 \mu \mathrm{m}$ to $\sim$ $1.3 \mu \mathrm{m}$ as the concentration of niobium was increased in the mixed oxides and 
agglomerate size of $\sim 2 \mu \mathrm{m}$ was observed for the $\mathrm{Nb}_{2} \mathrm{O}_{5}$ mesophases. The high-angle XRD patterns of Ga-Nb mixed oxides calcined at $350^{\circ} \mathrm{C}$ displayed broad peaks suggestive of semi-crystalline nature of these mesophases. This was further confirmed by the SAED patterns, which displayed broad and diffusive rings indicating formation of extremely small crystals $\sim 3$ to $4 \mathrm{~nm}$. These novel mesophases are expected to be active in both acid-catalyzed as well as redox reactions.

Furthermore, we demonstrated the synthesis of mesoporous galliummolybdenum mixed oxide phases at low loadings of molybdenum $(0.15 \% \mathrm{wt})$. This phase displayed high surface area with unimodal pore size distribution. Phase segregation was observed in Ga-Mo mixed oxides as the concentration of molybdenum increased. This was confirmed by the high-angle XRD patterns, which displayed two distinct set of peaks corresponding to crystalline $\mathrm{MoO}_{3}$ phase and $\mathrm{Ga}_{2} \mathrm{O}_{3}$ phase. 


\section{CHAPTER 6}

\section{CATALYTIC PROPERTIES OF MESOPOROUS GALLIUM OXIDE AND GALLIUM-NIOBIUM MIXED OXIDES}

\subsection{Epoxidation of Cyclooctene}

The epoxidation of cis-cyclooctene in the presence of $\mathrm{H}_{2} \mathrm{O}_{2}$, illustrative of the redox properties of gallium oxide is presented in this section. The ideal catalyst for this reaction should have high activity for cyclooctene conversion and selectivity for epoxide, use aqueous $\mathrm{H}_{2} \mathrm{O}_{2}$ as an oxidant, be stable, easy to separate from the products, and operate in environmentally acceptable solvents. A schematic representation of the epoxidation of cis-cyclooctene is shown in Figure 6.1.

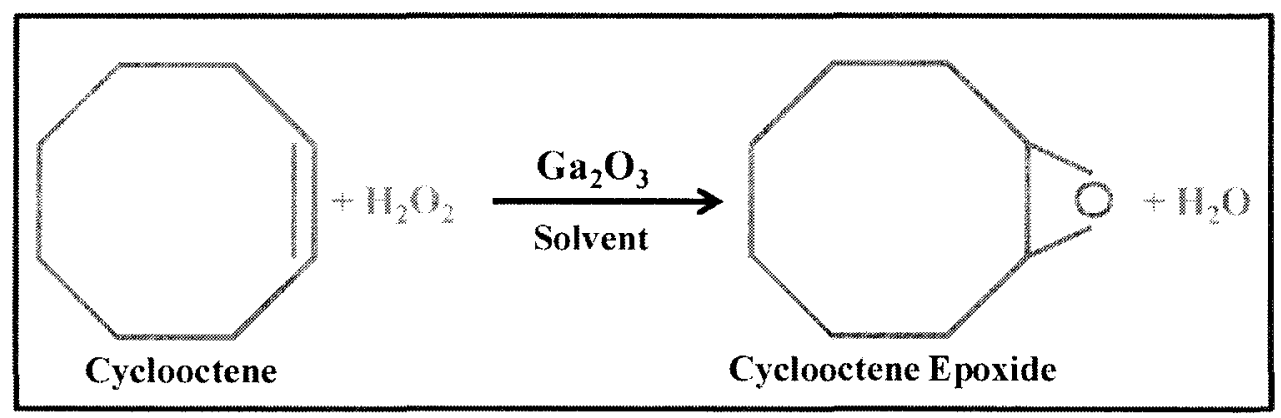

Figure 6.1. The epoxidation of cyclooctene with hydrogen peroxide over mesoporous $\mathrm{Ga}_{2} \mathrm{O}_{3}$.

It is well known that the oxides of various elements, such as gallium and aluminium mainly have the capacity to form surface peroxide groups (for example $\mathrm{Ga}-\mathrm{OOH}$ ) and such - $\mathrm{OOH}$ groups are capable of serving as active sites for epoxidation $[16,17]$. In this section we present the catalytic data for the epoxidation of cyclooctene over mesoporous gallium oxides. To gain information on the effect of 
the pore size and other textural properties, mesoporous $\mathrm{Ga}_{2} \mathrm{O}_{3}$ was prepared with three different structure-directing agents; CTAB, Pluronic F127 and Pluronic P123. To compare the effect of the crystalline nature of the materials (semicrystalline vs crystalline), mesoporous $\mathrm{Ga}_{2} \mathrm{O}_{3}$ was prepared by evaporation-induced self-assembly (EISA) and self-assembly hydrothermal-assisted (SAHA) synthesis approaches. The first approach led to the formation of mesoporous semicrystalline $\mathrm{Ga}_{2} \mathrm{O}_{3}$ while SAHA led to the formation of pure crystalline mesoporous $\mathrm{Ga}_{2} \mathrm{O}_{3}$. Figure 6.2 shows the SEM images of the mesoporous $\mathrm{Ga}_{2} \mathrm{O}_{3}$ prepared with different SDA. Agglomerate sizes between $2-7.5 \mu \mathrm{m}$ were observed. The crystallite size for all these samples remained relatively constant at $\sim 4 \mathrm{~nm}$ (Scherrer's equation). The epoxidation activity of all the catalysts was evaluated at $60^{\circ} \mathrm{C}$ for $2 \mathrm{~h}$ employing ethyl acetate as the solvent. All the catalysts showed significant activity with the selected substrate (cis-cyclooctene), although the level of cyclooctene conversion and epoxide selectivity varied as a function of the catalysts, as shown in Table 6.1. It is clear that the conversion of cyclooctene correlate with the agglomerate size. Agglomerate size between 2-3 $\mu \mathrm{m}$ led to higher conversions of cyclooctene; while the agglomerate sizes between $\sim 4.5$ to $7.5 \mu \mathrm{m}$ led to lower cyclooctene conversion as shown in Figure 6.3. Furthermore, except for sample S6, the general trend is that larger pore sizes led to higher conversions, most likely due to improved mass transfer of guest-product molecules. 
Table 6.1. Catalytic epoxidation of cis-cyclooctene over mesoporous $\mathrm{Ga}_{2} \mathrm{O}_{3}$ prepared via evaporation-induced self-assembly and self-assembly hydrothermal-assisted approach.

\begin{tabular}{|c|c|c|c|c|c|c|c|}
\hline $\begin{array}{c}\text { Sample } \\
\text { ID }\end{array}$ & $\begin{array}{c}\text { Surfactant/ } \\
\text { amount }[\mathbf{g}]\end{array}$ & $\begin{array}{c}\text { Surface } \\
\text { area } \\
{\left[\mathbf{m}^{2} / \mathbf{g}\right]}\end{array}$ & $\begin{array}{c}\text { Pore } \\
\mathbf{d i a m e t e r} \\
{[\mathbf{n m}]}\end{array}$ & $\begin{array}{c}\text { Average } \\
\text { agglomerate } \\
\mathbf{s i z e}[\boldsymbol{\mu m}]\end{array}$ & $\begin{array}{c}\text { Pore } \\
\text { volume } \\
{\left[\mathbf{c m}^{\mathbf{3} / \mathbf{g}]}\right.}\end{array}$ & $\begin{array}{c}\text { C.O. } \\
\text { Conversion } \\
\mathbf{( \% )}\end{array}$ & $\begin{array}{c}\text { Selectivity } \\
\mathbf{( \% )}\end{array}$ \\
\hline $\mathrm{E} 1$ & $\mathrm{~F} 127 / 0.5$ & 173 & 3.6 & 6.3 & 0.16 & - & - \\
\hline $\mathrm{E} 2$ & $\mathrm{CTAB} / 1.0$ & 298 & 2.0 & 7.5 & 0.12 & 4.3 & - \\
\hline $\mathrm{S} 1$ & $\mathrm{CTAB} / 0.5$ & 139 & 4.9 & 3.0 & 0.21 & 16.4 & 100 \\
\hline $\mathrm{S} 2$ & $\mathrm{CTAB} / 1.0$ & 189 & 3.6 & 4.5 & 0.19 & 6.6 & 100 \\
\hline $\mathrm{S} 3$ & $\mathrm{~F} 127 / 0.5$ & 139 & 7.6 & 2.2 & 0.32 & 15.7 & 100 \\
\hline $\mathrm{S} 4$ & $\mathrm{~F} 127 / 1.0$ & 170 & 6.8 & 2.5 & 0.34 & 12.1 & 100 \\
\hline $\mathrm{S} 5$ & $\mathrm{P} 123 / 0.3$ & 137 & 6.5 & 2.0 & 0.26 & 12.8 & 100 \\
\hline $\mathrm{S} 6$ & $\mathrm{P} 123 / 0.9$ & 137 & 14.2 & 6.5 & 0.59 & 4.0 & 100 \\
\hline
\end{tabular}

$\mathrm{E}=$ mesoporous $\mathrm{Ga}_{2} \mathrm{O}_{3}$ prepared by employing EISA; $\mathrm{S}=$ mesoporous $\mathrm{Ga}_{2} \mathrm{O}_{3}$ prepared by employing SAHA.

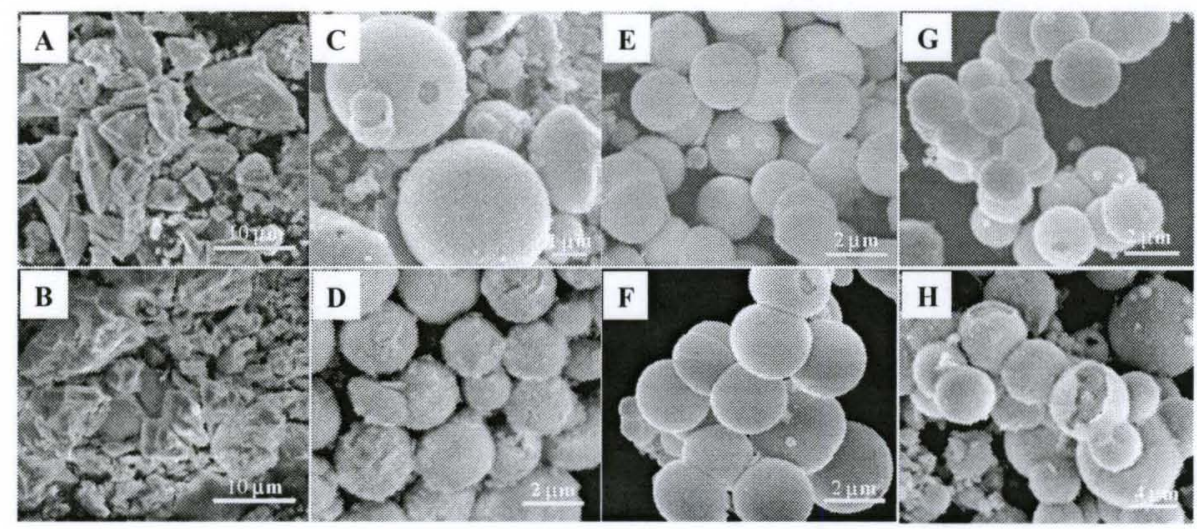

Figure 6.2. $\mathrm{SEM}$ images of mesoporous $\mathrm{Ga}_{2} \mathrm{O}_{3}$ phases synthesized via A-B) EISA (E1 and E2) and C-H) SAHA (S1-S6) employing CTAB (C, D), F127 (E, F) and P123 $(\mathrm{G}, \mathrm{H})$ as the SDA.

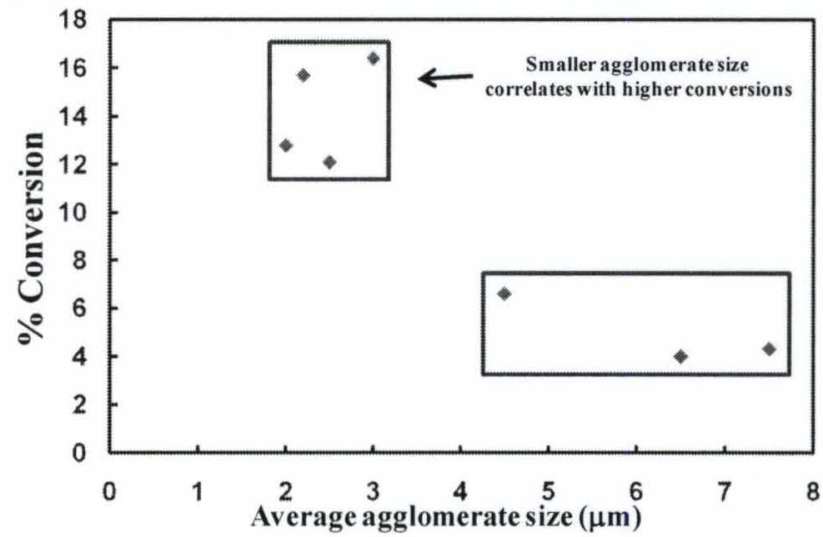

Figure 6.3. Correlation between the cyclooctene conversion and mesoporous $\mathrm{Ga}_{2} \mathrm{O}_{3}$ agglomerate size. 
The cyclooctene conversion (X\%), epoxide selectivity ( $\mathrm{S} \%$ ) and yield of the epoxide ( $\mathrm{Y} \%$ ) were calculated by the following equations:

$$
\begin{aligned}
& X(\%)=\frac{\text { cyclooctene in the feed }- \text { cyclooctene in the product }}{\text { cyclooctene in the feed }} \times 100 \\
& S(\%)=\frac{\text { Epoxide in the product-Epoxide in the feed }}{\text { cyclooctene converted }} \times 100 \\
& Y(\%)=\text { Conversion }(X \%) \times \text { Epoxide selectivity }(S \%)
\end{aligned}
$$

At $60^{\circ} \mathrm{C}$, all the catalysts showed $100 \%$ selectivity towards epoxycyclooctane, whereas the conversion of cyclooctene varied between $4 \%$ to $16 \%$. Epoxide was the only detectable product. The GC peaks corresponding to $\mathrm{M}^{+} 110$ and $\mathrm{M}^{+} 125$ in the mass spectra were used to identify and quantify the concentrations of cyclooctene and epoxide, respectively. Figure 6.4 shows the gas chromatogram of pure cyclooctene and Figure 6.5 shows the reaction product containing the epoxide.

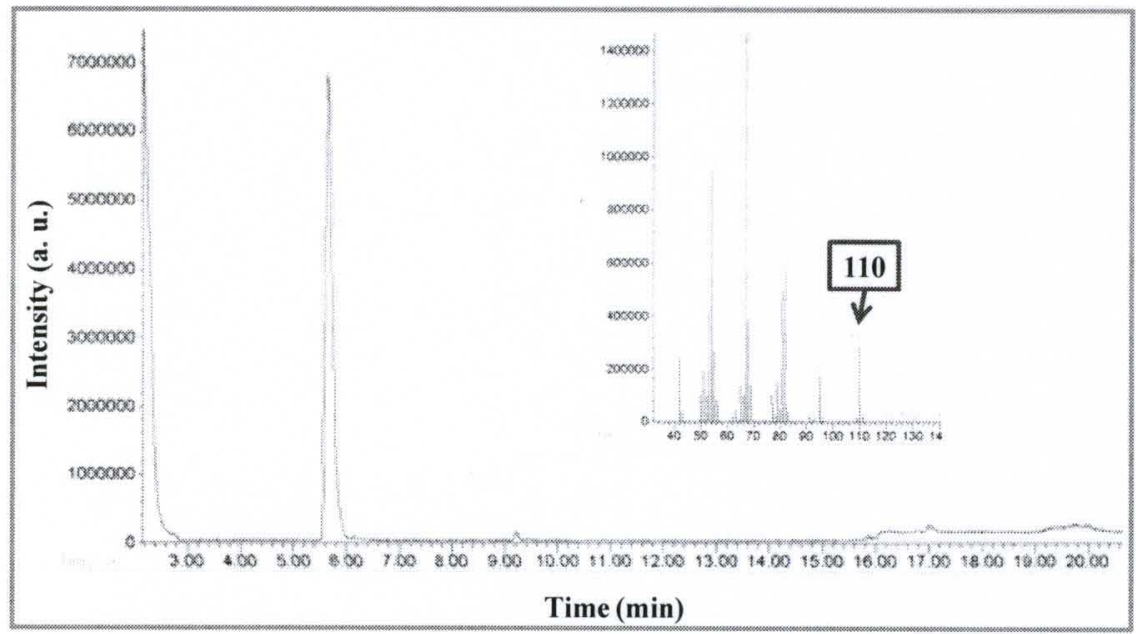

Figure 6.4. Gas chromatograph of pure cyclooctene. 


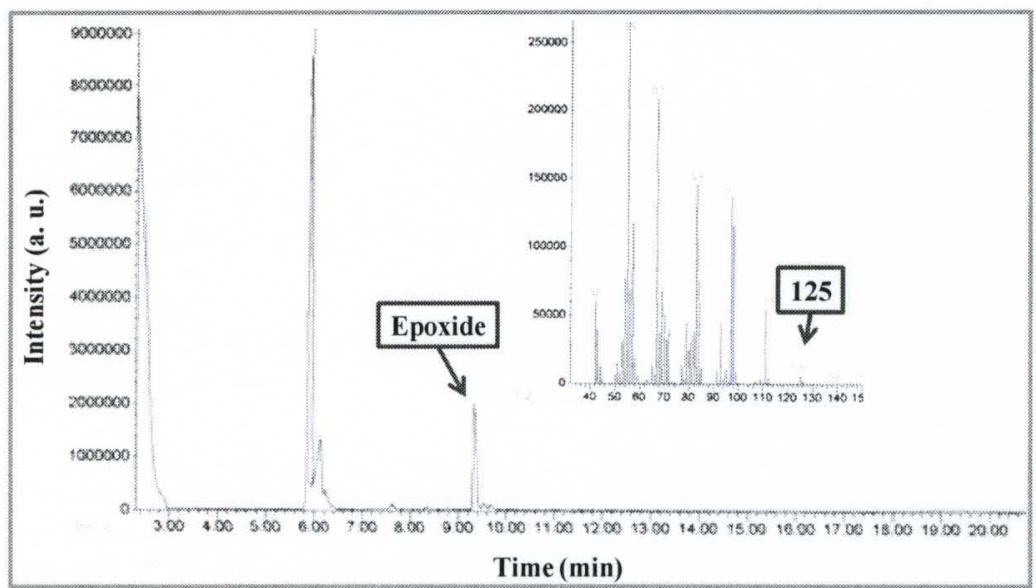

Figure 6.5. Gas chromatograph of the epoxidation products of cis-cyclooctene after 2 h of reaction at $60^{\circ} \mathrm{C}$.

When the reaction temperature was increased to $80^{\circ} \mathrm{C}$, an increase in the cyclooctene conversion was observed. The highest cyclooctene conversion observed was $\sim 52 \%$ with a selectivity of $83 \%$ toward cyclooctene epoxide for the sample prepared with $\mathrm{CTAB}$ as SDA. The yield of cyclooctene epoxide also increased with increase in temperature. However the selectivity towards the epoxide decreased at $80^{\circ} \mathrm{C}$. The cyclooctene conversion, epoxide selectivity and yield for the various mesoporous Ga2O3 catalysts synthesized via SAHA are shown in Figure 6.6. Again higher yields are observed for the samples displaying smaller agglomerate size.

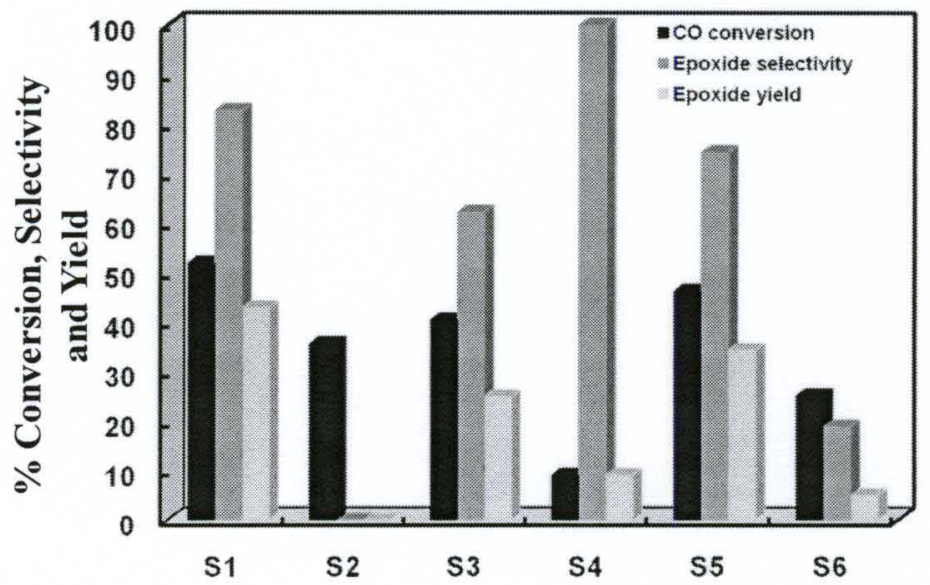

Figure 6.6. Cyclooctene conversion, epoxide selectivity and epoxide yield over mesoporous $\mathrm{Ga}_{2} \mathrm{O}_{3}$ synthesized by SAHA after $2 \mathrm{~h}$ of reaction at $80^{\circ} \mathrm{C}$. 
The mass number of the byproducts was around 224-226. They are, most likely related to the dimer of cyclooctene. Figure 6.7 shows the gas chromatogram of the epoxidation products obtained at $80^{\circ} \mathrm{C}$.

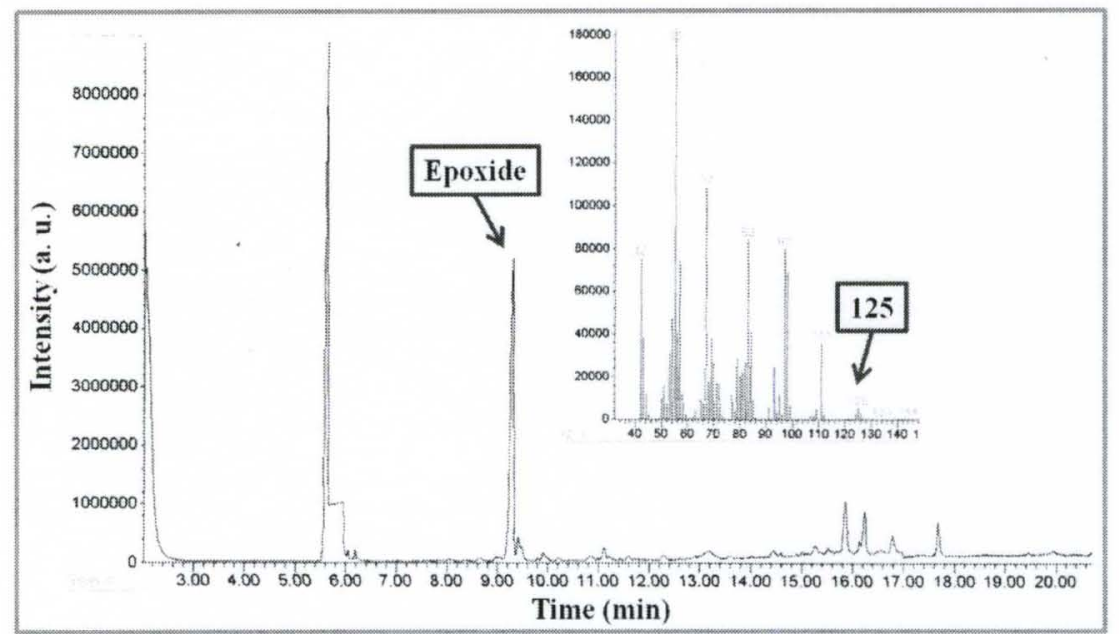

Figure 6.7. Gas chromatogram of the epoxidation products of cyclooctene after $2 \mathrm{~h}$ of reaction at $80^{\circ} \mathrm{C}$.

\subsubsection{Study of the epoxidation activity with different solvents}

The effect of solvents on the catalytic epoxidation of cyclooctene over $\mathrm{Ga}_{2} \mathrm{O}_{3}$ prepared using P123 as structure directing agent was studied. The nature of the solvent of a liquid-phase catalytic process can play a strong role in determining both the conversion and selectivity of the reaction. The solvent can influence the access of the reagents to the catalytic sites and facilitate their coordination to the active centers. They can also poison the active sites by competitive adsorption / coordination. In some cases, the solvent can display catalytic activity on its own.

Cyclooctene conversion and epoxide selectivity (reaction temperature $60^{\circ} \mathrm{C}$, time $2 \mathrm{~h}$ ) as a function of the solvent used are reported in Table 6.2. Fairly similar cyclooctene conversions were observed when ethyl acetate and methanol were used as solvents. The selectivity was preserved at $100 \%$. The catalytic activity, if any, of these 
solvents was checked by running the epoxidation reaction under the same experimental conditions that were used for $\mathrm{Ga}_{2} \mathrm{O}_{3}$ but without the solid catalysts. There was no change in the cyclooctene concentration, thus confirming that the solvents did not catalyze the epoxidation reaction.

Table 6.2. Influence of solvents on the epoxidation of cyclooctene with $50 \mathrm{wt} \%$ aqueous $\mathrm{H}_{2} \mathrm{O}_{2}$ over mesoporous $\mathrm{Ga}_{2} \mathrm{O}_{3}$ prepared by employing $\mathrm{P} 123(0.3 \mathrm{~g})$ as the SDA.

\begin{tabular}{|c|c|c|c|}
\hline Solvent & $\begin{array}{c}\text { Boiling point } \\
\left({ }^{\circ} \mathbf{C}\right)\end{array}$ & $\begin{array}{c}\text { CO conversion } \\
(\mathbf{X} \%)\end{array}$ & $\begin{array}{c}\text { Selectivity } \\
(\mathbf{S} \%)\end{array}$ \\
\hline Ethyl Acetate & 77 & 12.8 & 100 \\
\hline Acetonitrile & 82 & 7.4 & 100 \\
\hline Methanol & 65 & 15.0 & 100 \\
\hline
\end{tabular}

\subsubsection{Kinetics}

As an example of the kinetics, the epoxidation reaction over mesoporous $\mathrm{Ga}_{2} \mathrm{O}_{3}$ prepared with neutral structure directing agent was monitored at different times to gain some insight into the kinetics of the process. Specifically for the sample prepared with the neutral surfactant (P123), a steady increase in the cyclooctene conversion was observed with $100 \%$ selectivity for the epoxide after $6 \mathrm{~h}$ of reaction. After $8 \mathrm{~h}$ of reaction $28 \%$ conversion of cyclooctene was obtained, however, the epoxide selectivity decreased to $\sim 65 \%$ as shown in Figure 6.8 . The rate of reaction constant $k$ for this reaction was determined by the differential method and was observed to be $3.3 \times 10^{-6}\left[\mathrm{M}^{-1} \mathrm{~min}^{-1}\right]$. The presence of gallium as the active center for epoxidation and the larger pores of these mesoporous gallium oxide samples favor the diffusion of reagents and products. 


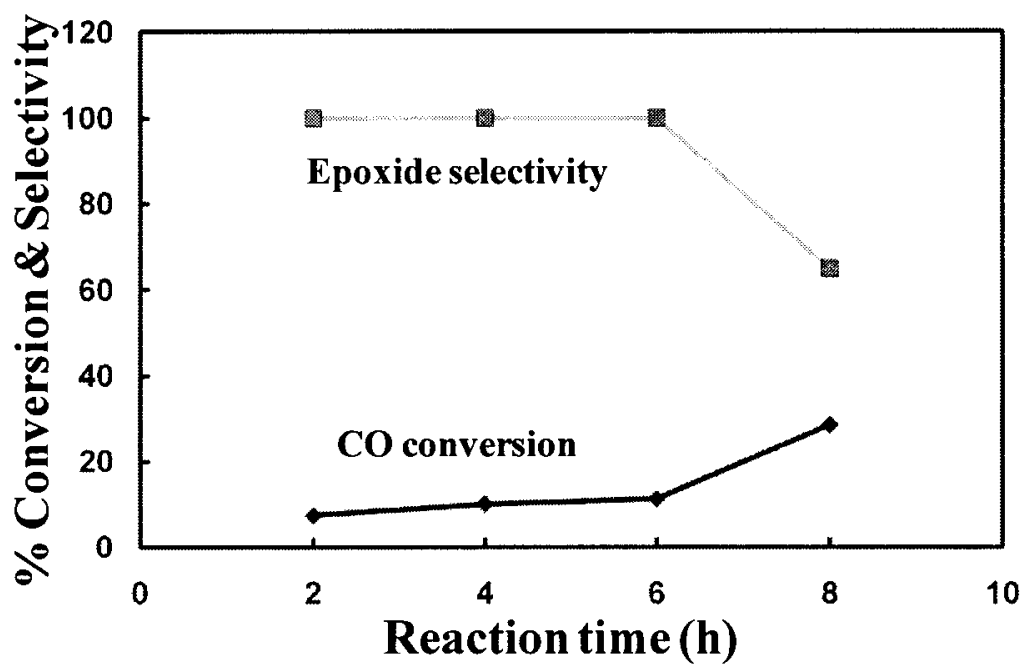

Figure 6.8. Cyclooctene conversion and epoxide selectivity with respect to time over $\mathrm{Ga}_{2} \mathrm{O}_{3}$ prepared by employing $\mathrm{P} 123(0.3 \mathrm{~g})$ as SDA.

\subsubsection{Conclusions}

We demonstrate the epoxidation of cyclooctene to epoxycyclooctane over mesoporous $\mathrm{Ga}_{2} \mathrm{O}_{3}$ synthesized via evaporation-induced self-assembly (EISA) and self-assembly hydrothermal-assisted (SAHA) approaches. For the epoxidation of cyclooctene to epoxycyclooctane carried out at $60^{\circ} \mathrm{C}$ we found that the mesoporous gallium oxide displayed $100 \%$ selectivity towards epoxide with the conversion of cyclooctene in the 4 to $16 \%$ range. As the reaction temperature was increased to $80^{\circ} \mathrm{C}$, an increase in the cyclooctene conversion was observed. The highest cyclooctene conversion observed was $\sim 52 \%$ with a selectivity of $83 \%$ toward the epoxide. A clear correlation was observed between the cyclooctene conversion and gallium oxide agglomerate size at both reaction conditions. Agglomerate size between 2-3 $\mu \mathrm{m}$ led to higher cyclooctene conversion, whereas the agglomerate sizes between $4.5-7.5 \mu \mathrm{m}$ led to lower cyclooctene conversions. 


\subsection{Skeletal Isomerization of Methyl Oleate}

Methyl oleate is an unsaturated, linear fatty acid methyl ester (FAME) and is a major component of biodiesel obtained from triglyceride oils, like soy beans oil, by transesterification with methanol [194]. One of the major drawbacks of such FAME biodiesels, compared to petro diesels, is their high freezing points due to which they cannot be used in very cold climates. Skeletal isomerization, over acid sites, of the linear, unsaturated esters to branched esters or dehydrogenation (over redox sites) of the mono-olefinic esters to the diolefinic esters can reduce their freezing points. A schematic representation of skeletal isomerisation of methyl oleate to its branched isomers is shown in Figure 6.9.

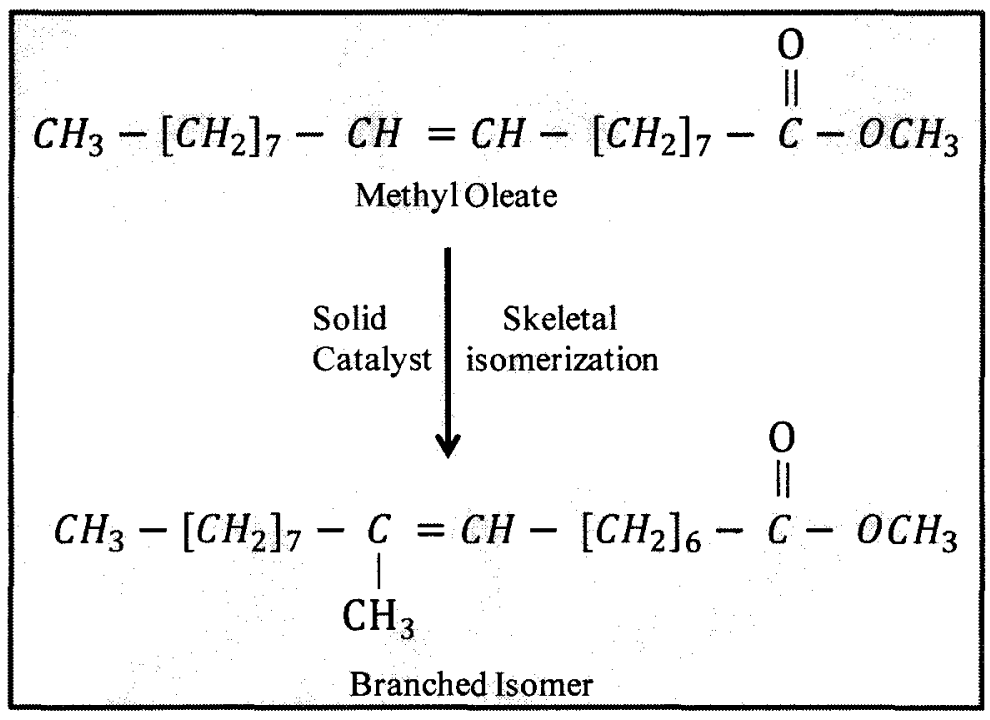

Figure 6.9. A general schematic representation of skeletal isomerisation of methyl oleate to its branched isomers.

The branched iso-stearic acid, for example, has a lower freezing point compared to the linear isomer of stearic acid $\left(-30 \mathrm{vs} .+70^{\circ} \mathrm{C}\right)$. Similarly, the freezing point of diolefinic linoleic acid is lower than that of the mono-olefinic oleic acid $(-5$ vs. $+16^{\circ} \mathrm{C}$ ). Yori et al. [72] reported the skeletal isomerization and cracking of methyl oleate over mordenite and sulfated zirconia. Leaching of the sulfonic acid groups and 
deactivation were major problems observed in these catalysts. Zhang and Zhang [192] reported the skeletal isomerization of methyl oleate over beta zeolites. The presence of mesoporosity in their samples was identified as an important parameter enhancing catalytic activity by reducing diffusional limitations in their narrow zeolite pores.

Our synthesized gallium-niobium mixed oxides possess both acidic and redox sites and are expected to catalyze double bond and skeletal isomerization as well as dehydrogenation reactions. Mesoporosity is an added advantage in the reactions of these long chain molecules to avoid transport and diffusional limitations.

\subsubsection{Catalytic Activity}

The catalytic activity of the mesoporous gallium oxide, niobium oxide and gallium-niobium mixed metal oxide was evaluated by reacting $0.2 \mathrm{~g}$ of the catalyst (activated in nitrogen overnight at $220^{\circ} \mathrm{C}$ ) with $2 \mathrm{ml}$ of the probe molecule (methyl oleate) in a standard batch autoclave (Parr Instruments) at $220^{\circ} \mathrm{C}$ and autogeneous pressures for $20 \mathrm{~h}$. No solvents or carrier gases were used. At the end of the period, the reactor was cooled to room temperature. The catalyst was removed by filtration and the reaction products were analysed by GC-MS (HP 5890 Gas Chromatograph equipped with 5970 Mass Selective Detector; $30 \mathrm{~m}$ X $0.32 \mathrm{~mm}$ column, HP-5 coated with $5 \%$ phenyl methyl poly siloxane stationary phase), and ${ }^{1} \mathrm{H}$ and ${ }^{13} \mathrm{C}$ NMR spectrometry (Varian 7600 AS $400 \mathrm{MHz}$ ). Conversion (X) of methyl oleate and selectivity for skeletal isomerization products (S1) and for other products (S2) and the yield (Y) was calculated as follows:

$$
X(\%)=\frac{\left(C_{18} \text { in the feed }-C_{18} \text { in the product }\right)}{C_{18} \text { in the feed }} \times 100
$$




$$
\begin{aligned}
& S_{1}(\%)=\frac{(\text { skeletal isomers in product-skeletal isomers in }}{C_{18} \text { converted }} \\
& S_{2}(\%)=\frac{\left(\left(C_{14}+C_{16}\right) \text { in product }-\left(C_{14}+C_{16}\right) \text { in feed }\right)}{C_{18} \text { converted }} \times 100 \\
& Y(\%)=\text { Conversion } \times \text { Selectivity }
\end{aligned}
$$

\subsubsection{Product Analysis}

The results of the catalytic transformations of methyl oleate over the mesoporous $\mathrm{Ga}-\mathrm{Nb}$ mixed oxides are shown in Table 6.3. The surface acidity of the catalysts, measured by the adsorption of dipropyl amine, is also shown in Table 6.3.

Table 6.3. Catalytic properties of methyl oleate over mesoporous $\mathrm{Ga}-\mathrm{oxide}, \mathrm{Ga}-\mathrm{Nb}$

\begin{tabular}{|c|c|c|c|c|c|c|c|}
\hline $\begin{array}{c}\text { Sample } \\
\text { ID }\end{array}$ & $\begin{array}{c}\text { ICP composition } \\
\text { Ga/Nb molar } \\
\text { ratio }\end{array}$ & $\begin{array}{c}\text { Acidity } \\
\text { Moles of DPA/g } \\
\text { of Catalyst } \\
\left(\times 10^{-6}\right)\end{array}$ & $\begin{array}{c}\text { MO } \\
\text { conversion } \\
(X \% w t)\end{array}$ & $\begin{array}{l}\text { Selectivity for } \\
\text { isomerisation } \\
\left(\mathrm{S}_{1} \% \mathrm{wt}\right)\end{array}$ & $\begin{array}{c}\text { Yield } \\
\text { (Y\%wt) }\end{array}$ & $\begin{array}{l}\text { Selectivity for } \\
\begin{array}{l}\left(\mathrm{C}_{14}+\mathrm{C}_{16}\right) \\
\left(\mathrm{S}_{2} \% w \mathrm{t}\right)\end{array}\end{array}$ & $\begin{array}{c}\text { Others } \% \\
\text { wt " }\end{array}$ \\
\hline $\mathrm{Ga}_{2} \mathrm{O}_{3}$ & - & 0.28 & 9.7 & 46.4 & 4.5 & 55.5 & 0.0 \\
\hline $\mathrm{GaNb}]$ & 2.80 & 0.64 & 10.8 & 43.8 & 4.7 & 50.0 & 7.0 \\
\hline $\mathrm{GaNb2}$ & 0.84 & 0.70 & 19.5 & 53.4 & 10.4 & 20.7 & 25.9 \\
\hline GaNb3 & 0.14 & 0.96 & 22.4 & 48.3 & 10.8 & 24.6 & 27.1 \\
\hline GaNb4 & 0.08 & 0.74 & 56.5 & 86.0 & 48.6 & 0.0 & 14.0 \\
\hline GaNb4A & - & - & 11.9 & 43.6 & 5.2 & 36.4 & 0.0 \\
\hline GaNb5 & 0.03 & 0.67 & 13.3 & 38.0 & 5.1 & 53.6 & 8.4 \\
\hline $\mathrm{Nb}_{2} \mathrm{O}_{5}$ & - & 0.61 & 18.0 & 70.0 & 12.6 & 26.3 & 3.7 \\
\hline
\end{tabular}
mixed oxides, and $\mathrm{Nb}$-oxide.

a "Others" include oleic acid (predominantly over niobia), dehydrogenated (mainly gallia) and deoxygenated (mainly mixed Ga-Nb oxides) products.

GaNb4-Reference sample prepared in the absence of a SDA.

The products consisted of branched methyl and ethyl isomers of methyl oleate, dehydrogenated diolefinic product from methyl oleate (methyl linoleate), methyl

palmitates, $C_{16}: 1$ (from the dehydrogenation of methyl palmates, $C_{16}: 0$, an impurity in the methyl oleate). Product identification was done by a combination of gas chromatography, mass spectrometry and ${ }^{1} \mathrm{H} /{ }^{13} \mathrm{C}$ NMR and IR spectroscopies. The 
gas chromatographic peaks corresponding to $\mathrm{M}^{+} 296$ and $\mathrm{M}^{+} 294$ peaks in the mass spectra were used to identify and quantify the concentrations of methyl oleate and linoleate, respectively. The double bond isomers of methyl oleate have the same molecular weight as methyl oleate and hence, could not be distinguished by mass spectrometry. They were also not separated from methyl oleate under our gas chromatographic separation conditions. The concentration of the skeletal isomers was obtained from gas chromatography/mass spectrometry and also from the ratio of the intensities of the ${ }^{1} \mathrm{H}$ NMR peaks at 5.3-5.5 ppm (characteristic of internal olefinic CH protons) and those at $1.92-2.08 \mathrm{ppm}$ (characteristic of allylic protons), respectively. The concentration of oleic acid was estimated from gas chromatography, acid-base titration as well as changes in the ${ }^{13} \mathrm{C}$ NMR peaks of the carbonyl carbon (of the ester) at $174.3 \mathrm{ppm}$ and the methyl carbon of the ester at $51.5 \mathrm{ppm}$. The quantification of the oleic acid concentration was done using peaks in the $2.37-2.41 \mathrm{ppm}$ region in the $1 \mathrm{H}$ NMR spectra by procedures described by J. K. Satyarthi et al [251]. 


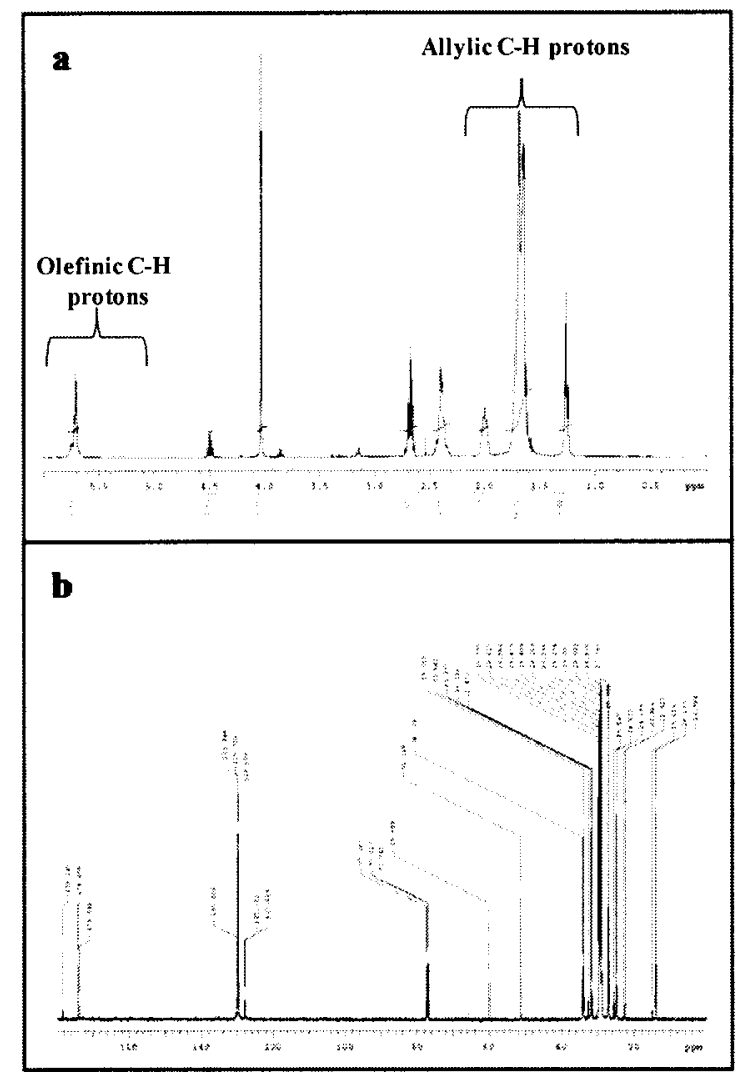

Figure 6.10. a) ${ }^{1} \mathrm{H}$ NMR and b) ${ }^{13} \mathrm{C}$ NMR patterns for the isomerization products of methyl oleate obtained by using GaNb4 catalyst.

Oleic acid (also found over pure niobia and samples rich in $\mathrm{Nb}_{2} \mathrm{O}_{5}$ ) was probably formed by the hydrolysis of methyl oleate by the residual water or surface hydroxyl groups. It is important to mention that hydroxyl groups on pure niobia are completely removed only above $350^{\circ} \mathrm{C}$. As shown in Table 6.3 both the acidity and catalytic activity of the catalysts increase with increasing niobia content, reach a maximum for GaNb3-GaNb4 samples and decrease thereafter. Even though a linear correlation between acidity and catalytic activity is not observed, a clear dependence of activity on acidity may be discerned in these data as shown in Figure 6.11. 


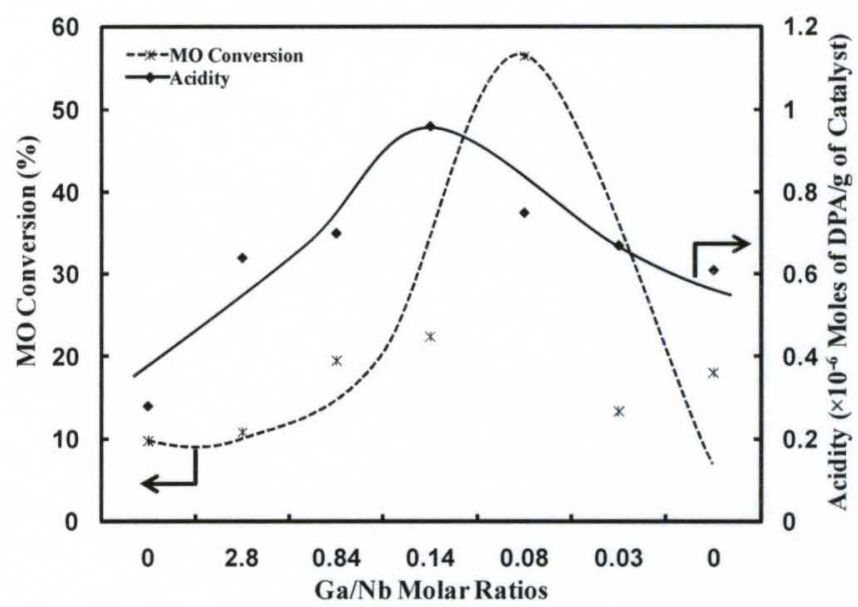

Figure 6.11. Ga-Nb composition vs methyl oleate conversion and acidity.

The superior catalytic performance of GaNb4 sample can also be partly attributed to its higher crystallinity as compared to the other samples. This was confirmed by the high resolution TEM images shown in Figure 6.12. For comparison purposes, we evaluated the catalytic activity of a control sample which was prepared in the absence of the SDA (sample GaNb4A in Table 6.3). The catalytic performance of the control sample was poor as compared to the mesoporous sample of the same composition as shown in Table 6.3.
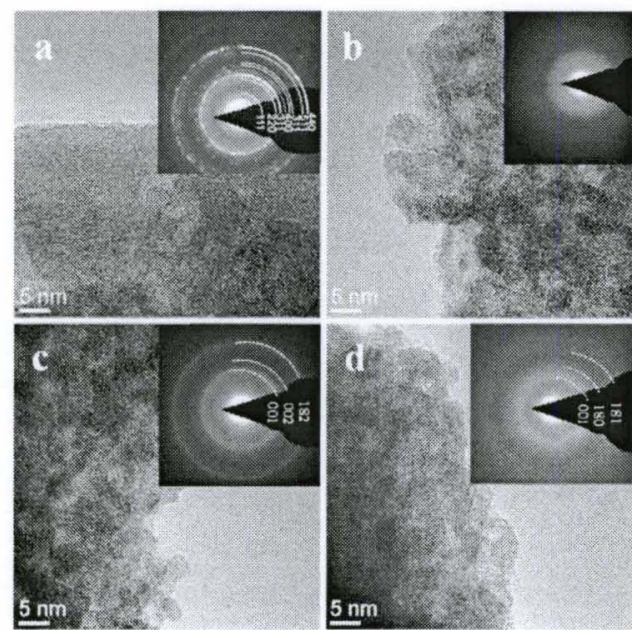

Figure 6.12. HRTEM images of the crystals of mesoporous a) $\mathrm{Ga}_{2} \mathrm{O}_{3}$, b) $\mathrm{GaNb} 3$ mixed oxide, c) $\mathrm{GaNb} 4$ mixed oxide and d) $\mathrm{Nb}_{2} \mathrm{O}_{5}$ with their respective $\mathrm{SAED}$ patterns as inset. 


\subsubsection{Catalytic Transformations of Biodiesel to its Branched Isomers}

The catalytic transformations of biodiesel over mesoporous $\mathrm{Ga}-\mathrm{Nb}$ mixed oxides are shown in Table 6.4 Biodiesel is a mixture of linear, saturated and unsaturated fatty acid methyl esters containing 14,16 and 18 carbon atoms in the linear chain. Over acidic and/or bifunctional (acidic and redox) catalysts, the various components undergo a complex series of reactions, which can, in principle, lead to either a decrease or an increase in the concentration of the individual components. It is difficult to define a single parameter which is indicative of "biodiesel conversion". In Table 6.4, actual changes in the concentrations of the various components of biodiesel during reaction are shown. For the mesoporous $\mathrm{Ga}-\mathrm{Nb}$ oxides the product distributions will not be limited by diffusion or spatial constraints and are more likely to be influenced by the inherent catalyst properties like surface acidity and redox activity as shown in Table 6.4. The extent of cracking over these mesoporous Ga- $\mathrm{Nb}$ oxides is lower than that seen over microporous molecular sieves due to the lower acidity of the former as compared to the microporous sieves. Fatty acids and FAME oligomers have higher pour points than the FAME molecules. To obtain a significant reduction in the pour points of FAMEs by catalytic skeletal isomerization over solid catalysts, these fatty acids and oligomers have to be removed from the product by distillation. 
Table 6.4. Catalytic transformations of Biodiesel over mesoporous Ga-Nb mixed oxides.

\begin{tabular}{|c|c|c|c|c|c|c|c|c|}
\hline FAME & BD Feed & $\mathbf{G a}_{\mathbf{2}} \mathbf{O}_{\mathbf{3}}$ & GaNb1 & GaNb2 & GaNb3 & GaNb4 & GaNb5 & $\mathbf{N b}_{\mathbf{2}} \mathbf{O}_{\mathbf{3}}$ \\
\hline $\mathrm{C}_{14}+\mathrm{C}_{16}$ & 15.2 & 13.9 & 16.1 & 17.2 & 17.1 & 21.7 & 18.0 & 19.8 \\
\hline $\mathrm{C} 18: 1$ & 30.9 & 23.5 & 25.0 & 28.6 & 26.6 & 25.0 & 28.3 & 25.6 \\
\hline $\mathrm{C} 18: 2$ & 15.6 & 11.7 & 13.9 & 13.6 & 10.0 & 13.4 & 16.5 & 21.6 \\
\hline $\mathrm{C} 18: 3$ & 30.9 & 22.4 & 20.8 & 27.6 & 25.6 & 22.1 & 25.5 & 17.6 \\
\hline $\mathrm{C} 18: 0$ & 7.4 & 7.9 & 5.1 & 4.9 & 5.0 & 7.3 & 4.9 & 7.2 \\
\hline Others & 0.0 & 20.6 & 13.7 & 8.1 & 15.7 & 10.5 & 6.8 & 8.2 \\
\hline
\end{tabular}

Product distribution; Reaction conditions: $220^{\circ} \mathrm{C}$ for $6 \mathrm{~h}$; catalyst $-5 \mathrm{wt} \%$ of biodiesel.

\subsubsection{Conclusions}

In summary, we demonstrate the catalytic transformations of methyl oleate, a major component of biodiesel over mesoporous $\mathrm{Ga}-\mathrm{Nb}$ mixed oxide phases. These mesoporous oxides are bifunctional in nature, displaying activity in acid-catalyzed as well as redox reactions. These materials isomerize the long-chain, linear, monoolefinic ester, methyl oleate, and a major constituent of FAME biodiesel, into its branched isomers and dehydrogenate it to the diolefinic ester, methyl linoleate. Methyl oleate conversion of $57 \%$ with a selectivity of $86 \%$ and yield of $\sim 50 \%$ was obtained over mixed oxide sample with Ga-Nb composition of $0.3-0.7 \%$ wt. The superior catalytic performance of GaNb4 sample is attributed to its higher acidity, crystallinity and mesoporosity. The mesoporous nature of these novel mixed phases is an advantage as it avoids transport and diffusional limitations of these long chain molecules. The ability of mesoporous $\mathrm{Ga}-\mathrm{Nb}$ mixed oxide phases to isomerize as well as dehydrogenate the fatty acid esters is an interesting finding that has potential applications in manufacture of biodiesel with superior cold flow properties. 


\section{CHAPTER 7}

\section{CONCLUDING REMARKS AND FUTURE DIRECTIONS}

\subsection{Concluding Remarks}

We have demonstrated the synthesis of thermally stable mesoporous gallium oxide and gallium-based mixed oxide phases based on basic principles of selfassembly of inorganic precursors in the presence of structure directing agents. In particular, these mesophases were synthesized in the presence of ionic and non-ionic structure directing agents via evaporation-induced self-assembly (EISA), selfassembly hydrothermal-assisted (SAHA) and self-assembly microwave-assisted heating approaches. The textural properties such as surface areas and pore sizes were effectively fine-tuned by the nature and relative concentration of the structure directing agents. We also incorporated niobium and molybdenum transition metals for the synthesis of mesoporous gallium-based mixed oxide phases by employing a selfassembly hydrothermal-assisted (SAHA) approach. These resultant mesophases displayed surface areas as high as $360 \mathrm{~m}^{2} / \mathrm{g}$, with unimodal pore size distribution, and controlled crystallinity, combined with thermal stability. Based on these remarkable properties, these mesophases are highly attractive catalysts in a number of model reactions. We have also demonstrated the catalytic performance of these mesophases in three model reactions; 1) epoxidation of cyclooctene, 2) isomerisation of methyl oleate and 3) catalytic transformation of biodiesel to its branched isomers. The specific deliverables from this work are:

1. Thermally stable mesoporous gallium oxide phases were successfully synthesized by employing EISA, SAHA and microwave-assisted heating approaches. 
Various structure directing agents such as CTAB (cationic surfactant), F127 and P123 (neutral surfactants) were employed for the mesostructure formation. In general, when $\mathrm{CTAB}$ was used as SDA, the self-assembly between the negatively charged inorganic species ( $\left.\mathrm{I}^{-}\right)$and the positively charged polar head group of the surfactant $\left(\mathrm{S}^{+}\right)$directed the mesostructure formation. For neutral surfactants hydrogen bonding between the neutral surfactant and neutral inorganic species is the most likely pathway for the mesostructure formation.

2. EISA produced semi-crystalline mesoporous gallium oxide phases that displayed unimodal pore size distribution in the $2-15 \mathrm{~nm}$ range and relatively high specific surface areas up to $\sim 300 \mathrm{~m}^{2} / \mathrm{g}$. High angle X-ray diffraction patterns for samples prepared via EISA displayed two broad peaks assigned to the (311) and (440) planes of cubic spinel confirming the semi-crystalline nature of the mesoporous walls. This was further confirmed by the SAED analysis which displayed a diffused ring pattern, suggesting the formation of $\sim 3$ to $5 \mathrm{~nm}$ crystals.

3. SAHA led to the formation of uniform nanocrystalline mesoporous gallium oxide hollow spheres with narrow size distribution. The average size of the spheres was $0.3-6.5 \mu \mathrm{m}$ depending on the hydrothermal treatment temperature and the employment of ethylene glycol as an organic additive. These mesophases displayed surface areas as high as $221 \mathrm{~m}^{2} / \mathrm{g}$ with unimodal pore diameter in the $5-15 \mathrm{~nm}$ range. The high angle XRD patterns revealed strong reflections corresponding to cubic spinel type structure. SAED analysis displayed a spot-like form of the pattern with sharp, well-defined diffraction rings that are the indications of a large-grain nanocrystalline material morphology, which is in agreement with TEM observations and XRD data. The cubic lattice parameter $\mathrm{a}=0.829 \pm 0.003 \mathrm{~nm}$, were derived from 
the two most intense and sharp rings ((311) and (440)), and corresponds well with the cubic spinel type structure of $\mathrm{Ga}_{2} \mathrm{O}_{3}$.

4. Mesoporous gallium oxide nanocrystals were also synthesized by selfassembly microwave-assisted heating, using non-ionic tri-block copolymer (F127) and cationic surfactant (CTAB) as structure directing agents. The uniform, rapid and localized heating provided by microwave-assisted heating, led to the formation of homogeneous crystalline nanoclusters of mesoporous gallium oxide. The crystallite size of these gallium oxide nanoparticles varied from $\sim 3$ to $8 \mathrm{~nm}$. The XRD patterns confirm the transition from semi-crystalline to fully crystalline mesoporous gallium oxides displaying cubic-spinel type structure with the increase in microwave heating time from 15 to $120 \mathrm{~min}$. These mesophases displayed surface areas as high as 360 $\mathrm{m}^{2} / \mathrm{g}$ with unimodal pore size distribution in the $\sim 3-7 \mathrm{~nm}$ range.

5. Mesoporous bi-functional, gallium-niobium mixed oxides were successfully synthesized by employing Pluronic (F127) as the structure directing agent via SAHA approach. These mesophases displayed surface areas as high as $366 \mathrm{~m}^{2} / \mathrm{g}$ with unimodal pore size distribution in the $\sim 3$ to $6 \mathrm{~nm}$ range. The average agglomerate size was observed to increase from $\sim 0.3 \mu \mathrm{m}$ to $\sim 1.3 \mu \mathrm{m}$ as the concentration of niobium was increased in the mixed oxides and agglomerate size of $\sim 2 \mu \mathrm{m}$ was observed for the pure $\mathrm{Nb}_{2} \mathrm{O}_{5}$ mesophase. The high-angle XRD patterns of $\mathrm{Ga}-\mathrm{Nb}$ mixed oxides calcined at $350^{\circ} \mathrm{C}$ displayed broad peaks suggestive of semi-crystalline nature of these mesophases. This was further confirmed by the SAED patterns, which displayed broad and diffusive rings indicating formation of extremely small crystals $\sim 3$ to $4 \mathrm{~nm}$. Furthermore, we synthesized mesoporous gallium-molybdenum mixed oxide phases with $0.15 \mathrm{wt} \%$ Mo. Phase segregation was observed in Ga-Mo mixed oxides for high molybdenum loadings $(0.3 \mathrm{wt} \%$ to $0.5 \mathrm{wt} \%)$. This was confirmed by the high-angle 
XRD patterns, which displayed two distinct set of peak corresponding to the highly crystalline $\mathrm{MoO}_{3}$ phase and others corresponding to the $\mathrm{Ga}_{2} \mathrm{O}_{3}$ phase.

6. We demonstrated the epoxidation of cyclooctene to epoxycyclooctane over mesoporous $\mathrm{Ga}_{2} \mathrm{O}_{3}$. For the epoxidation of cyclooctene to epoxycyclooctane carried out at $60^{\circ} \mathrm{C}$ we found that the mesoporous gallium oxide displayed $100 \%$ selectivity towards epoxide with the conversion of cyclooctene in the 4 to $16 \%$ range. As the reaction temperature was increased to $80^{\circ} \mathrm{C}$, an increase in the cyclooctene conversion was observed. The highest cyclooctene conversion observed was $\sim 52 \%$ with a selectivity of $83 \%$ toward the epoxide. A clear correlation was observed between the cyclooctene conversion and mesoporous gallium oxide agglomerate size at both reaction conditions. Agglomerate size between 2-3 $\mu \mathrm{m}$ led to higher cyclooctene conversion, where as the agglomerate sizes between 4.5-7.5 $\mu \mathrm{m}$ led to lower cyclooctene conversions.

7. We also demonstrated the skeletal isomerization of methyl oleate, a major component of biodiesel over these novel mesoporous $\mathrm{Ga}-\mathrm{Nb}$ mixed phases. The novel mesoporous oxides are bifunctional in nature, displaying activity in acid-catalyzed as well as redox reactions. These materials isomerize the long-chain, linear, monoolefinic ester, methyl oleate, and a major constituent of FAME biodiesel, into its branched isomers and dehydrogenate it to the diolefinic ester, methyl linoleate. Methyl oleate conversion of $57 \%$ with a selectivity of $86 \%$ and yield of $\sim 50 \%$ was obtained over mixed oxide sample with Ga-Nb composition of $0.3-0.7 \%$ wt. The superior catalytic performance of sample with Ga-Nb composition of 0.3 to $0.7 \mathrm{wt} \%$ is attributed to its higher acidity, crystallinity and mesoporosity. The mesoporous nature of these novel mixed phases is an advantage as it avoids transport and diffusional limitations of these long chain molecules. The ability of mesoporous Ga- 
$\mathrm{Nb}$ mixed oxide phases to isomerize as well as dehydrogenate the fatty acid esters is an interesting finding that has potential applications in manufacture of biodiesel with superior cold flow properties.

\subsection{Future Directions}

This work addresses the novel self-assembly methods for the rational design of thermally stable mesoporous gallium oxide and gallium-based mixed oxide catalysts displaying high surface area, unimodal pore size, and controlled extent of crystallinity (from amorphous to fully crystalline) and crystal size.

Although we demonstrated the formation of mesoporous gallium-molybdenum mixed oxides, we still observed phase segregation as the concentration of molybdenum increased. There is a need to understand the parameters that are responsible for this phase segregation, and to find ways to avoid the formation of two distinct phases by exploring the different chemical parameters such as nature of inorganic precursors, gel compositions, $\mathrm{pH}$ of the solution as well as the processing parameters such as hydrothermal treatment temperature and time and calcination temperature.

We have also demonstrated the catalytic performance of mesoporous $\mathrm{Ga}_{2} \mathrm{O}_{3}$ for the epoxidation of cyclooctene at $60^{\circ} \mathrm{C}$ and observed $100 \%$ selectivity toward epoxide formation. But the cyclooctene conversions were low. Therefore, future experiments should focus on obtaining better conversions by improving the catalytic properties of $\mathrm{Ga}_{2} \mathrm{O}_{3}$ by incorporating other transition metals such as Titanium.

Alternatively, different substrates such as cyclohexene, styrene etc. can be targeted to study the catalytic performance of these mesoporous oxide phases. In addition to epoxidation, other reactions such as oxidative dehydrogenation of alkanes and isomerisation of long chain paraffins should be studied. Another potential research 
direction could be focused on the biodiesel production by transesterification of triglycerides over these novel mesoporous oxide phases, since there is a need to replace or complement the current homogeneous catalysts with heterogeneous ones, and also because biodiesel has lately emerged as an alternative fuel due of its lower environmental impact as compared to petroleum diesel fuels. 


\section{REFERENCES}

1. Greenwood, N. N.; Earnshaw, A.; Chemistry of the Elements, Pergamon Press, Oxford, 1984.

2. Arean, C. O.; Bellan, A.L.; Mentruit, M. P.; Delgado, M. R.; Palomino, G. T.; Microporous and Mesoporous Materials, 2000, 40, 35.

3. Roy, R.; Hill, V. G.; Osborn, E. F.; Journal of American Chemical Society, $1952,74,719$.

4. Zheng, B.; Hua, W.; Yue, T.; Gao, Z.; Journal of Catalysis, 2005, 232, 143.

5. Roy, R.; Hill, V. G.; Osborn, E. F.; Industrial and Engineering Chemistry Research, 1953, 45, 819.

6. Zinkevich, M.; Morales, F. M.; Nitsche, H.; Ahrens, M.; Ruhle, M.; Aldinger, F.; Z. Metallkd, 2004, 95, 9 .

7. Hou, Y.; Wu, L.; Wang, X.; Ding, Z.; Li, Z.; Fu, X.; Journal of Catalysis, $\mathbf{2 0 0 7}, 250,12$.

8. Collins, S. E.; Baltanas, M. A.; Bonivardi, A. L.; Langmuir, 2005, 21, 962.

9. Collins, S. E.; Baltanas, M. A.; Bonivardi, A. L.; Journal of Physical Chemistry B, 2006, 110, 5498 .

10. Zheng, B.; Hua, W.; Yue, Y.; Gao, Z.; Journal of Catalysis, 2005, 232, 143.

11. Nakagawa, K.; Kajita, C.; Idle, Y.; Okamura, M.; Kato, S.; Kasuya, H.; Ikenaga, N.; Suzuki, T.; Catalysis Letters, 2000, 64, 215.

12. Shimizu, K.; Satsuma, A.; Hattori, T.; Applied Catalysis B, 1998, 16, 319.

13. Bethke, K.; Kung, M.; Yang, B.; Shah, M.; Alt, D.; Li, C.; Kung, H.; Catalysis Today, 1995, 26, 169. 
14. Nakagawa, K.; Okamura, M.; Ikenaga, N.; Suzuki, T.; Kobayashi, T.; Chemical Communications, 1998, 1025.

15. Michorczyk, P.; Ogonowski, J.; Applied Catalysis A: General, 2003, 251, 425.

16. Pescarmona, P. P.; Janssen, K. P. F.; Jacobs, P. A.; Chemistry-A European Journal, 2007, 13, 6562.

17. Pescarmona, P. P.; Jacobs, P. A.; Catalysis Today, 2008, 137, 52.

18. Bohm, J.; Angewandte Chemie, 1940, 53, 131.

19. Kim, S. W.; Iwamoto, S.; Inoue, M.; Ceramics International, 2009, 35, 1603.

20. Pohl, K.; Naturwissenschaften, 1968, 55, 82.

21. Yada, M.; Ohya, M.; Machida, M.; Kijima, T.; Langmuir, 2000, 16, 4752.

22. Yada, M.; Takenaka, H.; Machida, M.; Kijima, T.; Journal of Chemical Society, Dalton Transactions, 1998, 1547.

23. Delgado, M. R.; Areán, C. O.; Materials Letters, 2003, 57, 2292.

24. Sun, X.; Li, Y.; Angewandte Chemie, International Edition, 2004, 43, 3827.

25. Berbenni, V.; Milanese, C.; Bruni, G.; Marini, A.; Journal of Thermal Analysis and Calorimetry, 2005, 82, 401.

26. Bremer, H.; Bogatzki, B.; Zeitschrift fur Chemie, 1968, 8, 309.

27. Inoue, M.; Nishikawa, T.; Otsu, H.; Kominami, H.; Inui, T.; Journal of the American Ceramic Society, 1998, 81, 1173-1183.

28. Chen, T.; Tang, K.; Applied Physics Letters, 2007, 90, 051304.

29. Inoue, M.; Kimura, M.; Inui, T.; Chemistry of Materials, 2000, 12, 55.

30. Inoue, M.; Kimura, M.; Inui, T.; Advanced Science and Technology, 1999, 16, 593.

31. Inoue, M.; Kimura, M.; Inui, T.; Chemical Communications, 1999, 957.

32. Harwig, T.; Kellendonk, F.; Journal of Solid State Chemistry, 1978, 24, 225. 
33. Dai, L.; Chen, X. L.; Zhang, X. N.; Jin, A. Z.; Zhou, T.; Hu, B. Q.; Zhang, Z.; Journal of Applied Physics, 2002, 92, 1062.

34. Cheng, B.; Samulski, E. T.; Journal of Materials Chemistry, 2001, 11, 2901.

35. Shama, S.; Sunkara, M. K.; Journal of American Chemical Society, 2002, 124, 12288.

36. Ponce, F. A.; Bour, D. P.; Nature, 1997, 386, 351.

37. Someya, T.; Werner, R.; Forchel, A.; Catalano, M.; Cingolani, R.; Arakawa, Y.; Science, 1999, 285, 1905.

38. Bae, S. Y.; Seo, H. W.; Park, J.; Yang, H.; Kim, H.; Kim, S.; Applied Physics Letters, 2003, 82, 4564.

39. Liang, C. H.; Meng, G. W.; Wang, G. Z.; Wang, Y. W.; Zhang, L. D.; Zhang, S. Y.; Applied Physics Letters, 2001, 78, 3202.

40. Li, Y. X.; Trinchi, A.; Wlodarski, W.; Galatsis, K.; Kalantarzadeh, K.; Sensors and Actuators B: Chemical, 2003, 93, 431.

41. Fasol, G.; Science, 1996, 272, 1751.

42. Choi, Y. C.; Kim, W. S.; Park, Y. S.; Lee, S. M.; Bae, D. J.; Lee, Y. H.; Park, G. S.; Choi, W. B.; Lee, N. S.; Kim, J. M.; Advanced Materials, 2000, 12 , 746.

43. Han, W. Q.; Kohler-Redlich, P.; Ernst, F.; Ruhle, M.; Solid State Communications, 2000, 115, 527.

44. Chun, H. J.; Choi, Y. S.; Bae, S. Y.; Seo, H. W.; Hong, S. J.; Park, J.; Yang, H.; Journal of Physical Chemistry B, 2003, 107, 9042.

45. Wu, X. C.; Song, W. H.; Huang, W. D.; Pu, M. H.; Zhao, B.; Sun, Y. P.; Du, J. J.; Chemical Physics Letters, 2000, 328, 5. 
46. Gundiah, G.; Govindaraj, A.; Rao, C. N. R.; Chemical Physics Letters, 2002, $351,189$.

47. Dai, Z. R.; Pan, Z. W.; Wang, Z. L.; Journal of Physical Chemistry B, 2002, $106,902$.

48. Kim, B. C.; Sun, K. T.; Park, K. S.; Im, K. J.; Noh, T.; Sung, M. Y.; Kim, S.; Nahm, S.; Choi, Y. N.; Park, S. S.; Applied Physics Letters, 2002, 80, 479.

49. Chang, K. W.; Wu, J. J.; Advanced Materials, 2004, 16, 545.

50. Zhang, H. Z.; Kong, Y. C.; Wang, Y. Z.; Du, X.; Bai, Z. G.; Wang, J. J.; Yu, D. P.; Ding, Y.; Hang, Q. L.; Feng, S. Q.; Solid State Communications, 1999, $109,677$.

51. Li, J.; Chen, X.; Qiao, Z.; He, M.; Li, H.; Journal of Physics: Condensed Matter, 2001, 13, L937.

52. Kresge, C. T.; Leonowicz, M. E.; Roth, W. J.; Vartuli, J. C.; Beck, J. S.; Nature, 1992, 359, 710.

53. Beck, J. S.; Vartuli, J. C.; Roth, W. J.; Leonowicz, M. E.; Kresge, C. T.; Schmitt, K. D.; Chu, C. T. W., Olson, D. H.; Sheppard, E. W.; McCullen, S. B.; Higgins, J. B.; Schlenker, J. L.; Journal of the American Chemical Society, 1992, 114, 10834 .

54. Schuth, F.; Chemistry of Materials, 2001, 13, 3184.

55. Taguchi, A.; Schuth, F.; Microporous and Mesoporous Materials, 2005, 77, 1.

56. Carreon, M. A.; Guliants, V. V.; European Journal of Inorganic Chemistry, 2005, 1, 27.

57. Kresge, C. T.; Leonowicz, M. E.; Roth, W. J.; Vartulli, J. C.; 1992, US Patent $5,098,684$. 
58. Carreon, M. A.; Guliants, V. V.; Catalyst Design Through Dual Templating, 2009, Wiley-VCH, p. 295.

59. Patarin, J.; Lebeau, B.; Zana, R.; Current, Opinion in Colloid and Interface Science, 2002, 7, 107.

60. Antonelli, D. M.; Ying, J. Y.; Current, Opinion in Colloid and Interface Science, 1996, 1, 523.

61. Tas, A. C.; Majewski, P. J.; Aldinger, F.; Journal of American Ceramics Society, 2002, 85, 1421.

62. Ristic, M.; Popovic, S.; Music, S.; Materials Letters, 2005, 59, 1227.

63. Yada, M.; Machida, M.; Kijima, T.; Chemical Communications, 1996, 769.

64. Yada, M.; Hiyoshi, H.; Ohe, K.; Machida, M.; Kijima, T.; Inorganic Chemistry, 1997, 36, 5565.

65. Yada, M.; Kitamura, H.; Machida, M.; Kijima, T.; Langmuir, 1997, 13, 5252.

66. Yada, M.; Hiyoshi, H.; Machida, M.; Kijima, T.; Journal of Porous Materials, 1998, 5, 133.

67. Yada, M.; Kitamura, H.; Machida, M.; Kijima, T.; Inorganic Chemistry, 1998, $37,6470$.

68. Yada, M.; Kitamura, H.; Ichinose, A.; Machida, M.; Kijima, T.; Angewandte Chemie International Edition, 1999, 38, 3506.

69. Sienel, G.; Rieth, R.; Rowbottom, K. T.; Ullmann's Encyclopedia of Organic Chemicals, Wiley-VCH, Weinheim, 1999.

70. Zhang, Y.; Van Gerpen, J. H.; Lee, I.; Johnson, L. A.; Hammond, E. G.; Marley, S. J.; Journal of the American Oil Chemists' Society, 1996, 73, 1549.

71. Korbitz, W.; Renewable Energy, 1999, 16, 1078. 
72. Yori, J. C.; D’Amato, M. A.; Grau, J. M.; Pieck, C. L.; Vera, C. R.; Energy and Fuels, 2006, 20, 2721.

73. Monnier, A.; Schüth, F.; Huo, Q.; Kumar, D.; Margolese, D.; Maxwell, R. S.; Stucky, G. D.; Krishnamurty, M.; Petroff, P.; Firoouzi, A.; Janicke, M.; Chmelka, B. F.; Science, 1993, 261, 1299.

74. Tanev, P. T.; Pinnavaia, T. J.; Science, 1995, 267, 865.

75. Meynen, V.; Cool, P.; Vansant, E. F.; Microporous and Mesoporous Materials, 2009, 125, 170.

76. Tardieu, A.; Luzzati, V.; Biochimica et Biophysica Acta-Biomembranes, 1970, $219,11$.

77. Israelachvili, J. N.; Mitchell, D. J.; Ninham, B. W.; Journal of Chemical Society, Farady Transactions, 1976, 72, 1527.

78. Rosen, M. J.; Sufractants and Interfacial Phenomena, 2nd ed.; Wiley: New York, 1989.

79. Myers, D.; Surfactant Science and Technology, 2nd ed.; VCH: New York, 1992.

80. Raman, N. K.; Anderson, M. T.; Brinker, C. J.; Chemistry of Materials, 1996, $8,1682$.

81. Sayari, A.; Liu, P.; Microporous and Mesoporous Materials, 1997, 12, 149.

82. Ying, J. Y.; Mehnert, C. P.; Wong, M. S.; Angewandte Chemie International Edition English, 1999, 38, 56.

83. Firouzi, A.; Kumar, D.; Bull, L. M.; Besier, T.; Sieger, P.; Huo, Q.; Walker, S. A.; Zasadzinski, J. A.; Glinka, C.; Nicol, J.; Margolese, D. I.; Stucky, G. D.; Chemlka, B. F.; Science, 1995, 267, 1138.

84. Huo, Q.; Leon, R.; Petroff, P. M.; Stucky, G. D.; Science, 1995, 268, 1324. 
85. Huo, Q.; Margolese, D. I., Stucky, G. D.; Chemistry of Materials, 1996, 8, 1147.

86. Ciesla, U.; Demuth, D. G.; Leon, R.; Petroff, P. M.; Stucky, G. D.; Unger, K. K.; Schuth, F.; Journal of the Chemical Society, Chemical Communications, $1994,1387$.

87. Attard, G. S.; Glyde, J. C.; Goltner, C. G.; Nature, 1995, 378, 366.

88. Bagshaw, S. A.; Prouzet, E.; Pinnavaia, T. J.; Science, 1995, 269, 1242.

89. Bagshaw, S. A.; Pinnavaia, T. J.; Angewandte Chemie-International Edition, English, 1996, 35, 1102.

90. Zhao, D.; Huo, Q.; Feng, J.; Chmelka, B. F.; Stucky, G. D.; Journal of American Chemical Society, 1998, 120, 6024.

91. Yang, H.; Kuperman, A.; Coombs, N.; Mamiche-Afara, S.; Ozin, G. A.; Nature, 1996, 379, 703.

92. Yang, H.; Coombs, N.; Sokolov, I.; Ozin, G. A.; Nature, 1996, 381, 589.

93. Lu, Y.; Ganguli, R.; Drewien, C. A.; Anderson, M. T.; Brinker, C. J.; Gong, W.; Guo, Y.; Soyez, H.; Dunn, B.; Huang, M. H.; Zink, J. I.; Nature, 1997, 389,364 .

94. Grosso, D.; Cagnol, F.; Soler-Illia, G. J. de A. A.; Crepaldi, E. L.; Amenitsch, H.; Brunet-Bruneau, A.; Burgeois, A.; Sanchez, C.; Advanced Functional Materials, 2004, 14, 309.

95. Lu, Y.; Fan, H.; Stump, A.; Ward, T. L.; Rieker, T.; Brinker, C. J.; Nature, 1999, 398, 223.

96. Brinker, C. J.; Lu, Y.; Sellinger, A.; Fan, H.; Advanced Materials, 1999, 11, 579. 
97. Frasch, J.; Lebeau, B.; Soulard, M.; Patarin, L.; Zana, R.; Langmuir, 2000, 16, 9049.

98. Tiemann, M.; Goletto, V.; Blum, R.; Babonneau, F.; Amenitsch, H.; Linden, M.; Langmuir, 2002, 18, 1005.

99. Cagnol, F.; Grosso, D.; Soler-Illia, G. J. de A. A.; Crepaldi, E. L.; Babonneau, F.; Amenitsch, H.; Sanchez, C.; Journal of Materials Chemistry, 2003, 13, 61. 100. Grosso, D.; Balkenende, A. R.; Albouy, P. A.; Lavergne, M.; Babonneau, F.; Journal of Materials Chemistry, 2000, 10, 2085.

101. Clark, T.; Ruiz, J. D.; Fan, H.; Brinker, C. J.; Swanson, B. I.; Parikh, A. N.; Chemistry of Materials, 2000, 12, 3871.

102. Carreon, M. A.; Guliants, V. V.; Mesostructuring Metal Oxides through Evaporation-Induced Self-Assembly: Fundamentals and Applications, Nanoporous Solids, Recent Advances and Prospects, Elsevier, 2008, 16, 407.

103. Hurd, A. J.; Steinberg, L.; Granular Matter, 2001, 3, 19.

104. Lu, Y.; Fan, H.; Doke, N.; Loy, D. A.; Assink, R. A.; LaVan, D. A.; Brinker, C. J.; Journal of the American Chemical Society, 2000, 122, 5258.

105. Rao, G. V. R.; Lopez, G. P.; Bravo, J.; Pham, H.; Datye, A. K.; Xu, H.; Ward, T. L.; Advanced Materials, 2002, 14, 1301.

106. Bore, M. T.; Rathod, S. B.; Ward, T. L.; Datye, A. K.; Langmuir, 2003, 19, 256.

107. Zhang, Z.; Yan, X.; Tian, B.; Yu, C.; Tu, B.; Zhu, G.; Qiu, S.; Zhao, D.; Microporous and Mesoporous Materials, 2006, 90, 23.

108. Yu, K.; Smarsly, B.; Brinker, J. C.; Advanced Functional Materials, $2003,13,47$. 
109. Platschek, B.; Petkov, N.; Bein, T.; Angewandte Chemie, International Edition, 2006, 45, 1134.

110. Hatton, B. D.; Landskron, K.; Whitnall, W.; Perovic, D. D.; Ozin, G. A.; Advanced Functional Materials, 2005, 15, 823.

111. Malfatti, L.; Costacurta, S.; Kidchob, T.; Innocenzi, P.; Casula, M.; Amenitsch, H.; Dattilo, D.; Maggini, M.; Microporous and Mesoporous Materials, 2009, 120, 375.

112. Klichko, Y.; Khashab, N. M.; Yang, Y-W; Angelos, S.; Stoddart, J. F.; Zink, J. I.; Microporous and Mesoporous Materials, 2010, 132, 435.

113. Sayah, R.; Nadar, L.; Vocanson, F.; Battie, Y.; Reynaud, S.; Vera, R.;

Boukenter, A.; Destouches, N.; Microporous and Mesoporous Materials, 2011, 139, 45 .

114. Soler-Illia, G. J. A. A.; Sanchez, C.; Lebeau, B.; Patarin, J.; Chemical Reviews, 2002, 102, 4093.

115. Yang, P.; Zhao, D.; Margolese, D. I.; Chmelka, B. F.; Stucky, G. D.; Nature, 1998, 396, 152.

116. He, X.; Antonelli, D.; Angewandte Chemie International Edition, $\mathbf{2 0 0 2 ,} 41,214$.

117. Soler-Illia, G. J.; De. A. A.; Louis, A.; Sanchez, C.; Chemistry of Materials, 2002, 14, 750.

118. Crepaldi, E. L.; Soler-Illia, G. J. de, A. A.; Grosso, D.; Cagnol, F.; Ribot, F.; Sanchez, C.; Journal of the American Chemical Society, 2003, 125, 9770.

119. Yun, H.; Zhou, H.; Honma, I.; Chemical Communications, 2004, 2836. 
120. Henderson, M. J.; Gibaud, A.; Bardeau, J. F.; White, J. W.; Journal of Materials Chemistry, 2006, 16, 2478.

121. Beyers, E.; Cool, P.; Vansant, E. F.; Microporous and Mesoporous Materials, 2007, 99, 112.

122. Choi, S. Y.; Lee, B.; Carew, D. B.; Mamak, M.; Peiris, F. C.; Speakman, S.; Chopra, N.; Ozin, G. A.; Advanced Functional Materials, 2006, 16,1731 .

123. Carreon, M. A.; Choi, S. Y.; Mamak, M.; Chopra, N.; Ozin, G. A.; Journal of Materials Chemistry, 2007, 17, 82.

124. Brezesinski, T.; Groenewolt, M.; Gibaud, A.; Pinna, N.; Antonietti, M.; Smarsly, B. M.; Advanced Materials, 2006, 18, 2260.

125. Fox, M. A., Dylay, M. T., Chem. Rev. 1993, 93, 341.

126. Yamaguchi, T.; Applied Catalysis A: General, 1990, 61, 1.

127. Hagfeldt, A.; Gratzel, M.; Chemical Reviews, 1995, 95, 49.

128. Sakatani, Y.; Grosso, D.; Nicole, L.; Boissiere, C.; Soller-Illia, G. J. de A. A.; Sanchez, C.; Journal of Materials Chemistry, 2006, 16, 77.

129. Hou, K.; Tian, B.; Li, F.; Bian, Z.; Zhao, D.; Huang, C.; Journal of Mathematical Chemistry, 2005, 15, 2414.

130. Lancelle-Beltran, E.; Prene, P.; Boscher, C.; Belleville, P.; Buvat, P.; Sanchez, C.; Advanced Materials, 2006, 18, 2579.

131. Martinez-Ferrero, E.; Sakatani, Y.; Boissiere, C.; Grosso, D.; Fuertes, A.; Fraxedas, J.; Sanchez, C.; Advanced Functional Materials, 2007, 17, 3348. 132. Petukhov, D. I.; Eliseev, A. A.; Kolesnik, I. V.; Napolskii, K. S.; Lukashin, A. V.; Tretyakov, Y. D.; Grigoriev, S. V.; Grigorieva, N. A.; Eckerlebe, H.; Microporous and Mesoporous Materials, 2008, 114, 440. 
133. Chassagneux, F.; Chiriac, R.; Bessueille, F.; Karabulut, M.; Bois, L.; Parola, S.; Microporous and Mesoporous Materials, 2011, 139, 52.

134. Mura, S.; Greppi, G.; Roggio, A. M.; Malfatti, L.; Innocenzi, P.; Microporous and Mesoporous Materials, 2011, 142, 1.

135. Castro, Y.; Julian-Lopez, B.; Boissiere, C.; Viana, B.; Grosso, D.; Sanchez, C.; Micropororous and Mesoporous Materials, 2007, 103, 273.

136. Brezesinski, T.; Antonietti, M.; Groenewolt, M.; Pinna, N.; Smarsly, B.; New Journal of Chemistry, 2005, 29, 237.

137. Kuemmel, M.; Grosso, D.; Boissiere, C.; Smarsly, B.; Brezesinski, T.; Albouy, P. A.; Amenitsch, H.; Sanchez, C.; Angewandte Chemie International Edition, 2005, 44, 4589.

138. Brezesinski, T.; Groenewolt, M.; Antonietti, M.; Smarsly, B.; Angewandte Chemie International Edition, 2006, 45, 781.

139. Grosso, D.; Boissiere, C.; Smarsly, B.; Brezesinski, T.; Pinna, N.; Albouy, P. A.; Amenitsch, H.; Antonietti, M.; Sanchez, C.; Nature Materials, 2004, 3, 787.

140. Yuan, L.; Bhatt, S.; Beaucage, G.; Guliants, V. V.; Mamedov, S.; Soman, R. S.; Journal of Physical Chemistry B, 2005, 109, 23250.

141. Carreon, M. A.; Guliants, V. V.; Yuan, L.; Hughett, A. R.; Dozier, A.; Seisenbaeva, G. A.; Kessler, V. G.; European Journal of Inorganic Chemistry, 2006, 24, 4983.

142. Pan, J. H.; Lee, W. I.; Chemistry of Materials, 2006, 18, 847.

143. Jasinski, P.; Suzuki, T.; Anderson, H. U.; Sensors and Actuators B, $\mathbf{2 0 0 3}, 95,73$. 
144. Centi, G.; Cavani, F.; Trifiro, F.; Selective Oxidation by Heterogeneous Catalysis. Fundamental and Applied Catalysis, Kluwer Academic/Plenum Publishers, New York, 2001.

145. Wakefield, G.; Holland, E.; Dobson, P. J.; Hutchison, J. L.; Advanced Materials, 2001, 13, 1557.

146. Postula, W. S.; Feng, Z.; Philip, C. V.; Akgerman, A.; Anthony, R. G.; Journal of Catalysis, 1994, 145, 126.

147. Feng, Z.; Postula, W. S.; Philip, C. V.; Anthony, R. G.; Journal of Catalysis, 1994, 148, 84.

148. Chen, X., Knez, M., Berger, A., Nielsch, K., Gosele, U., Steinhart, M., Angewandte Chemie International Edition, 2007, 46, 6829.

149. Kim, Y.; Kim, C.; Choi, I.; Rengaraj, S.; Yi, J.; Environmental Science and Technology, 2004, 38, 924.

150. Schaep, J.; Vandecasteele, C.; Peeters, B.; Luyten, J.; Dotremont, C.; Roels, D.; Journal of Membrane Science, 1999, 163, 229.

151. Poizot, P.; Laruelle, S.; Grugeon, S.; Dupont, L.; Tarascon, J.M.; Nature, 2000, 407, 496.

152. Liaw, B. J.; Cheng, D. S.; Yang, B. L.; Journal of Catalysis, 1989, 118,312 .

153. Pankhurst, Q. A.; Pollard, R. J.; Journal of Physics: Condensed Matter, 1993, 5, 8487.

154. Pelino, M.; Colella, C.; Cantalini, C.; Faccio, M.; Ferri, G.; D’Amico, A.; Sensors and Actuators B, 1992, 7, 464.

155. Sayari, A.; Chemistry of Materials, 1996, 8, 1840. 
156. Yusuf, M. M.; Imai, H.; Hirashima, H.; Journal of Sol-Gel Science and Technology, 2002, 25, 65 .

157. Takahara, Y.; Kondo, J. N.; Takata, T.; Lu, D.; Domen, K.; Chemistry of Materials, 2001, 13, 1194.

158. Stone, V. F.; Davis, R. J.; Chemistry of Materials, 1998, 10, 1468.

159. Beyers, E.; Cool, P.; Vasant, E. F.; Microporous and Mesoporous Materials, 2007, 99, 112.

160. Sakatani, Y.; Grosso, D.; Nicole, L.; Boissiere, C.; Soller-Illia, G. J.; De, A. A.; Sanchez, C.; Journal of Materials Chemistry, 2006, 16, 77.

161. Perkas, N.; Wang, Y.; Koltypin, Y.; Gedanken, A.; Chandrasekaran, S.; Chemical Communications, 2001, 11, 988.

162. Yoshitake, H.; Tatsumi, T.; Chemistry of Materials, 2003, 15, 1695.

163. Carreon, M. A.; Guliants, V. V.; Yuan, L.; Hughett, A. R.; Dozier, A.; Seisenbaeva, G. A.; Kessler, V. G.; European Journal of Inorganic Chemistry, 2006, 24, 4983.

164. Lin, J-H.; Biswas, P.; Guliants, V. V.; Misture, S.; Applied Catalysis A: General, 2010, 387, 87.

165. Byrappa, K.; Yoshimura, M.; Handbook of Hydrothermal Technology (Noyes Publications/William Andrew Publishing LLC, U.S.A. 2001).

166. Roy, R.; Journal of Solid State Chemistry, 1994, 111, 11.

167. Sômiya, S.; Hydrothermal Reactions for Materials Science and Engineering. An Overview of Research in Japan (Elsevier Science Publishers Ltd., U.K. 1989).

168. Yoshimura, M.; Suchanek, W. L.; Byrappa, K.; MRS Bulletin, 2000 25,17 . 
169. Gersten, B.; Lencka, M.; Riman, R. E.; Chemistry of Materials, 2002, $14,1950$.

170. Riman, R. E.; in High Performance Ceramics: Surface Chemistry in Processing Technology, edited by R. Pugh and L. Bergström (Marcel-Dekker, U.S.A. 1993), 29.

171. Suchanek, W. L.; Riman, R. E.; Advances in Science and Technology, 2006, 45, 184.

172. Deshmane, C. A.; Jasinski, J. B.; Carreon, M. A.; European Journal of Inorganic Chemistry, 2009, 22, 3275.

173. Li, Y.; Yang, W.; Journal of Membrane Science, 2008, 316, 3.

174. De Vos, D. E.; Sels, B. F.; Jacobs, P. A.; Advanced Synthesis and Catalysis, 2003, 345, 457.

175. Lane, B. S.; Burgess, K.; Chemical Reviews, 2003, 103, 2457.

176. Grigoropoulou, G.; Clark, J. H.; Elings, J. A.; Green Chemistry, 2003, $5,1$.

177. Van Santen, R. A.; Kuipers, H. P. C. E.; Advances in Catalysis, 1987, $35,265$.

178. Sheldon, R. A.; Kochi, J. K.; Metal-catalyzed Oxidations of Organic Compounds, Academic Press, New York, 1981.

179. Landau, R.; Sullivan, G. A.; Brown, D.; Chemtech, 1979, 602.

180. Sheldon, R. A.; Journal of Molecular Catalysis A: Chemical, 1980, 7, 107.

181. Swern, D.; Organic Peroxides, Wiley Interscience, New York, 1971.

182. Jones, C. W.; Applications of Hydrogen Peroxide and Derivatives, MPG Books Ltd.; Cornwall, UK 1999. 
183. Jorgensen, K. A.; Chemical Reviews, 1989, 89, 431.

184. Adam, W.; In Peroxide Chemistry Mechanistic and Preparative Aspects of Oxygen Transfer, Wiley-VCH, Darmstadt, Germany, 2000.

185. Sanderson, W. R.; Pure and Applied Chemistry, 2000, 72, 1289.

186. Mandelli, D.; Van Vliet, M. C. A.; Sheldon, R. A., Schuchardt, U.; Applied Catalysis A, 2001, 219, 209.

187. Van Vliet, M. C. A.; Mandelli, D.; Arends, I. W. C. E.; Schuchardt, U.; Sheldon, R. A.; Green Chemistry, 2001, 3, 243.

188. Choudhary, V. R.; Patil, N. S.; Chaudhari, N. K.; Bhargava, S. K.; Journal of Molecular Catalysis A: Chemical, 2005, 227, 217.

189. Cesquini, R. G.; De Silva, J. M., Woitiski, C. B.; Mandelli, D.; Rinaldi, R.; Schuchardt, U.; Advanced Synthesis and Catalysis, 2002, 344, 911.

190. Rinaldi, R.; Sepulveda, J.; Schuchardt, U.; Advanced Synthesis and Catalysis, 2004, 346, 281.

191. Rinaldi, R.; Schuchardt, U.; Journal of Catalysis, 2004, 227, 109.

192. Zhang, S.; Zhang, Z. C.; Catalysis Letters, 2007, 115, 114.

193. Ha, L.; Mao, J.; Zhou, J.; Zhang, Z. C.; Zhang, S.; Applied Catalysis A: General, 2009, 356, 52.

194. Naik, C. V.; Westbrook, C. K.; Herbinet, O.; Pitz, W. J.; Mehl, M.; Proceedings of the Combustion Institute, 2011, 33, 383.

195. Knothe, G.; Fuel Processing Technology, 2005, 86, 1059.

196. Berman, L. U.; Loeb, M. L.; The Dimer Acids, Humko Sheffield Chemical, 1975.

197. Ngo, H. L.; Nunez, A.; Lin, W.; Foglia, T. A.; European Journal of Lipid Science and Technology, 2007, 108, 214. 
198. Reaume, S. J.; Ellis, N.; Journal of the American Oil Chemists' Society, 2010, DOI 10.1007/s11746-010-1718-3.

199. Nowak, I.; Quartararo, J.; Derouane, E. G.; Vedrine, J. C.; Applied Catalysis A: General, 2003, 251, 107.

200. Tanabe. K; Okazaki, S.; Applied Catalysis A: General, 1995, 13, 191.

201. Jouliet, J. P.; Metal Oxide Chemistry and Synthesis: From Solution to Solid State, Wiley, 2000.

202. Brinker, C. J.; Scherer, G. W.; The Physics and Chemistry of Sol-Gel Processing, Academic Press, Inc., 1990.

203. Kosmulski, M.; Journal of Colloid and Interface Science, 2001, 238, 225.

204. Huo, Q.; Margolese, D. I.; Ciesla, U.; Feng, P.; Gier, T. E.; Siager, P.; Leon, R.; Petroff, P. M.; Schuth, F.; Stucky, G. D.; Nature, 1994, 368, 317.

205. Sing, K. S. W. Everett, D. H.; Haul, R. H. W.; Moscou, L.; Pierotti, R. A.; Rouquerol, J.; Siemieniewska, T.; Pure and Applied Chemistry. 1985, 57, 603.

206. Greg, S. J.; Sing, K. S. W.; Adsorption Surface Area and Porosity, Academic Press, London, 1969.

207. Jiang, X.; Herricks, T.; Xia, Y.; Advanced Materials, 2003, 15, 15.

208. Zhao, D.; Sun, J.; Li, Q.; Stucky, G. D.; Chemistry of Materials, 2000, 12,275 .

209. Yang, H.; Vovk, G.; Coombs, N.; Sokolov, I.; Ozin, G. A.; Journal of Materials Chemistry, 1998, 8, 743.

210. Huo, Q.; Feng, J.; Schuth, F.; Stucky, G. D.; Chemistry of Materials, $1997,9,14$. 
211. Bo. L.; Quan, X.; Wang, X.; Chen, S.; Journal of Hazardous Materials, 2008, 157, 179.

212. Ai, Z.; Zhang, L.; Kong, F.; Liu, H.; Xing, W.; Qiu, J.; Materials Chemistry and Physics, 2008, 111, 162.

213. Hu, Y.; Liu, C.; Zhang, Y.; Ren, N.; Tang, Y.; Microporous and Mesoporous Materials, 2009, 119, 306.

214. Gerbec, J. A.; Magana, D.; Washington, A.; Strouse, G. F.; Journal of the American Chemical Society, 2005, 127, 15791.

215. Huang, M.; Li, L.; Guo, Y.; Electrochimica Acta, 2009, 54, 3303.

216. Fantini, M. C. A.; Matos, J. R.; Cides da Silva, L. C.; Mercuri, L. P.; Chiereci, G. O.; Celer, E. B.; Jaroniec, M.; Materials Science and Engineering $B, \mathbf{2 0 0 4}, 112,106$.

217. Tompsett, G. A.; Conner, W. C.; Yngvesson, K. S.; ChemPhysChem, 2006, 7, 296.

218. Park I.; Pinnavaia, T. J.; Microporous and Mesoporous Materials, 2009, 118, 239.

219. Araujo, A. S.; Jaroniec, M.; Thermochimica Acta, 2000, 345, 173.

220. Prouzet, E.; Boissiere, C.; Kim, S. S.; Pinnavaia, T. J.; Microporous and Mesoporous Materials, 2009, 119, 9.

221. Pomonis, P. J.; Petrakis, D. E.; Ladavos, A. K.; Kolonia, K. M.; Armatas, G. S.; Sldari, S. D.; Dragani, P. C.; Zarlaha, A.; Stathopoulas, V. N.; Sdoukos, A. T.; Microporous and Mesoporous Materials, 2004, 69, 97.

222. Tagusagawa, C.; Takagaki, A.; Iguchi, A.; Takanabe, K.; Kondo, J. N.; Ebitani, K.; Tatsumi, T.; Domen, K.; Catalysis Today, DOI:10.1016/j.cattod.2010.10.049. 
223. He, X.; Antonelli, D. M.; Angewandte Chemie, International Edition, 2002, 41, 214.

224. Yu, X.; Xu, Z.; Han, S.; Journal of Porous Materials, 2010, 17, 99.

225. Kurmaev, E. Z.; Moewes, A.; Bureev, O. G.; Nekrasov, I. A.; Cherkashenko, V. M.; Korotin, M. A.; Ederer, D. L.; Journal of Alloys and Compounds, 2002, 347, 213.

226. Liu, Y.; Qian, Y.; Zhang, M.; Chen, Z.; Wang, C.; Materials Research Bulletin, 1996, 31, 1029.

227. Hussain, Z.; Journal of Materials Research, 2001, 16, 2695.

228. Zheng, H. C.; Inorganic Chemistry, 1998, 37, 1996.

229. Gall, P.; Gougeon, P.; Journal of Solid State Chemistry, 2008, 181, 1.

230. Tanabe, K.; Catalysis Today, 2003, 78, 65.

231. Tanabe, K.; Okazaki, S.; Applied Catalysis A: General, 1995, 133, 191.

232. Wachs, I. E.; Jehng, J. M.; Deo, G.; Hu, H.; Arora, N.; Catalysis Today, 1996, 28, 199.

233. Liu, H. F.; Liu, R. S.; Liew, K. Y.; Johnson, R. E.; Lunsford, J. H.; Journal of American Chemical Society, 1984, 106, 4117.

234. Zhang, W.; Oyama, S. T.; Journal of Physical Chemistry, 1996, 100, 10759.

235. Silva, I. F.; Klimkiewicz, M.; Eser, S.; Energy and Fuels, 1998, 12, 554.

236. Ressler, J.; Wienold, T.; Jentoft, R. E.; Journal of Catalysis, 2002, 210, 67. 
237. Kerr, T. A.; Leroux, F.; Nazar, L. F.; Chemistry of Materials, 1998, 10, 2588.

238. Yao, J. N.; Yang, Y. A.; Loo, B. H.; Journal of Physical Chemistry B, 1998, 102, 1856.

239. Yang, Y. A.; Cao, Y. W.; Loo, B. H.; Yao, J. N.; Journal of Physical Chemistry B, 1998, 102, 9392.

240. Ferreira, F. F.; Souza Cruza, T. G.; Fantini, M. C. A.; Tabacniks, M. H.; de Castro, S. C.; Morais, J.; de Siervo, A.; Landers, R.; Gorenstein, A.; Solid State Ionics, 2000, 136, 357.

241. Hosono, K.; Matsubara, I.; Muryama, N.; Woosuck, S.; Izu, N.; Chemistry of Materials, 2005, 17, 349.

242. Wang, J.; Rose, K. C.; Lieber, C. M.; Journal of Physical Chemistry, 1999, 103,8405 .

243. Song, R. Q.; Xu, A. W.; Deng, B. Fang, Y. P.; Journal of Physical Chemistry $B$, 2005, 109, 22758.

244. Nowak, I.; Misiewicz, M.; Ziolek, M.; Kubacka, A.; Corberan, V. C.; Sulikowski, B.; Applied Catalysis A: General, 2007, 325, 328.

245. Chen, X.; Yu, T.; Fan, X.; Zhang, H.; Li, Z.; Ye, J.; Zou, Z.; Applied Surfcae Science, 2007, 253, 8500.

246. Ayudhya, S. K. N.; Sootitantawat, A.; Praserthdam, P.; Satayaprasert, C.; Materials Chemistry and Physics, 2008,110, 387.

247. Deshmane, C. A.; Jasinski, J. B.; Carreon, M. A.; Microporous and Mesoporous Materials, 2010, 130, 97.

248. Onfroy T.; Clet, G.; Houalla, M.; Journal of Physical Chemistry B, 2005, 109, 14588. 
249. Wang, S.; Zhang, Y.; Ma, X.; Wang, W.; Li, X.; Zhang, Z.; Qian, Y.; Solid State Communications, 2005, 136, 283.

250. Zakharova, G. S.; Taschner, C.; Volkov, V. L.; Hellmann, I.; Klingeler, R.; Leonhardt, A.; Buchner, B.; Solid State Sciences, 2007, 9, 1028. 251. Satyarthi, J. K.; Srinivas, D.; Ratnasamy, P.; Energy and Fuels, 2009, 23, 2273. 


\title{
CURRICULUM VITAE
}

\author{
Chinmay Deshmane \\ PhD Candidate, Chemical Engineering \\ 782 Raymond Kent Court, Louisville, KY-40217 \\ chinmaydeshmane25@gmail.com, (337) 412-4462
}

\section{Summary}

- Chemical engineer with strong academic background and six years of research experience in materials synthesis, characterization and heterogeneous catalysis.

- Expertise in the operation of high pressure/high temperature reactors and fixedbed continuous flow reactors and also in the analysis of hydrocarbons, biodiesels and carbohydrates using gas-chromatography/mass spectroscopy and HPLC.

\section{Education}

PhD: Chemical Engineering, University of Louisville, KY August 07-Present GPA: $3.6 / 4.0$

Advisor: Dr. Moises A. Carreon

MS: Chemical Engineering, University of Louisiana, Lafayette August 05-July 07

GPA: $3.7 / 4.0$

Advisor: Dr. R. D. K. Misra

BS: Chemical Engineering, University of Pune, India July 01-May 05

GPA: $3.5 / 4.0$ 


\section{Expertise}

- Synthesized thermally stable high surface area $\left(\sim 366 \mathrm{~m}^{2} / \mathrm{g}\right)$ nanocrystalline gallium oxide and gallium-niobium mixed metal oxides with controlled pore size distribution ( 2 to $15 \mathrm{~nm}$ ) using high pressure/high temperature and microwave reactors.

- Studied the hydroisomerization of long chain paraffins and decarboxylation of fatty acids over mesoporous oxides using continuous flow fixed bed reactor.

- Extensive characterization experience to analyze the structural and morphological properties of mesoporous materials using BET porosimeter and surface area analyzer, Scanning Electron Microscopy (SEM), X-ray Diffraction (XRD), Energy Dispersive Spectroscopy (EDS).

- Experience in the operation and maintenance of gas-chromatograph/mass spectrometer [HP-5890].

\section{Research Experience}

Graduate Research (PhD): University of Louisville, KY

August 07-Present

- Thermally stable high surface area, semi-crystalline and nanocrystalline, mesoporous, gallium oxide and gallium based mixed metal (Nb, Mo) oxides were prepared with controlled pore size distribution in $\sim 2$ to $15 \mathrm{~nm}$ range employing various structure directing agents via Evaporation-Induced SelfAssembly (EISA) and Self-Assembly Hydrothermal-Assisted (SAHA) and Self-Assembly Microwave-Assisted methods.

- Studied the skeletal isomerization of Methyl Oleate (Biodiesel) to its branched isomers in order to lower the freezing point, for their application in regions with temperatures below $-10^{\circ} \mathrm{C}$. These mesoporous oxides were also tested for 
the epoxidation of light alkenes and transesterification of triglycerides for the synthesis of biodiesel.

- Effect of loading Pt over gallium-niobium mixed metal oxide was explored for the hydroisomerization of n-hexadecane.

Graduate Research (MS): University of Louisiana, Lafayette

August 05-July 07

- Studied the effect of nanoclay and calcium carbonate reinforcements on the mechanical properties (impact and tensile strength) of polymer nanocomposites and their characterization using Differential Scanning Calorimetry (DSC) and SEM to study the physical and textural properties of these nanocomposites.

- High density polyethylene and polypropylene nanocomposites processed in batch scale displayed high impact toughness over a temperature range of -40 to $70^{\circ} \mathrm{C}$ as compared to the neat polymers.

Teaching Assistant January 08-

December 10

- Tutored for materials science, safety health and environment, and advance reactor design classes.

\section{Publications}

1. C. A. Deshmane, J. B. Jasinski, P. Ratnasamy and M. A. Carreon, "Epoxidation of cyclooctene over mesoporous gallium and Ga-Nb mixed oxide catalysts", J. of Mater. Chem., Submitted, April 2011.

2. E. E. Macias, C. A. Deshmane, J. B. Jasinski, M. A. Carreon and P. Ratnasamy, "Catalytic transesterification of methyl oleate and biodiesel over mesoporous gallium-niobium oxides", Catal. Commun., 2011, 12, 644-650. 
3. C. A. Deshmane, J. B. Jasinski, P. Ratnasamy and M. A. Carreon, "Synthesis and catalytic properties of mesoporous, bifunctional, gallium-niobium mixed oxides", Chem. Commun., 2010, 46, 6347-6349.

4. C. A. Deshmane, J. B. Jasinski, and M. A. Carreon, "Microwave-assisted synthesis of nanocrystalline mesoporous gallium oxide", Micro. and Meso. Mater. 2010, 130, 97-102.

5. C. A. Deshmane, J. B. Jasinski, and M. A. Carreon, "Thermally stable nanocrystalline mesoporous gallium oxide phases", Eur. J. Iorg. Chem. 2009, $22,3275-3281$.

6. Q. Yuan, C. A. Deshmane, T. C. Pesacreta, and R. D. K. Misra, "Nanoparticle effects on spherulites structure and phase formation in polypropylene crystallized at moderately elevated pressures: The influence of fracture resistance", Mater. Sci. and Engr. A: 2008, 480, 181-188.

7. C. A. Deshmane, Q. Yuan, and R. D. K. Misra, "On the fracture characteristics of impact tested HDPE-calcium carbonate nanocomposites", Mater. Sci. and Engr. A: 2007, 452-453, 592-601.

8. C. A. Deshmane, Q. Yuan, R. S. Perkins, and R. D. K. Misra, "On striking variation in impact toughness of polyethylene-clay and polypropylene-clay nanocomposite systems: The effect of clay-polymer interaction", Mater. Sci. and Engr. A: 2007, 458, 150-157.

9. C. A. Deshmane, Q. Yuan, and R. D. K. Misra, "High strength-toughness combination of melt intercalated nanoclay-reinforced thermoplastic olefins", Mater. Sci. and Engr. A: 2007, 460-461, 277-287. 


\section{Presentations}

1. Oral: AIChE 2010 (Utah), 2009 (Nashville), 2008 (Philadelphia).

2. Poster: NACS 2009 (San Fransisco), AIChE 2008 (Philadelphia) E-EXPO 2008 (Louisville).

\section{Awards and Activities}

- KOKES Award for the NACS $21^{\text {st }}$ National Annual Meeting, San Fransisco, CA June 2009.

- Overall $3^{\text {rd }}$ prize for poster presentation "On the fracture characteristics of impact tested high density polyethylene-calcium carbonate nanocomposites", Engineering and Technology Week, Lafayette 2007.

- President of the Graduate student council for Chemical Engineering Department, University of Louisiana, 2006-2007.

- Secured $2^{\text {nd }}$ position for a talk in technical paper presentation competition CHENIGMA-2K2, Pune 2002.

\section{Other Operational Experience}

NMR Spectroscopy (Varian 7600 AS), Differential Scanning Calorimeter (DSC), Thermogravimetric Analyzer, Twin Screw Extruder (CW Brabender), Izod Impact Testing, MTS 210 Tensile Testing Machine.

\section{Other Skills}

- Well trained in HP CHEMSTATION, POLYMATH, and MS Office software.

- Organizing team member of conference CHEMTATIONS 2004, in University of Pune, India. 